\title{
Floating Breakwater
}

\section{Field Assessment Program, \\ Friday Harbor, Washington}

\author{
by
}

B.H. Adee, E.P. Richey, and D.R. Christensen

\section{TECHNICAL PAPER NO. 76-17 \\ OCTOBER 1976}
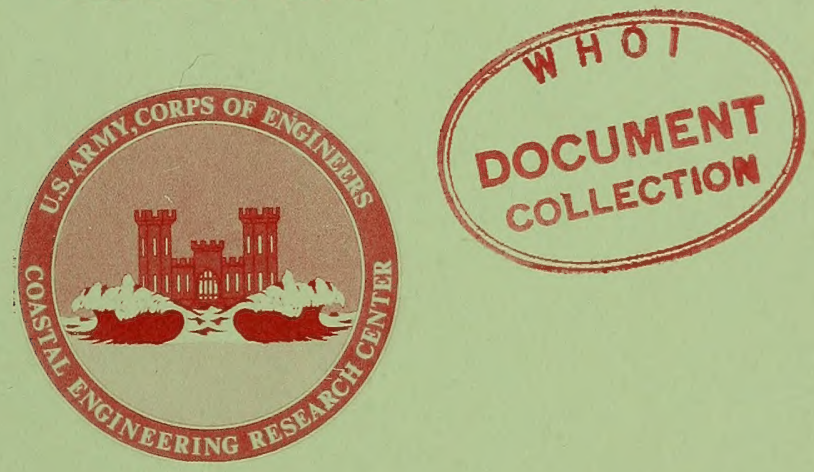

Approved for public release;

distribution unlimited.

GB

450

, 14

no. $76-17$

Prepared for

U.S. ARMY, CORPS OF ENGINEERS

COASTAL ENGINEERING

RESEARCH CENTER .

Kingman Building

Fort Belvoir, Va. 22060 
Reprint or republication of any of this material shall give appropriate credit to the U.S. Army Coastal Engineering Research Center.

Limited free distribution within the United States of single copies of this publication has been made by this Center. Additional copies are available from:

National Technical Information Service

ATTN: Operations Division

5285 Port Royal Road

Springfield, Virginia 22151

Contents of this report are not to be used for advertising, publication, or promotional purposes. Citation of trade names does not constitute an official endorsement or approval of the use of such commercial products.

The findings in this report are not to be construed as an official Department of the Army position unless so designated by other authorized documents. 


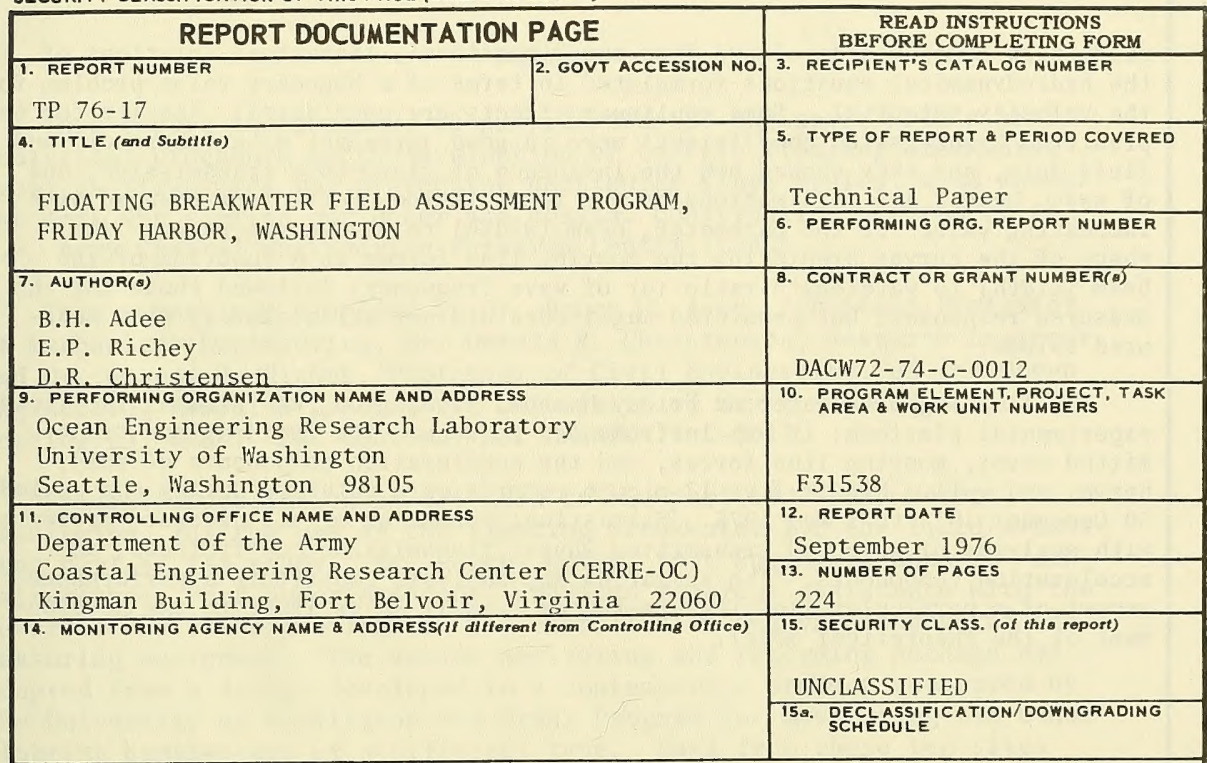

\section{DISTRIBUTION STATEMENT (of this Report)}

Approved for public release; distribution unlimited.

17. DISTRIBUTION STATEMENT (of the abstract entered in Block 20 , if different from Report)

18. SUPPLEMENTARY NOTES

19. KEY WORDS (Continue on reverse side if necessary and Identlfy by block number)

Breakwaters

Floating breakwaters

Friday Harbor, Washington
Wave attenuation
Wave reflection

Waves

Wave transmission

20. ABSTRACT (Continue an reverse side if necosary and identify by block numbor)

A theoretical model for predicting the dynamic behavior of a floating breakwater is presented along with a report on a field experiment designed to provide basic data for verifying the model. Additional data were taken from the literature and from auxiliary laboratory experiments.

The dynamic behavior characteristics investigated were: (a) Total transmitted and reflected waves and their components; (b) wave forces on the breakwater; (c) motions of the breakwater; and (d) forces on the mooring lines. The 
prediction model was developed from two-dimensional, linearized solutions of the hydrodynamical equations formulated in terms of a boundary value problem for the velocity potential. Some nonlinear effects are considered. Results for the predicted transmission coefficients were in good agreement with 1aboratory and field data, and they showed how the influence of fixed-body transmission, and of sway, heave, and roll motions on the transmission coefficient changed with increasing values of the parameter, beam (width) to wavelength ratio. The shape of the curves predicting the mooring line forces as a function of the beam (width) to wavelength ratio (or of wave frequency) followed those for the measured responses, but predicted magnitudes did not agree closely with measured values.

The floating breakwater at Friday Harbor, Washington, was used as the field experimental platform; it was instrumented to record the incident and transmitted waves, mooring line forces, and the acceleration components of sway, heave, and rol1. Ninety-five 17-minute records were obtained during the period 30 December 1974 to 5 May 1975. Statistical summaries of all data are presented with analyses of selected transmitted waves, transmission coefficients, and acceleration components. The summaries and analyses constitute a performance report of a particular floating breakwater as well as an input to the development of the theoretical mode1. 


\section{PREFACE}

This report is published to provide coastal engineers with a basic analytical procedure in the evaluation of certain floating breakwater types as structures for protecting particular sites against wind waves. The work was carried out under the coastal construction program of the U.S. Army Coastal Engineering Research Center (CERC) .

This report was prepared by Dr. Bruce H. Adee, Assistant Professor of Mechanical Engineering, Mr. Derald R. Christensen, Research Engineer, and Dr. Eugene P. Richey, Professor of Civil Engineering, of the Ocean Engineering Research Laboratory, University of Washington, Seattle, Washington, under CERC Contract No. DACW72-74-C-0012.

Special appreciation is extended to the port of Friday Harbor, Washington, for the use of the floating breakwater for the field assessment part of the study. Mr. Robert Hovey, Port Engineer, and Mr. Jack Fairweather, Port Superintendent, provided generous assistance with the numerous logistics problems in the installation and maintenance of the measuring equipment. The sensor monitoring and recording package was adapted from a design developed in a contemporary project sponsored by the University of Washington Sea Grant Program for monitoring two other floating breakwaters of a different type. Data from these two sites were used for comparative purposes in the analyses of the Friday Harbor breakwater.

Dr. D. Lee Harris, Chief, Oceanography Branch, was the CERC contract monitor for the report under the general supervision of $\mathrm{Mr}$. R.P. Savage, Chief, Research Division.

Comments on this publication are invited.

Approved for publication in accordance with Public Law 166, 79th Congress, approved 31 July 1945, as supplemented by Public Law 172, 88th Congress, approved 7 November 1963.

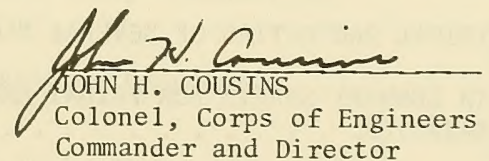


CONVERSION FACTORS, U.S. CUSTOMARY TO METRIC (SI) . . . . 7

SYMBOLS AND DEFINITIONS . . . . . . . . . . . . 8

I INTRODUCTION. . . . . . . . . . . . . . . . . 9

II THEORETICAL ANALYSIS. . . . . . . . . . . . . . . . 12

1. Linear Theoretical Mode1. . . . . . . . . . . . 13

2. Nonlinear Theoretical Model . . . . . . . . . . 19

3. Results . . . . . . . . . . . . . . . 22

III FIELD DATA. . . . . . . . . . . . . . . . . 4 49

1. Layout. . . . . . . . . . . . . . . . . 49

2. Instrumentation .. . . . . . . . . . . . 49

3. Wind Data... . . . . . . . . . . . . 49

4. Waves................ . . . . . 49

5. Cable Forces. . . . . . . . . . . . . . 53

6. Motion Package. . . . . . . . . . . . . . 53

7. Data Acquisition System . . . . . . . . . . . 53

8. Data Processing and Analysis. . . . . . . . . . 54

IV COMPARISON OF THEORY WITH FIELD DATA FOR FRIDAY HARBOR

BREAKWATER. . . . . . . . . . . . . . . . . 64

$\mathrm{V}$ CONCLUSIONS . . . . . . . . . . . . . . . . . . 71

LITERATURE CITED. . . . . . . . . . . . . . . . . 72

APPENDIX

A HYDROSTATIC RESTORING FORCES AND SPRING CONSTANTS . . . . . 74

B MOORING ANALYSIS. . . . . . . . . . . . . . . . 79

C LINEAR HYDRODYNAMIC COEFFICIENTS. . . . . . . . . . . . . . 104

D FlOATING BREAKWATER ANALYSIS. . . . . . . . . . . . . 107

E DERIVATION OF PRESSURE TO SECOND ORDER FOR TWO PROGRESSIVE WAVES AT DIFFERENT FREQUENCIES. . . . . . . . . . . . . . 148

F PHYSICAL PROPERTIES OF SEVERAL FLOATING BREAKWATERS . • • • 156

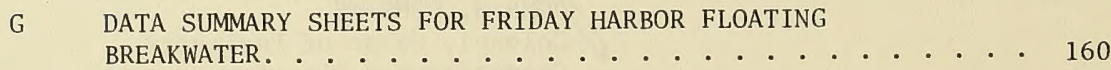

H INCIDENT AND TRANSMITTED WAVE SPECTRAL PLOTS. . . . . . . . 180 


\section{CONTENTS}

APPENDIX-Continued

I LOW-FREQUENCY SPECTRAL ANALYSIS OF FORCE DATA . . . . . . 192

J HIGH-FREQUENCY SPECTRAL ANALYSIS OF FORCE AND MOTION DATA .................. . . . 200

K WAVE MEASUREMENT. . . . . . . . . . . . . . . . 218

TABLE

Summary of anchor cable force statistics. . . . . . . . . . . 61

FIGURES

1 Aerial view of Friday Harbor breakwater . . . . . . . . . . . . 11

2 A two-dimensional floating breakwater . . . . . . . . . . . 14

3 Linear system representative of a floating breakwater . . . . . . 20

4 Filtered low-frequency seaward mooring line force, Tenakee, Alaska................... . . . . 21

5 Transmission coefficient for proposed Oak Harbor breakwater . . . . . . . . . . . . . . . . 24

6 Transmission coefficient for a rectangular breakwater . . . . . . 26

7 Transmission coefficient for a rectangular breakwater restricted to sway motion only . . . . . . . . . . . . 27

8 Transmission coefficient for a rectangular breakwater
restricted to heave motion only. . . . . . . . . . . . . 29

9 Transmission coefficient for a rectangular breakwater . . . . . . 30

10 Transmission coefficient for Alaska-type breakwater mode1 . . . . 31

11 Transmission coefficient for rigidly fixed Alaska-type breakwater model .. . . . . . . . . . . . . . 33

12 Transmission coefficient for Alaska-type breakwater, Tenakee, Alaska. . . . . . . . . . . . . . . . 34

13 Theoretically predicted transmission coefficient, Friday Harbor breakwater. . . . . . . . . . . . . . . . . . 


\section{CONTENTS}

FIGURES-Continued

14 Theoretically predicted sway motion response, Friday Harbor

breakwater

15 Theoretically predicted heave motion response, Friday Harbor breakwater

16 Theoretica11y predicted roll motion response, Friday Harbor breakwater

17 Seaward mooring line force for proposed Oak Harbor breakwater

18 Seaward mooring line mooring-force coefficient, Tenakee,

Alaska

19 Recorded time series, Tenakee, Alaska

20 Theoretically predicted long-period sway response of Alaskatype breakwater, Tenakee, Alaska.

21 Theoretical1y predicted seaward mooring line mooring-force coefficient, Friday Harbor breakwater.

22 Theoretically predicted long-period sway response, Friday

Harbor breakwater.

23 General location map.

24 Field experiment site location map. . . . . . . . . . . . . 51

25 Instrumentation location plan, Friday Harbor breakwater . . . .

26 Instrumentation and recording package layout.

27 Average transmission curves for Friday Harbor breakwater.

28 Transmission coefficient for Friday Harbor breakwater . . . . .

29 Sway acceleration response for Friday Harbor breakwater . . . .

30 Heave acceleration response for Friday Harbor breakwater.

31 Roll acceleration response for Friday Harbor breakwater . . . .

32 Seaward mooring 1ine mooring-force coefficient, Friday Harbor breakwater. 
U.S. customary units of measurement used in this report can be converted to metric (SI) units as follows:

\begin{tabular}{ccl}
\hline Multiply & by & \multicolumn{1}{c}{ To obtain } \\
\hline \hline inches & 25.4 & millimeters \\
square inches & 2.54 & centimeters \\
cubic inches & 6.452 & square centimeters \\
feet & 16.39 & cubic centimeters \\
& 30.48 & centimeters \\
square feet & 0.3048 & meters \\
cubic feet & 0.0929 & square meters \\
yards & 0.0283 & cubic meters \\
square yards & 0.9144 & meters \\
cubic yards & 0.836 & square meters \\
miles & 0.7646 & cubic meters \\
square miles & 1.6093 & kilometers \\
acres & 259.0 & hectares \\
foot-pounds & 0.4047 & hectares \\
ounces & 1.3558 & newton meters \\
pounds & 28.35 & grams \\
ton, long & 453.6 & grams \\
ton, short & 0.4536 & kilograms \\
degrees (angle) & 1.0160 & metric tons \\
Fahrenheit degrees & 0.9072 & metric tons \\
\hline \hline
\end{tabular}

${ }^{1}$ To obtain Celsius $(\mathrm{C})$ temperature readings from Fahrenheit $(\mathrm{F})$ readings, use formula: $\mathrm{C}=(5 / 9)(\mathrm{F}-32)$.

To obtain Kelvin $(K)$ readings, use forumla: $K=(5 / 9)(F-32)+273.15$. 


\begin{tabular}{|c|c|}
\hline$A_{1}, A_{2}$ & Amplitudes of two incident waves \\
\hline $\mathrm{a}_{1}$ & Amplitude of sway, heave, or roll motion for $i=1,2,3$ \\
\hline B & Characteristic beam of breakwater \\
\hline $\mathrm{C}_{0}$ & Body contour \\
\hline $\mathrm{C}_{\mathrm{T}}$ & Transmission coefficient \\
\hline$F_{j}(t)$ & Sway, heave, or roll exciting forces or moment for $j=1,2,3$ \\
\hline $\mathrm{KH}_{\mathrm{ij}}$ & $\begin{array}{l}\text { Hydrostatic restoring-force coefficient for force in the } j \text { th } \\
\text { direction due to motion in the ith direction }\end{array}$ \\
\hline $\mathrm{KM}_{\mathrm{ij}}$ & Similar to $\mathrm{KH}_{\mathrm{ij}}$ but due to the mooring system \\
\hline $\mathrm{k}_{1}, \mathrm{k}_{2}$ & Wave numbers of two incident waves \\
\hline $\mathrm{L}$ & Incident wavelength \\
\hline$m_{i j}$ & Mass or moment of inertial when $i=j, 0$ when $i \neq j$ \\
\hline$\vec{n}$ & Unit interior normal to body surface \\
\hline$P(x, y, t)$ & Pressure \\
\hline $\overrightarrow{\mathrm{r}}$ & Vector from center of gravity to a point on the body surface \\
\hline$\alpha_{i}, \dot{\alpha}_{i}, \ddot{\alpha}_{i}$ & Sway, heave, or roll motion; speed or acceleration \\
\hline$\delta$ & Phase angle \\
\hline$\delta_{1}, \delta_{2}$ & Phase angles for two incident waves \\
\hline$\eta(x, t)$ & Free-surface elevation \\
\hline$\eta_{I}(x, t)$ & Wave surface elevation for incident wave \\
\hline$n_{T}(x, t)$ & Wave surface elevation for transmitted wave \\
\hline$\lambda_{i j}$ & $\begin{array}{l}\text { Damping coefficient for force in the } j \text { th direction related to } \\
\text { velocity in the ith direction }\end{array}$ \\
\hline$\mu_{i j}$ & $\begin{array}{l}\text { Added-mass or inertial-force coefficient for force in the } \\
j \text { th direction related to acceleration in the ith direction }\end{array}$ \\
\hline$\rho$ & Fluid density \\
\hline$\phi$ & Velocity potential \\
\hline$\omega$ & Frequency \\
\hline$v_{1}, \omega_{2}$ & Frequencies for two incident waves \\
\hline
\end{tabular}


FLOATING BREAKWATER FIELD ASSESSMENT PROGRAM, FRIDAY HARBOR, WASHINGTON

\author{
by \\ B.H. Adee, E.P. Richey, \\ and D.R. Christensen
}

\title{
I. INTRODUCTION
}

Floating structures for use in the attenuation of water waves were introduced by Joly (1905). Little was done with the concept until the Bombardon floating breakwater was deployed to form a harbor during the Normandy invasion of World War II. The use of mobile harbors for potential military applications provided the incentive for extensive work during the postwar years. Representative articles from this period include those by Minikin (1948) who discussed floating breakwaters in general terms, Carr (1951) who used basic mechanics to predict transmission characteristics, and the review of the performance of the BomBardon by Lochner, Faber, and Penny (1948). In 1957, the Naval Civil Engineering Laboratory, Port Hueneme, California, began a concerted exploration of the existing knowledge of transportable units that could serve as breakwaters or piers. Results of the study are summarized in Naval Civil Engineering Laboratory (1961), which was an invaluable state-of-the-art assessment with particular emphasis on military uses under the rather severe site criteria of an incident wave with a 15-foot height, 13-second period, minimum water depth of 40 feet, inshore transmitted wave height of 4 feet, and tidal range of 12 feet. A sequel to the earlier study (Naval Civil Engineering Laboratory, 1971) surveyed concepts for "transportable" breakwaters, including over 60 in the "floating" category. Although no breakwater system was disclosed which would meet the stringent military site criteria and transportability requirement, these state-of-the-art reviews sparked renewed interest in the floating breakwater for nonmilitary applications. A review of developments in floating breakwaters was summarized by Richey and Nece (1974); Seymour (1974) introduced a new and innovative concept for wave attenuation using a system of tethered floats which may have application over a wide range of wave conditions.

Continually increasing pleasure boat ownership has nearly exhausted the available supply of moorage space in many areas. The need for additional moorage space in conjunction with escalating construction costs and more stringent environmental restrictions require careful scrutiny of alternatives to the traditional fixed breakwater and excavation techniques employed in marina construction. Productive time in weatherdependent, waterborne activities such as construction, logging, and cargo handling could be increased if protective floating, transportable breakwaters were used. Other uses in the control of shoreline erosion and in the emerging mariculture industry may also be found. 
The information on the performance of floating breakwaters, i.e., their wave attenuating characteristics, mooring line forces, and motions, is contained primarily in reports of laboratory scale model tests with monochromatic incident waves; the few exceptions are the early analytical work by $\operatorname{Carr}$ (1951) and the occasional piece of information from a ful1scale test Iike that performed by Harris (1974). There is a need for a fundamental analytical procedure to predict the performance characteristics of floating breakwaters with arbitrary cross section when exposed to a given incident wave. This procedure could be used to systematically compare performance information available in the literature, to examine new design proposals, and either eliminate or reduce and systematize auxiliary experimental studies.

The development of the predictive procedure was the primary thrust of the project with the concommitant field assessment of a full-scale floating breakwater in operation at Friday Harbor, Washington (Fig. 1). The analytical model developed from the two-dimensional, linearized solutions of the hydrodynamical equations formulated in terms of a boundary value problem for the velocity potential. The model was refined progressively by comparisons with results already reported in the literature, by auxiliary laboratory tests, and by the results from the Friday Harbor field program, where measurements of incident and transmitted waves, mooring line forces, and acceleration in sway, heave, and roll were measured over a 6-month period. 


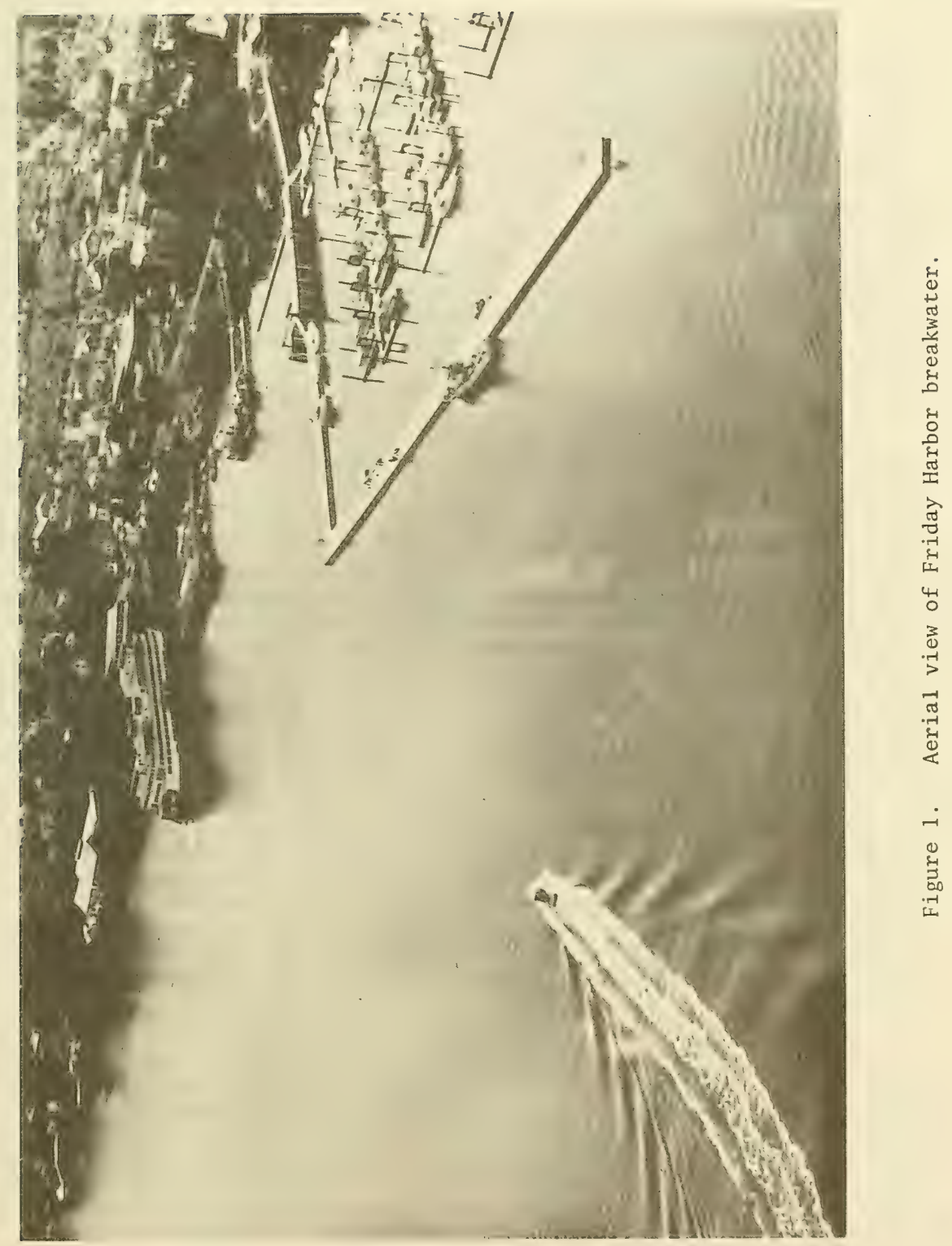




\section{THEORETICAL ANALYSIS}

In the analysis of complex systems such as floating breakwaters, there is a great need for model-scale experiments to predict their performance and provide data for the application of rational engineering design principles. Full-scale measurements are also extremely valuable in verifying scaling relationships and in providing confidence that the data obtained from smaller scale experiments are reasonable.

When one considers the myriad possible breakwater configurations which have been proposed to date and the different conditions which prevail at each potential breakwater site, the number of required model tests and the attendant expense are very large. To avoid this expense and also to permit parametric studies aimed at obtaining optimum breakwater configurations, a theoretical model was developed. The goal was to theoretically predict the performance which could be measured in laboratory studies or at prototype installations.

The initial restriction imposed on the theoretical model was to consider only two-dimensional conditions. Under this restriction the breakwater is assumed to be very long in one direction with long-crested waves approaching so that their crests are parallel to the long axis of the breakwater. At most breakwaters where the wave climate results from wind-generated waves, this condition would rarely be approached. However, experiments performed using a boat wake to generate incident waves on the beam and at an angle to a breakwater indicate larger breakwater motions and larger transmitted waves when the incident wave crests approach parallel to the long axis of the breakwater (Stramandi, 1975). As a design tool, a two-dimensional theory provides information on the worst conditions which might be expected to occur. In addition, the extensive two-dimensional wave-channel experiments provide the data needed to test the theoretical model.

Throughout the development of the theoretical model, every attempt was made to orient the model toward providing a useful tool applicable to realistic problems. To perform the calculations the user need only know the incident wave frequencies of interest, the contour of the breakwater cross section (catamaran- or trimaran-type cross sections are permitted), and the physical properties of the breakwater (these include mass, mass moment of inertia, and the static restoring-force coefficients).

The approach used here has been to employ the techniques which naval architects have developed to deal with ship motion problems. Mathematically, the hydrodynamic equations are formulated in terms of a. boundary value problem for the velocity potential. Solution of this complete problem is presently impossible because the free-surface boundary condition is nonlinear. An approximate solution may be obtained if restrictions are imposed on the boundary value problem, and the procedure of linearization is applied. The restrictions limit the applicability of 
the solution to cases of small incident wave amplitude and small motion response of the breakwater.

When using the linearized theory which is presented here, one must be well aware of the limits of applicability which are imposed on the results in order to permit the formulation of a tractable mathematical problem. Care must also be exercised because these restrictions may exclude phenomena which occur in nature from appearing in the mathematical analysis. For instance, field observations clearly demonstrate the occurrence of mooring line force oscillations at periods greater than those which could be attributed directly to wind-generated wave excitation. Using a linearized approach, these long-period oscillations would not appear in the analysis. A theoretical model which includes nonlinear behavior of the system is required if these long-period oscillations are to be included.

A possible nonlinear mechanism for the transfer of wave energy to lower frequencies has been postulated and is presented to supplement the linear analysis.

1. Linear Theoretical Mode1.

The problems involved in theoretically predicting the performance of a two-dimensional floating breakwater are illustrated in Figure 2. Here an incident wave approaches the breakwater on the beam. A part of the energy contained in the incident wave is reflected, part passes beneath the breakwater, and some is lost through dissipation. Another part of the incident wave energy excites the motions of the breakwater. These motions are restrained by the mooring system. The oscillating breakwater in turn generates waves which travel away from the breakwater in the directions of the reflected and transmitted waves. The total transmitted wave is the sum of the component which passes beneath the breakwater and the components generated by the breakwater motions. The total reflected wave is composed similarly.

In completing the calculations, the information which is of most interest to the designer includes:

(a) Total transmitted and reflected waves including their components.

(b) Wave forces on the breakwater.

(c) Motions of the breakwater.

(d) Forces on the mooring lines.

For the two-dimensional breakwater, definitions for the motions are shown in Figure 2. Sway is defined as the oscillation perpendicular to the long axis, or along the $x$-coordinate axis. Heave is the vertical 


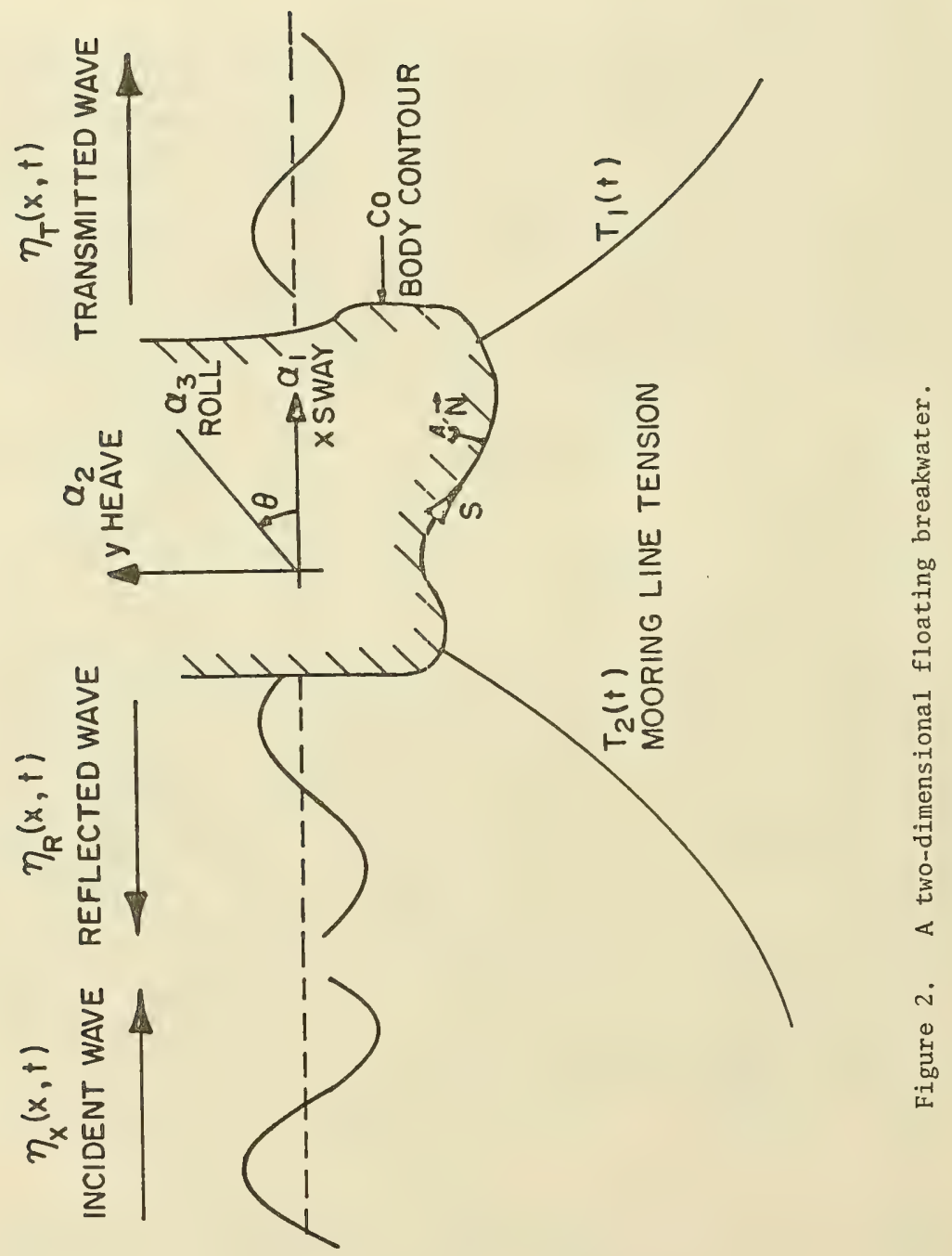


motion of the breakwater along the $y$-coordinate axis, and roll is the rotation about the long axis or the z-coordinate direction.

As long as the problem is linear, computing the performance of a floating breakwater may be separated into three parts:

(a) Formulate equations of motion,

Calculate hydrostatic forces and moments.

Evaluate hydrodynamic coefficients in equations of motion.

Compute exciting forces on breakwater.

Solve for the motions and motion-generated waves.

Compute forces in the mooring lines.

(b) Solve for the waves diffracted by a rigidly restrained breakwater.

(c) Sum components to obtain total reflected and total transmitted waves.

When combined, these parts of the calculation provide complete performance data for a two-dimensional breakwater.

a. Breakwater Motions. In deriving the equations of motion, Newton's law is used.

$$
m_{i j} \ddot{\alpha}_{i}=\Sigma \text { forces; }
$$

here:

$\alpha_{i}=$ motion of the breakwater in sway, heave, and roll for $i=1,2,3$, respectively. The dot above indicates differentiation with respect to time.

$m_{i j}=$ mass or mass moment of inertia when $i=j$ and zero when $i \neq j$.

Expanding this equation to include the various forces in the summation yields:

$$
\begin{aligned}
m_{i j} \ddot{\alpha}_{i}= & F_{j} \text { (inertial) }+F_{j} \text { (wave damping) } \\
& +F_{j} \text { (friction) }+F_{j} \text { (hydrostatic) }+F_{j} \text { (mooring) } \\
& +F_{j} \text { (wave exciting) }
\end{aligned}
$$


The inertial force (or added-mass force) arises when the breakwater accelerates, which also accelerates the fluid around it. The motion-generated waves are moving away from the breakwater and result in the wavedamping term. A term representing the forces due to viscosity is included, but these forces are neglected in the analysis. Experience in ship motion analysis (Salvesen, 1970) has shown this to be acceptable for all motions but roll, where damping may make a more significant contribution than for sway and heave motions. At present, the main reason for neglecting the frictional forces is that they lead to nonlinear terms in the equations of motion, which make their solution far more complex. Hydrostatic forces arise because of changes in the displaced volume of the breakwater when it moves. In this analysis the mooring forces are modeled as simple springs with their contribution to the damping and inertial forces considered small in comparison to similar terms resulting from the breakwater motion. The wave exciting force results from the incident waves striking the breakwater.

If we neglect the nonlinear terms and assume that the fluid is inviscid, then the equations of motion describing the coupled sway, heave, and roll motions of the breakwater are of the form:

$$
\begin{aligned}
\sum_{i=1}^{3}\left\{\left(m_{i j}+\mu_{i j}\right) \ddot{\alpha}_{i}+\lambda_{i j} \dot{\alpha}_{i}+\left(K H_{1 j}+K M_{i j}\right) \alpha_{i}\right\}=F_{j}(t) \\
\text { for } j=1,2,3 .
\end{aligned}
$$

The symbols are defined as follows:

$\mu_{i j}=$ added-mass coefficient with the $\mu_{i j} \ddot{\alpha}_{i}$ representing the added-mass force or moment in the jth direction due to acceleration in the ith direction.

$\lambda_{i j}=$ damping-force coefficient relating damping force or moment in the $j$ th direction to velocity in the ith direction.

$\mathrm{KH}_{i j}=$ hydrostatic spring constant relating the restoring force or moment in the jth direction to displacement in the ith direction.

$\mathrm{KM}_{i j}=$ similar to $\mathrm{KH}_{i j}$ but due to the mooring system.

$\mathrm{F}_{j} \quad=$ exciting force or moment in the $j$ th direction.

In order to solve these equations, the physical mass and moment of inertia, added mass and damping coefficients, static spring constants, and the exciting forces must all be known. Mass and moment of inertia are computed directly from the specifications of the breakwater section. The $\mathrm{KH}_{i j}$ are derived directly from hydrostatic considerations in Appendix $\mathrm{A}$, while approximate values for $\mathrm{KM}_{i j}$ are obtained by using a discretized approximation for the mooring line as described in Appendix B. Potential 
theory and the principle of linear superposition permit derivations for the hydrodynamic coefficients and forcing function $\mu_{i j}, \lambda_{i j}$ and $F_{j}(t)$.

Steady-state solutions of the form:

$$
\alpha_{i}(t)=a_{i} \sin \left(\omega t+\delta_{i}\right) \text { for } i=1,2,3
$$

are assumed. Substitution of the assumed solution (eq. 3) into the equations of motion (eq. 2) yields a set of linear algebraic equations which may be solved for the unknown amplitudes and phase angles $a_{i}$ and $\delta_{i}$. Transfer functions, $H_{i}$, are then defined by the $a_{i}$ and $\delta_{i}$ since the incident waves are assumed to be sinusoidal.

b. Hydrodynamic Coefficients and Waves. Potential theory is employed in computing the reflected and transmitted waves, hydrodynamic coefficients and the exciting forces. Under the assumptions of small incident waves, small breakwater motions and an inviscid fluid, the velocity potentials may be found and the problem subdivided using the principle of linear superposition. The total velocity potential:

$$
\phi_{\text {total }}=\phi_{\text {incident }}+\phi_{\text {diffracted }}+\phi_{\text {motion }}^{(i)} \text { for } i=1,2,3
$$

is the sum of the incident wave potential, the diffracted wave potential and the potential resulting from forced sway, heave, and roll motions.

The incident wave potential is well known and may be expressed directly. Obtaining the diffracted wave and breakwater motion potentials requires the solution of boundary value problems. These problems and their solutions are described in Appendix C. Appendix D provides the computer program used to calculate breakwater performance.

When the velocity potentials have been obtained, the free-surface elevation at any position is found using the linearized free-surface boundary condition:

$$
n(x, t)=-\frac{1}{g} \phi_{t}(x, 0, t) .
$$

Here:

$$
\begin{aligned}
n(x, t)= & \text { free-surface elevation measured from stillwater } \\
& \text { level }(y=0), \\
g & \text { acceleration of gravity, } \\
\phi_{t}(x, 0, t)= & \text { derivative of the velocity potential with respect to } \\
& \text { time evaluated at } y=0 .
\end{aligned}
$$




$$
\begin{aligned}
n_{\text {total }}(x, t)= & -\frac{1}{g}\left\{\phi_{t \text { incident }}(x, 0, t)+\phi_{t \text { diffracted }}(x, 0, t)\right. \\
& \left.+\phi_{t}{ }^{(i)} \text { motion }(x, 0, t)\right\} .
\end{aligned}
$$

The fluctuating component of pressure in the fluid and on the breakwater hull surface may be computed using Bernoulli's equation:

$$
P(x, y, t)=-\rho \phi_{t}(x, y, t) \text {. }
$$

By computing pressures on the hull surface and integrating these around the contour, the forces on the breakwater may be computed. The force per unit length acting on the breakwater is then:

$$
F(t)=\int_{C_{0}} p \vec{n} d s .
$$

In this case,

$$
\begin{aligned}
& \mathrm{F}(\mathrm{t})=\text { force on the breakwater, } \\
& \overrightarrow{\mathrm{n}} \quad=\text { unit interior normal vector on the hull surface, } \\
& \mathrm{C}_{\mathrm{O}} \quad=\text { contour of breakwater cross section. }
\end{aligned}
$$

The rolling moment is:

$$
M(t)=\int_{C_{0}} P \vec{r} \times \vec{n} d s,
$$

where,

$\vec{r}=$ the vector from the center of gravity to a point on the surface.

To compute the exciting forces on the breakwater in linear theory, the pressure due to the incident and diffracted waves is integrated over the hull surface. These forces and moments become:

$$
\begin{aligned}
& F_{1}(t)=\left\{-\rho \int_{C_{0}}\left[\phi_{t \text { incident }}(s, t)+\phi_{t} \text { diffracted }(s, t)\right] \vec{n} d s\right\} \cdot \vec{i}, \\
& F_{2}(t)=\left\{-\rho \int_{C_{0}}\left[\phi_{t} \text { incident }(s, t)+\phi_{t \text { diffracted }}(s, t)\right] \vec{n} d s\right\} \vec{j}, \\
& F_{3}(t)=\left\{-\rho \int_{C_{0}}\left[\phi_{t \text { incident }}(s, t)+\phi_{t} \text { diffracted }(s, t)\right] \vec{r} \times \vec{n} d s\right\} \cdot k
\end{aligned}
$$

Hydrodynamic coefficients are found using the potential resulting from forced oscillation of the breakwater. In this case the pressure 
integrated over the surface has a component in phase with acceleration and a component in phase with velocity. The component in phase with acceleration is normally referred to as the added mass, while the component in phase with velocity is the damping.

The hydrodynamic coefficients shown in this section are derived in greater detail in Appendix C.

c. Mooring Forces. At the time the spring constants for the mooring lines are computed, mooring force coefficients are also calculated. These are:

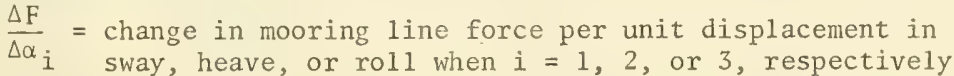

The forces in the mooring lines may then be computed once the motions have been found.

$$
\text { Mooring Force }=\sum_{i=1}^{3}\left(\frac{\Delta F}{\Delta \alpha_{i}}\right) \alpha_{i}(t)
$$

The description of the linear system is now complete. The block diagram in Figure 3 shows the relationships among the calculations which are required.

\section{Nonlinear Theoretical Model.}

Measurements taken at the Tenakee, Alaska, floating breakwater before this research program was begun indicated the presence of a longperiod oscillatory motion of the breakwater. These long-period motions were manifested most clearly in the measured mooring line forces. Looking at these, one can visually observe an oscillation with a period of about 60 seconds superimposed over the expected shorter period oscillations. Figure 4 shows the results of a spectral analysis of the seaward mooring line data after a low-pass filter has been applied (the technique for performing the spectral analysis is given in Section III of this report).

The linear theoretical model permits the system to respond only at the frequency of the incident wave. In order to explain the presence of these long-period oscillations, nonlinearities must be included in the analysis. To perform a mathematically complete analysis including all nonlinear effects is beyond the present state of the art. However, in the case of the floating breakwater, one can show that if two incident waves are considered and second-order terms are retained, then an exciting force is present at the difference between the frequencies of the incident waves. The complete derivation in Appendix $\mathrm{E}$ shows that the nonlinear pressure may be expressed as: 


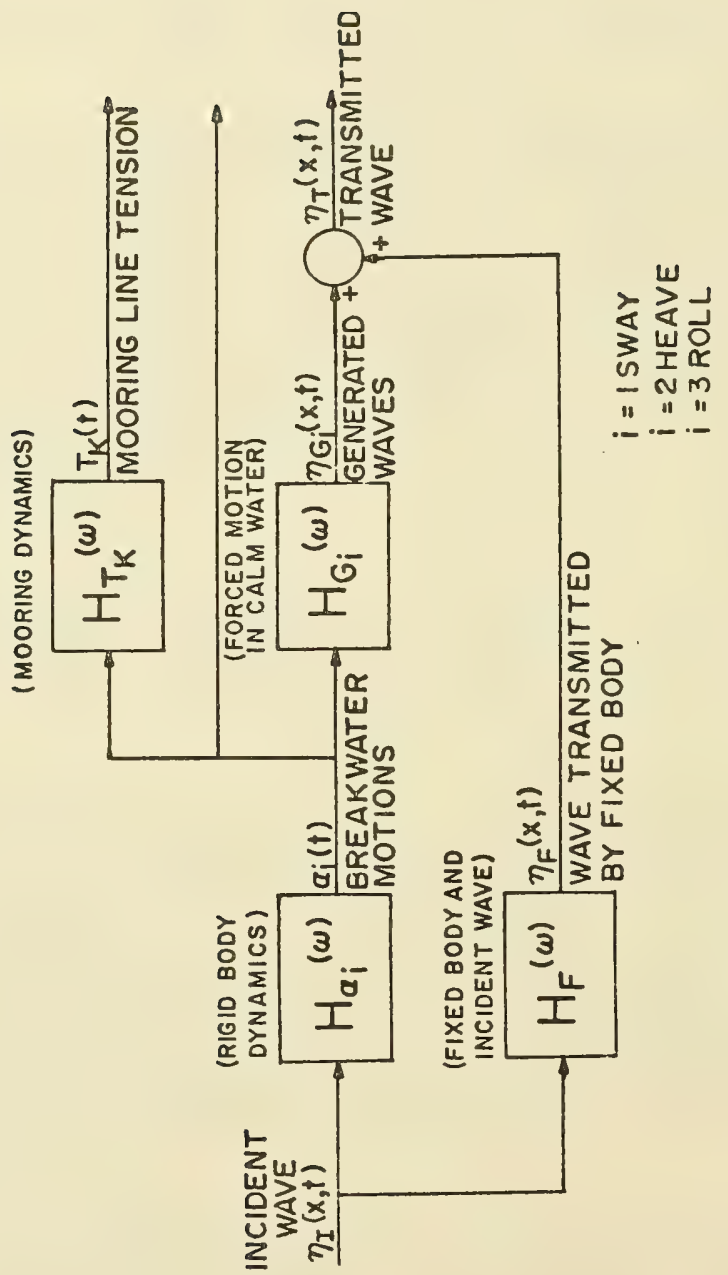

ن 


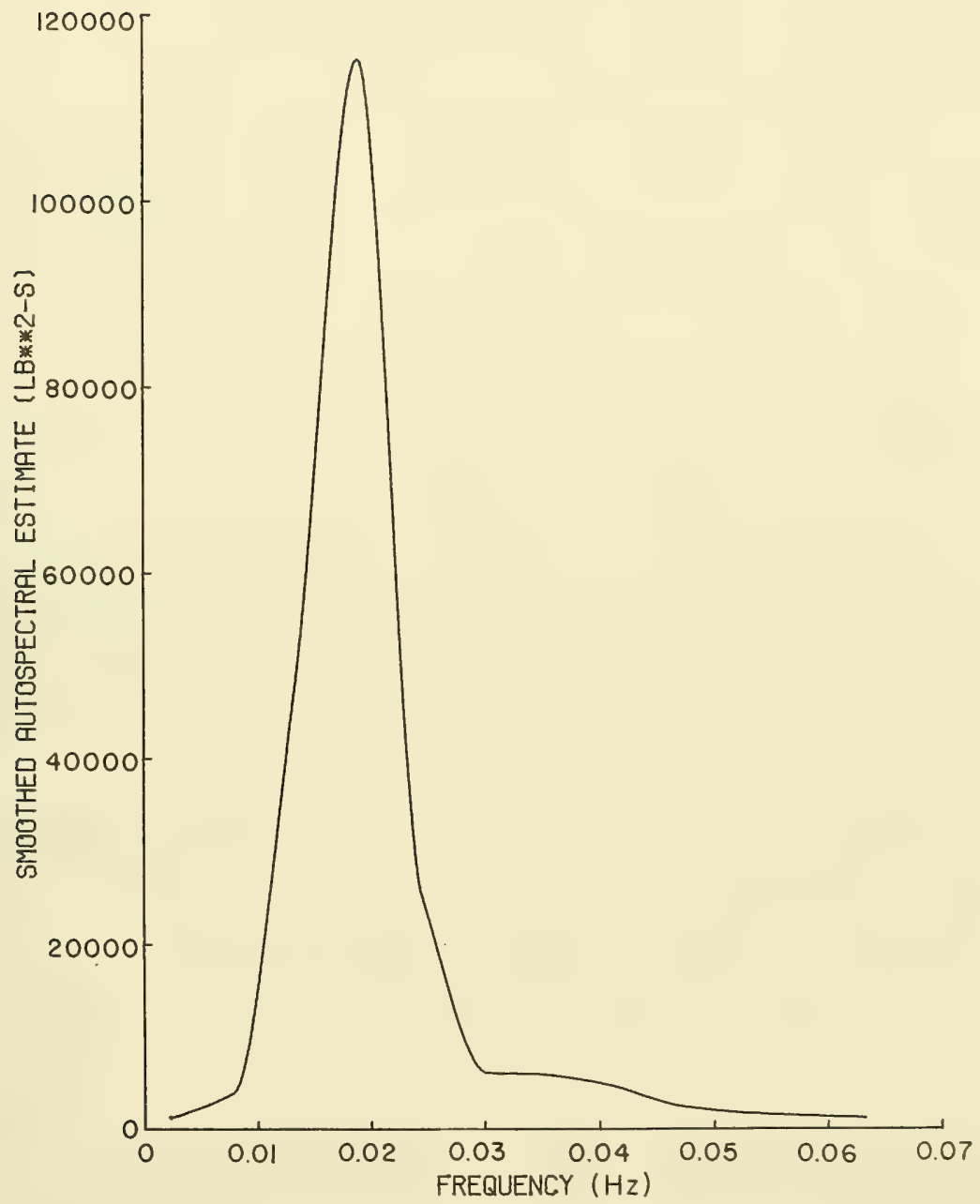

Figure 4. Filtered low-frequency seaward mooring line force, Tenakee, Alaska (record TK7-23). 


$$
\begin{aligned}
P(t)= & -\frac{\rho}{2}\left\{\omega_{1}{ }^{2} A_{1}{ }^{2} e^{2 k_{1} t}+\omega_{2}{ }^{2} A_{2}{ }^{2} e^{2 k_{2} y}\right. \\
& -2 \omega_{1} \omega_{2} A_{1} A_{2} e^{\left(k_{1}+k_{2}\right) y} \cos \left[\left(k_{1}-k_{2}\right) x\right. \\
& \left.\left.-\left(\omega_{1}-\omega_{2}\right) t+\delta_{1}-\delta_{2}\right]\right\},
\end{aligned}
$$

where,

$$
\begin{aligned}
& \rho \quad \text { fluid density, } \\
& \omega_{1}, \omega_{2}=\text { incident wave frequencies, } \\
& \mathrm{A}_{1}, \mathrm{~A}_{2}=\text { incident wave amplitudes, }{ }^{2}, \omega_{1}^{2} \\
& \mathrm{k}_{1}, \mathrm{k}_{2}=\text { incident wave numbers }=\frac{\omega_{2}}{\mathrm{~g}}, \frac{\mathrm{w}^{2}}{\mathrm{~g}}, \\
& \delta_{1}, \delta_{2}=\text { incident wave phase angles. }
\end{aligned}
$$

Combining this pressure with the pressure obtained from the linear theory and integrating over the hull would provide additional exciting-force terms at zero frequency and at the difference frequency. Carrying the nonlinear exciting-force terms back through the linear response analysis should provide a quasi-1inear approach. While there is no reason to expect this to provide exact correlation with measured data, the quasilinear approach would at least permit the natural phenomena to enter into the mathematical analysis.

One would expect terms to appear in the second-order pressure (eq. 11) at twice the incident wave frequency and at the sum of the incident wave frequencies. Terms at twice each of the incident wave frequencies can be derived by applying the trigonometric relationships to the terms at zero frequency. While a term at the sum of the incident wave frequencies does not appear in the second-order incident wave potential, this term may result when the second-order potentials representing diffraction or forced oscillation in calm water are included.

A great deal more effort is required in this area to complete the analysis. There is also one other area where a nonlinear, or quasilinear, analysis should be investigated. This is in the roll-damping. coefficient. Here, viscous effects seem to be important, and while the problem has not been dealt with within the present study, investigators have included a term proportional to velocity squared in the equation for roll motion.

\section{Results.}

The computer program given in Appendix D has been developed to 
calculate the values of hydrodynamic coefficients, breakwater motions, and the wave field. Input variables include:

(a) The body contour, $\mathrm{C}_{\mathrm{O}}$, represented by a series of points on the contour.

(b) The physical properties of the body: mass, mass moment of inertia, and position of the center of gravity.

(c) The mooring system spring constants.

(d) The hydrostatic restoring spring constants.

(e) The incident wave frequency, $\omega$.

In this program the exciting forces and moments appearing in the equations of motion and the fixed-body parts of the transmitted and reflected waves are found by computing the forces, moments, and waves which result when a rigidly fixed body is struck by a sinusoidal incident wave of frequency $\omega$. Motions are found by computing the steady-state solution to the three equations of motion. The hydrodynamic coefficients and the waves generated by the body motions are found by computing the forces, moments, and waves which result when the body is forced to oscillate in stillwater in pure sway, pure heave, or pure roll.

The physical properties used in the performance calculations for the various breakwaters are collected in Appendix F.

a. Wave Transmission. To assess the performance of a floating breakwater, one quantity which is commonly used is the transmission coefficient. This is simply the transmitted wave amplitude divided by the incident wave amplitude, $\left|\eta_{\mathrm{T}}(\mathrm{x}, \mathrm{t})\right| /\left|\eta_{\mathrm{I}}(\mathrm{x}, \mathrm{t})\right|$ for monochromatic incident waves.

(1) Proposed Oak Harbor Breakwater. At one time the Corps of Engineers was considering a marina and floating breakwater at Oak Harbor, Washington. Model experiments were carried out by Davidson (1971) to determine transmission characteristics and mooring forces. The breakwater itself had a catamaran-type cross section. A comparison between the theoretically predicted and experimentally measured transmission coefficient is shown in Figure 5. This figure as well as the others plotted in this section and Section IV were drawn using a CALCOMP plotter. The plotting program uses a parabolic fit to determine additional points between the given data. Varying numbers of data points were used to describe each curve depending on its behavior. Data points were closely spaced in regions where the theoretical predictions indicated large changes in curvature. Wavelength is calculated in all the figures using the relationship between wavelength and period for waves in deep water.

In this case, the results compare reasonably well except for the 


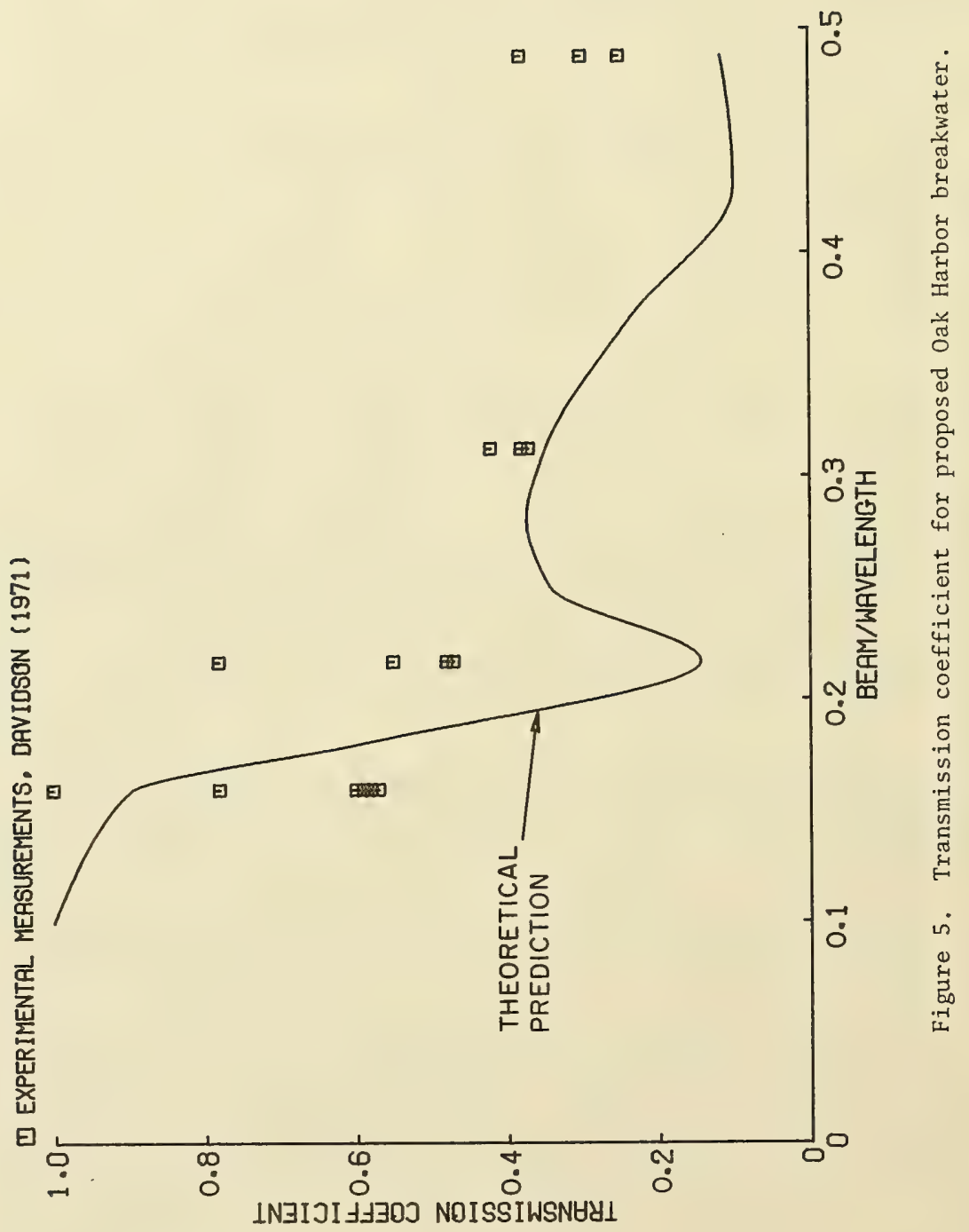


predicted dip in transmission just above a B/L (beam/wavelength) of 0.2 . There is also some difference at higher $B / L$ ratios.

The theory predicts that the part of the transmitted wave which would result where the body is rigidly fixed is almost 1 for a B/L less than 0.1 and drops rapidly at higher $\mathrm{B} / \mathrm{L}$ ratios to the point where it is of little consequence beyond 0.2 . Waves generated by the breakwater motions play an increasing role for $\mathrm{B} / \mathrm{L}$ ratios above 0.15 . Heave motion is the major contributor to the transmitted wave in the very narrow band of $\mathrm{B} / \mathrm{L}$ between 0.15 and 0.18 with a predicted heave resonance at a B/L of about 0.18. The dip occurs because the waves generated by heave and sway motions are almost $180^{\circ}$ out of phase and cancel each other out. At $B / L$ ratios above 0.25 , sway motion assumes an increasingly dominant role. Roll motions are small throughout and generate only very small waves.

(2) Rectangular Breakwater. A breakwater of rectangular cross section with the same beam and draft as the proposed Oak Harbor breakwater was tested at the University of Washington by Nece and Richey (1972). Results for the water depth of 29.5 feet are shown in Figure 6.

Again the agreement is reasonable. Further experiments with this model have confirmed the existence of the trough at a B/L of 0.2 . However, this phenomenon can be observed only for very small wave heights. For practical purposes, the dip may be smoothed over considerably. The major discrepancy is at the high $B / L$ ratios where the theory shows considerably greater transmission than is actually measured in the model tests. Since the transmitted wave is almost totally a result of sway motion, the problem must lie in the wave predicted by this motion.

Over the entire range of wavelengths of interest, the predicted results follow the pattern previously discussed for the proposed Oak Harbor breakwater. The transmitted wave is almost completely a result of fixed-body transmission followed by regions of heave resonance, heave and sway cancellation, and finally, sway wave generation as the B/L increases.

It is interesting to note that there is very little difference between the open-well breakwater and the closed rectangle of the same overall dimensions.

(3) Rectangular Breakwater Tested by Sutko and Haden. In some recent experiments Sutko and Haden (1974) have examined the effect that restricting breakwater motions has on the transmission coefficient. They used a rectangular breakwater model with a beam-to-draft ratio of 1.5. Plexiglas end assemblies were used to restrict the breakwater motions.

Figure 7 shows the transmission coefficient when the breakwater is restricted to sway motions only. Here, the transmitted wave contains a component resulting from the fixed-body transmission and a component 


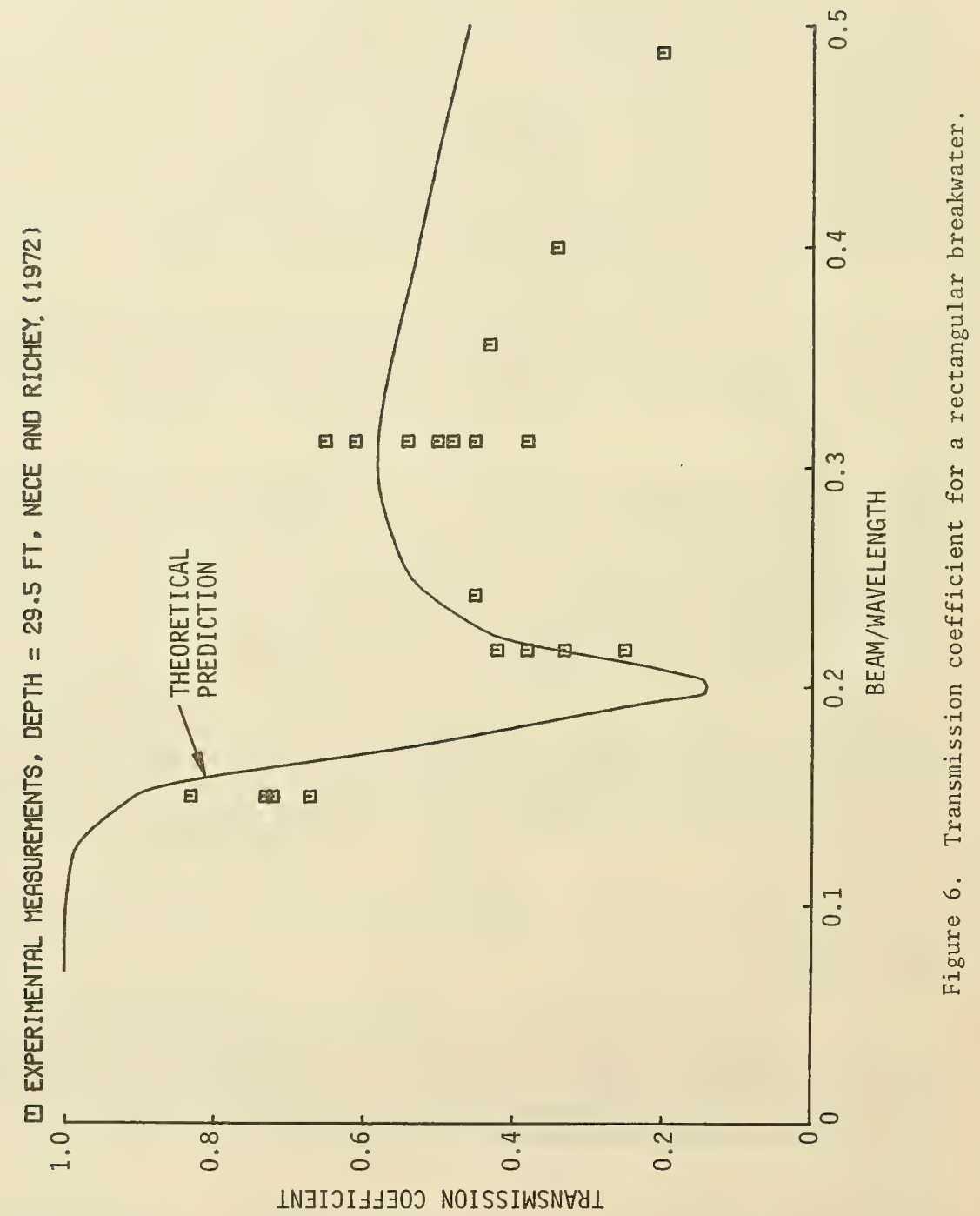




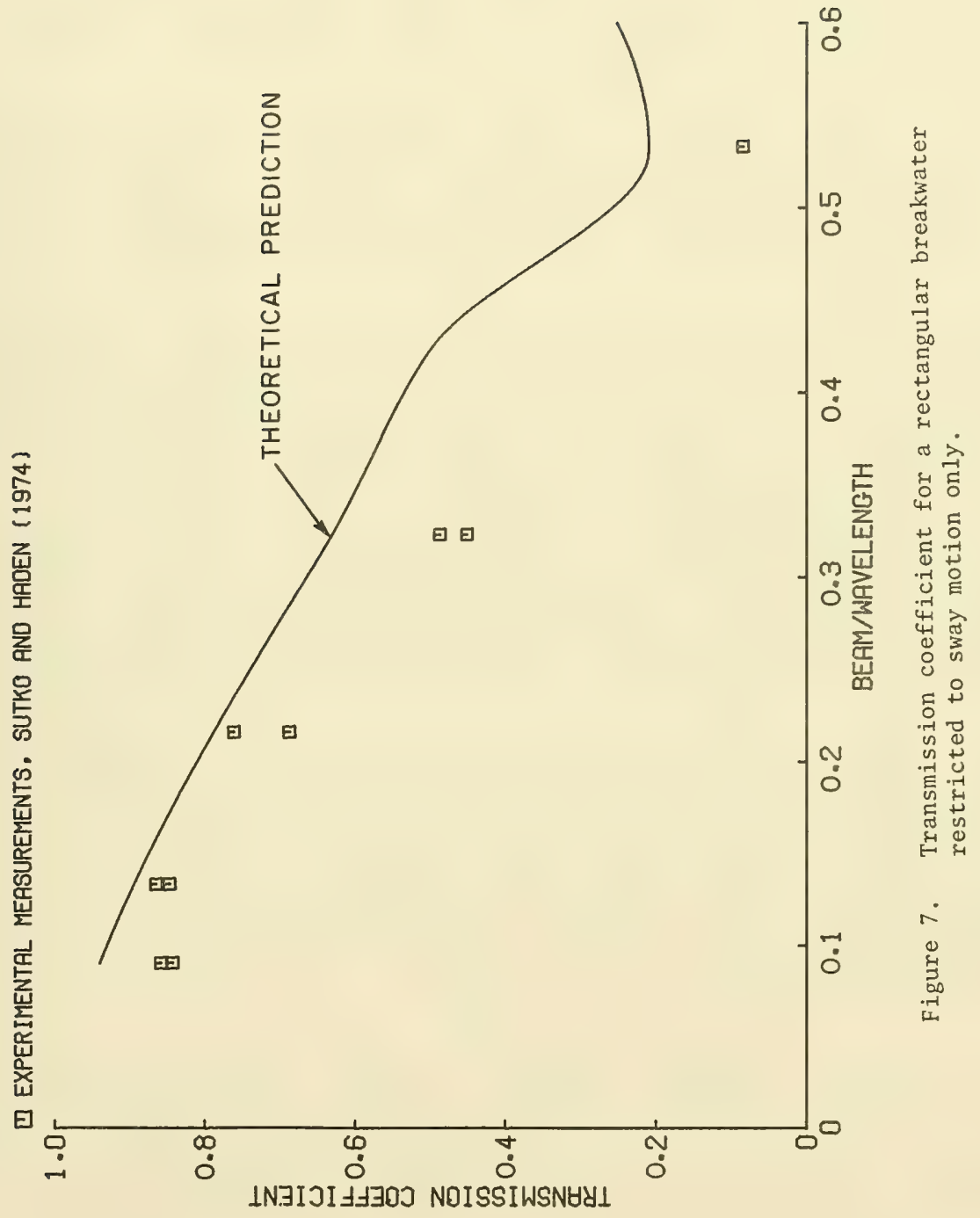


resulting from the wave generated by the sway motion. At very 10 w $B / L$ ratios the fixed-body transmission is the more important component. At a B/L of about 0.1 both the fixed-body transmission and the sway-generated wave are of equal importance. At B/L ratios higher than 0.215 , the wave generated by sway motion dominates. The agreement between theory and experiment is quite reasonable for this case.

A comparison when the breakwater is restricted to heave motion only is shown in Figure 8. There is clearly a discrepancy in this case between measured and theoretically predicted transmission coefficient near the $\mathrm{B} / \mathrm{L}$ ratio of 0.13 . As a matter of fact, the theory predicts a heave resonance in this region which does not seem to be supported by the measured data.

In examining the mechanism used to restrain the breakwater motion, it seemed possible that this apparatus was introducing damping into the system. To test this supposition, transmission coefficients were computed with the calculated hydrodynamic damping increased by an arbitrary amount. The major effect of increasing the damping was to decrease the transmission near the heave resonance region. With damping at three times the hydrodynamic value, the results were quite close to the experimental measurements. Increasing the damping beyond this had very little additional effect on the predicted transmission coefficient. The scatter which appears in the experimental data in this region is a further indication that some nonrepeatable effect may be influencing the experimental results. So long as the additional damping is included in the theoretical calculations, the results compare well with experimental measurements.

Figure 9 shows a comparison between model measurements when the model is unrestrained except by a horizontal mooring cable and the theoretically predicted results without mooring restraints. The theoretical results are characteristic of the rectangular breakwater with the dip in transmission near a B/L equal to 0.2 . The pattern of interactions between motion-generated waves and fixed-body transmission is similar to the previous description. The agreement between these results indicates that the theoretical model may also yield the correct results when the model is free to heave only. At least further experimental investigation is warranted.

(4) Alaska-Type Breakwater. The State of Alaska has embarked on an ambitious program for constructing moorages using floating breakwaters. As part of a Sea Grant project the University of Washington has been studying the performance of this type breakwater. A theoretically predicted transmission coefficient and the transmission coefficient measured in model tests are shown in Figure 10. The model tests were conducted using very small incident waves (wave heights on the order of 0.2 to 0.3 feet at prototype scale). Results for larger wave slopes were not included in the figure but do show the same trends with lower values of transmission coefficient. Theoretical predictions without added damping and with double the hydrodynamic damping are shown in Figure 10. 


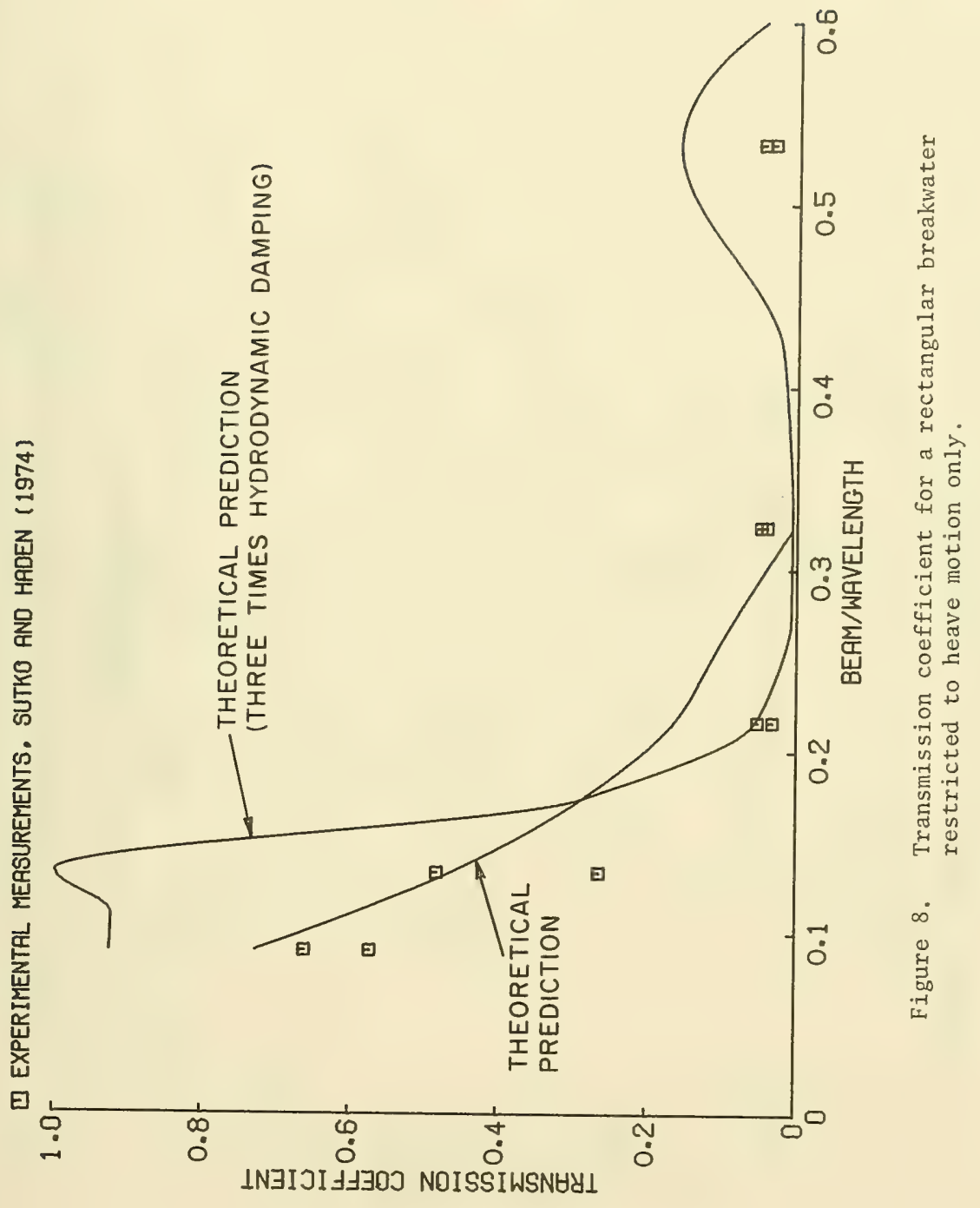




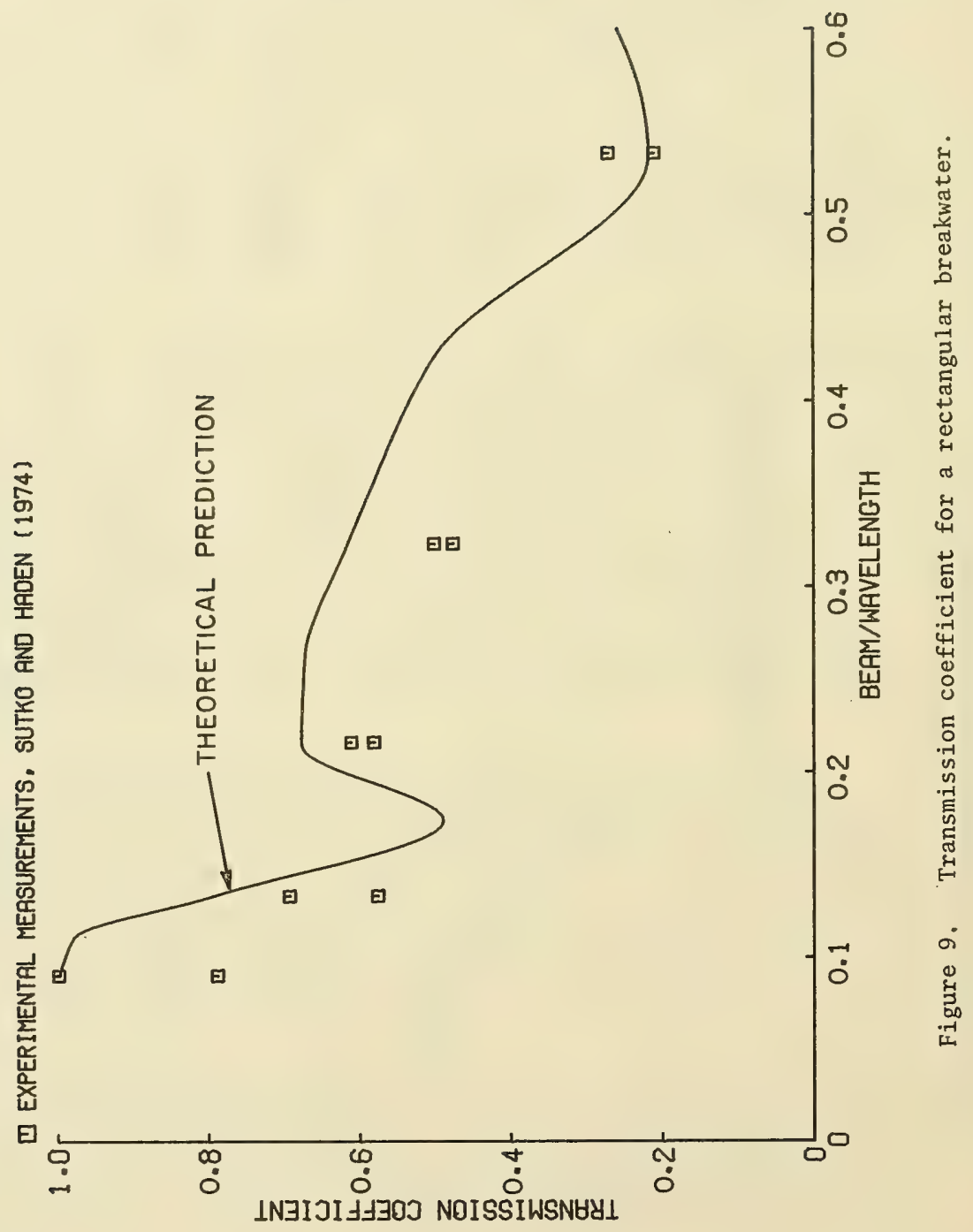




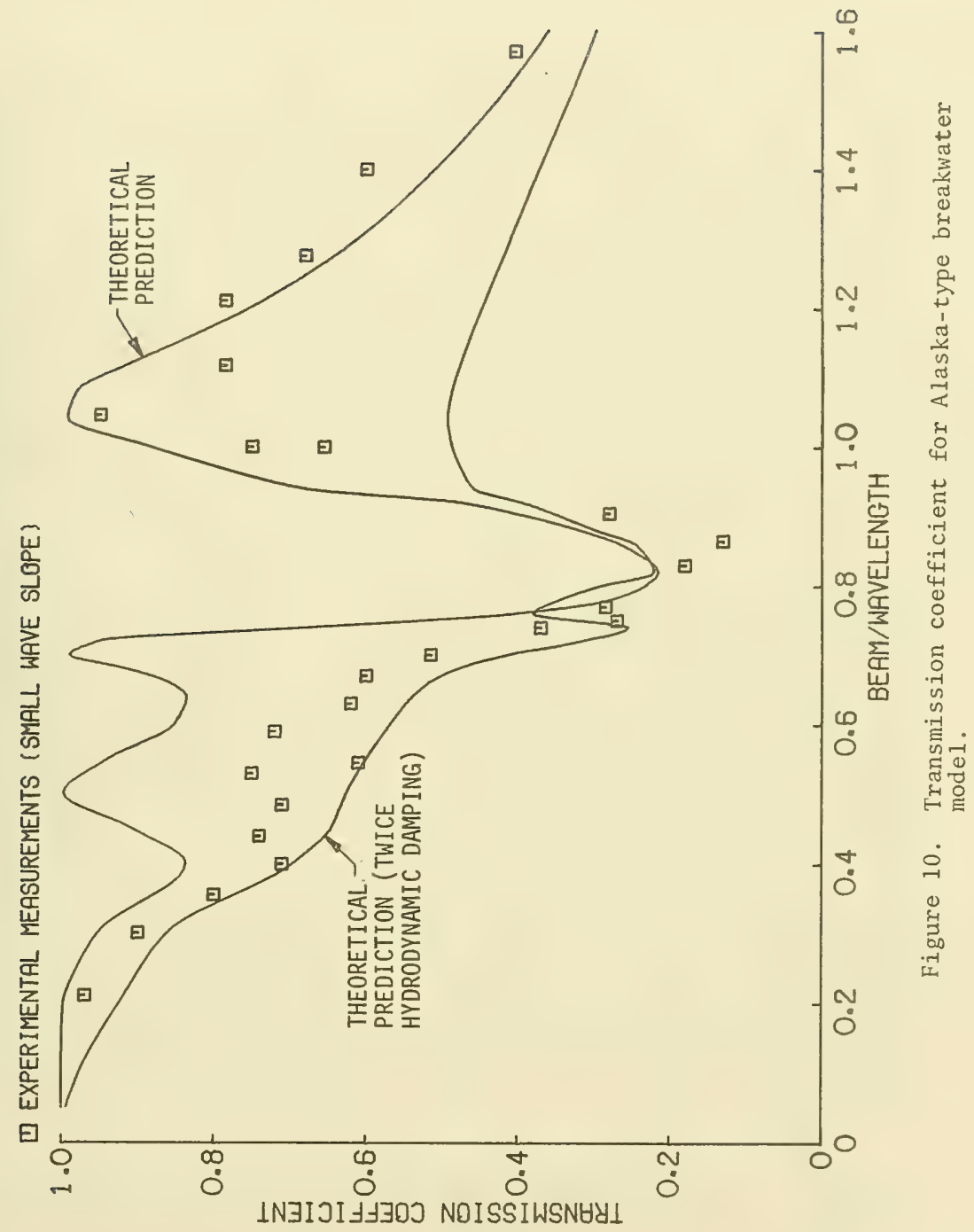


Clearly the increased damping makes a significant difference in the results.

Some insight into the performance of this breakwater may be gained by following the theoretical results as a function of $\mathrm{B} / \mathrm{L}$. At very low $\mathrm{B} / \mathrm{L}$ the fixed-body transmission dominates. The trough at a B/L of 0.4 comes mainly from the interaction of the roll-generated wave and the fixed-body transmission. For the next peak at B/L of 0.5 the rollgenerated wave dominates as the roll resonant frequency is encountered. The next trough at B/L of 0.65 is a result of all three motion-generated waves interacting with the fixed-body transmission making only a relatively small contribution to the transmitted wave. The following peak at $\mathrm{B} / \mathrm{L}$ of 0.7 results from interactions among the motion-generated waves which are of about equal magnitude. At a B/L of 0.86 the heave-generated wave dominates again, but as B/L increases beyond this the effect of heave and roll are rapidly decreasing while sway motion is becoming the dominant wave-generating mechanism. In the region of B/L between 0.4 and 1.0 , changing the physical properties of the breakwater can have a marked effect in shifting the peaks and troughs by altering the heave and roll resonant frequencies.

Experience with linear ship motion theory has shown that the worst agreement between predicted and measured motions occurs when rolling motions are considered (Salvesen, 1970). This discrepancy is often overcome by arbitrarily increasing the computed roll damping to compensate for the viscous damping which is neglected. As indicated in Figure 10, when damping is added the theory gives a better prediction where roll motion plays a significant role. This places a significant restriction on the theory requiring careful monitoring of predicted roll motion. Where the theory predicts large roll motion, additional damping will be required to obtain results comparable to measurements.

Figure 11 shows the predicted fixed-body transmission coefficient and the results of model tests. Agreement is quite close except at B/L of 0.78 . The peak in predicted transmission may be due to a resonance of the waves within the well of the catamaran breakwater. There is another peak near B/L of 1.4 indicating the presence of higher harmonic resonances as we11. Model tests show at least a slight hump in this region suggesting that the theoretical prediction clearly overestimates the effect of this phenomena, but that this probably is occurring in real life.

For the data measured in the field, the transmission coefficient is defined as the square root of the transmitted wave spectral density divided by the incident wave spectral density. Figure 12 shows the transmission coefficient derived from the data obtained at the Tenakee, Alaska breakwater. The theoretically predicted transmission coefficient with the computed hydrodynamic damping doubled is also shown for comparison. Details of the technique used in the spectral analysis of the field data may be found in Section III. 


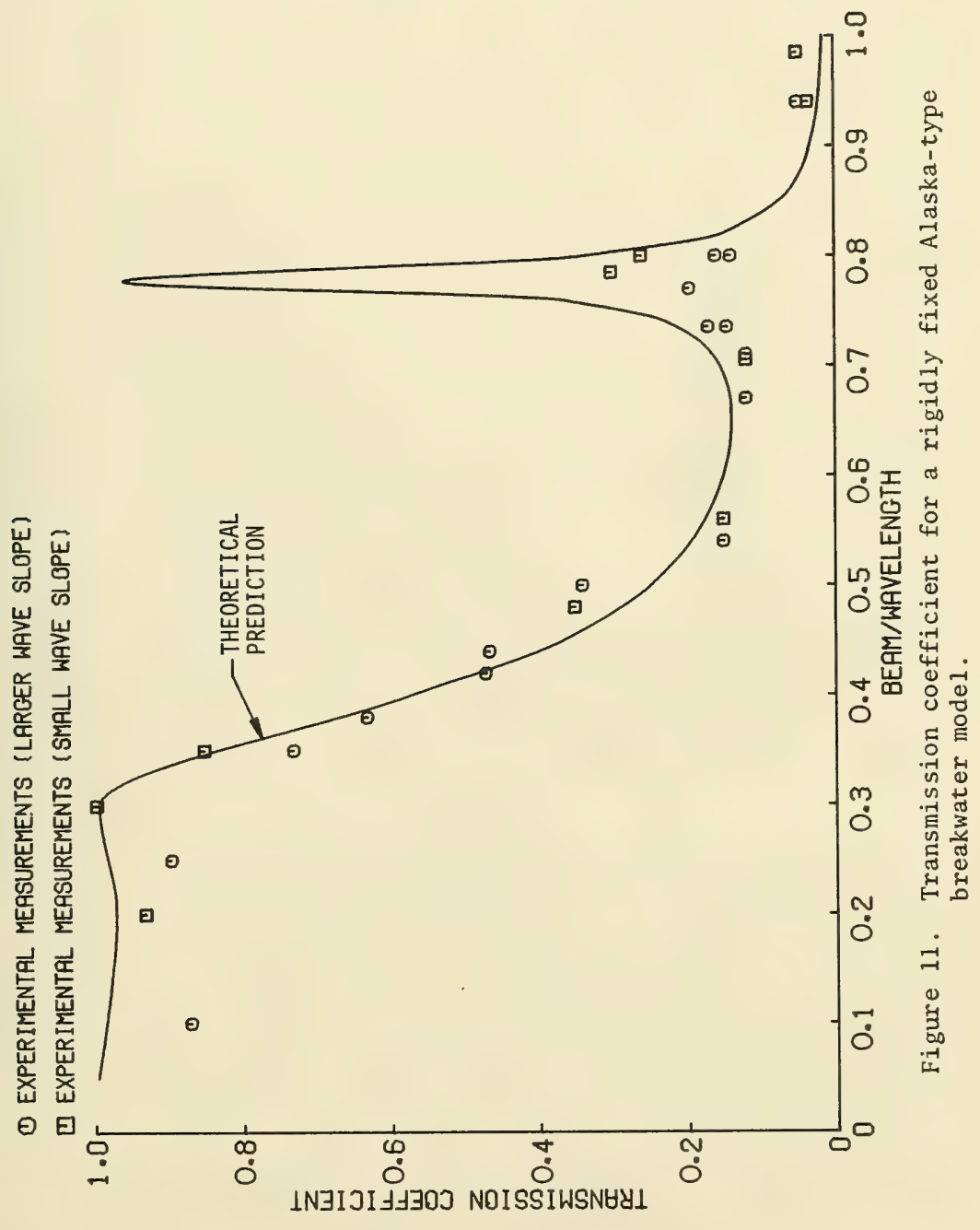




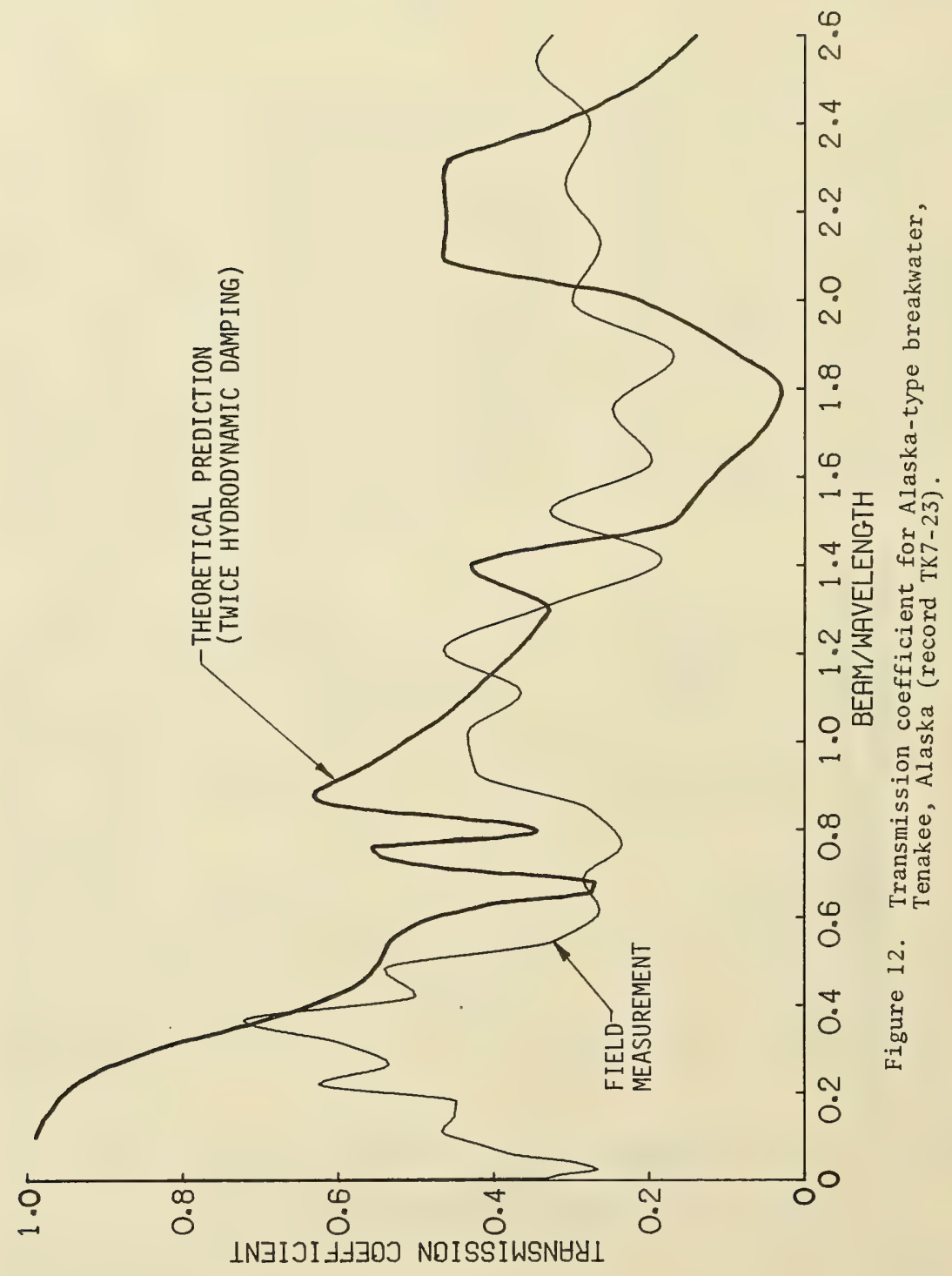


It should be noted that the model for the Alaska-type breakwater was not built to the correct scale to represent the prototype. Further investigation of the physical properties of the prototype after the model tests were complete revealed that it was heavier than originally predicted. The physical properties used in making the theoretical calculations are correct for all the comparisons made in this report. However, care must be exercised in comparing the model test results and the field measurements directly. The physical properties for all the breakwaters discussed in this section are in Appendix F.

The first trough in the transmission coefficient curve results because the wave generated by roll tends to cancel the fixed-body transmission. The sway-generated wave is small but cancels a little bit of the heave-generated wave. The total transmitted wave is then almost in phase with the heave-generated wave at a slightly reduced amplitude. Complex interactions among the components of the transmitted wave continue to result in oscillations of the transmission coefficient up through a B/L of 0.9. At values of $B / L$ above this, the transmitted wave is primarily a result of sway motion except for the peak at B/L equal to 1.4 which results from an increase in the fixed-body transmission. Considering the complexity of the breakwater response, the agreement should be considered to be reasonably good.

(5) Friday Harbor Breakwater. The computed transmission coefficient for the Friday Harbor breakwater is shown in Figure 13. As in the case of the Alaska breakwater calculations, the computations of wave-damping coefficients have been arbitrarily doubled to reduce the excessive calculated motions in the region of resonant motions. In this figure the spacing of data points varies. More points are used to specify the curve in regions of rapid change so that the plotted result accurately represents the theoretical prediction.

In Figure 13, the first trough in transmission coefficient at about $B / L=0.5$ results from heave- and roll-generated waves canceling the fixed-body wave transmission. This transmission coefficient is well below the transmission coefficient which would be obtained with the breakwater rigidly restrained and only fixed-body transmission waves passing through. As B/L increases, there is a peak at about 0.7. At this point the heave-generated wave has almost vanished, and the fixed-body transmission is also small. The larger transmission coefficient is primarily the result of a roll-generated wave with a smaller component resulting from sway motion. The next trough at a B/L of 0.9 occurs as the heave motion-generated wave increases and cancels the roll and sway motiongenerated components. The fixed-body transmission is very small at $B / L$ of 0.9. As B/L increases beyond 0.9 the transmitted wave is almost totally the result of sway motion of the breakwater.

At larger $\mathrm{B} / \mathrm{L}$ ratios there are several oscillations in the 


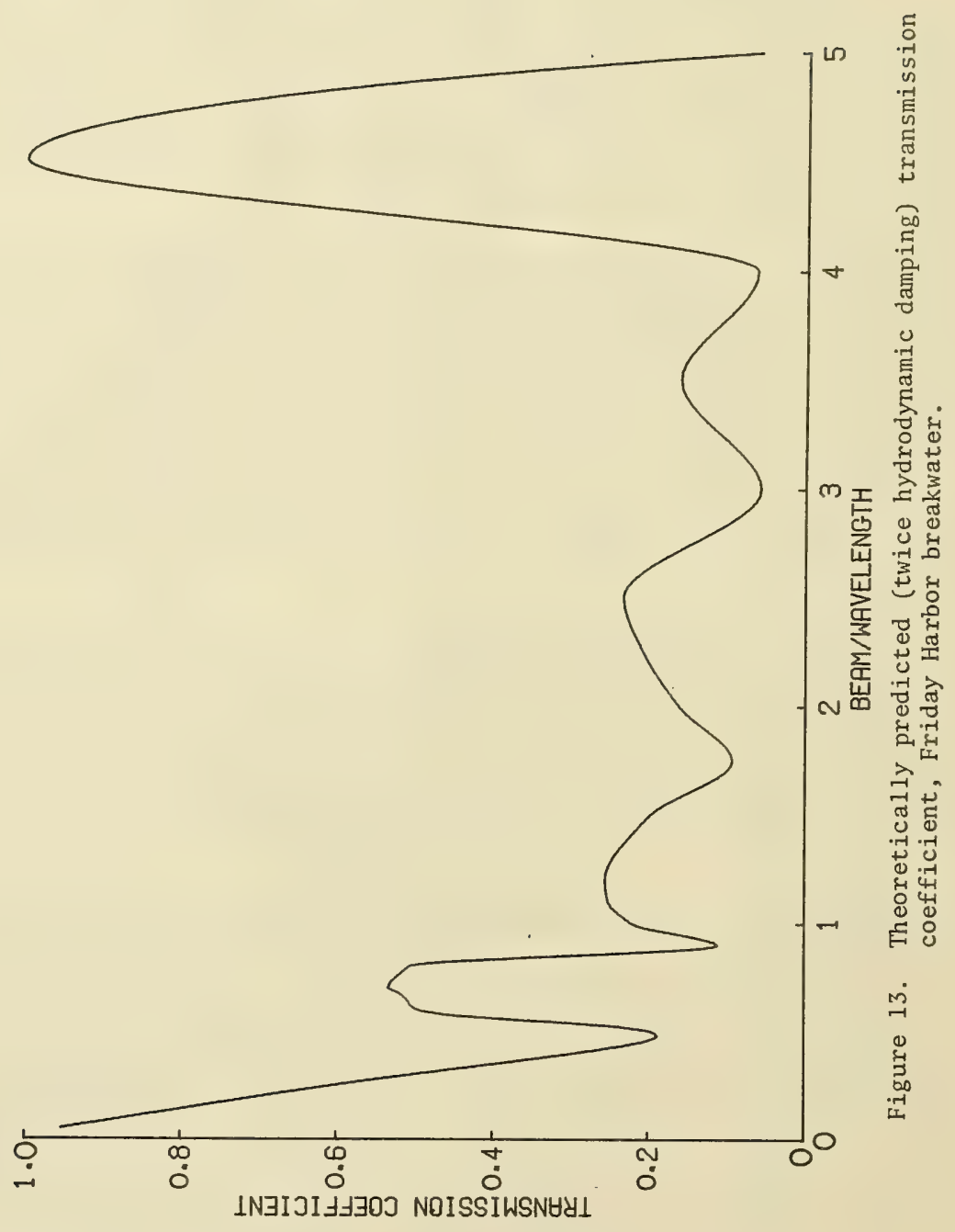


transmission coefficient curve. In this region one must be careful of the analysis because there are certain "irregular frequencies" or "John" frequencies where the approach adopted here breaks down mathematically (John, 1950). These are described with reference to the integral equation technique by Frank (1967). It is extremely difficult to predict where the first of these irregular frequencies will occur when the breakwater cross section is as complicated as the Friday Harbor breakwater. If this cross section were rectangular with the sane exterior dimensions as the Friday Harbor breakwater, then the first irregular frequency would occur at $B / L \simeq 1.7$. In practice, one may watch for this mathematical phenomenon by checking the determinant of the matrix inverted to solve the system of equations. In fact, this does decrease in the region of $\mathrm{B} / \mathrm{L}$ of 1.7 but does not indicate a singular matrix for the calculation in this region of $\mathrm{B} / \mathrm{L}$. Since this is beyond the frequency range of primary interest, it is best to simply view the results at $B / L$ greater than 1.7 with extreme caution. The oscillations in the transmission coefficient in this region of $B / L$ are probably the result of these irregular frequencies.

b. Breakwater Motions. In the wave channel experiments performed to date, there has been no attempt to compute the breakwater motions. While the transmission coefficient is the primary measure of breakwater performance, the motions may be very important to the designer, particularly if boats are to be tied to the breakwater. For the theoretical analysis, this is a critical intermediate step where extensive experimental measurements used for comparison would be invaluable.

Friday Harbor Breakwater. The theoretically predicted motions of the Friday Harbor breakwater are shown in Figures 14, 15, and 16. The motion response is almost the same as one would expect from an uncoupled spring, mass, dashpot linear system. The only unusual behavior is the null response in heave at B/L of about 0.75 . This null occurs at a point where there is a phase shift in the "added-mass" force, a phenomenon which has been observed in experiments with catamaran-type cross sections (Lee, Jones, and Bedel, 1971), and is a result of resonant wave conditions within the open well of the catamaran.

c. Mooring Line Forces. In recent years a great deal of effort has been expended in understanding and predicting mooring line performance, particularly for moored ships and drilling rigs (e.g., American Society of Civil Engineers, 1971). While many of these analysis techniques could be applied to the moorings of floating breakwaters, this has not been done to date. There are also very few model-scale experiments in which mooring forces have been measured and only a few cases where good field data are available.

Two techniques for calculating the spring constants for mooring lines have been used. At first the catenary equations were applied to find the change in force per unit displacement. While this approach leads to a fairly simple algorithm for the calculation, there are a few problems. In several cases spring constants were needed when the mooring 


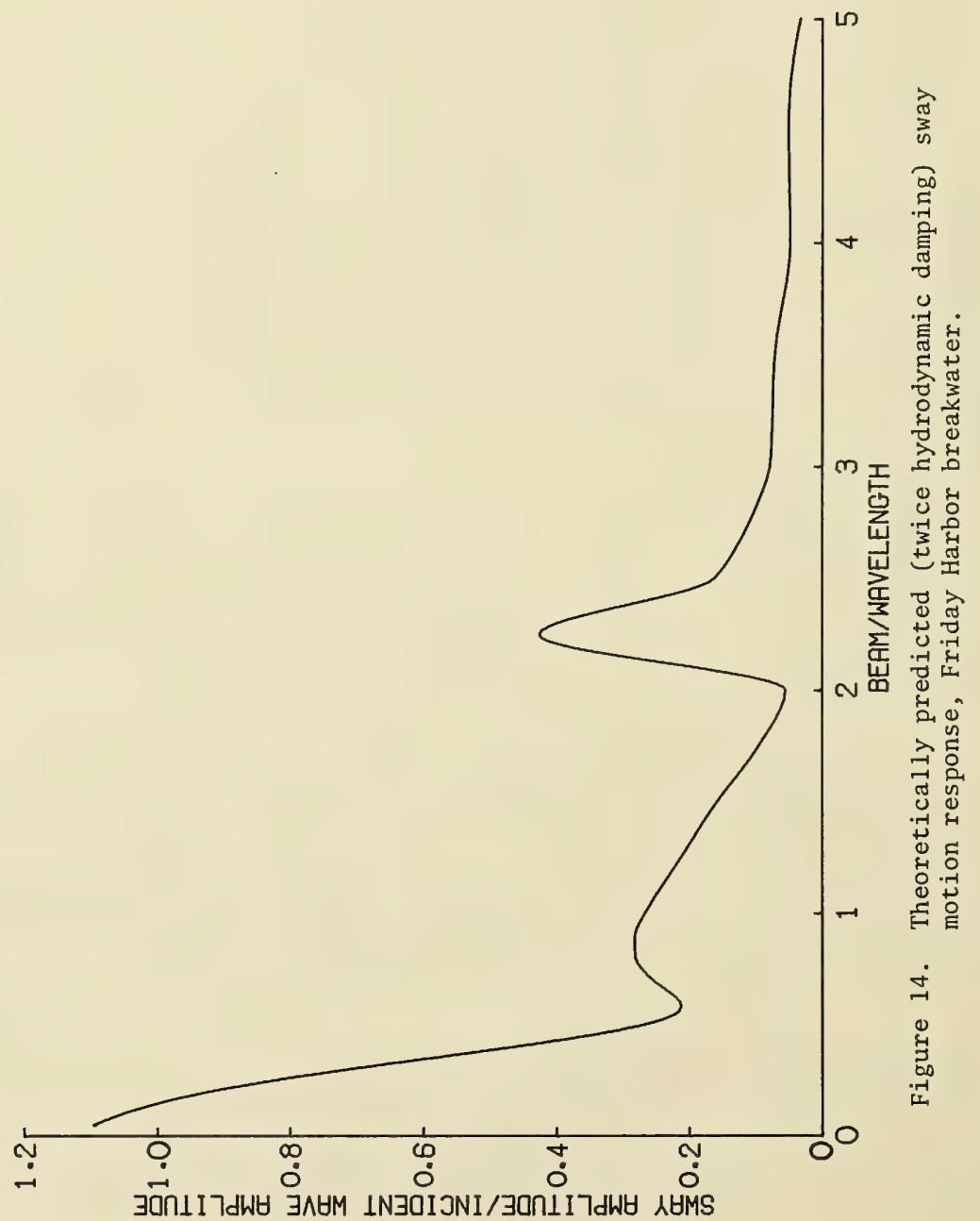




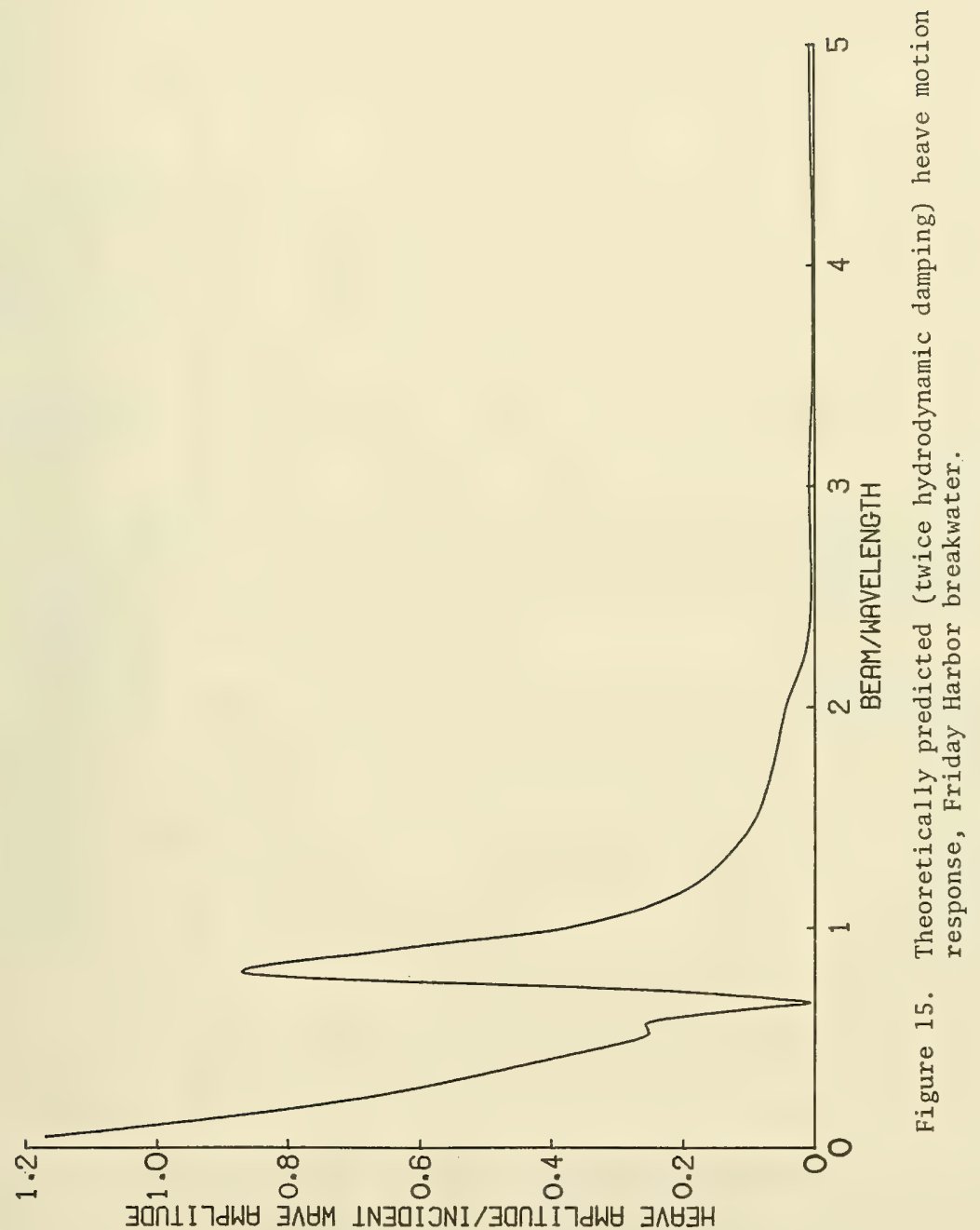

$\exists 0 \cap \perp I 7 d W \forall \quad \exists \wedge \forall M \perp N \exists Q I J N I / \exists O n \perp I 7 d W \forall \exists \wedge \forall \exists H$ 


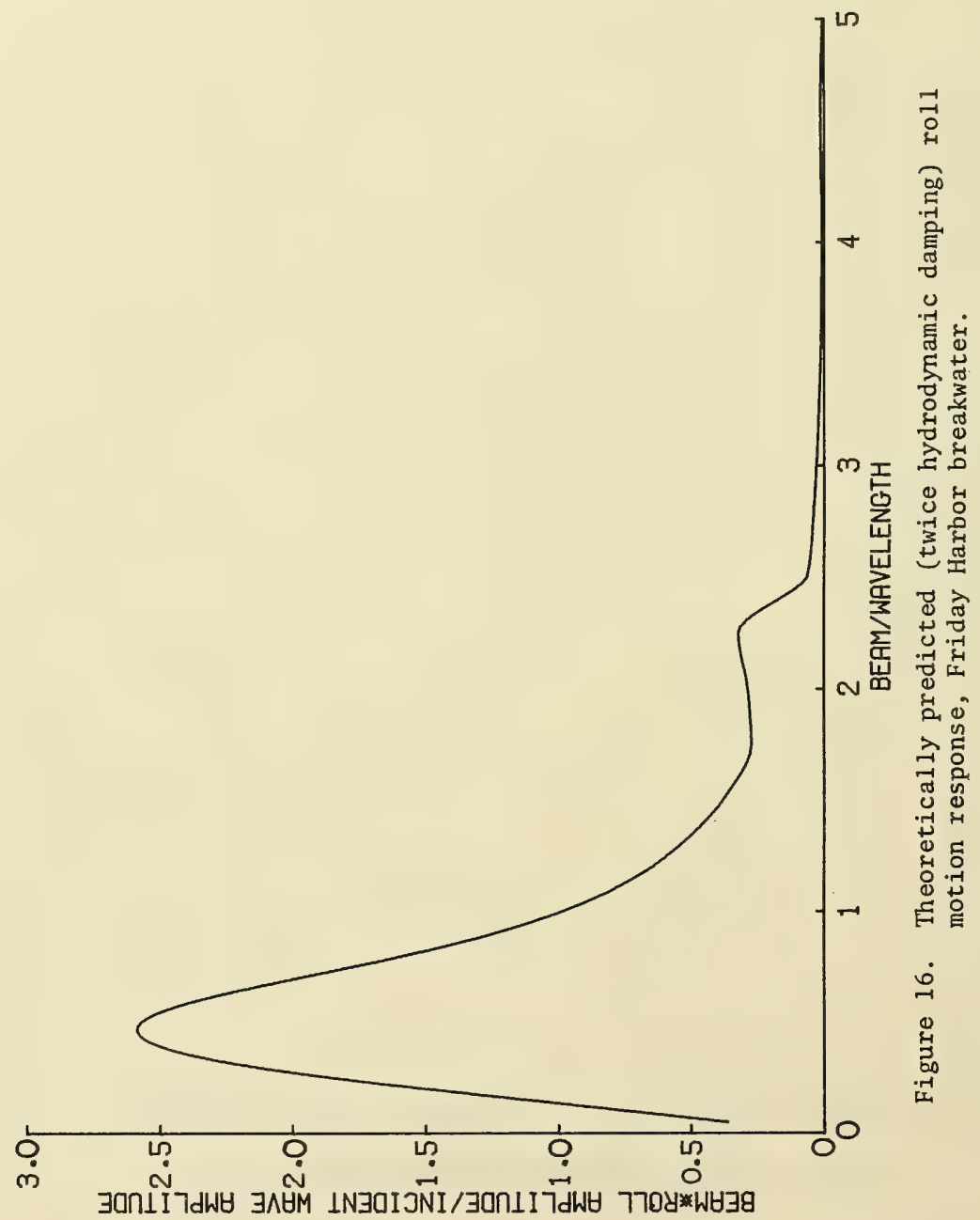


line was too taut to allow it to become tangent to the bottom at the anchor. If this condition occurs, or as it is approached, the catenary equations no longer apply. For many full-scale installations, a combination chain and synthetic line anchor cable is used. This combination anchor cable presents problems in attempting to use the catenary equations.

Comparisons between the mooring line forces calculated using the catenary equations to predict spring constants showed poor agreement with measured results (Adee, 1975). While the general trends were reproduced, an increase in the predicted spring constants of about a factor of 4 would have been required to bring the theoretical prediction into agreement with the measured results.

To overcome the problems encountered in using the catenary equations, a system based on discretization of the mooring line and static equilibrium was developed. This method is described in Appendix B.

(1) Proposed Oak Harbor Breakwater. One of the few mode1 tests in which mooring line forces were measured was performed by Davidson (1971) for the floating breakwater proposed for Oak Harbor, Washington. The model configuration with properties scaled to the prototype is included in Appendix F. The shape of this breakwater is basically an inverted bathtub with foam flotation.

Applying the theory to predict the mooring line force in the seaward anchor line at a water depth of 29.5 feet, one obtains the results shown in Figure 17. The mooring-force coefficient is defined as the amplitude of the force oscillation divided by incident wave amplitude times the weight per unit length of the breakwater. In this figure, the large range of the experimental results is directly related to incident wave amplitude. The smaller incident wave amplitudes generally produce lower measured mooring line forces per unit amplitude except at the beam to wavelength ratio of 0.49 . Since the linear theory is mathematically correct only in the limit as wave amplitude tends to zero, one would expect the best correlation between theoretically predicted and measured results for small amplitude incident waves. The results shown in Figure 17 are consistent with this expectation. However, the very large difference in mooring line forces as incident wave amplitude increases indicates a highly nonlinear response.

A potential explanation for the nonlinear response observed in these experiments results from the condition of the mooring lines at the 29.5-foot water depth used for the model tests. Under these conditions, the mooring lines no longer maintain a catenary shape. When the initial tension in the mooring lines is increased to this level, they respond with very large changes in mooring line force for very small displacements of the breakwater. Consequently, small deviations in the planned positioning of the anchors will lead to large changes in forces in the mooring line. This condition clearly should be avoided in prototype installations where very large mooring line forces are to be avoided. 


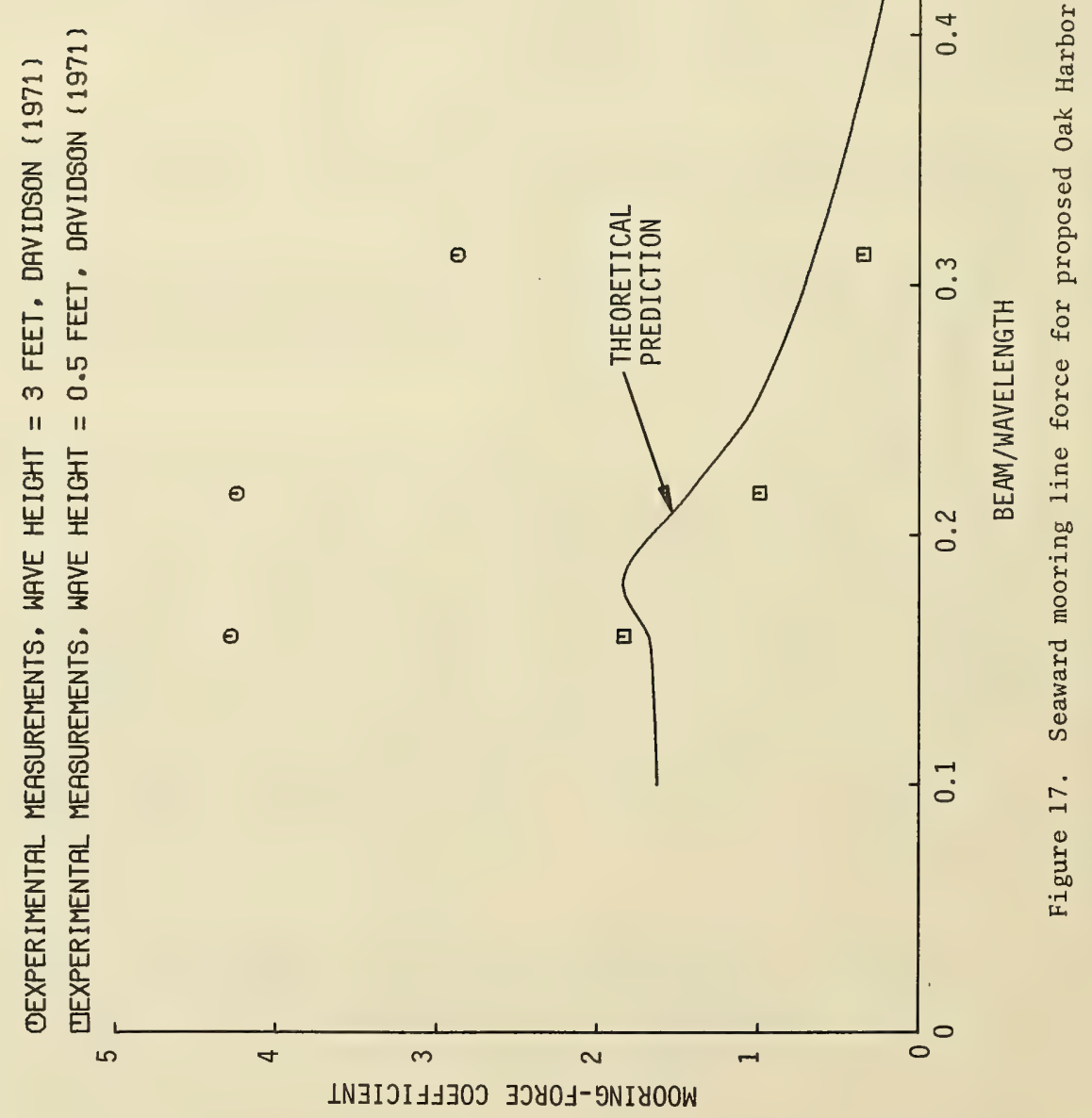


A second possible explanation of the nonlinearity results when the "drift force" on the breakwater is considered. If one carries the hydrodynamic analysis to second order, there are terms at zero frequency which yield a force on the breakwater in the direction in which the incident waves are traveling. This force has the same effect as increasing the initial tension in the mooring line and is proportional to wave amplitude squared. Increasing the initial tension tends to increase the spring constants of the mooring lines leading to larger oscillating forces as well.

\section{(2) Alaska-Type Breakwater. Mooring-force coefficients} theoretically predicted and measured for the Tenakee, Alaska, breakwater are shown in Figure 18. For the field data the mooring-force coefficient is obtained by taking the square root of the mooring-force spectral density divided by the incident wave spectral density and then dividing by the weight per unit length of the breakwater. Again, as with the Oak Harbor model experiments, there is good agreement, especially in predicting the peak in the curve near B/L of 0.65 .

One important aspect of the mooring line problem which should not be overlooked is a comparison between the model-scale results and the field measurements. For the Alaska-type breakwater, all the measured results indicate the amplitude of oscillation in mooring line force is in the order of hundreds of pounds, not thousands of pounds, as was predicted for the Oak Harbor breakwater in the model-scale tests.

When the mooring line tension data recorded at Tenakee are plotted as a function of time as in Figure 19, one observes that there clearly are oscillations associated with the incident waves. However, there are also low-frequency oscillations which are of greater magnitude. A complete explanation of the origin of these low-frequency forces has not been developed. However, one possible explanation is that these forces are a result of breakwater oscillation at the sway resonant frequency. Since the spring constant for sway motion is very small, one would expect a long natural period. Theoretically predicted sway motion response for the breakwater is plotted in Figure 20. Predicted natural periods are 64,37 , and 29 seconds for tidal conditions of mean lower low water (MLLW), +10 and +20 feet, respectively. By applying a high-pass filter to the field data, one obtains the spectrum of force oscillation shown in Figure 4. Here, a peak is at a period of about 53 seconds (tide height $=+7$ feet). The predicted sway natural frequency is at 45 seconds when the tide height is +7 feet, which indicates that this explanation is plausible.

(3) Friday Harbor Breakwater. The predicted performance of a seaward mooring line on the Friday Harbor breakwater is shown in Figure 21 for a tide height of +5.33 feet. The Friday Harbor mooring lines are different than those at the other breakwaters. They are composed of a section of chain attached to the breakwater, followed by a length of nylon rope and, finally, another section of chains at the bottom. This particular tidal condition was chosen because it is the condition during record FH 7-8 used later for comparison. 


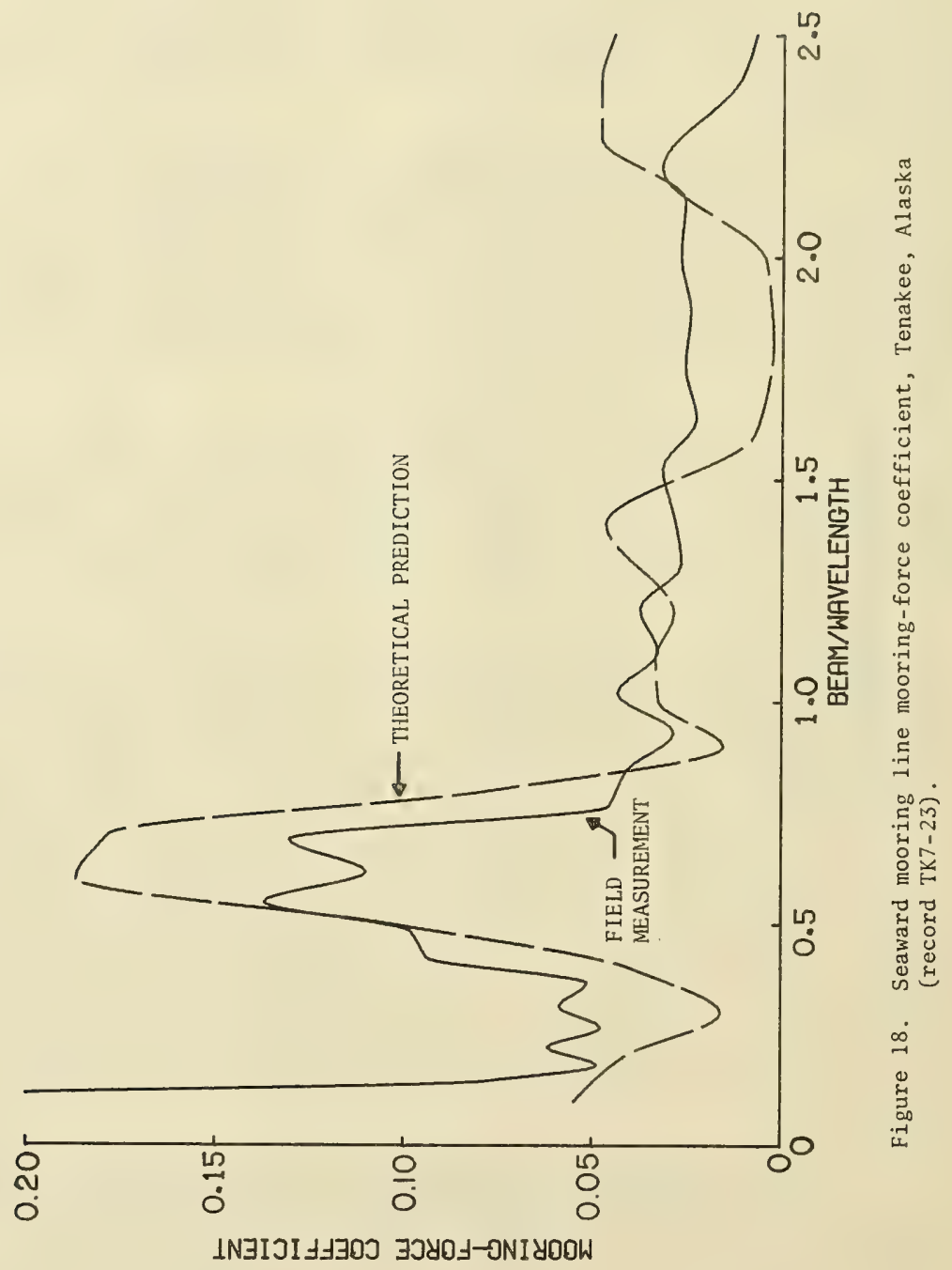




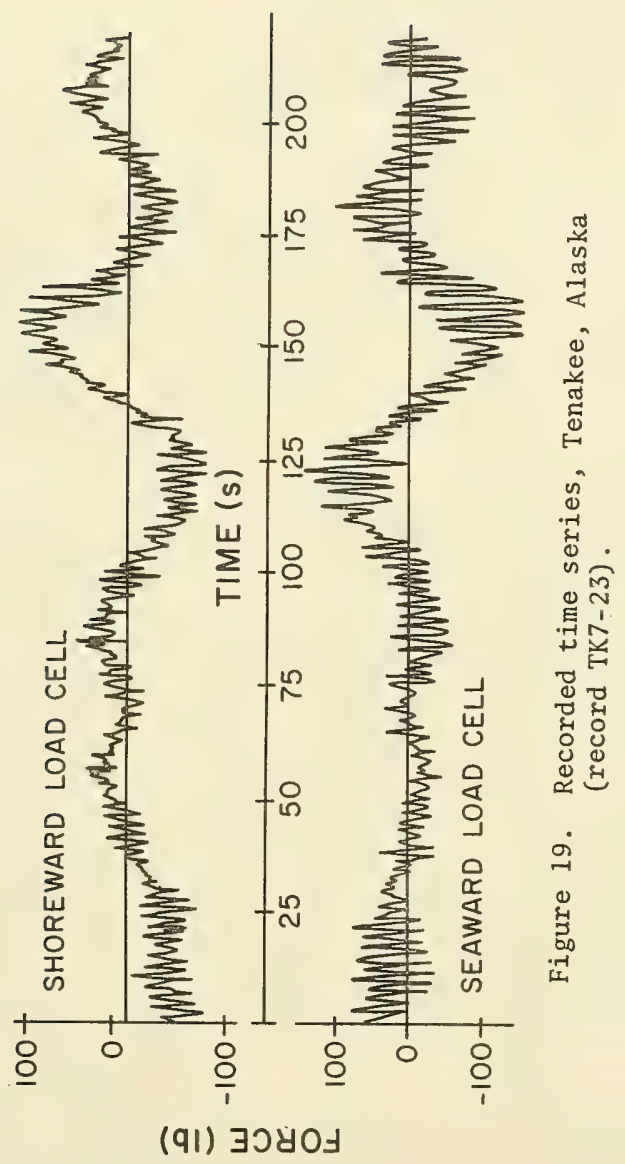




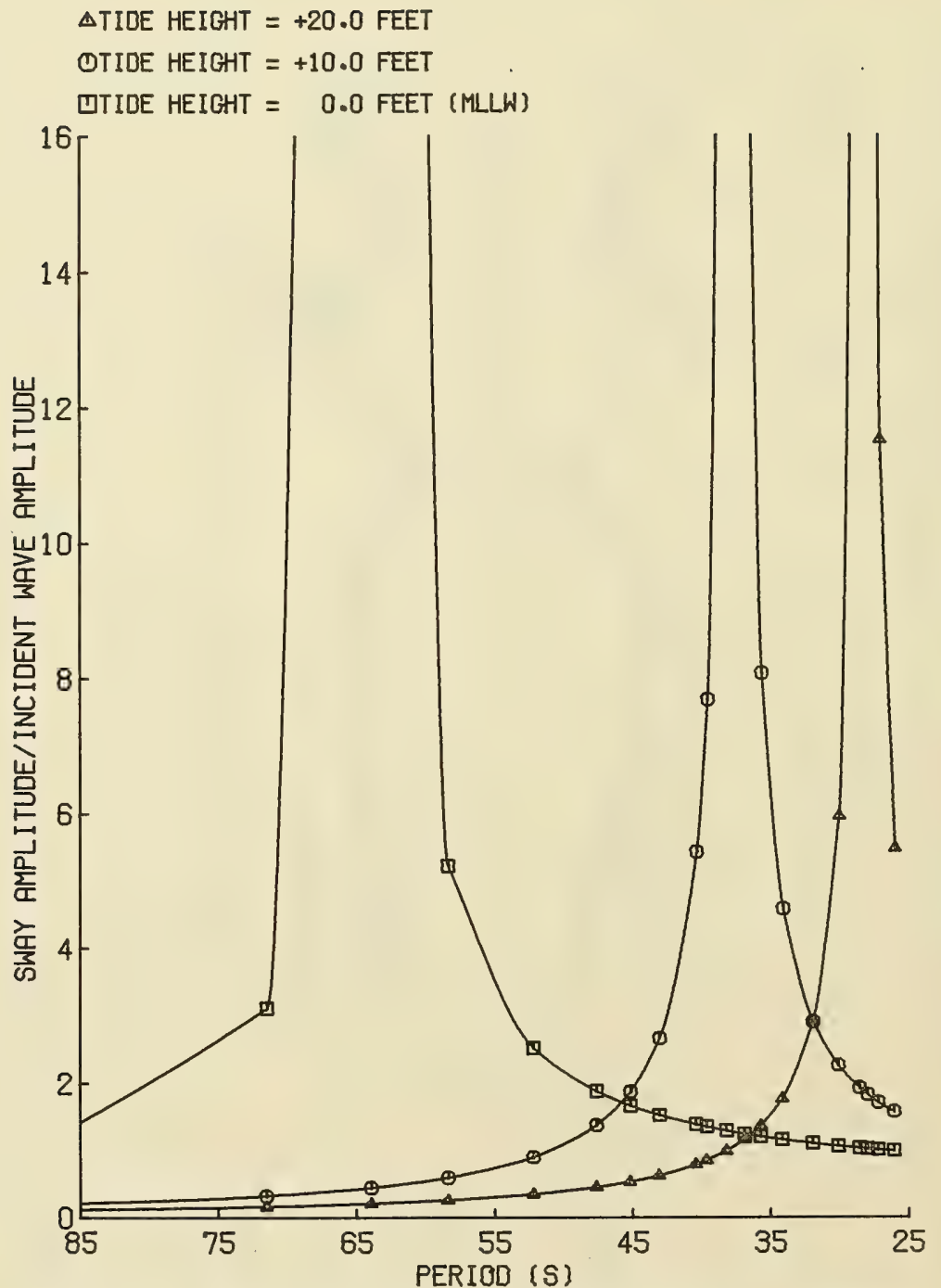

Figure 20. Theoretically predicted long-period sway response of Alaska-type breakwater, Tenakee, Alaska. 


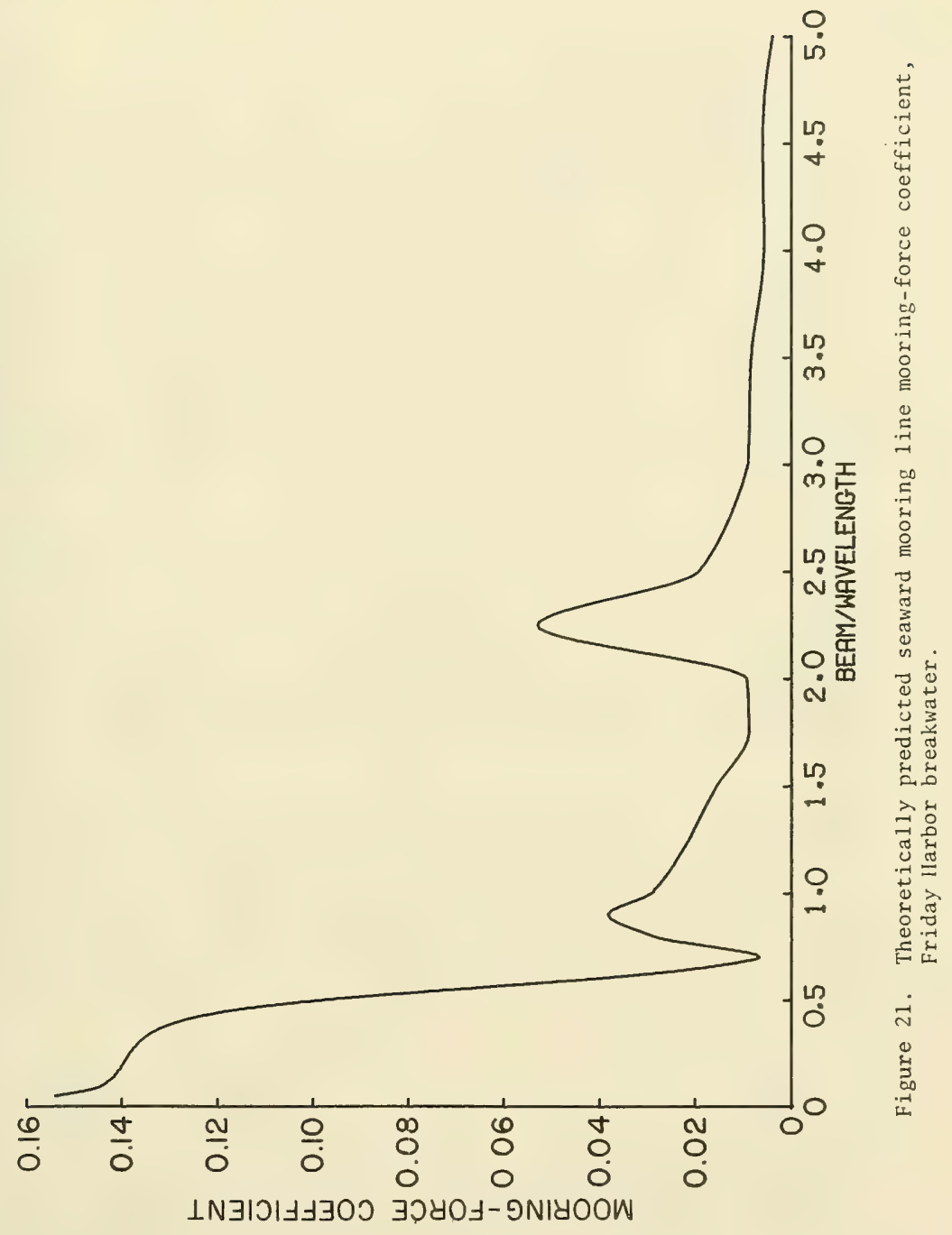


Low-frequency predicted sway motion and resonance are shown in Figure 22 for MLLW, +5.33 feet, +10 feet, and +15 feet tide heights.

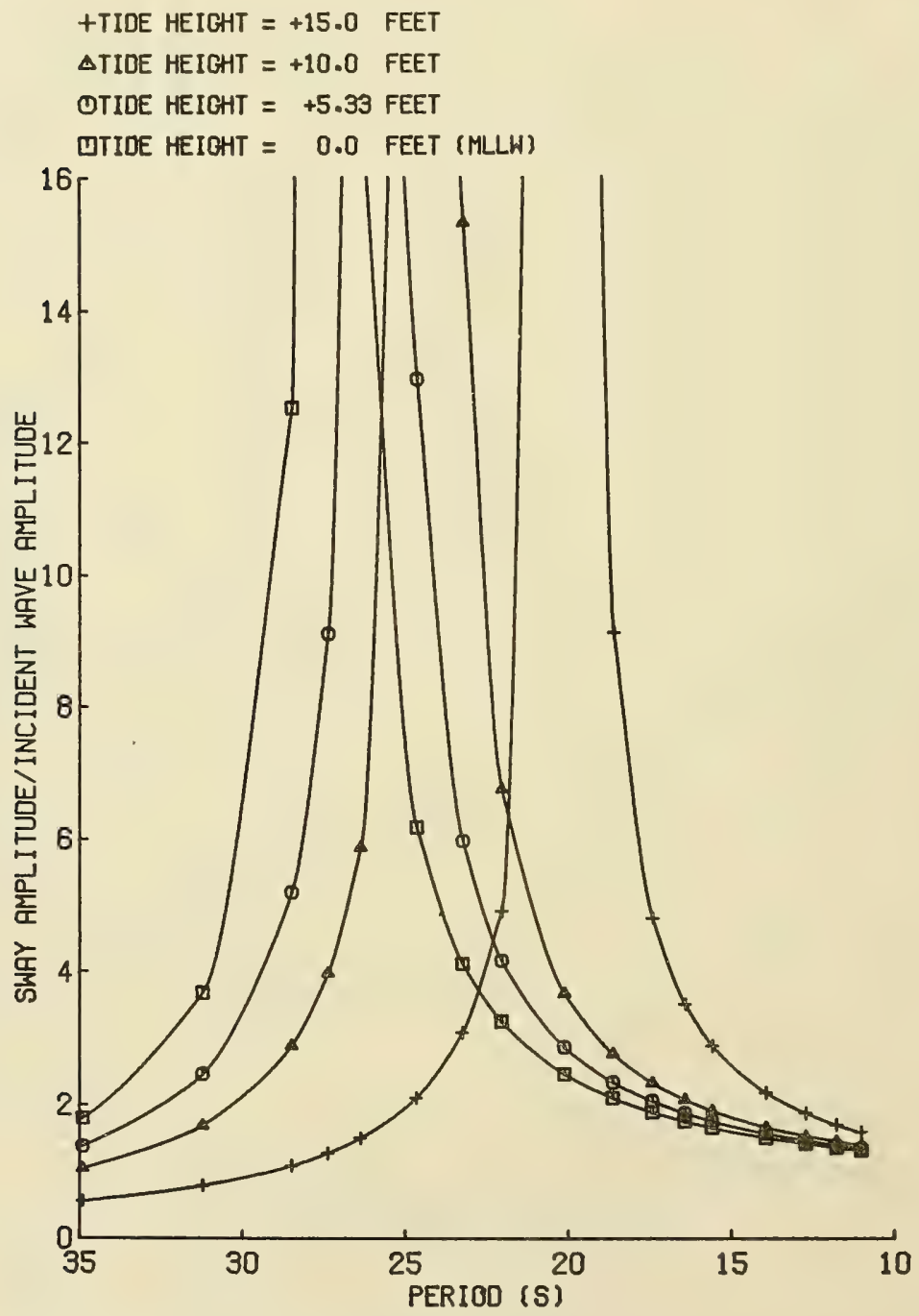

Figure 22. Theoretically predicted long-period sway response, Friday Harbor breakwater. 


\section{Layout.}

The site of the floating breakwater instrumented in this study is located at Friday Harbor, Washington, on San Juan Island, just east of Victoria, British Columbia (Fig. 23). The breakwater is 25 feet wide, 904 feet long, anchored in approximately 40 feet of water, and was installed in October 1972. The structure is made of Polyolefin flotation tanks linked together by a matrix of large wooden timbers. It is laid out in an expanded L-shape, the inside angle being $115^{\circ}$, with the shorter leg (227 ft.) directed toward shore and the longer leg (627 ft.) toward magnetic north. The site itself is protected on three sides by San Juan and Brown Islands off the harbor entrance. This leaves an 0.25 -mile-wide channel into the harbor with a northeasterly fetch of about 1.7 nautical miles. Southeasterly winds can also generate waves of importance parallel to the shorter leg where the fetch is about 1 nautical mile.

\section{Instrumentation.}

The shorter leg was instrumented in this study for two reasons: (a) the most frequent winds are out of the southeast, and (b) barges were to be tied to the longer leg during the winter months for added protection. However, the wave gages are positioned to give the proper incident and transmitted wave data for all relative wind directions (Figs. 24 and 25).

Four types of time-dependent data which are basic to describing the response of the breakwater were collected: (a) wind velocity and direction; (b) wave heights at key locations; (c) anchor cable forces; and (d) directional acceleration and angular motions of the breakwater. The locations of the measuring sensors are shown on Figure 25. Signals from the sensors were carried by underwater cable to the recording system which was located in a small building mounted near the center of the short leg.

\section{Wind Data.}

Windspeed and dimaction were measured by Weather Measure Corporation's W121 sensor. Some additional circuitry was required to record the windspeed, and the sensor was recalibrated to this circuit. The sensor was mounted on the breakwater at the intersection of the two legs at 20 feet above the water surface.

\section{Waves.}

Wave characteristics were measured at four locations with the second 
A यद 4 (n)

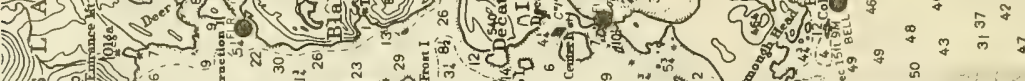
1)) (3) S.

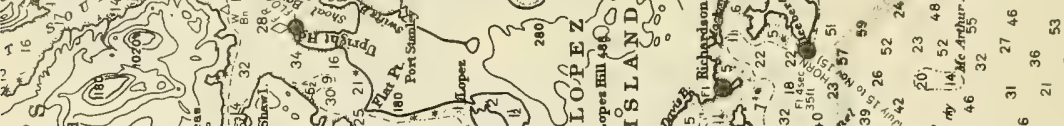
दू (2) (3)

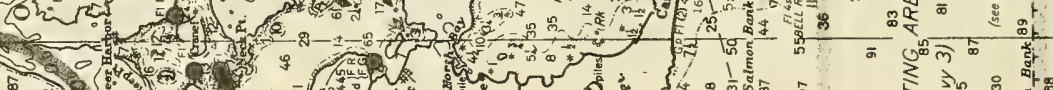
- लs है $\overline{0}$ 年

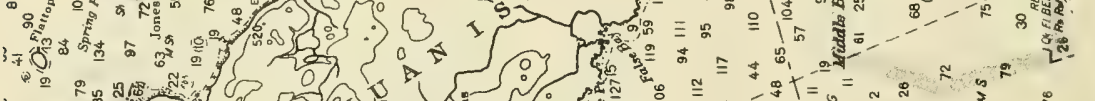

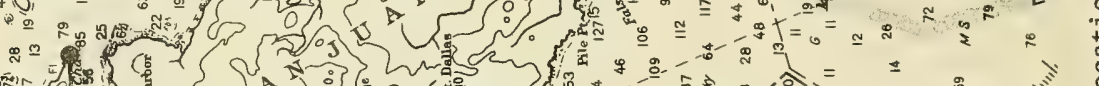
का

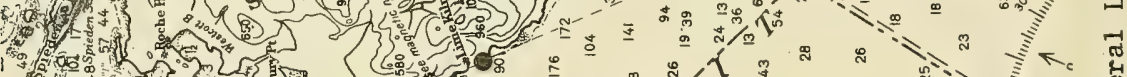
- a d. 然\& -0 2 on 西5 年 等 (n) 


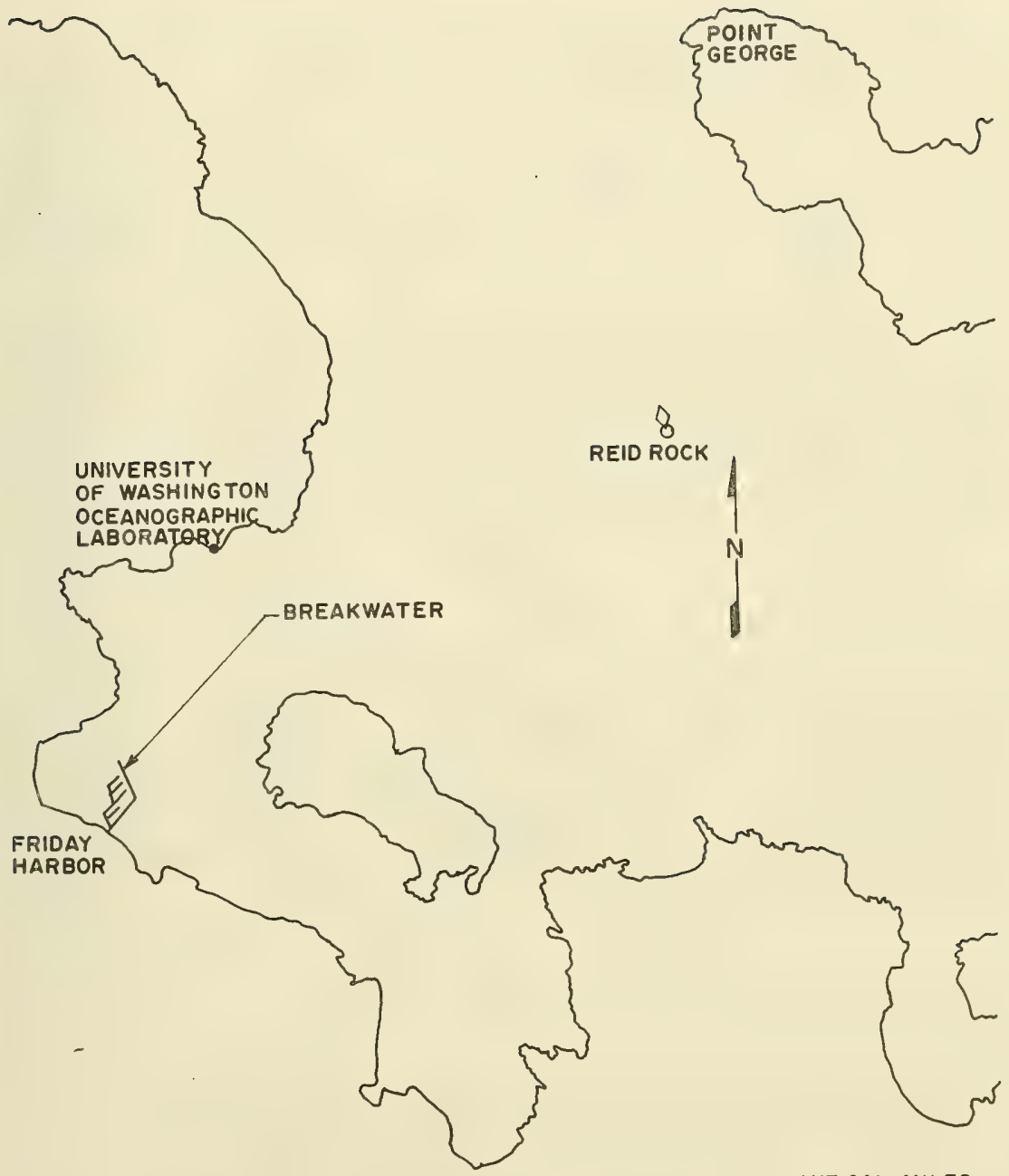

SCALE: I IN. $=0.275$ NAUTICAL MILES

Figure 24. Field experiment site location map. 


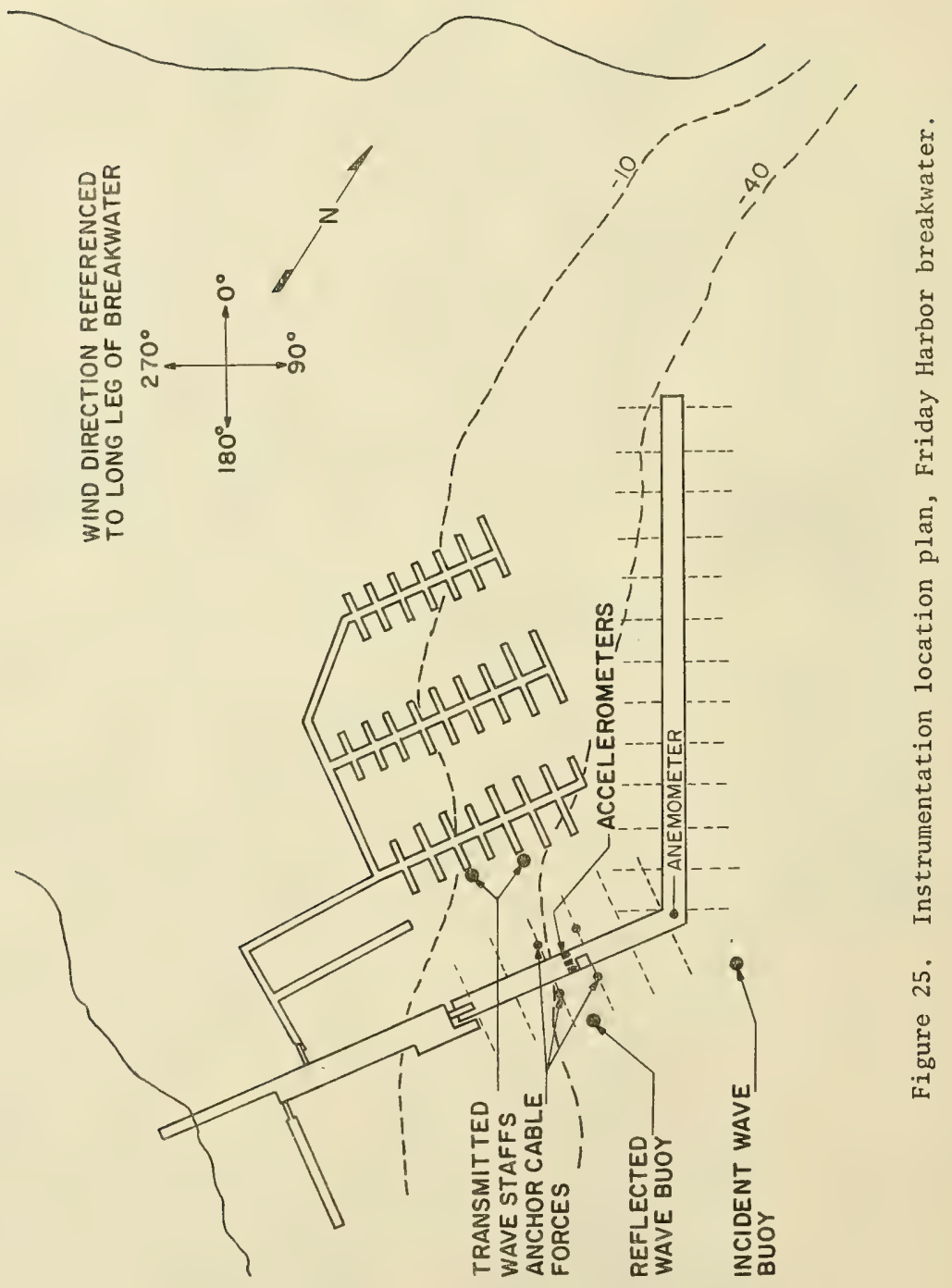


transmitted gage being used as a backup. Two spar buoys instrumented to measure wave elevation were located outboard of the breakwater and positioned so that one measured the incident wave field, and the other measured the incident plus reflected wave field. Two stationary gages were attached to pilings behind the breakwater to measure transmitted wave height. All four gages were of the resistance type. The spar buoys were used outside the breakwater to help reduce navigation hazards and because of the costs and logistics of placing stationary piling at these locations.

The buoys were made of two sections of PVC pipe, the lower section being 6 inches in diameter and 15 feet long, and the upper section of 3-inch diameter and 12 feet in length with the upper 8 feet wound with a resistance wire. Four feet were exposed above the water surface, and a 2.5-foot-diameter disc was attached to the bottom to damp vertical motions. The natural periods in heave and roll, respectively, are 18 and 14 seconds, well above the anticipated maximum wave period of about 4 seconds. See Appendix $J$ for a complete description of the wave staff and buoy designs.

\section{Cable Forces.}

Anchor cable forces were measured using a bonded strain gage-type load cell that was placed in the anchor chains beneath the water surface. These cells and the associated electronics were designed and built for this project. They have an overall system accuracy of 0.75 percent of the designed or rated total load cell capacity over a temperature range of $10^{\circ}$ Celsius (design load 12,500 pounds). These load cells employ a fourarm wheatstone bridge circuit which has two strain gages in each leg of the bridge and are self-temperature compensating. The units are 0-ring sealed and wired directly to the bridge amplifier circuitry mounted in the recording package.

\section{Motion Package.}

Breakwater accelerations were measured using three Kistler servoaccelerometers (Model 303T). One accelerometer, oriented horizontally, was mounted at the center of the breakwater to measure the sway acceleration. The other two were oriented vertically and mounted at opposite outboard edges of the breakwater to measure the vertical accelerations. The heave acceleration was obtained by taking the average of the signals from the two outboard accelerometers; the roll acceleration was obtained by taking the difference of these two signals and dividing by the distance between them. The accelerometer locations are indicated in Figure 25.

\section{Data Acquisition System.}

The data recording and electronic package was built around the Sea 
Data Corporation's Series 610 four-track increnental digital cassette tape recorder. The complete package, which included all the electronic circuitry for the individual transducers plus the tape recorder, was housed in a watertight, 6-inch-diameter PVC cylinder 5 feet in length. The system was designed to be operated manually or in a completely automated mode, thus requiring only periodic tape changes (Fig, 26) .

In its automatic mode, the system was activated when the windspeed reached or exceeded a preset value and stayed there for at least 1 minute. At this point, a single 17-minute sample of all the inputs was taken. Each 68 minutes following this, another 17-minute sample was recorded if the wind was still above its preset value; if not, the system was shutdown until the windspeed increased. Each 17-minute record consisted of 2,048 samples, taken at 0.5 -second intervals, of all 13 channels plus a clock channel. Twenty-five of these records could be recorded on a single cassette tape.

\section{Data Processing and Analysis.}

The initial step in the data handling was to transfer the data from the individual cassettes to seven-track magnetic tape by means of the Sea Data reader. These tapes were then converted to a computer compatible format on the University of Washington's CDC 6400 computer. The histograms for all records plus the basic statistics, $i . e .$, the minimum, maximum, mean values and standard deviations as well as the transmission coefficients based on these standard deviations, were then computed and tabulated (App. G). A digital filter, with a cutoff frequency of 0.05 hertz (Gold and Radar, 1969) was applied to the transmitted wave data prior to these tabulations to remove tidal drift. The transmission coefficients given in these summary sheets are a ratio of the standard deviations for the transmitted and the incident wave gages.

In the initial conversion, the data were checked for reader errors. These points were smoothed using a linear interpolation between the preceding and the following good data points. Following this, the data were checked for extreme values. Data points departing from the mean by more than five standard deviations were smoothed in the same manner as were the reader errors. In no case did the number of errors warrant elimination of a complete record (greater than six bad points). Record FH 11-1, however, had bad data for channels $3,4,5,7$, and 8 . This record was run manually while calibrations were being made, and the affected channels were not connected properly at this time. The final edited data were then stored on magnetic tape.

The autospectra for all the wave data for all records were computed with a more complete analysis of the force and acceleration data applied to the more desirable events.

Digital filtering techniques were used prior to spectral analysis on all the wave and force data. The procedures used follow those given 
Initiate data record
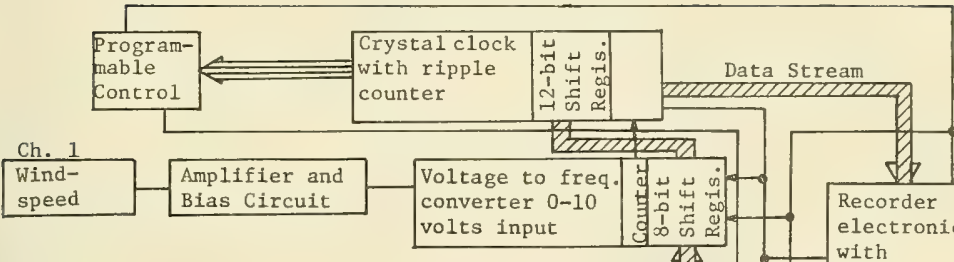

Recorder electronics with

Ch. 2

\begin{tabular}{|l|}
\hline Wind \\
Direction
\end{tabular}

Amplifier and Voltage to freq. Bias Circuit

Cin. 3

N.W. Load Cell

Bridge \& Ampliconverter 0-10 volts input

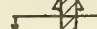

serial to

4-bit parallel conversion

version

Voltage to freq. converter 0-10 volts input

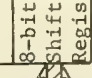
fier Circuit

Ch. 4

\begin{tabular}{l}
\hline S.W. \\
Load Cell \\
\hline Ch. 5 \\
\hline
\end{tabular}

N.E.

Load Cell

Ch. 6

S.E.

Load Cel1

Ch. 7

Trans.Wave
Staff \#1

Ch. 8

Voltage to freq. converter $0-10$

volts input

Trans. Wave

Staff \#2

Ch. 9

Incid. Wave

Buoy

Ch. 10

Ref. Wave

Buoy

\begin{tabular}{ll} 
Ch. II \\
N. Vert. \\
\hline Ace.
\end{tabular}

Ch. 12

Sway
Acc.

Ch. 13

S. Vert.

Acc.
Anplifier and

Bias Circuit

11

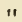

"

$" 1$

"

(n)

Amplifier and Bias Circuit
"1

1

"I

11

"

11

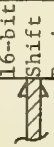

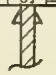

Cassette

Transport

(3200 bpi)

Figure 26. Instrumentation and recording package layout. 
by Gold and Radar (1969). The first step in the development of this filter function is to assume an ideal filter response function.

$$
\begin{aligned}
& F_{\ell}(f)= \begin{cases}1, & 0 \leq|f| \leq f_{c} \\
0, & f_{c}<|f| \leq f_{n}\end{cases} \\
& F_{h}(f)= \begin{cases}0, & 0 \leq|f|<f_{c} \\
1, & f_{c} \leq|f| \leq f_{n}\end{cases}
\end{aligned}
$$

where $f_{c}$ is the cutoff frequency, $f_{n}$ the Nyquist frequency, and $F_{\ell}(f)$ and $F_{h}(f)$ are the ideal low-pass and high-pass filter response functions.

The ideal filter response function is then Fourier-transformed to the time domain, giving the impulse response function, which is truncated by using an appropriate window function and transformed back to the frequency domain giving a complex frequency response function. The number of points used in representing the filter function is allowed to vary and the resulting convolution with the original time series is accomplished by using the overlap-add method of convolving smaller series with larger ones. This allows for more economical filtering procedures.

This gives three variables to choose from in the final filter function design: the length or number of points used in the filter, the type of window used to truncate the impulse response function, and the number of points to be truncated.

This procedure is analogous to spectral estimation techniques except for the truncation of the impulse response function. The larger the number of points used in the filter function, the better the estimate. The smoother the window function, the broader the transition band. In addition, the ripple or Gibb's phenomena is reduced. Generally speaking, the more points that are truncated (set to zero) the better the resulting approximation. In practice, the actual number is determined experimentally by comparing results for different truncation values. This results in setting approximately 20 percent of the impulse response function to zero. The hanning window function was used with 128 points in the filter response function and 38 points being set to zero in the impulse response function. That is:

$$
h(n \Delta t)=w(n \Delta t) h(n \Delta t)
$$

and

$$
w(n \Delta t)=\left\{\begin{aligned}
\frac{1}{2}\left(1+\cos \pi \frac{n-1}{45}\right), & 1 \leq n \leq 45 \\
0 \quad, & 45<n<83 \\
\frac{1}{2}\left(1-\cos \pi \frac{128-n}{45}\right), & 83 \leq n \leq 128,
\end{aligned}\right.
$$


where $h(n \Delta t)$ is the impulse response function and $w(n \Delta t)$ is the hanning window function. The final filter response function is defined as:

$$
F\left(f_{n}\right)=\sum_{n} \beta(n \Delta t) e^{-j 2 \pi n f_{n} \Delta t},
$$

where $j=\sqrt{-1}$ and $\Delta t$ is the constant time interval between samples.

The transition band or the frequency increment traversed by the cutoff of the filter function can be approximated by:

$$
\lambda=\frac{10}{128}=0.078
$$

and the maximum stopband attenuation for the hanning window is 55 decibels. These values can only be achieved through proper filter design. The actual values for the filters used are $\lambda=0.08$ and a maximum attenuation of greater than 55 decibels. The ripples in the passband for each filter used were below 0.01 percent. These values could be improved on by increasing the number of points used for the filter response function estimate. Also the stopband attenuation could be improved, at the expense of a wider transition band for a given size filter function by using the Blackman window function. However, the accuracy of the filter response functions used exceeds that of the measurements and is sufficient for this application.

After initial processing and prior to all spectral calculations a tapered cosine data window was applied to the first and last 10 percent of the data to reduce spillover of spectral energy to adjacent frequency points. For data stretching from $n=1$ to $n=N$, the formulas for the data window are:

$$
w(n \Delta t) \begin{cases}\frac{1}{2}\left(1-\cos \pi \frac{n-1}{0.1 N}\right) & \text { for } 1 \leq n \leq 0.1 N \\ 1 & \text { for } 0.1 N<n<0.9 N \\ \frac{1}{2}\left(1-\cos \pi \frac{N-n}{0.1 N}\right) & \text { for } 0.9 N \leq n \leq N .\end{cases}
$$

The data were then transformed directly using fast Fourier transformation procedures and smoothed by averaging adjacent raw spectral components. Initial sampling was performed at 0.5 -second intervals with 2,048 samples per record, and 20 adjacent points averaged together in the autospectral calculations to get the final smoothed spectral estimates. This gives a frequency resolution of 0.0195 hertz with 40 degrees of freedom per spectral estimate.

Al1 of the wave data was high-pass filtered, using the filtering techniques previously outlined with a cutoff frequency of 0.05 hertz. This was done to remove the tidal influence on the transmit5ed wave staffs and to eliminate any possilbe buoy motion in the incident wave records. Also the anchor cable force data were separated into a low-and 
high frequency signal using the same filtering procedures. For the high-frequency case this was done to remove the influence of the large low-frequency spikes in the spectra. A high-pass filter with a cutoff frequency of 0.1 hertz was used.

For a closer look at the low-frequency information in the anchor cable force data, a new time sertes was generated from the original record by sampling every eighth data point. To reduce aliasing of the higher frequency energy in the original signal, each record was low-pass filtered prior to this sampling using the filtering techniques previously outlined with a cutoff frequency of 0.2 hertz. The sampling of every eighth point of the original time series gives a sampling interval of 4 seconds, a Nyquist frequency of 0.125 hertz and a record length of 256 points or 1,024 seconds. Five raw spectral points were averaged together to give the final smoothed spectral estimates. This results in a frequency resolution of 0.0049 hertz with 10 degrees of freedom per spectral estimate.

A total of 95 records was recorded at the site from 1330 hours on 30 December to 3 May 1975. There were no known equipment failures or breakdowns except for one of the load cells going off scale at low tide on the first tape (FH 7, NW load cell channel 3). A complete summary of these events is given in Appendix G. Also, Figure 25 gives the relative locations of the individual transducers.

The wind direction in all cases is referred to the long leg, which has a north-south compass bearing (magnetic declination in this area is $23^{\circ}$ east). There are two wind-direction windows of interest. For the long $1 \mathrm{eg}$, the directions are approximately $50^{\circ}$ to $95^{\circ}$; for the short $1 \mathrm{eg}$, $130^{\circ}$ to $160^{\circ}$ (Figs. 24 and 25 ).

Two storm events were chosen for presentation and further analysis. These events cover records FH 7-6 through FH 7-12 and FH 11-8 through FH 11-14 (Apps. G and H). They were chosen because of their directions relative to the short and long legs, respectively, and because of their duration and magnitude. Both events lasted for over 7 hours with maximum windspeeds in excess of 35 miles per hour, with all the mean wind direction within or close to the desired wind-direction windows. Appendix $\mathrm{H}$ gives the pertinent wave spectra and transmission curves for the above two events.

The average overall response or transmission curves for the events within each wind-direction window and for all the recorded data, are given in Figure 27. These plots were obtained by averaging the square root of the ratio of the transmitted to the incident wave spectras for the records indicated for each curve. Therefore, they have the same frequenm cy resolution of $0.0195 \mathrm{hertz}$.

A puzzling feature in al1 the transmission response curves calculated from field data is the rise at lower frequency to a value near one and then dropping off again. This can partially be attributed to a lack of 


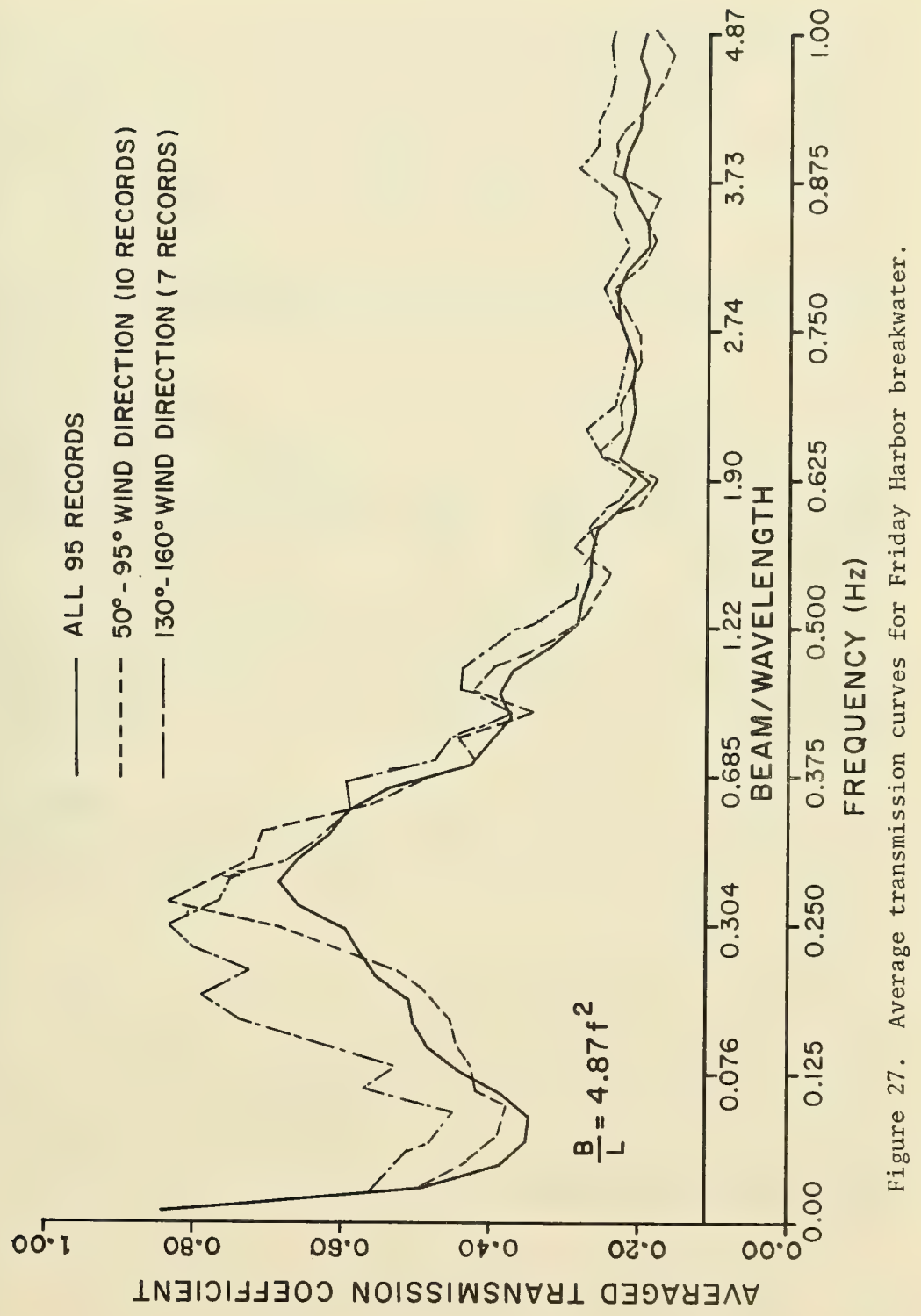


energy in the incident wave spectra at lower frequencies. This possibility can be backed up in part by data from two similar projects undertaken in the past 2 years on a styrofoam-filled concrete-type breakwater (Christensen and Richey, 1974). The first is located in relatively sheltered water while the second breakwater is located near the open ocean where swell becomes an influence and results in a much broader spread of spectral energy over the frequency band in question. The first breakwater showed similar response curves to Friday Harbor while the second tended to approach one near the lower frequencies and stay there (see App. H., Figs. H-10 and H-11).

Al1 of the anchor cable data showed a very dominant amount of energy at lower frequencies. Appendix I shows the results of the low-frequency analysis for three of the anchor cable force signals for record FH 7-8. The autospectra for the force gages show several large peaks in this lower frequency band (App. I, Figs. I-1, I-2, and I-3). The exact location of these peaks varies for different records, but in all records analyzed, the dominant amount of energy in the force spectra was contained in this lower frequency band of approximately 0.015 to 0.05 hertz. In most cases, however, a relatively dominant peak appeared in the 56to 63-second-period range. The anchor forces measured were al1 quite low; the largest range was only 628 pounds. The cables are spaced at 50 -foot intervals.

The phase and coherency spectra for three of the force gages for record FH 7-8 are given in Appendix I (Figs. I-4 through I-7). They show a strong linear relationship between the gages on the same side of the breakwatex and for the opposing gages. The forces in the two anchor lines on the same side were in phase; the two opposing were $180^{\circ}$ out of phase. This indicates that the sway or rol1 motions are dominant in this frequency range. The accelerations at these lower frequencies were too small to be recorded and could not be used to help confirm which motion was involved. However, in the overall frequency range (0 to 1.0 hertz) the variances for sway and heave were two orders of magnitude greater than roll, which indicates that sway would have to be the dominant motion involved here.

The analysis of the complete frequency range for the force data for FH 7-8 is shown in Appendix J (Figs. J-2 through J-8). The data were high-pass filtered $\left(f_{c}=0.1\right)$ for these spectra. A comparison of the variances computed for the high- and low-frequency sections of the force spectra showed that over 90 percent of the energy in all cases analyzed was contained in the lower frequencies. A summary of the force data, without any filtering, for all the data collected in this experiment is given in a table.

The autospectra for the force gages (FH 7-8) are relatively spread out (see App. J, Figs. J-2, J-3, and J-4), with the outside force gages showing a greater response to the lower frequency incident wave energy than the inside gages. However, the outside and the opposing gages show relatively high coherency, with the outside gages being in phase and the 
E

$E$

온

का

is

is

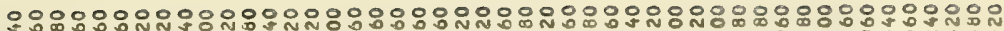

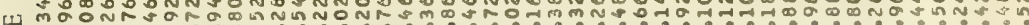

U

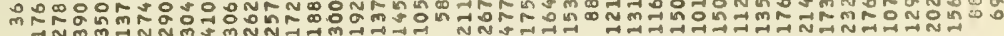

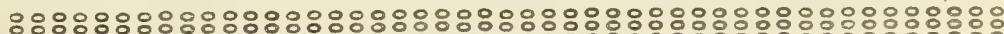

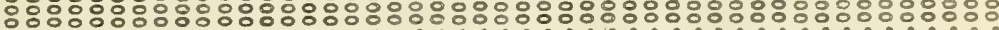

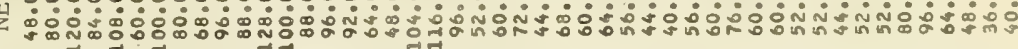
A

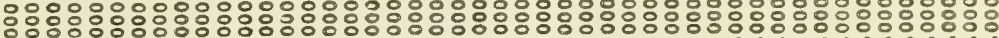

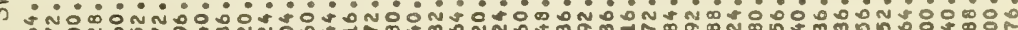

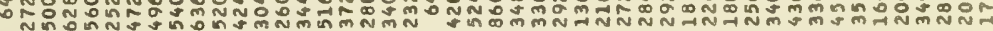

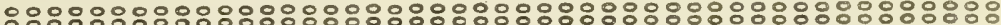

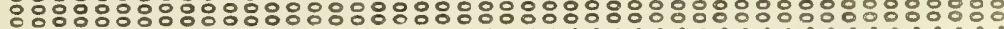

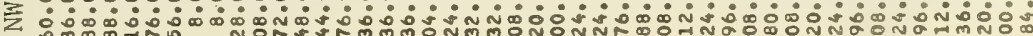

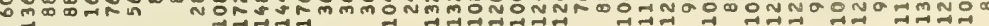

nO

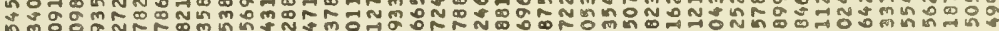
U O- N n N N .

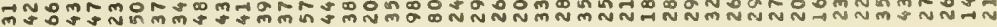

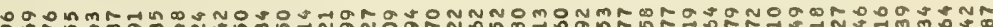

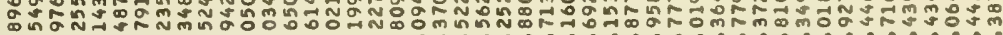

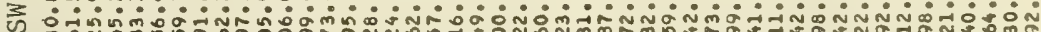

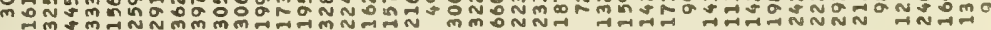

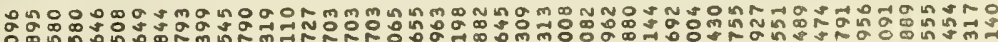
z

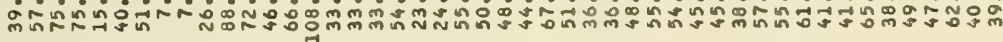

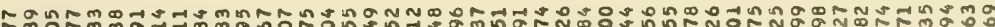
O U : m

여유 N แี

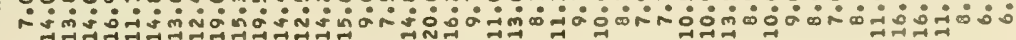

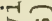
¿) $\frac{0}{0}$ 00 $\prod_{1}$

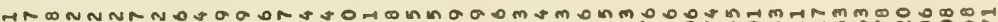

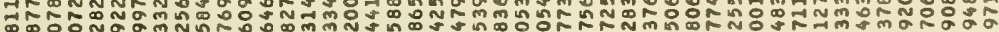
ऊ nng:

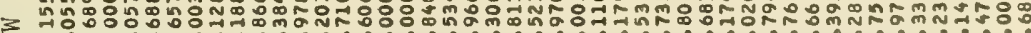
z

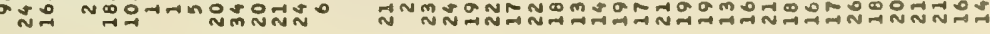
HNm non

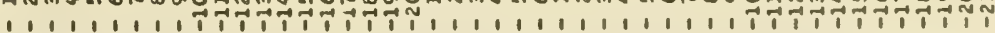

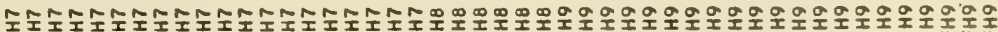

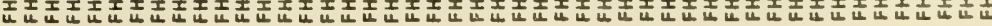




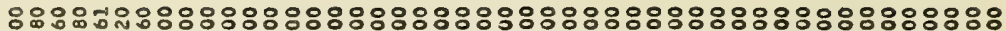

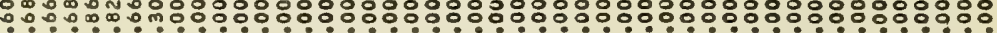

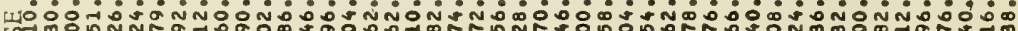
Uస N

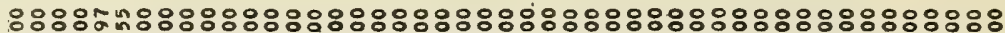
닝융워

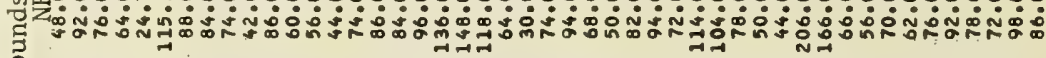

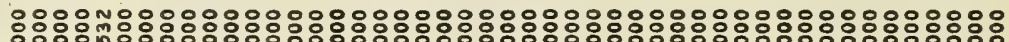

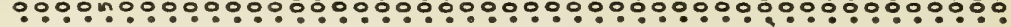
Z0 जN

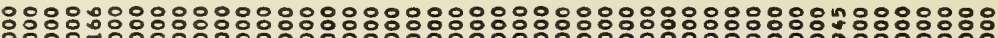
은. Zm:

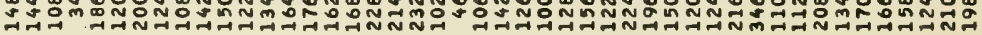

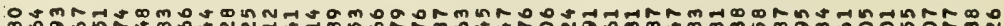

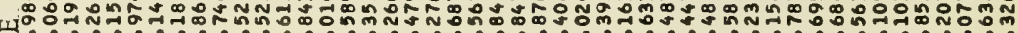

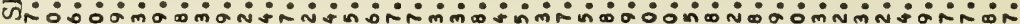
in

m

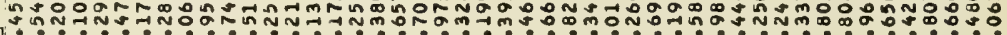
vZniñón

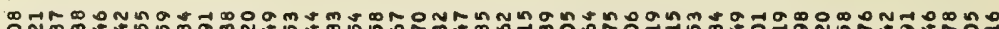

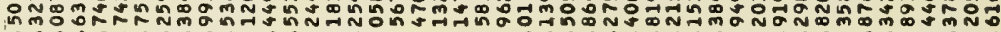
з

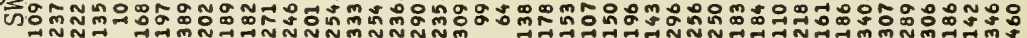

manT

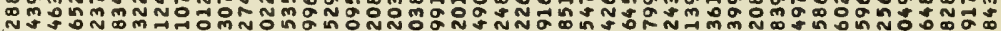

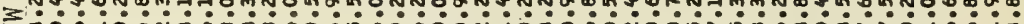

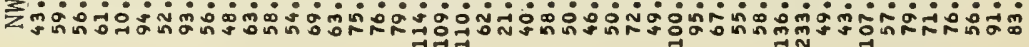

Nำ

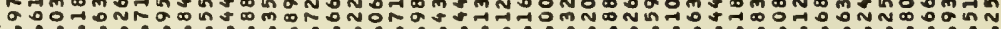
山

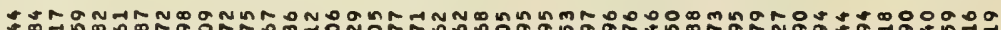

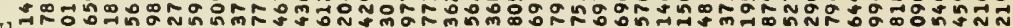

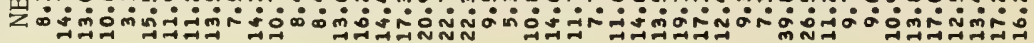
is

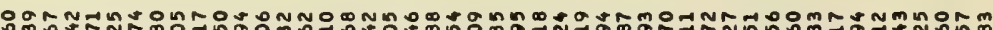
క प Jैw 乐 운 $N$ บ

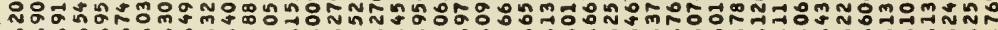
ZNÁn

N Iบบ ์

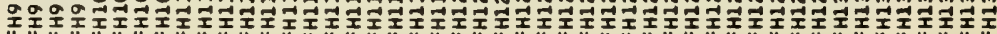

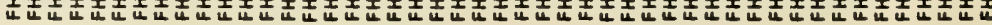


outside leading the inside gage by approximately $180^{\circ}$ over the frequency range of 0.25 to $0.37 \mathrm{hertz}$. This indicates that the forces are relatively uninfluenced by waves above approximately $0.37 \mathrm{hertz}$. This frequency range is also where the transmission curves rise to near unity. This agrees with the low-frequency analysis and suggests that the response is similar over the complete frequency range below 0.37 hertz.

The acceleration force, autospectral and cross-spectral analysis results, are also given in Appendix $J$ for the higher frequency range for record FH 7-8. No dominant features were observed in the motion spectra. Their peak values and spread of energy with frequency appear to follow the general character of the incident wave spectra in all records analyzed. This implies that any natural frequencies in each of the motions is outside the range of significant incident wave energy. The crossspectral analysis shows a high coherency and zero phase shift between the heave and roll accelerations. In both the sway and roll, and the sway and heave accelerations, the sway acceleration leads by approximately $180^{\circ}$ over the range of significant incident wave energy and then tapers to near-zero phase shift at higher frequencies. Also, the coherency is high enough over the incident wave energy band to imply near linearity between all three motions.

These conclusions are based on positive sway being outward from the short leg (south), heave positive up, and the positive roll to be clockwise around a positive axis pointing westerly toward shore. 
Although the Friday Harbor breakwater has a very complex geometry and does not respond as a rigid body to the incident wave excitation, it is important to draw some comparisons between the theoretical prediction of performance and the field measurements. In seeking a "typical event" from the enormous quantity of data gathered, the goal was to find a case where the wind was reasonably close to being on the beam of the short leg of the breakwater.

The one striking item which emerges from the data is the similarity of all the transmission coefficients examined. These curves seem identical no matter what the wind direction. This was not expected because there were barges tied to the breakwater along the entire long leg, while there were none along the shorter leg. A further investigation of the reasons for the similarity is certainly warranted.

The record selected for comparison with the theory was FH 7-8. Figure G-3 in Appendix G shows the incident and transmitted wave spectra and transmission coefficient. This record is also listed in the statistical sumnaries of Appendix F. The spectral analysis using a high-pass filter was performed as described in Section III.

A comparison of the theoretically predicted and measured transmission coefficient is shown in Figure 28. So long as the calculated hydrodynamic damping is doubled in the theoretical analysis, the results are quite good. As described in Section II, the peak in the transmission curve at a frequency of 0.95 hertz probably results from the "irregular frequency" phenomenon which occurs in this mathematical formulation.

Comparisons of sway, heave, and roll acceleration predictions with measurements are shown in Figures 29, 30, and 31, respectively. Here, the acceleration response has been nondimensionalized by multiplying by the beam or beam squared, as appropriate, and dividing by the acceleration of gravity times the incident wave amplitude.

In the case of sway acceleration, the theory overpredicts the values throughout the entire frequency range. The peak at $0.5 \mathrm{hertz}$ appears in the correct location, but the measured values would need to be doubled to bring the curves into better agreement.

For heave acceleration the curves appear to be in closer agreement, at least above the frequency of 0.4 hertz. Below 0.4 hertz there seems to be little correlation.

Roll acceleration seems to show the worst agreement of all. Here again, the predicted accelerations are considerably higher than the measured values.

There are several possible explanations for the discrepancy between predicted and measured accelerations. In the field, even if the wind 


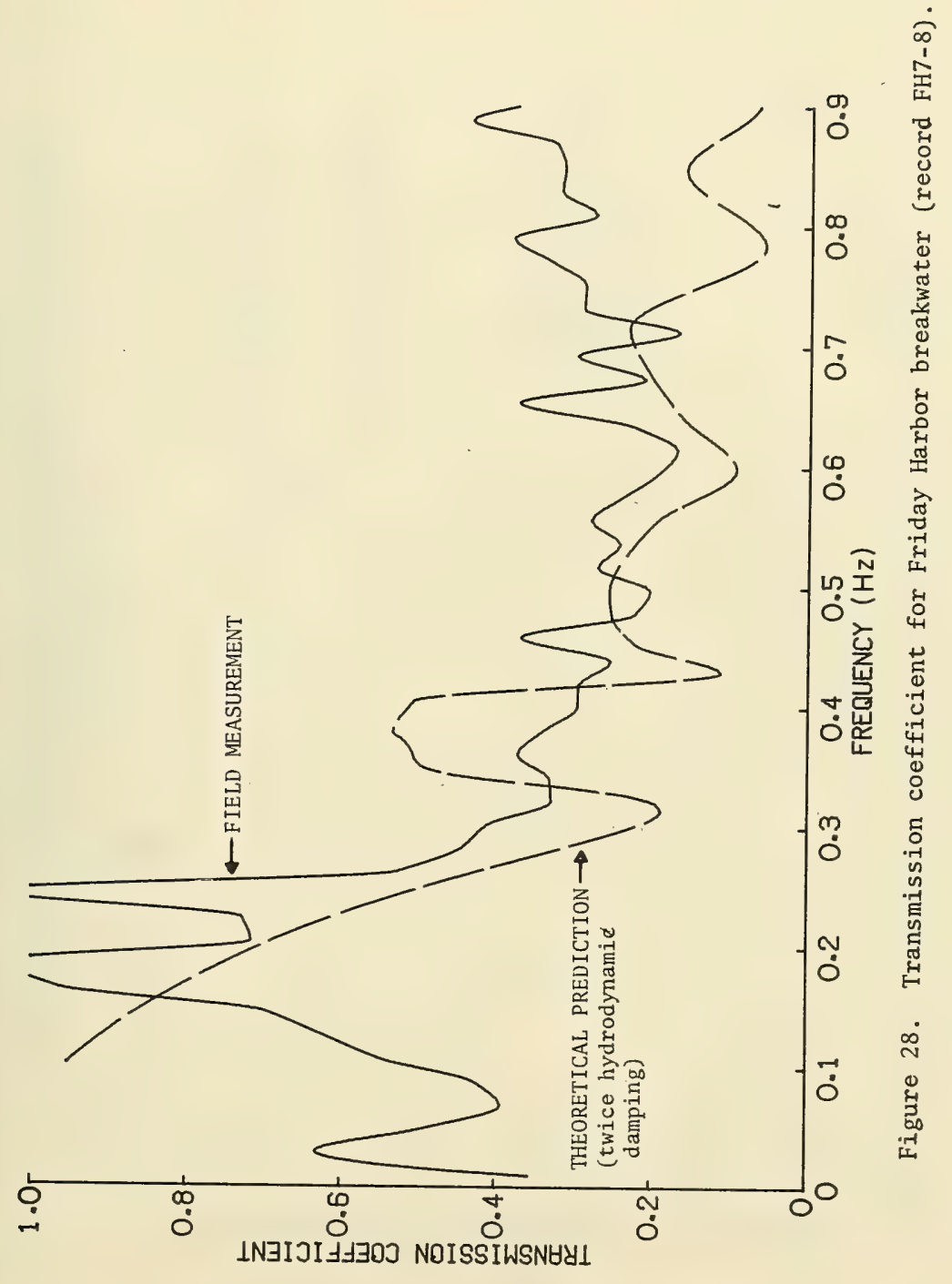




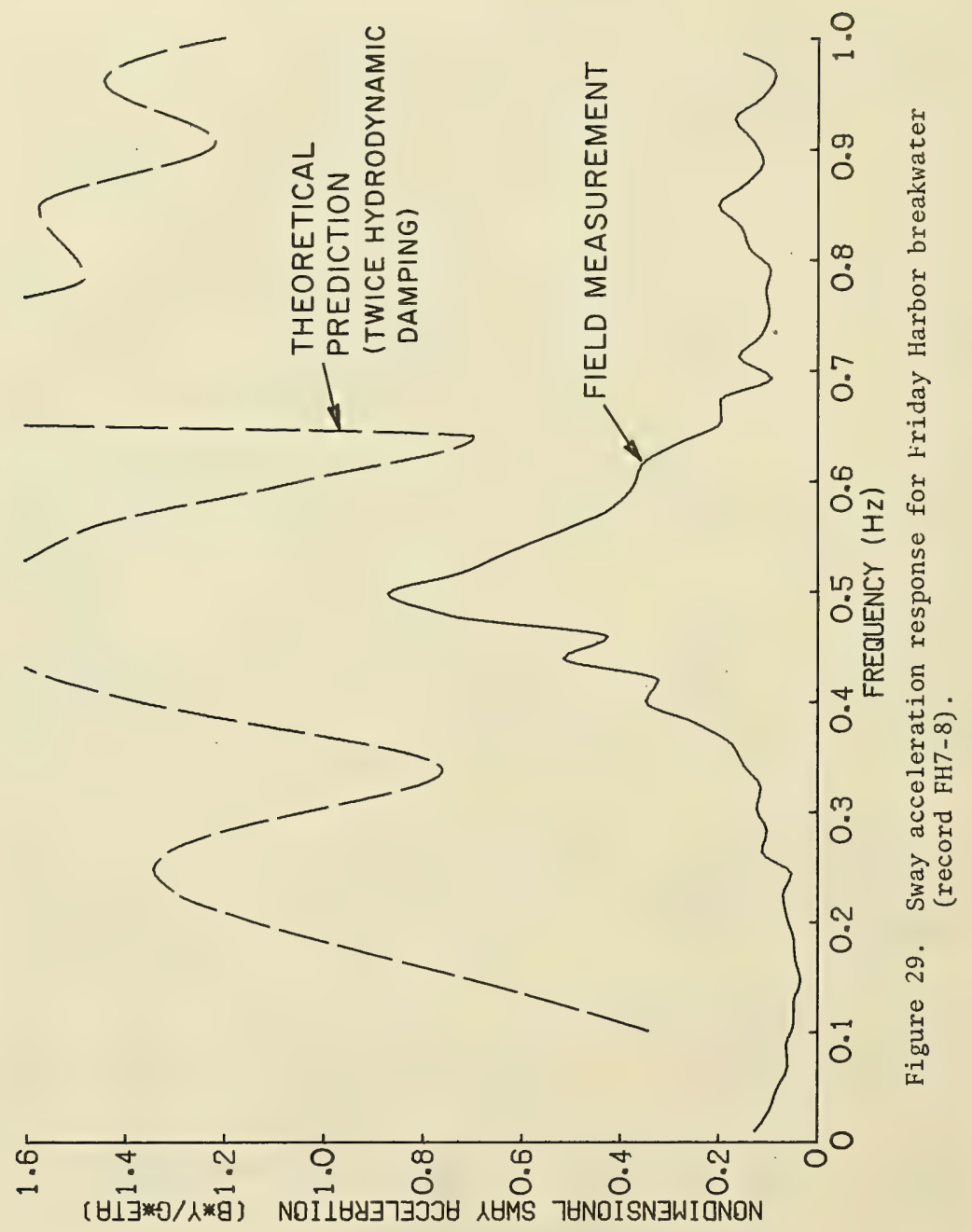




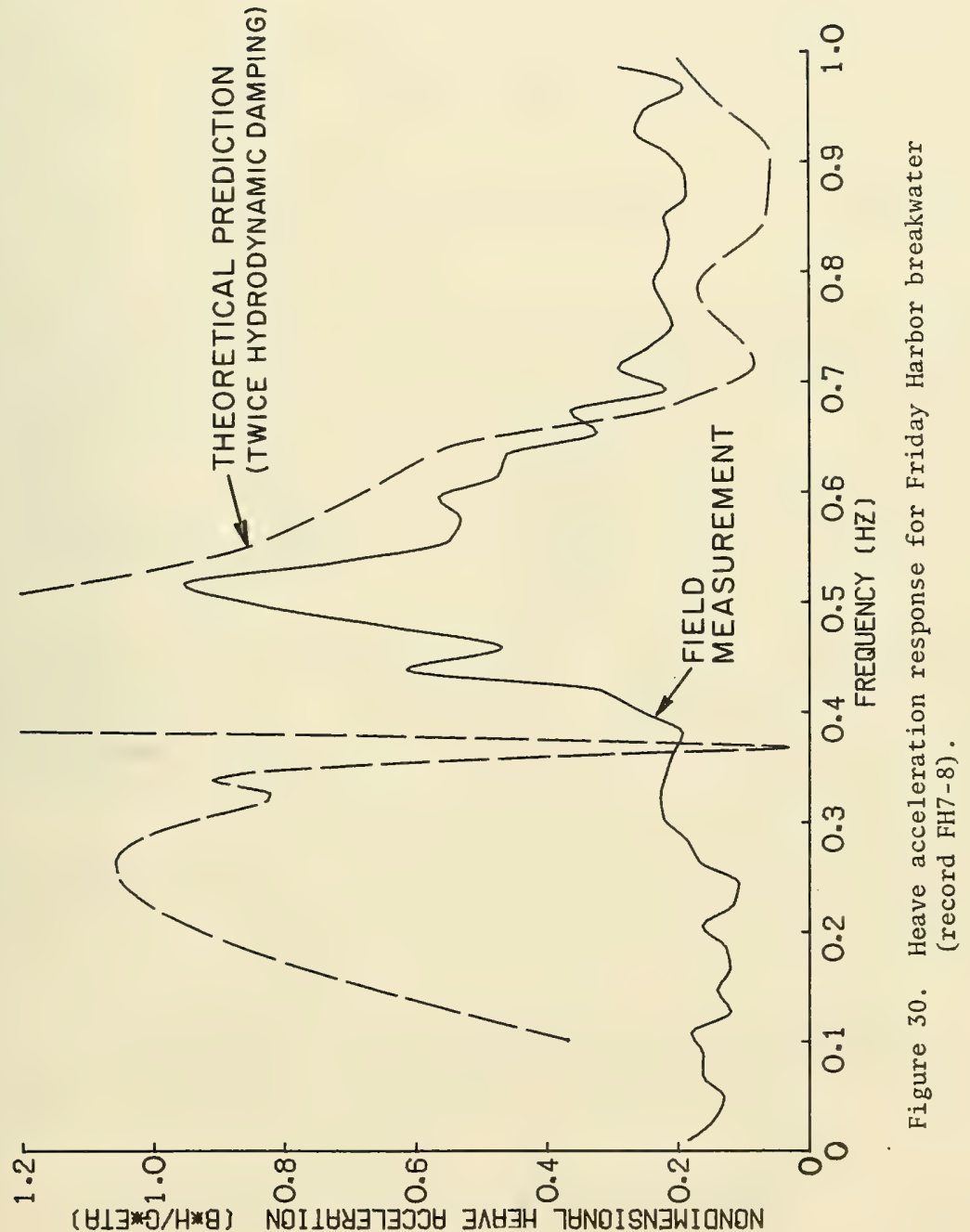




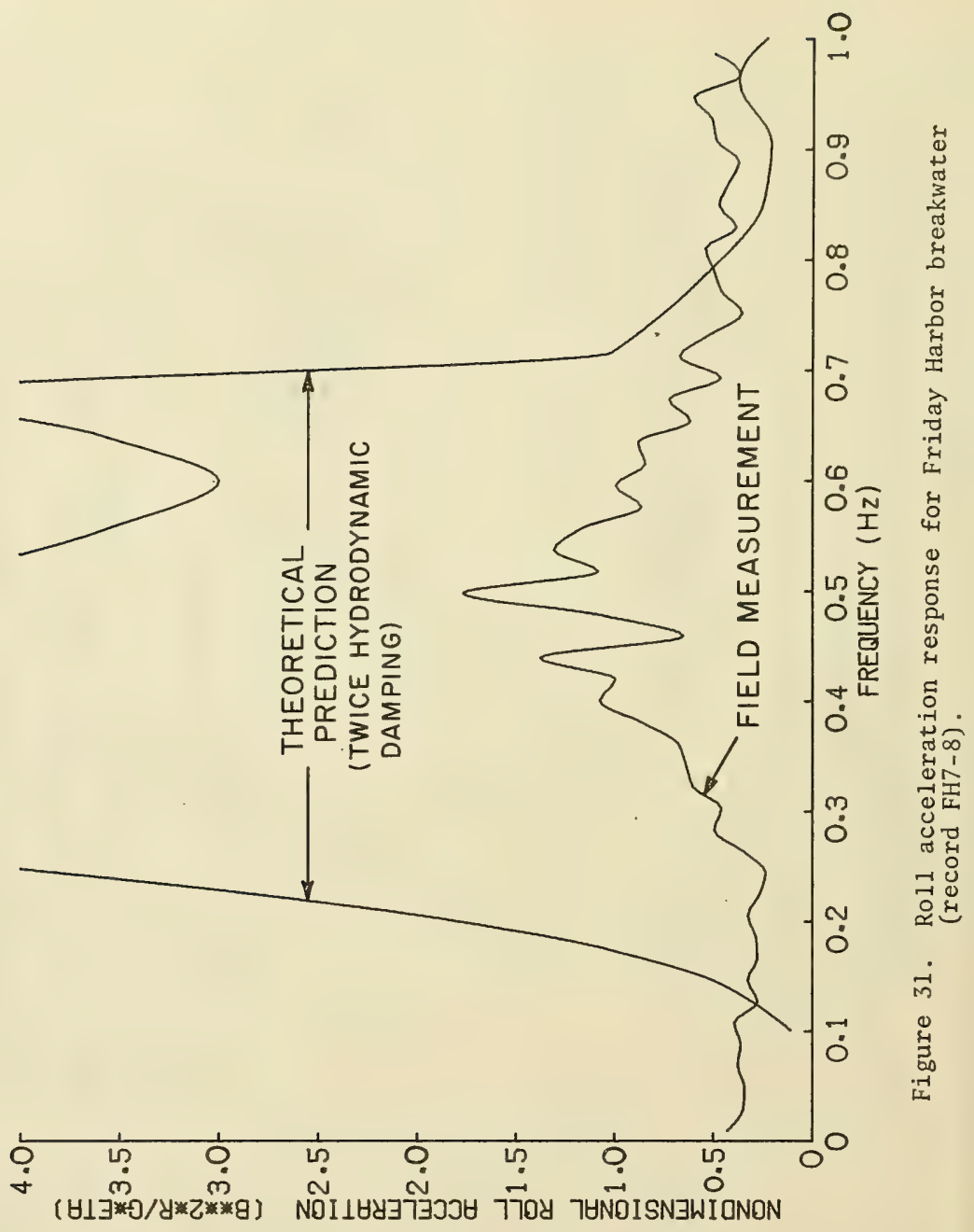


were blowing directly on the beam of the breakwater, one would not find the condition of long-crested waves impinging directly on the beam of the breakwater. As a result, the breakwater is not excited uniformiy along its entire length. Therefore, the breakwater itself provides restraint against motions which are excited in a local area. The construction of this particular breakwater is also quite flexible, which allows for considerable internal damping of the wave-excited motions. The barges tied to the long leg also serve to restrain the motion and provide additional damping.

There is a strong need, in this case, to provide laboratory data on the breakwater motions, which could be further correlated with the theory and the measured motions.

If one looks at the measured accelerations by themselves, a considerable resemblance in all three degrees of freedom appears. Further, if these accelerations are viewed along with the incident wave spectrum, considerable similarity appears again, suggesting that further investigation of the measurement scheme would also be welcome.

The final comparison to be made is between the theoretically predicted and measured mooring-force coefficient. The theoretical prediction and measured data for the seaward mooring line is shown in Figure 32. The correlation appears to be quite good in this case.

In looking at the time series of force on the mooring lines and the windspeed, one can observe a definite correlation between the wind gusts and increases in the mooring force. This is probably a result of the large barges tied to the structure which act almost as sails. If this is the case, the increase in tension caused by the mean wind on the barges needs to be accounted for. No attempt has been made to do this.

The most common method of presenting the spectral data obtained in the field uses a frequency scale rather than the nondimensional beam/ wavelength scale used in Section II. In this section the comparisons are made using a frequency scale. For the Friday Harbor breakwater (beam $=25$ feet) the conversion is:

$$
\frac{B}{L}=\frac{2 \pi B f^{2}}{g}=4.87 f^{2}
$$

assuming deepwater waves. 


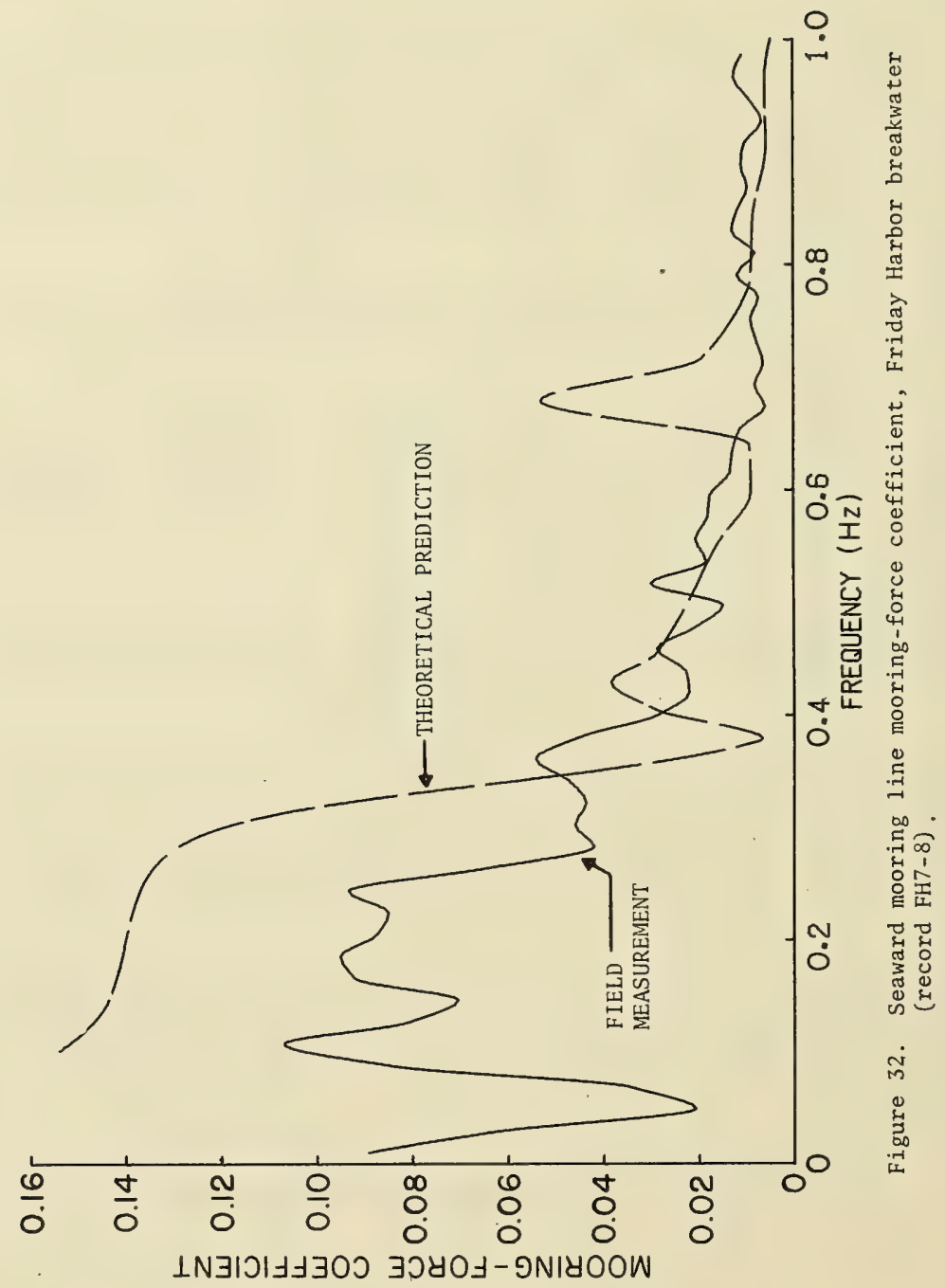




\section{CONCLUSIONS}

Results for the predicted transmission coefficients were in good agreement with laboratory and field data, and they showed how the influence of fixed-body transmission, and of sway, heave, and roll motions on the transmission coefficient changed with increasing values of the beam to wavelength ratio.

The curves predicting the mooring line forces as a function of the beam to wavelength ratio (or of incident wave frequency) followed those for the measured responses. Care must be exercised in the analysis of mooring line forces because there is strong evidence of nonlinear behavior.

An extreme storm event did not occur during the sampling season at Friday Harbor, nor during two winter sampling periods on the Alaskan breakwaters; however, the anchor forces measured were about an order of magnitude less than anticipated.

The barges tied to the long leg of the breakwater did not noticeably affect the transmission coefficients above a frequency of about 0.3 hertz, since the curves for all incident directions were approximately coincident above that mean frequency. Below the frequency of $0.3 \mathrm{hertz}$, it appears that the barges may have reduced the transmitted energy somewhat.

The extension of the theoretical model to include second-order terms showed the presence of additional exciting-force terms at zero frequency and at the difference frequency of the incident waves. Additional work on the basic theoretical model is needed to incorporate these terms into the calculations for mooring forces. The most appropriate means of verifying the role of the second-order terms may be in a model basin, where breakwaters of simple cross section and incident wave spectra having only two or three components could be employed under controlled conditions. 


\section{LITERATURE CITED}

ADEE, B.H., "Analysis of Floating Breakwater Mooring Forces," Ocean Engineering Mechanics, American Society of Mechanical Engineers, New York, 1975.

AMERICAN SOCIETY OF CIVIL ENGINEERS, "Berthing and Mooring Ships," Proceedings of a Nato Advanced Study Institute, Lisbon, Portugal, July 1965.

CARR, J.H., "Mobile Breakwaters," Proceedings of the Second Conference on Coastal Engineering, Nov. 1951, pp. 281-295.

CHRISTENSEN, D.R., and RICHEY, E.P., "Prototype Performance Characteristics of a Floating Breakwater," Marine Technical Report Series Number 24, 1974 Floating Breakwater Conference Papers, University of Rhode Island, Kingston, R.I., Apr. 1974.

DAVIDSON, D.D., "Wave Transmission and Mooring Force Tests of Floating Breakwater, Oak Harbor, Washington," Technical Report H-71-3, U.S. Army Engineer Waterways Experiment Station, Vicksburg, Miss., Apr. 1971.

FRANK, W., "Oscillations of Cylinders in or Below the Free Surface of Deep Fluids," Report 2375, Nava1 Ship Research and Development Center, Bethesda, Md., Oct. 1967.

GOLD, B., and RADAR, C.M., Digital Processing of Signals, McGraw-Hill, New York, 1969.

HARRIS, A.J., "The Harris Floating Breakwater," Marine Technical Report Series Number 24, 1974 Floating Breakwater Conference Papers, University of Rhode Island, Kingston, R.I., Apr. 1974.

JOHN, F., "On the Motion of Floating Bodies," Commuications on Pure and Applied Mathematics, Vo1. 3, 1950.

LEE, C.M., JONES, H., and BEDEL, J.W., "Added Mass and Damping Coefficients of Heaving Twin Cylinders in a Free Surface," Report 3695, Naval Ship Research and Development Center, Bethesda, Md., Aug. 1971.

LOCHNER, R., FABER, 0., and PENNY, W., "The Bombardon Floating Break-ater water," The Civil Engineer in War, The Institution of Civil Engineers, Vo1. 2, London, 1948, p. 256.

MINIKIN, R.R., "Floating and Foundationless Breakwaters," Engineering, Dec., 1948, pp. 557-579.

NECE, R.E., and RICHEY, E.P., "Wave Transmission Tests on Floating Breakwater for Oak Harbor, Washington," Technical Report No. 32, University of Washington, Charles W. Harris Hydraulies Laboratory, Seattle, Wash., Apr. 1972 . 
SAlVESEN, N., TUCK, E., and FALTinSEN, O., "Ship Motions and Sea loads," Transactions of the Society of Navat Architects and Marine Engineers, Vo1. 78, 1970, pp. 250-257.

STRAMANDI, N., "Transmission Response of Floating Breakwaters to Ship Waves," Masters Thesis, University of Washington, Seatt1e, Wash., 1975 .

SUTKO, A.A., and HADEN, E.L., "The Effect of Surge, Heave and Pitch on the Performance of a Floating Breakwater," Marine Technical Report Series Number 24, 1974 Floating Breakwater Conference Papers, University of Rhode Island, Kwngston, R.I., Apr. 1974.

NAVAL CIVIL ENGINEERING LABORATORY, "Mobile Piers and Breakwaters - An Exploratory Study of Existing Concepts," Technical Report 127, Port Hueneme, Calif., Apr. 1961.

NAVAL CIVIL ENGINEERING LABORATORY, "Transportable Breakwaters - A Survey of Concepts," Technical Report R-727, Port Hueneme, Calif., May 1971. 
Hydrostatic restoring forces and spring constants are computed for the two-dimensional analysis under the following assumptions:

(a) The body rotates about the origin of the coordinate system and all forces and moments are computed about that point.

(b) The body has vertical sides in the region of its waterplane.

(c) All motions are small.

1. Sway Motion.

In the horizontal plane the body is in neutral equilibrium. Therefore, there are no hydrostatic restoring forces and

$$
\mathrm{KH}_{11}=\mathrm{KH}_{12}=\mathrm{KH}_{13}=0 .
$$

2. Heave Motion.

Vertical displacement of the body results in a change in the buoyant volume of the body and consequently a change in the buoyant force on the body. Since this force must be perpendicular to the waterline, there is no change in the horizontal force as a result of vertical displacement and

$$
\mathrm{KH}_{21}=0 \text {. }
$$

If one considers a small vertical displacement, $\delta y$, there is a resulting change in volume:

$$
\delta V=-\delta y A_{W} \quad(\text { for } \delta y+u p w a r d s) .
$$

Here, $A_{W}$ is the waterplane area. The vertical force then is:

$$
\mathrm{F}=\mathrm{KH}_{22} \delta \mathrm{y}=-\rho \mathrm{gA}_{\mathrm{w}} \delta \mathrm{y},
$$

or

$$
\mathrm{KH}_{22}=\rho g \mathrm{~A}_{\mathrm{w}}=\rho g\left[\mathrm{x}_{\mathrm{b}}-\mathrm{x}_{\mathrm{a}}\right] \text {. }
$$

In this equation $x_{a}$ and $x_{b}$ denote the sides of the body as shown in the Figure in this appendix. Since the vertical force may be regarded as acting at the centroid of the waterplane area, $x_{c}$, the moment may be expressed. 


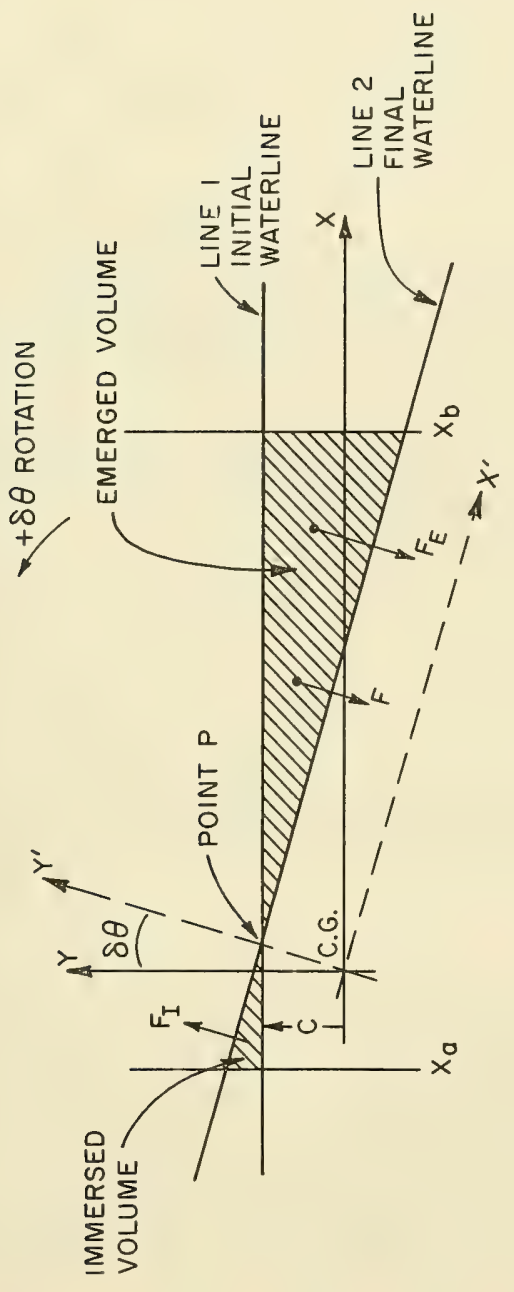

D

건 


$$
M=K_{23} \delta y=-\rho g A_{w} x_{c} \delta y .
$$

Substituting for $\mathrm{x}_{\mathrm{c}}$ and $\mathrm{A}_{\mathrm{W}}$ yields:

$$
\mathrm{KH}_{23}=-\operatorname{\rho gA}_{\mathrm{w}} \mathrm{x}_{c}=-\rho \mathrm{gA}_{\mathrm{w}} \frac{1}{2}\left[\mathrm{x}_{\mathrm{a}}+\mathrm{x}_{\mathrm{b}}\right]=\frac{1}{2} \rho g\left[\mathrm{x}_{\mathrm{a}}{ }^{2}-\mathrm{x}_{\mathrm{b}}{ }^{2}\right] \text {. }
$$

\section{Ro11 Motion.}

The analysis of roll motion-induced forces and moments is complicated by the fact that the body is assumed to rotate about the origin of the coordinate system and not the centroid of the waterplane.

The problem is illustrated in the figure. Here, line 2, the waterline after rotation through and angle $\delta \theta$ must pass through the intersection of the $y^{\prime}$ coordinate axis and the initial waterline. Equations for lines 1 and 2 may then be obtained.

$$
\begin{aligned}
& \text { Line 1: } y=c . \\
& \text { Line 2: } y=m x+b .
\end{aligned}
$$

The slope of line 2 is:

$$
\mathrm{m}=\frac{\Delta \mathrm{y}}{\Delta \mathrm{x}}=-\tan \delta \theta \text {. }
$$

Line 2 must also pass through the point $\mathrm{P}$ so that:

$$
x_{p}=+c \tan \delta \theta
$$

and

$$
y_{p}=c .
$$

These equations yield the relationship:

$$
b=c\left(1+\tan ^{2} \delta \theta\right) \text {. }
$$

To find the force acting on the body as a result of the rotation, the net lost or gained volume is needed.

$$
\begin{aligned}
\delta V & =\int_{x_{a}}^{x_{b}}(m x+b-c) d x \\
& =\int_{x_{a}}^{x_{b}}\left[\left(-x \tan \delta \theta+c\left(1+\tan ^{2} \delta \theta\right)-c\right] d x\right.
\end{aligned}
$$




$$
=-\frac{1}{2}\left[x_{b}^{2}-x_{a}^{2}\right] \tan \delta \theta+c\left[x_{b}-x_{a}\right] \tan ^{2} \delta \theta
$$

By applying the "small angle" approximation and neglecting terms of the order of $\delta \theta^{2}$. Then,

$$
\delta \mathrm{V} \approx \frac{1}{2}\left[\mathrm{x}_{\mathrm{a}}^{2}-\mathrm{x}_{\mathrm{b}}^{2}\right] \delta \theta
$$

and the force is:

$$
\mathrm{F} \approx \frac{1}{2} \rho g\left[\mathrm{x}_{\mathrm{a}}^{2}-\mathrm{x}_{\mathrm{b}}^{2}\right] \delta \theta \text {. }
$$

The $\mathrm{x}$ and $\mathrm{y}$ components of the force are:

$$
\mathrm{F}_{\mathrm{x}}=\mathrm{F} \cos \delta \theta \approx \frac{1}{2} \rho \mathrm{g}\left[\mathrm{x}_{\mathrm{a}}{ }^{2}-\mathrm{x}_{\mathrm{b}}{ }^{2}\right] \delta \theta \cos \delta \theta
$$

and

$$
F_{y}=F \sin \delta \theta \approx \frac{1}{2} \rho g\left[x_{a}^{2}-x_{b}^{2}\right] \delta \theta \sin \delta \theta .
$$

Again applying the small angle approximation one finds:

$$
\mathrm{F}_{\mathrm{x}} \approx \frac{1}{2} \rho g\left[\mathrm{x}_{\mathrm{a}}^{2}-\mathrm{x}_{\mathrm{b}}^{2}\right] \delta \theta
$$

and

$$
\mathrm{F}_{\mathrm{y}} \approx 0 \text {. }
$$

The hydrostatic spring constants coupling roll to sway and heave are then:

$$
\mathrm{KH}_{31}=0
$$

and

$$
\mathrm{KH}_{32}=\frac{1}{2} \rho g\left[\mathrm{x}_{\mathrm{a}}^{2}-\mathrm{x}_{\mathrm{b}}^{2}\right] \text {. }
$$

To obtain the moment induced by roll motion compute:

$$
\begin{aligned}
& \text { Moment of Gained Volume }=-\left(\frac{1}{2} \mathrm{x}_{\mathrm{a}}^{2} \tan \delta \theta\right)\left(\frac{2}{3} \mathrm{x}_{\mathrm{a}}\right) \approx \frac{1}{3} \mathrm{x}_{\mathrm{a}}^{3} \delta \theta, \\
& \text { Moment of Lost Volume } \approx \frac{1}{3} \mathrm{x}_{\mathrm{b}}^{3} \delta \theta
\end{aligned}
$$

and

$$
\text { Moment of Original Volume }=W_{b} \delta \theta \text {. }
$$

In this formula,

$$
W=\text { weight per unit length }
$$


and

$$
\begin{aligned}
y_{b}= & \text { distance the center of buoyancy is below the } \\
& \text { center of gravity. }
\end{aligned}
$$

The total moment then is:

$$
M=\frac{\rho g}{3}\left(x_{b}^{3}-x_{a}^{3}\right) \delta \theta+W y_{b} \delta \theta,
$$

and the spring constant becomes:

$$
\mathrm{KH}_{33}=\frac{\rho g}{3}\left(\mathrm{x}_{\mathrm{b}}^{3}-\mathrm{x}_{\mathrm{a}}^{3}\right)+W y_{\mathrm{b}} \text {. }
$$

Expressed in traditional naval architecture terminology, this reduces to:

$$
\mathrm{KH}_{33}=\mathrm{WGM} \text {, }
$$

where

$$
\mathrm{GM}=\text { metacentric height. }
$$

4. Collected Results.

$$
\begin{aligned}
\mathrm{KH}_{11}=\mathrm{KH}_{12} & =\mathrm{KH}_{13}=\mathrm{KH}_{21}=\mathrm{KH}_{31}=0 \\
\mathrm{KH}_{22} & =\rho g\left[\mathrm{x}_{\mathrm{b}}-\mathrm{x}_{\mathrm{a}}\right] \\
\mathrm{KH}_{23}=\mathrm{KH}_{32} & =\frac{1}{2} \rho g\left[\mathrm{x}_{\mathrm{a}}^{2}-\mathrm{x}_{\mathrm{b}}^{2}\right] \\
\mathrm{KH}_{33} & =\frac{\rho g}{3}\left[\mathrm{x}_{\mathrm{b}}^{3}-\mathrm{x}_{\mathrm{a}}^{2}\right]+\mathrm{Wy}_{\mathrm{b}} .
\end{aligned}
$$




\section{APPENDIX B}

\section{MOORING ANALYSIS}

1. Purpose of the Program.

Computer program BRKMOOR computes the forces and moments imparted by a pair of mooring cables on a floating breakwater section. BRKMOOR also computes the changes in the mooring cable tensions and the springconstant values for the moorings as the breakwater moves in sway, heave, or roll.

\section{Program Description.}

Program BRKMOOR is written primarily in FORTRAN IV although FORTRAN II print statements are used.

The program consists of the main program BRKMOOR and the subroutines LINE2, CHAIN, NYLON, EQULIB, SPRING, and LTERPS.

BRKMOOR calculates the forces in a mooring cable by using a discretized approximation to the cable. The cable is divided into the number of segments specified in the input data. Each segment may be of a different material or size. Each segment is in turn divided into a specified number of sections. The cable is considered to be made of these sections with the weight of each section concentrated at the node at the bottom of the section. Connecting each node is a straight but elastic section.

The main part of the program specifies 15 different angles at the attachment, ranging from nearly vertical to nearly straight to the farthest reasonable anchor position. A first guess at a top tension is made.

LINE2 then sums down the cable computing forces and coordinates of each node starting with the initial angle and initial tension. The position of the end of the cable is compared with the specified water depth at the anchor. The initial tension is adjusted and the summation repeated until the cable ends at the proper depth. Control then returns to the main program.

LINE 2 calls the subroutines NYLON or CHAIN to compute the strain of the cable section of the appropriate material. If other materials are used new subroutines should be written for strain computation, along with the appropriate calling expression in LINE2.

At each angle the cable forces at the attachment and the anchor position are stored in arrays. EQULIB then computes the breakwater equilibrium position for the specified conditions.

SPRING is called by EQULIB. SPRING computes the change in mooring 
cable tensions with breakwater displacement in sway, heave, and roll and the spring constants of the moorings on the breakwater.

LTERPS is a linear interpolation subroutine which computes the slop, $\frac{\Delta Y}{\Delta X}$, and the interpolated value of $Y$ for a given $X$ and an array of $X$ vs. $Y$ values. LTERPS is called by EQULIB and SPRING.

3. Type of Computer and Peripherals.

BRKMOOR was written for use on the CDC 6400 computer. It uses about 40,0008 words of memory. No peripherals other than the card reader and line printer are required.

4. Input Data.

The input to BRKMOOR is as follows:

Card \#1 - Title card, Format (8A10). 80 alphanumeric characters max.

Card \#2 - Breakwater geometry card, Format (5F10.0). YCG = Vertical location of breakwater CG relative to water surface.

$\mathrm{XCAB}(1)=x$ coordinate of cable \#1 attachment to breakwater (the CG is at $X=0$ and cable \#1 is defined as the cable with its anchor in the $+x$ direction).

$Y C A B(1)=y$ coordinate of cable \#1 attachment to breakwater.

$X C A B(2)=x$ coordinate of cable \#2 attachment to breakwater.

$\mathrm{YCAB}(2)=y$ coordinate of cable \#1 attachment to breakwater.

Card \#3 - Number of desired conditions Format (12).

(A1so number of condition cards to follow)

Card \#4 - Condition cards, Format (4F10.0).

(One card for each condition)

FEXT = Force applied to the breakwater not due to moorings in $x$ direction (could be due to wave action, tide, wind, etc. force in pounds).

SEP = Anchor separation in horizontal direction (feet). TENS1 = Nominal tension in cable \#1 (lb.).

TENS2 = Nominal tension in cable \#2 (1b.).

It should be noted that only the following condition combinations are possible:

SEP

SEP+FEXT

TENS1

TENS1+FEXT

TENS2

TENS2+FEXT

TENS1+TENS 2 
Card \#5 - Tide Card, Format (I1, 9X, 5F10,0). NTIDE $=$ Number of tide values to follow $(\max =5)$.

TIDE = Tide position in feet relative to that at which the anchor depths are given.

Card \#6 - Cable \#1 Parameters, Format (I2, 8X, 2F10.0).

NSEG $=$ Number of different segments (types of cable materials) from which the cable is constructed.

DEPTH = Depth of water at the anchor (feet).

BSLOPE = Slope of bottom in region of anchor (feet/feet).

Card \#7 - Cable segment properties Format (I5,5X,2F10.0,A10,F10.0). One card for each of the number of segments listed in card 6 parameter NSEG.

NSECT $=$ Number of sections into which it is desired to divide the cable segment.

ALSEG = The length of this cable segment.

WPF = Weight per foot in water of the cable material in this segment.

MATL = Material name (as the program now stands this must be CHAIN or NYLON (Name must begin in column 31).

DIAM = Diameter of the nylon rope or of the chain link in inches.

Card \#8 and \#9 - Same as cards \#6 and \#7 only as applies to cable. \#2.

Table B-1 illustrates the input cards for a test case. All the read statements for the program are in the main program along with comments and explanations of input requirements.

5. Mathematical Procedures and Program Limitations.

The basic cable computations which take place in LINE2 require some explanation. As was stated previously, the weight of each cable section is considered to be concentrated at the bottom of the section. In order to find the shape of the cable, summations of forces are computed for static equilibrium at each node. At each node we know the tension in the cable section above the node as well as the angle of that section with the horizontal. Figure B-1 illustrates the cable about the ith node.

If the angle $\phi_{i}$ is taken to be the angle from the horizontal, then the angle $\phi_{i+1}$ can be computed as follows:

$$
\phi_{i+1}=\tan ^{-1}\left[\frac{\mathrm{T}_{i} \sin \phi_{i}+W_{i}}{\mathrm{~T}_{i} \cos \phi_{i}}\right] \text {, }
$$

where

$$
\begin{aligned}
& T_{i}=\text { tension in section } i \\
& W_{i}=\text { weight of section } i \text { concentrated at node } i .
\end{aligned}
$$




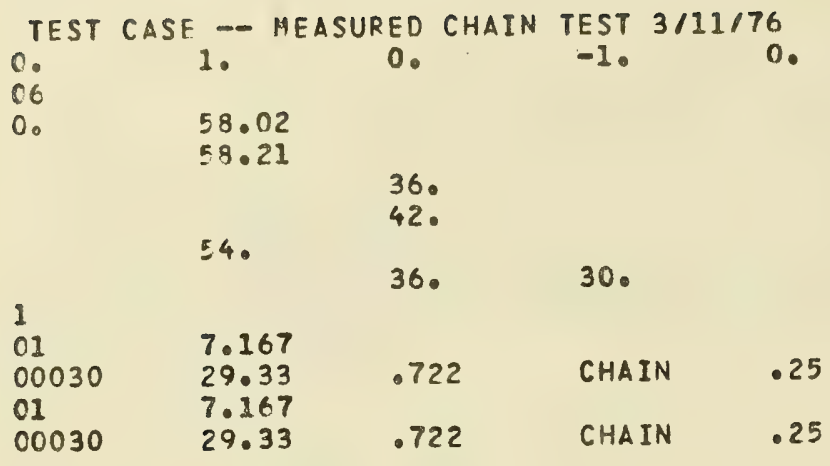

Table $B-1$. Example input for program BRKMOOR. 


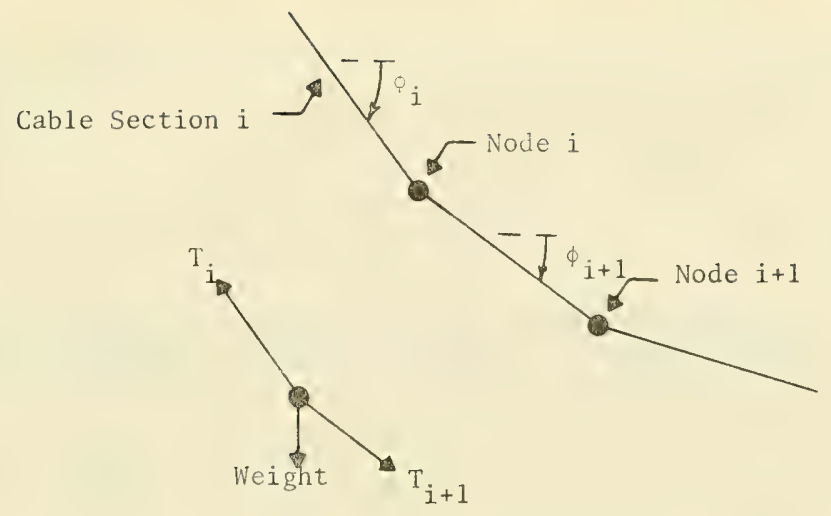

Figure B-1, Cable sections about node $i$ and free body diagram of node $i$.

This new angle is then used to compute the tension in the next section:

$$
\mathrm{T}_{i+1}=\frac{\mathrm{T}_{\mathrm{i}} \cos \phi_{i}}{\cos \phi_{i+1}} .
$$

LINE2 computes the angle and tension of each section starting from the top. At each section the angle is compared with the slope of the bottom. When the angle $\phi$ is parallel or more positive than the bottom then $\phi$ is set to the slope of the bottom.

The $\mathrm{x}$ and $\mathrm{y}$ coordinates of each node are computed.

$$
\begin{aligned}
& X_{i+1}=X_{i}+L_{E X T_{i+1}} \cos \phi_{i+1} \\
& Y_{i+1}=Y_{i}+L_{E_{E X T}} \sin \phi_{i+1},
\end{aligned}
$$

where $\quad x_{i}=x$ coordinate of node $i$

$$
\begin{aligned}
& Y_{i}=y \text { coordinate of node } i \\
& L_{E X T}=\text { length of section when under tension. }
\end{aligned}
$$


At the last node the $y$-coordinate is compared with the depth of the anchor. If there is a difference the initial tension value is adjusted. Guesses at the first and second tensions are made. From then on a secant (discrete form of Newton Raphson) iteration method is used to compute the subsequent initial tension values. An error of $0.0001^{*}$ depth is allowed. In most cases 4 or 5 iterations yield the desired accuracy. Som important values are printed for each iteration to aid in troubleshooting.

Within EQULIB and SPRING interpolation is required to find the values of tension forces and $x$ coordinates which are between the points computed by BRKMOOR and LINL2. The linear interpolation routing LTERPS was chosen over higher-order interpolation schemes because of the asymptotic nature of the tension versus $x$ values. If values are requestea beyond the ends of the computer arrays, they can be extrapolated, but a warning message will be printed by EQUILIB.

An iterative procedure is required within EQULIB if the anchor separation condition is selected. Again the secant iteration method is used. EQULIB prints out values at each interation which can aid in troubleshooting but which can normally be ignored.

Subroutine CHAIN computes the strain in a chain using the basic elastic properties of a steel bar with a total area equal to the area of both parts of the links, and a factor of 6 to allow for the deformation characteristics of the links. This factor of 6 came from a finite element computation.

Subroutine NYLON computes the strain in a nylon rope using a powerfunction fit of the form:

$$
\varepsilon=A X^{\beta} \text {, }
$$

where

$$
\begin{aligned}
\varepsilon & =\text { Strain, } \\
A & =0.02052 \\
B & =0.2237 \\
X=\frac{T}{D^{2}} & \\
T & =\text { Tension (pound) } \\
D & =\text { Diameter of rope (inches) } .
\end{aligned}
$$

This function was determined using a least-squares power-function fit of experimental data provided by Sampson Cordage Works for their 2-in-1 nylon braided rope.

An experimental verification test was conducted as a check of the program. A chain was suspended from a spring scale. Measurements were made of the length of the chain, its weight and the tension in two geometrical configurations. The program gave computed values of the tension very close to those measured. 
6. Flow Chart. tines.

Figure B-2 illustrates the flow chart of BRKMOOR and its subrou-

7. Program Comments and Glossary of Terms.

The program listing contains many comments which aid in following the $\log$ ic of the program. The important variable names are explained as well as the input requirements.

8. Run Time and Memory Size.

BRKMOOR requires about 40 seconds on the CDC 6400 to compile and compute results for one value of the tide parameter. Each additional tide value requires about 30 seconds additional time. These values are for cables divided into 50 sections each. Time should be somewhat proportional to the total number of cable sections. The number of test conditions has much less effect on time than does the tide. As stated previously, a central memory of about 40,000 octal is required.

9. Run and Card Deck Setup Procedures and Special Operation Instructions.

In order to run the FORTRAN source program deck on the University of Washington CDC 6400, the following deck is required:

BMOOR, T 40.
ACCOUNT
FORTRAN
LGO $($ LC=6000)
$7 / 8 / 9$
FORTRAN DECK
$7 / 8 / 9$ DATA DECK
$6 / 7 / 8 / 9$

Job card

(Account no., password)

LC = line count value; depends on how many tides and conditions are run

10. Sample Output Data.

Example output from program BRKMOOR is shown in Table B-2; a listing of program BRKMOOR is shown in Table B-3. 

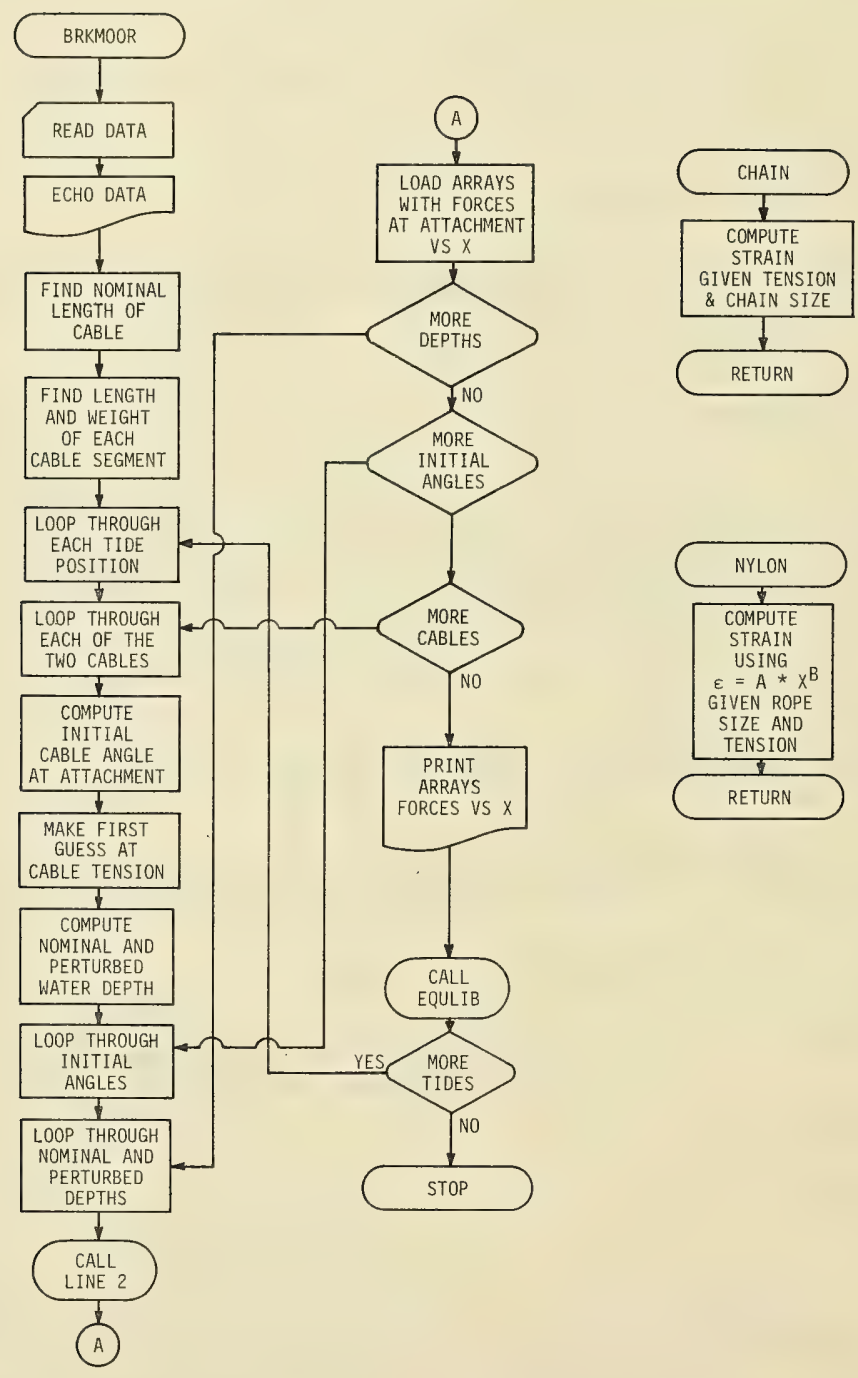

Figure B-2. Flow chart for program BRKMOOR. 


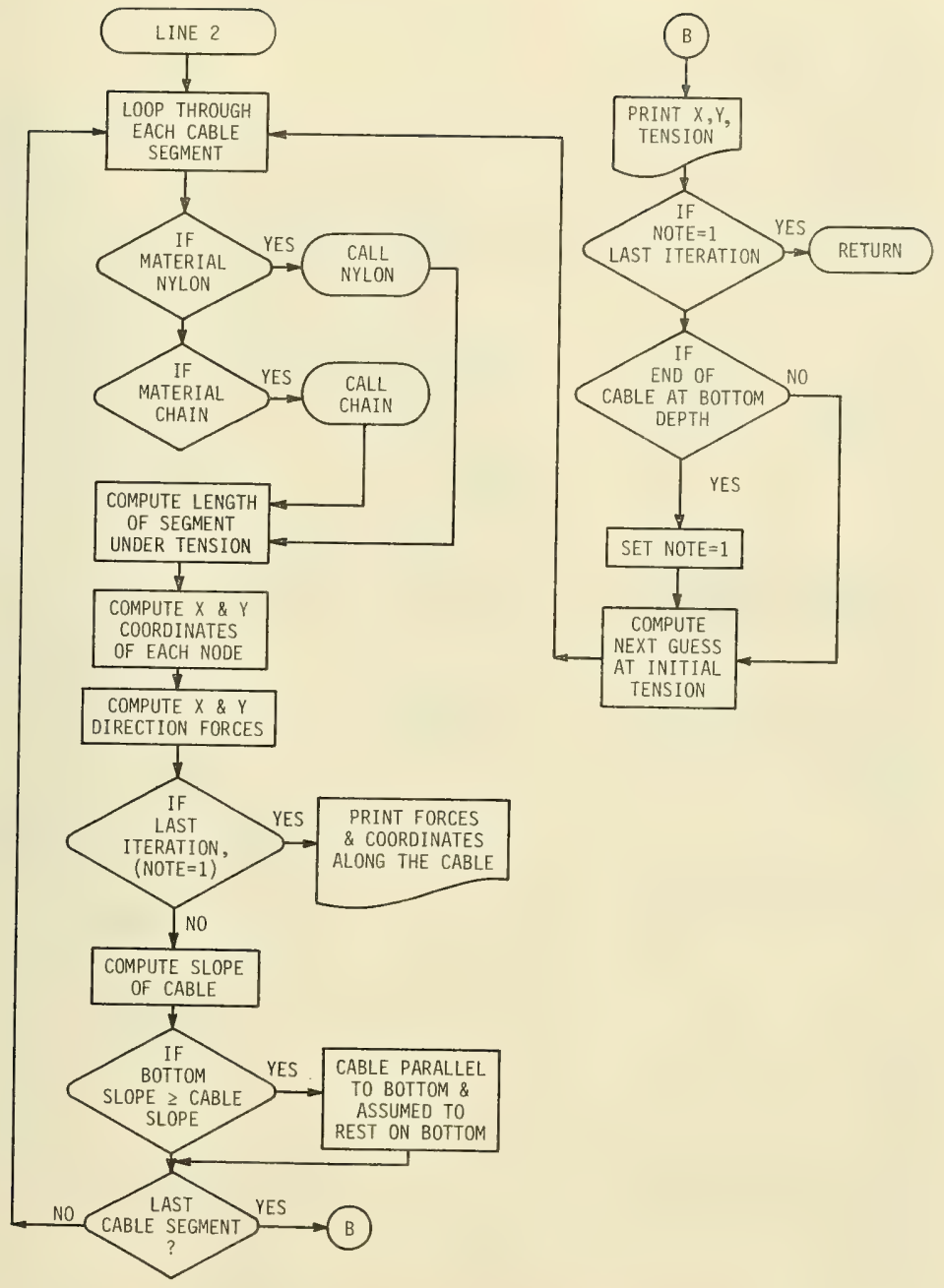

Figure B-2. Continued 


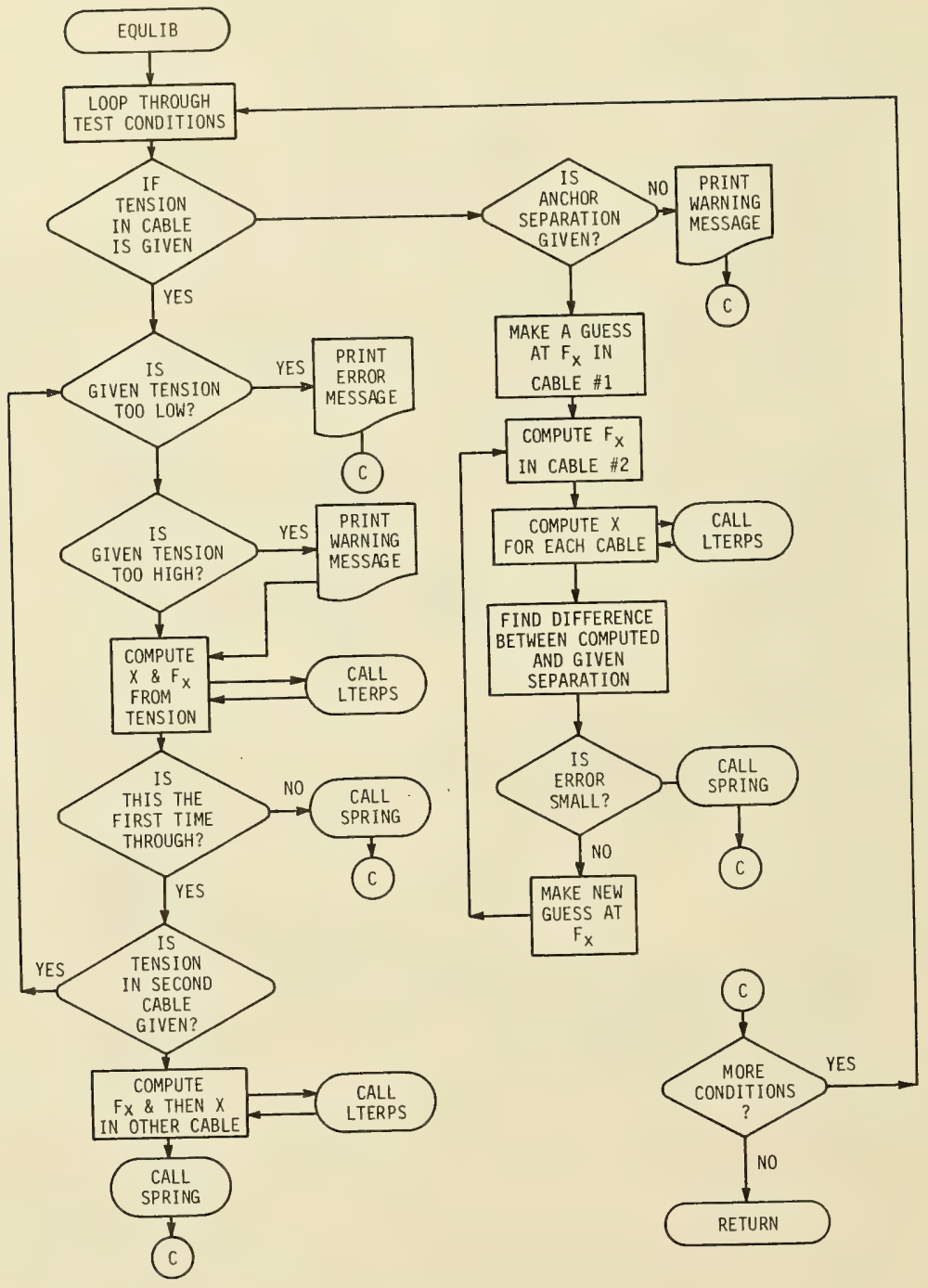

Figure B-2. Continued 


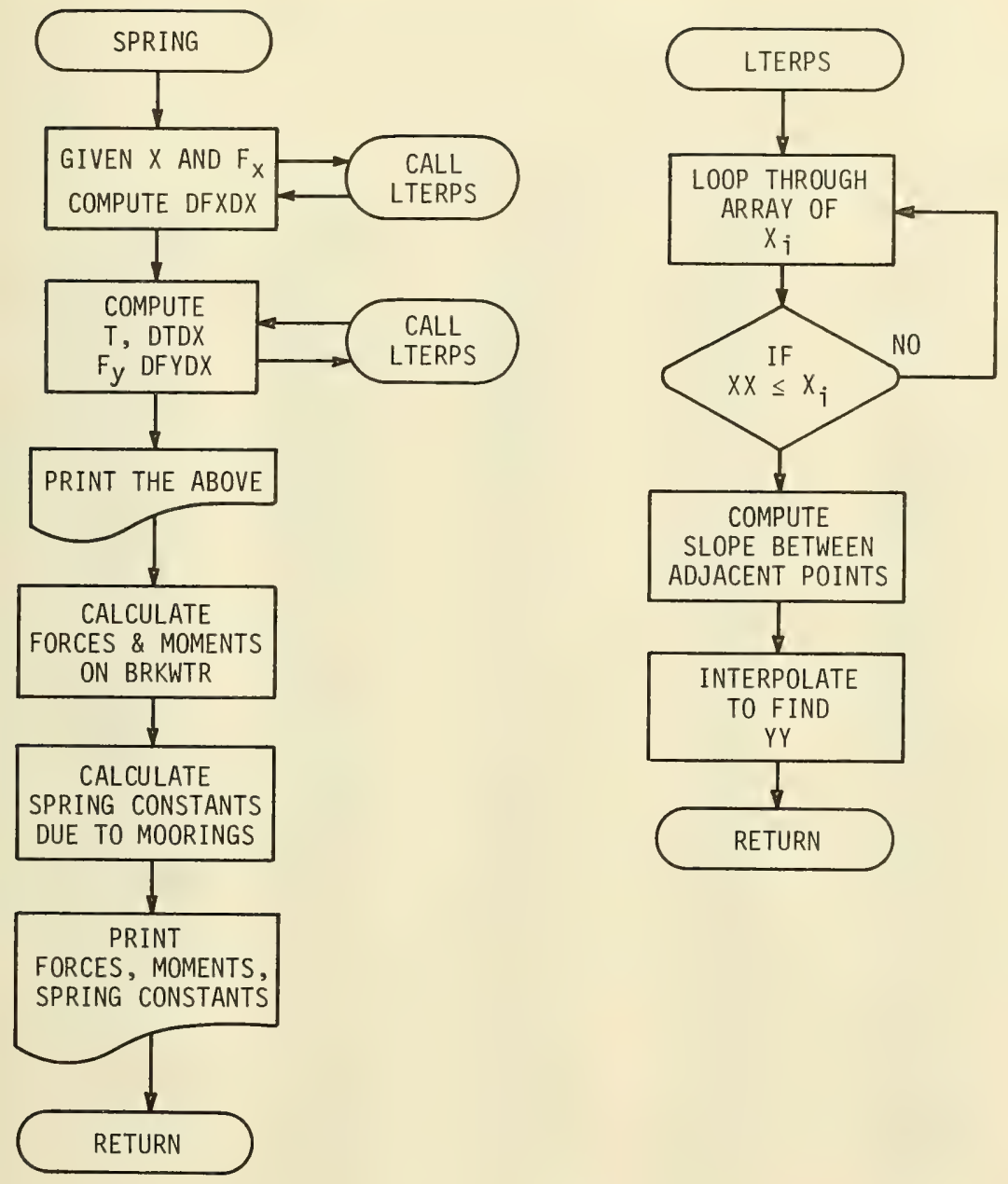

Figure B-2. Continued 
IN THE FOLLOWING TABLES - $X$ REL. TO CG, Y REL. TO WATER SURFACE

TEST CASE -- MEASURED CHAIN TEST $3 / 11 / 76$

MDORINE LINE NUMBER $=1$ TIDE $=-.000$

$r$

$-7.167$

$-7.167$

$-7.167$

$-7.167$

$-7.167$

$-7.167$

$-7.167$

$-7.167$

$-7.167$

$-7.167$

$-7.167$

$-7.167$

$-7.167$

$-7.167$

$-7.167$

$-7.239$

$-7.239$

$-7.239$

$-7.239$

$-7.239$

$-7.239$

$-7.239$

$-7.239$

$-7.239$

$-7.239$

$-7.239$

$-7.239$

$-7.239$

$-7.239$

$-7.239$

$-7.095$

$-7.095$

$-7.095$

$-7.095$

$-7.095$

$-7.095$

$-7.095$

$-7.095$

$-7.095$

$-7.095$

$-7.095$

$-7.095$

$-7.095$

$-7.095$

$-7.095$ $x$

24.605

25.294

25.893

26.387

26.804

27.174

27.507

27.814

28.099

28.366

28.619

28.859

29.089

29.290

29.410

24.544

25.258

25.839

26.346

26.769

27.142

27.477

27.790

28.077

28.347

28.602

28.844

29.077

29.277

29.395

24.658

25.328

25.945

26.427

26.839

27.205

27.536

27.837

28.122

28.386

28.636

28.874

29.102

29.303

29.426
TOP TENSION

5.202

5.802

$6.4 C 7$

7.158

B. 101

9.278

10.776

12.704

15.254

18.714

23.557

30.675

41.694

61.608

121.346

5.251

5.848

6.494

7.240

8.190

9.380

10.900

12.833

15.417

18.906

23.805

31.005

42.115

62.505

125.036

5.160

5.757

6.327

7.080

8.016

9.179

10.657

12.578

15.085

18.508

23.314

30.353

41.256

60.738

117.875
FORCEX

$$
\begin{array}{r}
.430 \\
.956 \\
1.574 \\
2.326 \\
3.257 \\
4.419 \\
5.899 \\
7.809
\end{array}
$$

10.338

13.777

18.601

25.695

36.687

56.444

114.814

.434

.963

1.595

2.353

3.292

4.468

5.967

7.888

10.449

13.919

18.797

25.971

37.058

57.266

118.305

.426

.948

1.555

2.301

3.223

4.372

5.833

7.732

10.224

13.626

18.410

25.425

36.302

55.647

111.530
FORCEY

$$
\begin{aligned}
& -5.184 \\
& -5.722 \\
& -6.211 \\
& -6.770 \\
& -7.417 \\
& -8.158 \\
& -9.019 \\
& -10.021 \\
& -11.216 \\
& -12.664 \\
& -14.454 \\
& -16.755 \\
& -19.809 \\
& -24.690 \\
& -39.276 \\
& -5.233 \\
& -5.768 \\
& -6.295 \\
& -6.847 \\
& -7.499 \\
& -8.248 \\
& -9.122
\end{aligned}
$$

$-10.122$

$-11.336$

$-12.795$

$-14.606$

$-16.935$

$-20.010$

$-25.050$

$-40.470$

$-5.142$

$-5.678$

$-6.133$

$-6.696$

$-7.339$

$-8.071$

$-8.918$

$-9.922$

$-11.092$

$-12.525$

$-14.305$

$-16.579$

$-19.601$

$-24.341$

$-38.152$

Table B-2. Example output from program BRKMOOR. 
MOORINE LINE NUMBER $=2$ TIDE $=-.000$

Y

$\begin{array}{ll}-7.167 & -24.605 \\ -7.167 & -25.294 \\ -7.167 & -25.893 \\ -7.167 & -26.387 \\ -7.167 & -26.804 \\ -7.167 & -27.174 \\ -7.167 & -27.507 \\ -7.167 & -27.814 \\ -7.167 & -28.099 \\ -7.167 & -28.366 \\ -7.167 & -28.619 \\ -7.167 & -28.859 \\ -7.167 & -29.089 \\ -7.167 & -29.290 \\ -7.167 & -29.410 \\ -7.239 & -24.544 \\ -7.239 & -25.258 \\ -7.239 & -25.839 \\ -7.239 & -26.346 \\ -7.239 & -26.769 \\ -7.239 & -27.142 \\ -7.239 & -27.477 \\ -7.239 & -27.790 \\ -7.239 & -28.077 \\ -7.239 & -28.347 \\ -7.239 & -28.602 \\ -7.239 & -28.844 \\ -7.239 & -29.077 \\ -7.239 & -29.277 \\ -7.239 & -29.395 \\ -7.095 & -24.658 \\ -7.095 & -25.328 \\ -7.095 & -25.945 \\ -7.095 & -26.427 \\ -7.095 & -26.839 \\ -7.095 & -27.205 \\ -7.095 & -27.536 \\ -7.095 & -27.837 \\ -7.095 & -28.122 \\ -7.095 & -28.386 \\ -7.095 & -28.636 \\ -7.095 & -28.874 \\ -7.095 & -29.102 \\ -7.095 & -29.303 \\ -7.095 & -29.426 \\ & \\ -7.095 & \end{array}$

TOP TENSION

$$
\begin{aligned}
& 5.202 \\
& 5.802 \\
& 6.407 \\
& 7.158 \\
& 8.161 \\
& 9.278
\end{aligned}
$$

10.776

12.704

15.254

18.714

23.557

30.675

41.694

61.608

121.346

5.251

5.848

6.494

7.240

8.190

$9.3 E 0$

10.900

12.833

15.417

18.906

23.805

31.005

42.115

62.505

125.036

5.160

5.757

6.327

7.080

8.016

9.179

10.657

12.578

15.085

18.508

23.314

30.353

41.256

60.738

117.875
FORCEX

$$
\begin{array}{r}
-.430 \\
-.956 \\
-1.574 \\
-2.326 \\
-3.257 \\
-4.419 \\
-5.899 \\
-7.809 \\
-10.338 \\
-13.777 \\
-18.601 \\
-25.695 \\
-36.687 \\
-56.444
\end{array}
$$

$-114.814$ $-.434$

$-.963$

$-1.595$

$-2.353$

$-3.202$

$-4.468$

$-5.967$

$-7.888$

$-10.449$

$-13.919$

$-18.797$

$-25.971$

$-37.058$

$-57.26 t$

$-118.305$

$-.426$

$-.948$

$-1.555$

$-2.301$

$-3.223$

$-4.372$

$-5.833$

$-7.732$

$-10.224$

$-13.626$

$-18.410$

$-25.425$

$-36.302$

$-55.647$

$-111.530$
FORCEY

$-5.184$

$-5.722$

$-6.211$

$-6.770$

$-7.417$

$-8.158$

$-9.019$

$-10.021$

$-11.216$

$-12.664$

$-14.454$

$-16.755$

$-19.809$

$-24.690$

$-39.276$

$-5.233$

$-5.768$

$-6.295$

$-6.847$

$-7.499$

$-8.248$

$-9.122$

$-10.122$

$-11.336$

$-12.795$

$-14.606$

$-16.935$

$-20.010$

$-25.050$

$-40.470$

$-5.142$

$-5.678$

$-6.133$

$-6.696$

$-7.339$

$-8.071$

$-8.918$

$-9.922$

$-11.092$

$-12.525$

$-14.305$

$-16.579$

$-19.601$

$-24.341$

$-38.152$

Table B-2. Continued 


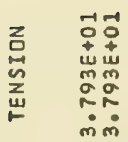

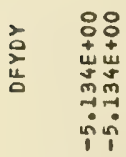

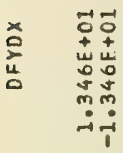

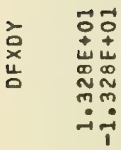

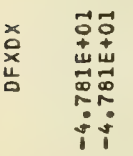

虫

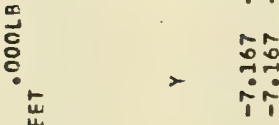

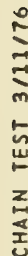

卢禹番

니인

i 8 ?

Ü:i

员是

这.

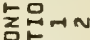

N岳山

뚜요 $\vec{\alpha}$

온⿺ㄴ

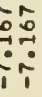

c)

岂

i

눈

엉 |

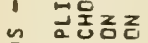

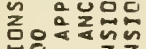

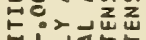

-

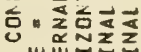

w出舟

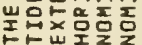

雍

운

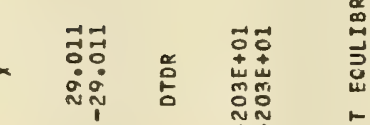

ב
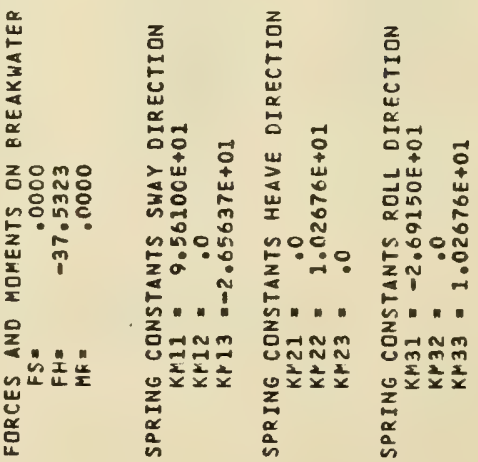
RUNT VERSICN FEB 74 B $13804 \quad 04109 / 76$

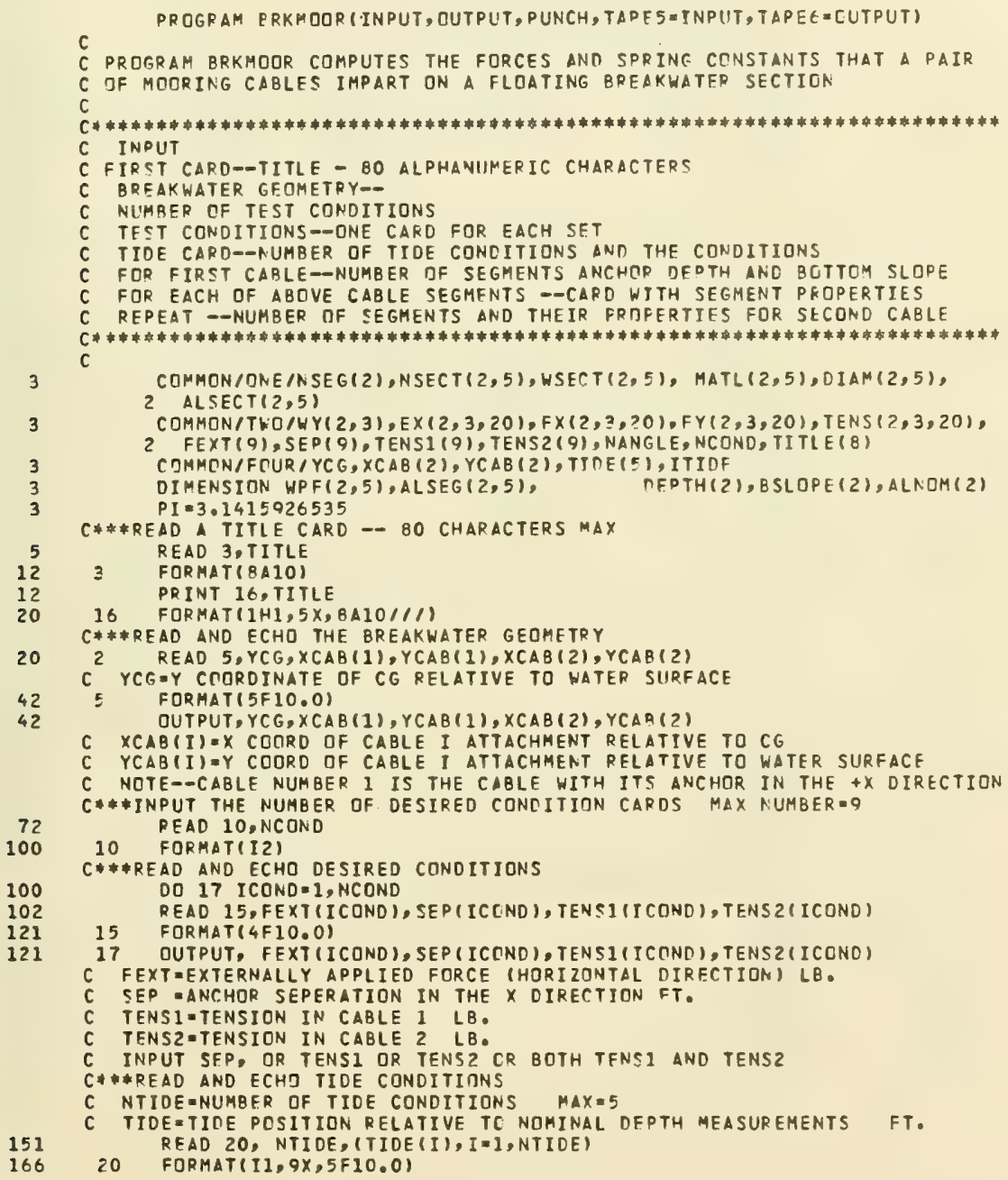

Table B-3. Listing of program BRKMOOR. 
RUNT VERSICN FEB 74 B $13: 04 \quad 04 / 09 / 76$

166

201

203

217

217

223

223

226

230

264

264

326

326

331

332

343

357

375

377

403

405

406

411

411

421

423

431

443

444

445

446

456

461

463

470

OUTPUT, NTIDE, TIDE

C LODP THROUGH THE TWO CABLES $0065 I=1,2$

C* * INPUT THE CABLE PRDPERTIES AND BOTTOM DEDTH AND SLDPE REAO 22, NSEG (I), DEPTH(I), BSLDPE(I)

22 FORHAT $(12,8 \times, 2 F 10.0)$

C NSEG = NUMBER OF CABLE SEGMENTS DR MATERIALS

C DEPTH = DEPTH OF THE WATER AT THE ANCHOR FT.

C BSLOPE= SLOPE DF THE BOTTOM (FT RISE/FT) PRINT 25

25 FORMATI///5X, \# NUMBER SECTIONS SEGMENT LFNGTH WT PER FOOT* $24 X *$ MATERIAL DIAMETER * I $N S=N S E G(I)$ DO $30 \mathrm{~J}=1, \mathrm{NS}$

C**\#FRR EACH CABLE SEGMENT INPUT

C NSECTII : NIMBER OF SECTIONS INTO WHICH CARLF SEGMENT I IS DIVIDEO

C ALSEG(I) =LENGTH OF CABLE SEGMENT I FT.

C WPF (I) = WEIGHT PER FOOT IN WATER OF CABIF SEGMENT I LB/FT

C MATL = MATERIAL OF CABLE SEGMENT EITHEP NYLON CR CHAIN

C MUST BE LEFT JUSTIFIED IN CATA FIELD

C DIAM-DIAMETER OF ROPE OR CHAIN LINK INCHES READ $40, N S E C T(I, J), A L S E G(I, J), \operatorname{WFF}(I, J), \operatorname{MATL}(I, J), D I A M(I, J)$

40 FCRMAT $(15,5 X, 2 F 10.0,110, F 10.0)$

30 PRINT 50,J,NSECT $(I, J)$, ALSFG(I,J),WPFII,J), MATLII, J),DIAM(I,J)

50 FORMAT $(X, I 5$, EX, I5, 8X,F10.2,4X,F10.2, OX,A10, $5 X, F 6.3)$

C***FIND THE NCMINAL LENGTH OF THE CABLE, LENGTH AND WEIGHT OF SECTIONS $A L N O M(I)=0$. DO $60 \mathrm{~J}=1$, NS $\operatorname{ALNOM}(I)=A L N O M(I)+\operatorname{ALSEG}(I, J)$ AL SECT II, J) $=A L S E G(I, J) / N S E C T(I, J)$

(O WSECT $(I, J)=W P F(I, J) * A L S E C T(I, J)$

E5 CONTINUE $B S L O P E(2)=-B S L O P E(2)$

C***LOQP THROUEH THE TIDE POSITICNS

DO 400 ITIDE $=1$, NTIDE

C***LOOP THROUGH THE CABLES

DO $150 \quad I=1,2$

PRINT 70

70 FORMAT(1H1,5X*NOTE--IN THE FDLLOWING TABLES $X$ AND Y ARE MEASURED 2RELATIVE TO THE CABLE ATTACHMENT $\$ / /)$

C DEY DIRECTION SEPFRATION BETHEEN ANCHOR ANN ATTACHMENT $D=D E P T H(I)+T I D E(I T I D E)+Y C A B(I)$

C*** COMPUTE INITIAL ANGLES TO BE USED

C NANGLE=NUMBER OF ANGLES USED MAX=2n NANGLE $=15$

PHIMIN= ASIN $(D / A L N O M(I))$

DELPHI $=(P I / 2$ - $P H I M I N) / F L O A T(N A N G L E+1)$

PHIONE $=-P I / 2$.

C**\#COMPUTE A FIRST GUESS FOR THE INITIAL TFASION FOR STEEPEST ANGLE AL SUM $=0$.

TZERO=0.

$D A F=D+(A L N O M(I)-D) * B S L D P E(I)$

NS $=$ NSEG (I)

DO $90 \mathrm{~J}=1, \mathrm{NS}$

NSS=NSECT (I, J)

DO $90 \mathrm{~K}=1$, NSS

Table B-3. Continued 
RUNT VERSICN FEB 74 B $13: 0404 / 09 / 76$

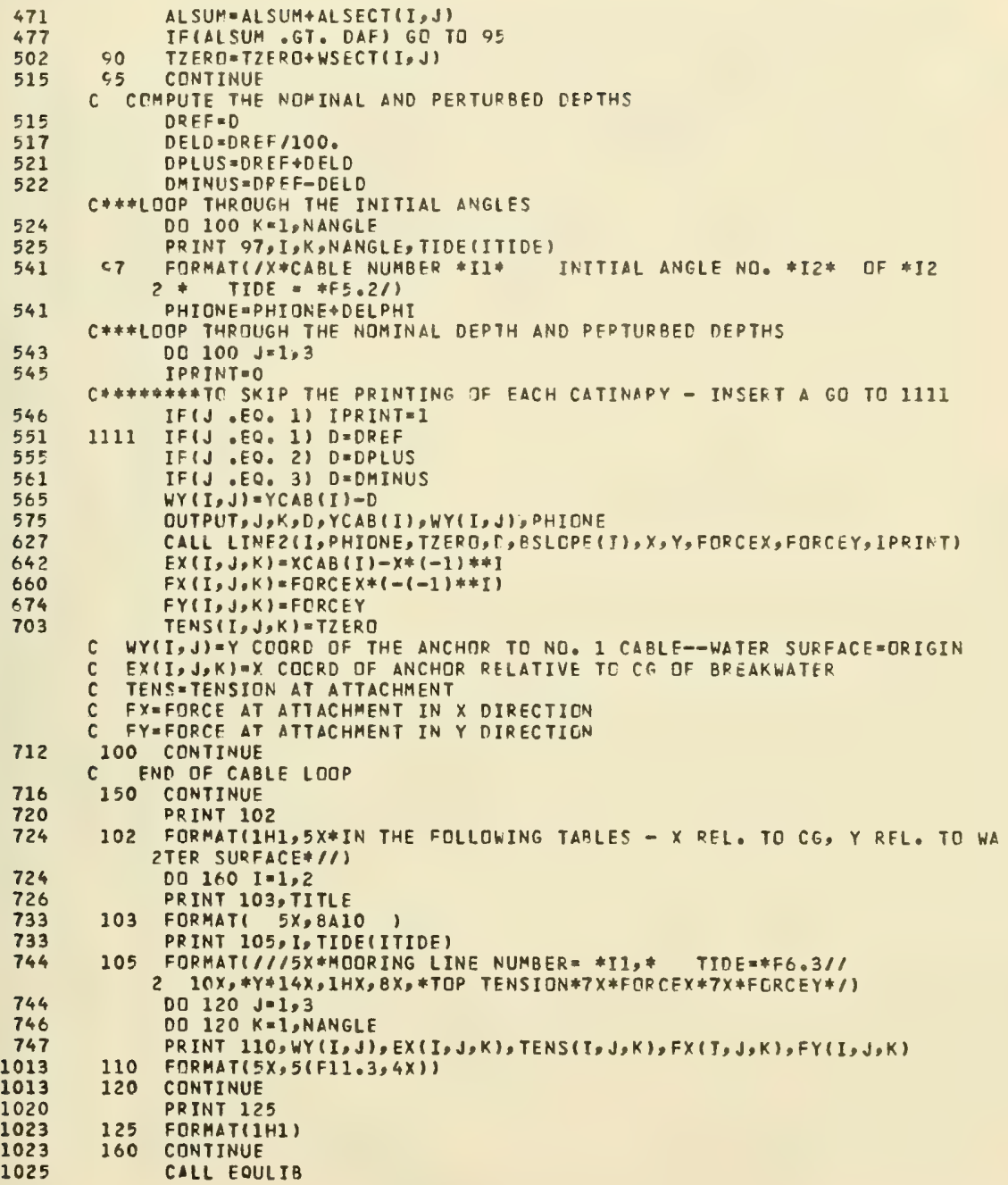

Table B-3. Continued 


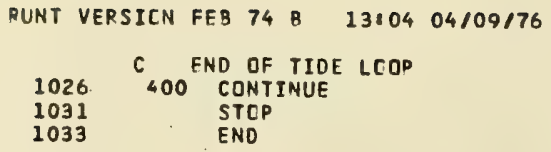

Table-B-3. Continued 
15

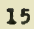

SUBROUTINE LINEZ(K, PHIONE, TZERO, DEPTH, BSLOPE, $X, Y, F O R C E X, F O R C E Y$, IP) COMMCN/ONE/NSEG(2),NSECT $(2,5), \operatorname{HSECT}(2,5), \operatorname{MATL}(2,5)$, DIAM $(2,5)$, 2 ALSECT $(2,5)$

C**THE INPUT TO SUBROUTINE LINE

C PHIONE=INITIAL ANGLE OF CABLE

C TZEROINITIAL GUESS OF TENSION AT TOP OF CABLF

C* * SUBROUTINE LINE COMPUTES

C TZFRO = TENSION AT CABLE TOP

C FORCEX FFORCE IN $X$ OIRECTION AT CABLE TOP

C FORCEY=FORCE IN $Y$ DIRECTION $\triangle T$ T CABLE TOP

C $X$ =HORIZONTAL SEPERATION BFTHEEN TOP ANO BOTTOM OF CABLE

C Y=VERTICAL SEPERATION BETWEEN TOP AND BOTTOM OF CABLE

C***GO DOWN THE CABLE SECTION BY SECTION COMPUTE TENSIDN, ANGLE,

$C$ EXTENDED LENGTH, $X$ AND $Y$ COOROINATES

$P I=3.14159$

NI TER $=0$

MNITER= 25

NOTE $=0$

$T=T Z E R O$

152 NITER=NITER+1

IF(IP.EO. C) GO TO 153

IF(NOTE.EQ. O) 60 TO 153

PRINT 155

155 FORMATI//5X*I J $X$

$153 \quad Y=0$.

$26 X, *$ LEXT PHI-DEGREES FCRCEY FCRCEX* 11

$x=0$.

PHI P PIONE

NSS=NSEG $(K)$

$15800200 \quad I=1$, NSS

NS $=$ NSECT $(K, I)$

DO $200 \mathrm{~J}=1, \mathrm{NS}$

PHID $=$ PHI*180./PI

IF(MATL $(K, I)$. EQ, 5HNYLON IGO TO 165

IF(MATLIK,I) .EQ. 5HCHAIN IGO TO 160

160 CALL CHAINIOIAM(K, I), T, STRAIN)

GO TO 170

165 CALL NYLONIDIAM(K, I), T, STRAIN)

170 ALEXT=ALSECT $(K, I) *(1,+$ STRAIN $)$

$X=X+A L E X T * \operatorname{COS}(P H I)$

$Y=Y+A L E X T * S I N(P H I)$

$T C O S=T * \operatorname{COS}(\mathrm{PHI})$

TSIN*T*SIN(PHI)

IFIIP.EQ. O) GO TO 185

IF (NCTE . EQ. O) GO TO 185

PRINT $180, I, J, X, Y, T, A L S E C T(K, I), A L E X T, P H I N, T S I N, T C O S$

180 FORMAT $(X, 215,8 F 10.3)$

185 IFII EEO. NSS AND. J EEQ. NSI GO TO 200

SLOPE = ITSIN+WSECT (K, I ) /TCOS

IF (SLOPE . GE. BSLOPE) SLOPE =BSLOPF

$P H I=A T A N(S L O P E)$

200

$T=T \operatorname{COS} / \operatorname{COS}(\mathrm{PHI})$

CONTINUE

FORCEX $=T Z E R O$ \#COS (PHIONE)

FORCEY = TZERC *SIN(PHIONE)

Table B-3. Continued 


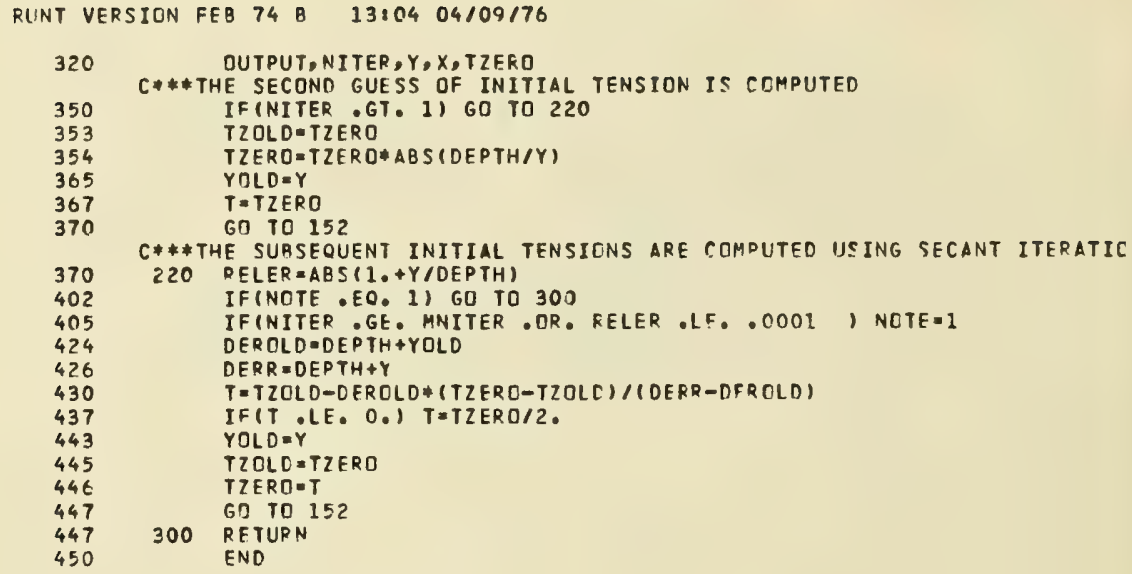

INT VERSICN FEB 74 B $1310404 / C 9 / 76$

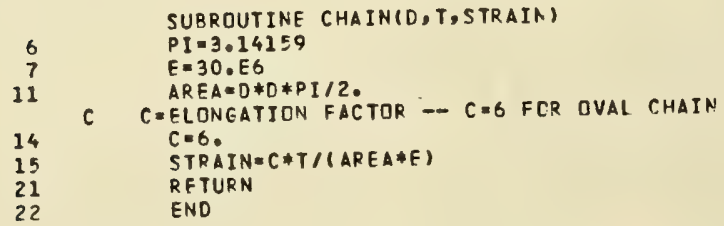

UNT VERSICN FEB 74 B $13804,04 / 09 / 76$

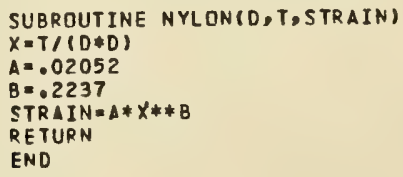

Table B-3. Continued 
2

2

SUBROUTINE EQULIB

CDMMON/TWO/LY $(2,3), E X(2,3,20), F X(2,3,2 C), F Y(2,3,20), T E N \leqq(2,3,20)$, 2 FEXT (9), SEP( 9$)$, TENS1 $(9)$, TENS2 (9), NANGLE, NCOND, TITLE ( 8 ) CCMMON/THREE/X(2), F(2)

DIMENSION SEPDIF(3), FO(3)

C***\#EQULIB FINOS THE BREAKWATER EOUILIBRIUM POSITION

$C *$ * LOOP THROUGT THE TEST CONDITIONS

DO 1 CO IC $=1$, NCDND

IFISEP(IC) . NE. O.) GO TO 20

IF(TENSI(IC) . NE.0.) GO TO 10

IF(TENS2 (IC) . NE.0.),GO TO 12

PRINT 155

155 FORMATI//X*NO INITIAL CONDITIONS SPECIFIEC*) GO TO ICO

C**\#FOR THE CASES WHERE INITIAL TENSION IS GIVEN THE FOLLOWING IS USED

$10 \quad T=T E N S I(I C)$

$I=1$

$j=2$

GO TO 14

12 T=TENSZ(IC)

$I=2$

$j=1$

14 DUTPUT, I, NANGLE, T

IF(T.GE. TENS $(I, 1,1)) \in O$ TO 18

PRINT 16

GO TO 100

18 IF(T.GE. TENS (I, I,NANGLE)) PRINT 17

16 FORMATI//5X*GIVEN TENSION CLOSE TO OP LESS THAN WEIGHT OF VERTICAL 2 MOORING LINE*/5X*NO FURTHER EVALUATION ATTFMPTED * //

17 FORMAT///5X*GIVEN TENSION TOO GREAT FOR EVALUATION WITHOUT*

2 *EXTRAPOLATION*/5X*USE RESULTS WITH CAUTIDN*/I)

CALL LTERPS (I, I, NANGLE, TENS, EX, T, X(I), DUMMY)

DUTPUT, $X(I), T$

CALL LTERPS $(I, 1$, NANGLE, TENS, FX, T, F(I), DUMMY $)$

กUTPUIT, F(I)

IFII.EO, I AAND. TENSZ(IC) .NE, O) GO TO 12

IF(TENSI (IC) . NE. O .AND. TENS2(IC) . NE. O) GO TO 40

$F(J)=-F(I)-F E X T(I C)$

OUTPUT, F(J)

CALL LTERPS $(J, 1, N A N G L E, F X, E X, F(J), X(J)$, DUMMY)

DUTPUT, $X(1)$

C NOTE- $F(I)=X$ DIRECTION FORCE ON CABLE I, $x(I)=x$ COOFC OF ANCHOR GO TO 40

C***FOR THE CASE WHERE ANCHOR SEPERATION IS GIVEN

C MAKE A FIRST AND SECOND GUESS AT FCRCE

$20 \quad[A=($ NANGL E+1)/2

$E P S=S E P(I C) * .0001$

DO $30 \quad I I=1,2$

$X(1)=E X(1,1,1 A)$

$F(1)=F X(1,1, I A)$

OUTPUT, F(I), II, FEXT(IC), SEP(IC), IA

$F O(I I)=F(1)$

$F(2)=-F(3)-F E X T(I C)$

DUTPUT, F(2)

CALL LTERPS $(2,1$, NANGLE, $F X, E X, F(2), X(2)$, DUMMY)

Table B-3. Continued 
RUNT VERSION FEB 74 B 13:04 04/09/76

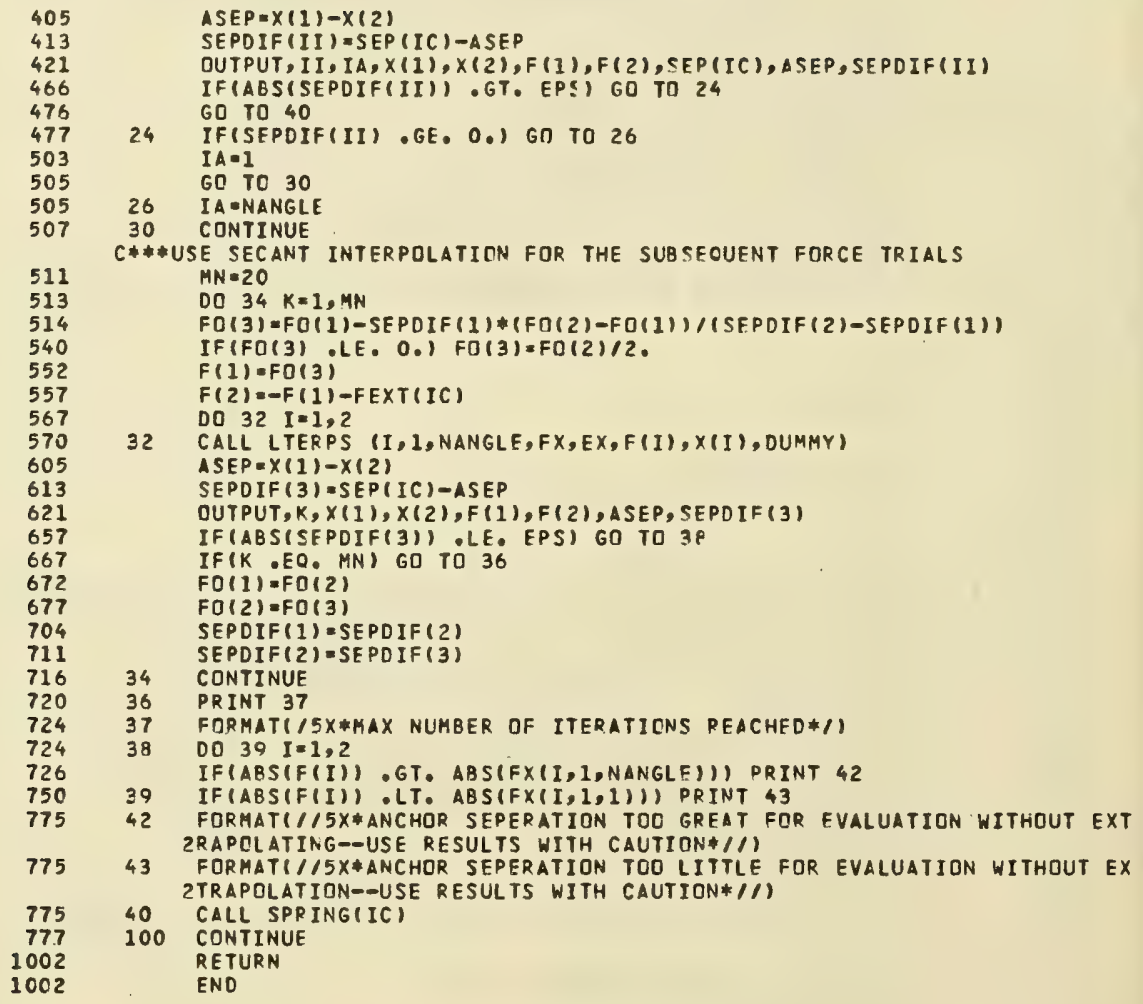

Table B-3. Continued 
SUBROUTINE SPRING(IC)

COMMON/TWO/WY $(2,3), E X(2,3,20), F X(2,3,20), F Y(2,3,20)$, TENS $(2,3,20)$,

2 FEXT (9), SEP(9), TENS1 $(9)$, TENS2 (9), NANGLE, NCOND, TITLE (8) COMMON/THREE/X(2), F(2) COMHON/FOUR/YCG, XCAB (2), YCAB (2), TTDE (5), ITIDE DIMENSION DFXDX(2),DFYDX (2), DFXDY (2),DFYDY $(2), D(3), F X X(2,3)$, 2 FYX(2,3),FV(2),DTDX(2),DTDY $(2), D T D R(2), T(2,3)$

REAL KM11,KM12,KH13,KM21,KH22, KM23, KM31, KM32, KM33

C\#*\#SUBRDUTINE SPRING COMPUTES THE BREAKWATER SPRING CONSTANTS

C** COMPUTE THE SPRING CONSTANTS FOR EACH CABLE

C HORIZONTAL FORCE AT EQUILIBRIUHEF(I) FOR CABLE I

C VERT FORCE AT EQUILIBRIUMEFV(I) FOR CABLE I

DO $14 \quad I=1,2$

$0012 \mathrm{~J}=1,3$

CALL LTERPS (I,J,NANGLE, EX,FX, X(I),FXX(I,J),DF)

IFIJ.EQ. 1) DFXDX(I) $=-D F$

CALL LTERPS (I,J,NANGLE, EX,TENS, X(I),T(I,J),OT)

IF (J.EQ. 1$)$ DTOX(I) $=-D T$

12 CALL LTERPS (I,J, NANGLE, EX, FY, X(I), FYX $(I, J), D(J))$

DTOY $(I)=(T(I, 3)-T(I, 2)) /(W Y(I, 2)-W Y(I, 3))$

DFYDX $(I)=-D(1)$

$F V(I)=F Y X(I, 1)$

DFYDY $(I)=(F Y X(I, 2)-F Y X(I, 3)) /(W Y(I, 2)-W Y(I, 3)) *(-1$,

DFXDY(I) $=(F X X(I, 2)-F X X(I, 3)) /(W Y(I, 2)-W Y(I, 3)) *(-1$.

14 CONTINUE

PR INT 16, TITLE

IE FORMAT(1HI, BAIO)

PRINT 15, TIDE(ITIDE), FEXT(IC), SEP(IC), TENSI(IC), TENS2(IC)

15 FORMATI// $X * F O R$ THE CONDITIONS $-\# /$

$15 X *$ TIDE $=* F 5.21$

$25 X * E X T E R N A L L Y$ APPLIED HDRIZONTAL FORCE, FEXT * *F10.3*LB. *

$35 X * H O R I Z O N T A L$ ANCHDR SEPERATION, SEP = \#F10.3*FEET*1

$45 X *$ NOMINAL TENSION IN CABLE $1=* F 10.3 * L B . * 1$

$55 X *$ NOMINAL TENSION. IN CAELE $2=* F 10.3 *$ LB.*/1) PRINT 18

18 FORMATI/5X*CABLE NO. FX*10X*FY*11X,1HX, $11 X * Y * 9 X * 0 F X D X * 7 X$, $2 * D F X D Y 7 X * D F Y O X * 7 X * D F Y D Y * 5 X$, *TENSION*/11

DO $20 \quad I=1,2$

20 PRINT 25, I, F(I),FV(I),X(I),WY(I,I),OFXDX(I),OFYOX(I),OFXOY II), 2 DFYDY I I, T (I, I)

25 FORMAT $(9 X, I 1,4(2 X, F 10.3), 5(X, E 11.3))$

$C *$ * NOW CALCULATE FORCES AND SPRING COASTANTS FOR THE BREAKWATER

C SESWAY MOTION +X DIRECTION FECT

C H=HEAVE MOTION $+Y$ DIRECTION

C R=ROLL MOTION COUNTERCLOCKWISE RADIANS

C FS=FORCES CAUSING SWAY DUE TO THE MOMRING IINES

C FHEFORCES CAUSING HEAVE DUF TO MOORING LINFS

C EMR IMOMENTS CAUSING ROLL DUE TO MOORTNE IINES

C CHANGE YCAB TO BE DIST TO CG IN Y DIRECTIDN $Y C A B(1)=Y C A B(1)-Y C G$

$Y C A B(2)=Y C A B(2)-Y C G$

$F S=F(1)+F(2)$

$F H=F V(1)+F V(2)$

$E M R=F V(1) * X C A B(1)+F V(2) * X C A B(2)-F(1) \neq Y C A B(1)-F(2) * Y C A B(2)$

$C * * * C A L C U L A T E$ CHANGE IN TENSIONS WITH BREAKWATER MOTIONS

Table B-3. Continued 
RUNT VERSICN FEB 74 B $13: 0404109176$

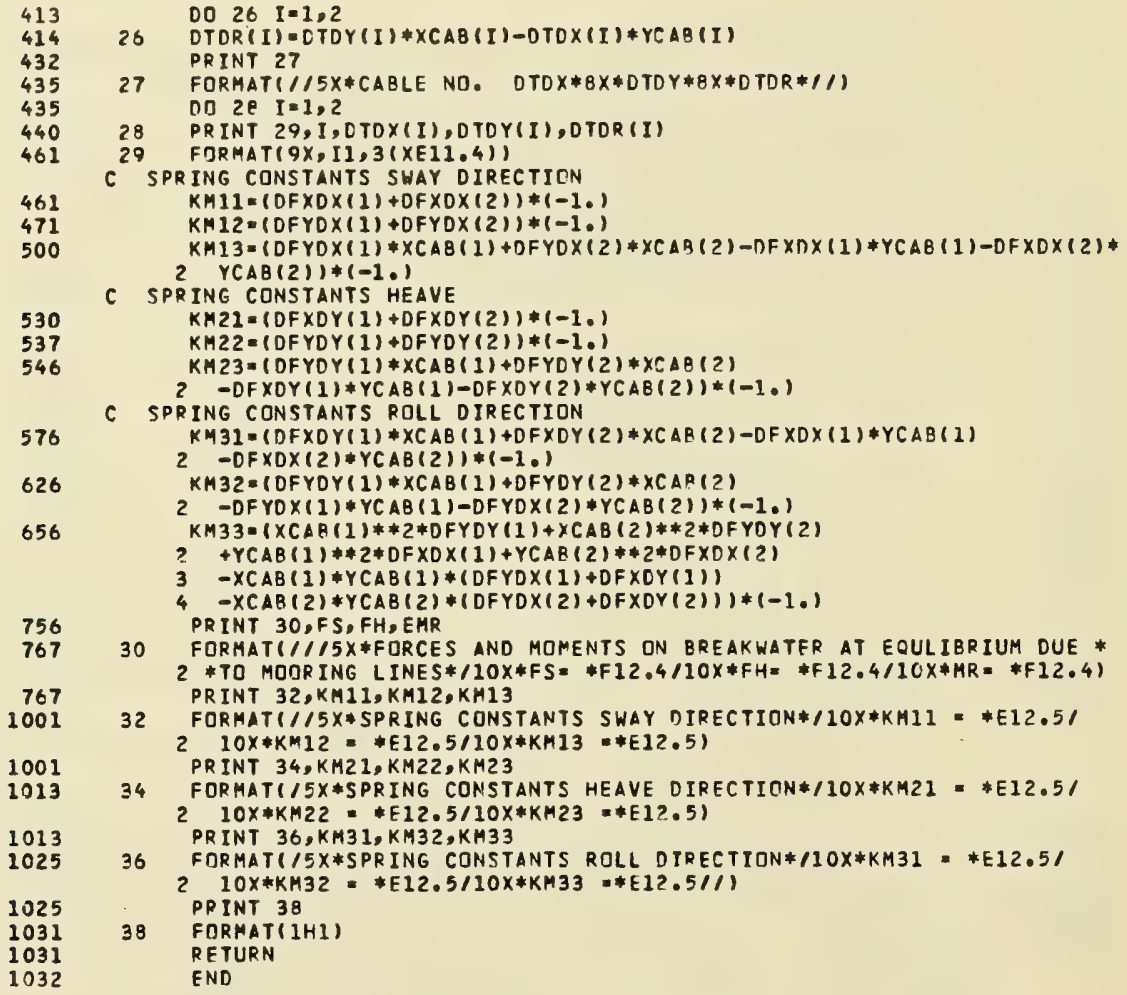

Table B-3. Continued 
13

13

15

16

20

27

55

60

111

131

132

134

136

167

176

176

SUARDUTINE LTERPS $(I, J, N, X, Y, X X, Y Y, D Y D X)$

DIMENSICN $X(2,3,20), Y(2,3,20)$

$N^{M} \mathrm{D}=\mathrm{N}-1$

DO $10 \mathrm{~K}=1$, NM?

$L=K+1$

IF $(X X, E Q, X(I, J, L))$ GO TO 30

IF $(A B S(X X) \cdot L T \cdot A B S(X(I, J, l))$ GO TO 20

10 CONTINUE

$20 D Y D X \equiv(Y(I, J, L I-Y(I, J, K)) /(X(I, J, L)-X(I, J, K))$ $Y Y=Y(I, J, K)+(X X-X(I, J, K)) *[Y O X$

RETURN

30

IF (L .EO. N) GO TO 20

$M=L+1$

DYDX $=(Y(I, J, M)-Y(I, J, K)) /(X(I, J, M)-X(I, J, K))$

$Y Y=Y(I, J, L)$

RETURN

END

Table B-3. Continued 


\section{LINEAR HYDRODYNAMIC COEFFICIENTS}

The linear theoretical model used in solving the floating breakwater problem has been discussed extensively by Frank (1967). He developed the approach to solving the boundary value problem which has come to be known as the "Frank close-fit method". The reader is referred to the original reference for a complete presentation of the method.

In this approach, the classical linear boundary value problem requires that Laplace's equation be satisfied throughout the fluid domain:

$$
\nabla^{2} \Phi(x, y, t)=0 \text { for } y<0
$$

The free-surface boundary condition is applied on the undisturbed free surface:

$$
\Phi_{t t}(x, 0, t)+g \Phi_{y}=0 \text { for } y=0 \text {. }
$$

The body-surface boundary condition requires that no fluid flow through the body surface:

$$
\left.\nabla \Phi(x, y, t) \cdot \vec{n}\right|_{C_{0}}=\vec{v}_{i}(s) \cdot \vec{n}(s) .
$$

The bottom boundary condition for infinite depth is of the form:

$$
\lim _{y \rightarrow-\infty} \Phi_{y}(x, y, t)=0
$$

In addition there is a radiation condition specifying that the waves travel away from the body.

Because the problem is assumed to be linear, the velocity potential may be decomposed and several boundary value problems considered. If this is done the total potential becomes:

$$
\Phi=\Phi_{1}+\Phi_{2}+\Phi_{3}+\Phi_{4}+\Phi_{5} \text {. }
$$

Here,

$$
\begin{aligned}
& \Phi_{1}=\text { potential representing pure sway motion in calm water, } \\
& \Phi_{2}=\text { potential representing pure heave motion in calm water, } \\
& \Phi_{3}=\text { potential representing pure roll motion in calm water, }
\end{aligned}
$$




$$
\begin{aligned}
& \Phi_{4}=\text { potential representing the waves diffracted by a fixed } \\
& \text { body, } \\
& \Phi_{5}=\text { incident wave potential. }
\end{aligned}
$$

Another velocity potential may be defined:

$$
\Phi_{6}=\text { potential for total fixed-body problem, }
$$

so that

$$
\Phi_{6}=\Phi_{4}+\Phi_{5} \text {. }
$$

Using this decomposition of the velocity potential, the boundary value problems may be expressed as:

$$
\begin{aligned}
& \nabla^{2} \Phi_{i}(x, y, t)=0 \text { for } y<0, \\
& \Phi_{i_{t t}}(x, 0, t)+g \Phi_{i_{y}}=0 \text { for } y=0, \\
& \lim _{y \rightarrow-\infty} \Phi_{i_{y}}(x, y, t)=0,
\end{aligned}
$$

and

$$
\left.\nabla \Phi_{i} \cdot \vec{n}\right|_{C_{0}}=\vec{V}_{i}(s) \cdot \vec{n}(s) \text { for } i=1,2,3
$$

or

$$
\left.\nabla \Phi_{i} \cdot \vec{n}\right|_{C_{0}}=0 \text { for } i=4,6
$$

These boundary value problems are solved directly using the Frank method which distributes singularities over the hull surface. These singularities satisfy the radiation condition, Laplace's equation, the freesurface boundary condition and the bottom boundary condition. To satisfy the body boundary condition requires the formulation of a set of linear equations whose solution reveals the strength of each singularity distributed on the body.

Once the velocity potential is found the pressure may be found from Bernoulli's equation:

$$
P(x, y, t)=-\rho \Phi_{t}(x, y, t) \text {. }
$$

The force on the body surface is:

$$
\overrightarrow{\mathrm{F}}=\int_{\mathrm{C}_{\mathrm{o}}} \mathrm{P}(\mathrm{s}) \overrightarrow{\mathrm{n}}(\mathrm{s}) \mathrm{ds},
$$

and the moment is: 
$M=\int_{C_{0}} P(s)[\vec{r} \times \vec{n}] d s$.

The added-mass and damping coefficients are found by considering the cases $i=1,2,3$. The forces and moments computed using these potentials may be separated into components in phase with acceleration and velocity. The component in phase with acceleration yields the added-mass coefficients and the component in phase with velocity yields the damping coefficients. Exciting forces and moments are computed when the case $i=6$ is considered.

Special Symbols for Appendix C.

$\vec{n}(s)=$ unit interior normal vector to the body surface

$\mathrm{s} \quad=$ indicates arc length along body contour

$\mathrm{C}_{\mathrm{O}} \quad=$ body contour

$P(s)=$ pressure on body surface

$\vec{V}(s)=$ velocity of body surface

$\Phi \quad=$ total velocity potential 


\section{APPENDIX D \\ FLOATING BREAKWATER ANALYSIS}

1. Purpose of the Program.

Computer program BRK2D performs a performance analysis for twodimensional floating breakwaters of arbitrary cross section. This analysis includes predictions of the hydrodynamic coefficients, the dynamics and mooring line forces.

2. Program Description.

Program BRK2D is written using both FORTRAN II and FORTRAN IV statements.

The program consists of the main program BRK2D and the subroutines COEFF, COMP, PHYSCL, POTOUT, DYNAMC, MORTEN, CPV, LNEQF .

The subroutines COEFF and COMP calculate the quantities needed to formulate the linear equations for the velocity potential. COMP calls on LNEQF to solve these linear simultaneous equations.

Subroutine PHYSCL calculates the physical quantities including added-mass and damping coefficients and surface elevations per unit amplitude of motion.

CPV is a subroutine which evaluates the Cauchy principal value integral in the Green function.

LNEQF is a packaged subroutine to solve simultaneous linear equations using the Gaussian reduction method.

3. Type of Computer and Peripherals.

BRK2D was written for use on the CDC 6400 computer. It uses about $55000_{8}$ words of memory. No peripherals other than the card reader, line printer and card punch are required.

4. Input Data.

The first cards in the data deck are label cards for the output. These are shown in the example input in Table D-1 for the example and are not included here. Following these cards, the input for BRK2D is:

Card \#1 - Title card, Format (8A10). 80 alphanumeric characters.

Card \#2 - Logical control card, Format $(5110,615)$.

$\mathrm{N}=$ Number of straight line segments used to fit the hull. $\mathrm{NW}=$ Number of points on the free surface where wave height is to be computed. 
NWAVEL = Number of wavelengths at which computations are to be performed.

ISYM = 1 for symmetric section.

= Anything else for non-symmetric section.

ISKIP $=1$ Do not solve equations of motion,

2 Do not solve potential problem (read in coefficients from data),

= Anything else solve potential problem and equations of motion.

LC $=$ Number of body segments which represent spaces between multiple hull configurations ( 1 to 5 ).

$\mathrm{JC}=$ Designates the segment number for segments representing spaces between multiple hulls.

Card \#3 - Parameter card, Format (5F10.3,3A10).

AREA = Crossectional area of immersed body.

$B=$ Characteristic beam as specified by BTITLE.

$D=$ Distance below free surface to origin of users coordinate system (all motions are referred to that point) .

ROE = Fluid density.

$\mathrm{GEE}=$ Acceleration of gravity.

BTITLE = Specifies $B$.

Card \#4 - Beam/wavelength specification, Format (10F8.5).

$\mathrm{BOL}=$ Beam/wavelength ratios for computation (up to 10 different ratios may be used).

Card \#5 - Offset cards, Format (2F10.3).

There must be $\mathrm{N}+1$ cards giving the offset points. In the version of the program used here, $\mathrm{N}$ must be less than or equal to 23 because of dimension statements.

$\mathrm{R}(\mathrm{I}, \mathrm{I})=\mathrm{X}$-coordinate of offset point.

$R(2, I)=Y$-coordinate of offset point.

Card \#6 - Hydrostatic spring constants, Format (9F8.3).

This is read in subroutine DYNAMC.

$\operatorname{RKHYD}(1,1)=\mathrm{KH}_{11}$.

$\operatorname{RKHYD}(1,2)=\mathrm{KH}_{12}$.

RKHYD $(1,3)=\mathrm{KH}_{1}$.

$\operatorname{RKHYD}(2,1)=\mathrm{KH}_{21}$.

$\operatorname{RKHYD}(2,2)=\mathrm{KH}_{22}$.

$\operatorname{RKHYD}(2,3)=\mathrm{KH}_{23}$.

RKHYD $(3,1)=\mathrm{KH}_{31}$.

RKHYD $(3,2)=\mathrm{KH}_{32}$.

$\operatorname{RKHYD}(3,3)=\mathrm{KH}_{33}$.

Card \#7 - Physical properties, Format $(6 \mathrm{~F} 10.3,3 \mathrm{~F} 5.2,15)$.

This is read in subroutine DYNAMC.

AREA = Crossectional area.

$B=$ Characteristic beam.

$X G=X$-coordinate of the center of gravity.

$Y G=Y$-coordinate of the center of gravity.

RMASS $=$ Mass per unit length of breakwater.

RINERT $=$ Mass moment of inertia per unit length of breakwater. 
DAMP (1) = Added damping in sway. In the equations of motion sway damping will be $1+$ DAMP (1) times the computed hydrodynamic damping.

DAMP (2) = Added damping in heave.

$\operatorname{DAMP}(3)=$ Added damping in roll.

NPUNCH $=0$, punch data cards containing computed transmission coefficient, motion response and mooringforce coefficient.

= Anything else, do not punch data cards.

Card \#8 - Mooring spring constants, Format (9F8.3).

This is read in subroutine DYNAMC.

$\operatorname{RKMOR}(1,1)=\mathrm{KM}_{11}$.

$\operatorname{RKMOR}(1,2)=\mathrm{KM}_{12}$.

$\operatorname{RKMOR}(1,3)=\mathrm{KM}_{13}$.

$\operatorname{RKMOR}(2,1)=\mathrm{KM}_{21}$.

$\operatorname{RKMOR}(2,2)=\operatorname{KM}_{22}$.

$\operatorname{RKMOR}(2,3)=\mathrm{KM}_{23}$.

$\operatorname{RKMOR}(3,1)=\mathrm{KM}_{31}$.

$\operatorname{RKMOR}(3,2)=\mathrm{KM}_{32}$.

$\operatorname{RKMOR}(3,3)=\mathrm{KM}_{33}$.

Card \#9 - Mooring-1ine response parameters, Format (6F10.2).

This card is read in subroutine MORTEN.

$\operatorname{DELT}(1,1)=\Delta \mathrm{F} / \Delta \alpha_{1}$ for shoreward mooring line. This is the change in mooring line force per unit displacement in sway.

$\operatorname{DELT}(1,2)=\Delta \mathrm{F} / \Delta \alpha_{2}$ for shoreware mooring 1 ine.

$\operatorname{DELT}(1,3)=\Delta \mathrm{F} / \Delta \alpha_{3}$ for seaward mooring line.

$\operatorname{DELT}(2,1)=\Delta \mathrm{F} / \Delta \alpha_{1}$ for seaward mooring line

$\operatorname{DELT}(2,2)=\Delta \mathrm{F} / \Delta \alpha_{2}$ for seaward mooring line.

$\operatorname{DELT}(2,3)=\Delta \mathrm{F} / \Delta \alpha_{3}$ for seaward mooring line.

Note: The last 3 cards (\#7, \#8, and \#9) provide the information needed for the dynamic analysis. If it is desirable to perform calculations varying the data, these cards may be repeated with different input data. There is a limit of 25 different sets of data. In the example data shown in Table D-1, there are 3 different conditions used.

5. Mathematical Procedures and Program Limitations.

The mathematics has been described in the report and Appendix C.

The main limitations are that at most 23 offset points may be used to describe the shape. This has been found to be very adequate for the configurations considered thus far. Little change in the results occurs when more than 15 points are used. Computer time increases about as the square of the number of points.

A listing of the program is given in Table D-2.

6. Flow Chart.

A flow chart is given in a figure of this appendix. 


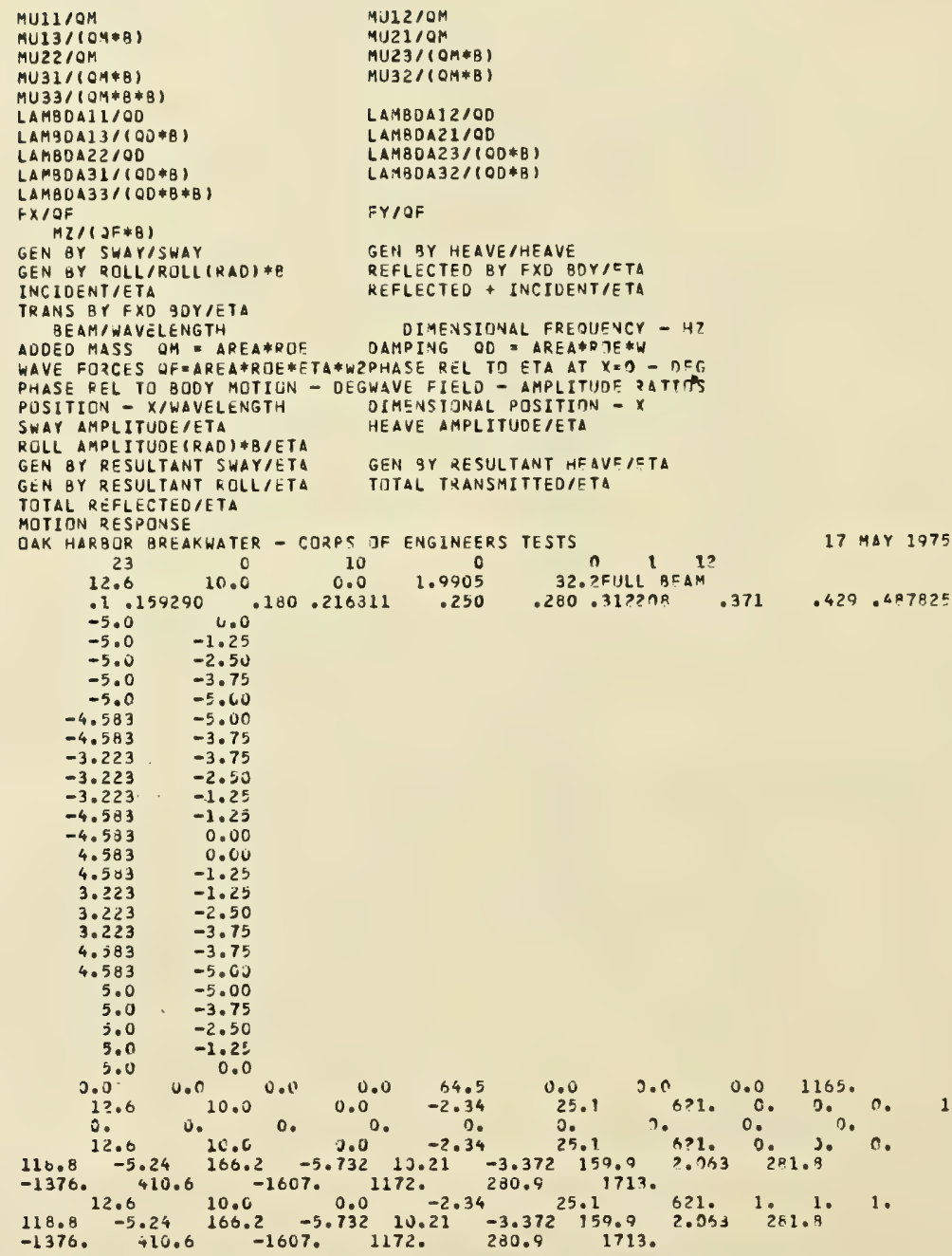

Table D-1. Example input for program BRK2D (Oak Harbor breakwater) . 
PROGRAM BRK?D (INPIJT, OUTPUT, PUNCH, TAPE5 = TNPIJT, TAPFE = JUTPUT) C***LATEST REVISIDN *****27 AUGUST 1775 C***PROGRAM BRK?D COMPUTES THE FIRST-IRDEQ RESPINSF OF AN JSCILLATING C CYLINDER ON OR NEAR THE FREE SIIRFATE DF AN ITEAL FLUID OF

C INFINITE DEPTH

COMMUN RIL2(25,25), QK56(25,25), POT $(25,25), 4$ DW $(25,25), F F(? 5,6)$, IFI $(25,6), \quad R I(25,25), R J(25,25), \quad R(25,4), R L(25,4)$, 2RMU $(3,3,10), \operatorname{RLAM}(3,3,10), F B(3,10), \operatorname{HELFP}(3,10)$. HWB $(25,6,10)$, 3 DELW $(25,5,10), X O L(25,10)$

COMMON/ONE/X(25), Y(25), XQ(25), YB(25), ANG(25), DEL(25), VV(25)

1. FEIN(25), =ITN(?,5), RNITRM(25,3), J?(5)

COMMON/ONEZ/CC3(25), $553(25)$

COMMON ITWOI N,NNW, NWAVEL, ISYM, ISKTO, VR, PIE, GAMMA,M,TK,TD

COMMON/THREE/ WAVEL $(10)$, WN(10), RTL(12), IL

COMMON/SIX/XN(5), CN $(5)$

COMMON/SEVEV/ $A R E A, R, D$, ROE, GEE, RTTTLE(3), TITLE(F)

COMMON, EIGHTILBLMU $(3,3,3), \operatorname{LBLAM}(3,3,7), \operatorname{LBLFB}(3,3), \operatorname{LBL} 4$ W $9(7,3)$, ILBL $(10,3)$, DEG $(3,16)$

COMMON ININE) LBLRAR $(3,3), \operatorname{LBLHWR}(5,3),\{R L R(5,3)$

COMMON/TEN/DELT $(2,3)$, FJR $(2,10)$, PHAS $(?, 10), F] R N D(2,10)$, PHAST $(2,10)$

REAL K

DATA KN/.263560319728,1.413403059127,3.593425771041,

1 7.035810005859.12.640800844276/

DATA CN/.5217556105330.398666811083..0759424496F17,

1 . C0361L75467972,.000023369977391

$P I E=\triangle T A N Z(0,0-2 \cdot)$

$T P=2 . * P I F$

GAMMA $=0.57721565$

C***BFGIN READING INPUT DATA AND PRINTING ECH? C.HECK

3000 FORMAT $(6410)$

$C * * * * * R E A D$ LABLES FOR PRI $\$ T$ DUT

PEAD 3000, ( ( (LBLMUT $[, J, L), L=1,3), J=1,3), I=1,3)$

READ 3000, ( ( (LBLAM I.J,L), L $=1,3), J=1,3), T=1,3)$

READ 3000, ( $L$,

READ 3000, ((LBLHWB (J,L), L $=2,3), J=1,7)$

READ 300J, (1 LAL $(J, L), L=1,3), J=1,10)$

READ 3000, ((LBLRAR $(J, L), L=1,3), J=1,3)$

READ 3000, ((LRLHAR (J,L), L 1,3$), J=1,5)$

READ 3000, (LBLR(L,L), L $=L, 3)$

KEAD 20, TITLE

20 FORMAT (8AIU))

PRINT 30. TITLE

30 FORMAT $(1 H 2,9 A 11 / / / /)$

READ $50, \mathrm{~N}, \mathrm{NW}$, NWAVEI, ISYM, ISKIP, LC, JC

50 FORMAT (5ILO, 6IS)

C N $\quad$ NUMBER OF STPAIGHT LINE SEGMENTS TO $9 E$ USED TO FTT THE HULL......NUTE. THEPE MIIST BE N+I QFFSET POINTS

NW . NUMSER JF POINTS JN FREF SIJPEATE WHERE WAVE HEIGHT TS TO BE COMPUTED. THIS IS IN ADJITION TO THE COMPUTATINN TF WAVE HEIGHT 4.3 WAVELENGTHS TN FITHER SIDE OF THE RODY WHICH IS PERFCRMED AUTJMATISALLY

NWAVEL = NUMAER CF WAVELENGTHS AT WHICH COMPUTATIONS ARF TI BE PERFJRYED

ISYM * 1 FOR SYMMETRIC SECTION

= ANYTHING FLSE FOR NON-CYMMFTDIC SECTION

Table D-2. Listing of program BRK2D 
Table D-2. Continued 
113 CUNTINUE

6*****COMPUTE (B/WAVEL) AVD NONDIMENSIJMAL WAVF NT.

$001151 \mathrm{~L}=1$. NAAVEL

534

541

BOL (IL) B B/WAVELIIL)

115 WN(IL) = TP * B/ JAVSL(IL)

551

503

555

557

561

603

C***READ IN OFESETS OF CYLINDER

NUP $=N+1$

NUPD = NUP + ?

NTOP $=$ NUPP + NW -1

$N 1=N+1+N W$

$P E \triangle D 130,(R I(1, I), R[(2, I), I=1, N U P)$

130 FOKMAT (2F10.5)

C RI $(1, I), R I(2, I)=$ DIMENSIDNAL $X$, Y CIORJINATE DF DFFSFT

C POINTS, RESPECTIVELY

603

IF (NA.LT. I) GJ TO 195

C**\#READ IN ADDITIONAL POINTS ON THE FRFE SIJRFACF WHEQE WAVE HFTGHTS

C ARE TO BE COMPUTED. TWIJ STIRAGE LOISTTINNG MIYST BE LEFT BLANK

C FUR THE POSITIOJ 4 WVELENGTHS FROM THE RINY

506

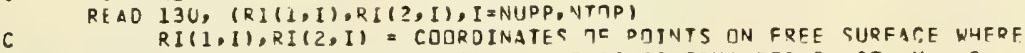

C WAVE HEIGHT IS TO BE CDMPUTED. THIS IS TRIIE FOR I.GT. N + 3

C**NON-DIMENSICVALIZE IJFFSETS

631

DO $18 U I=$ NUPP, NTPP

533

642

647

547

क5 1

55.

$X(I)=R I(I, I) / B$

(3)) $Y(I)=-1 . U E-C 8$

195 CONTINUF

$O C$ ISO I $\equiv 1$, NUP

$X_{B}(I)=R[(1,1) / B$

$170 \quad Y B(I)=R I(?, I) / 9$

C... COMPUTE MIDPJINT, ANGLE AND LENGTH TF STQATGHT-LINE SEGMENTE.

671

672

674

705

717

725

732

740

747

756

772

1007

1015

1023

1031

1034

1641

1045

1045

:****ANU COMPONENTS JF NORAAL TO BODY

$J F=0$

D[ $200 \mathrm{~J}=1, \mathrm{~N}$

$X(J)=0.5 *(X B(J)+X B(J+1))$

$Y(J)=0.5 *(Y Q(J)+Y 3(J+1))$

$T i=Y B(J+1)-Y B(J)$

$T 5=X B(J+1)-X B(J)$

$A N G(J)=A T A N Z(T 1, T 2)$

$\operatorname{CC} 3(\mathrm{~J})=\operatorname{COS}(A N G(\mathrm{~J}))$

$\operatorname{SS3}(J)=\operatorname{SIN}(A N G(J))$

$\operatorname{VV}(J)=X(J) * \operatorname{CC} 3(7)+Y(7) * 2 S 3(7)$

CEL(J) = SORT (T2*2* T1*\#2)

RNORM(J, 1$)=-553(\mathrm{~J})$

RNCRM(J, ?) = CCS $3(J)$

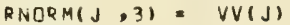

200 CDNTINUE

PRINT 30, TITLE

FRINT 250

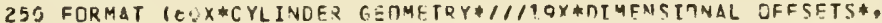

1. II $X * N J N-D I M E N S I I N A L$ OFFSETS*, FX*MTNDNTVTS OF SEGMFNTC*/I

$\begin{array}{ll}2 & 6 X * I *, 16 X * X *, 9 X * Y *, 19 x * \\ 3 & 18 X * S L D P E *, 4 X * L E N G T H * / 1\end{array}$

1113

1113

PEINT $270,(I, R I(I, I), P I(2, I), X E(T), Y A(I), X(T), Y(I), \Delta, V G(T)$,

$1 \quad O E L(I), I=1, N)$

270 FURMAT $(x,[6,4(10 \times 2 F 10.3))$

$N L=N+1$

Table D-2. Continued 


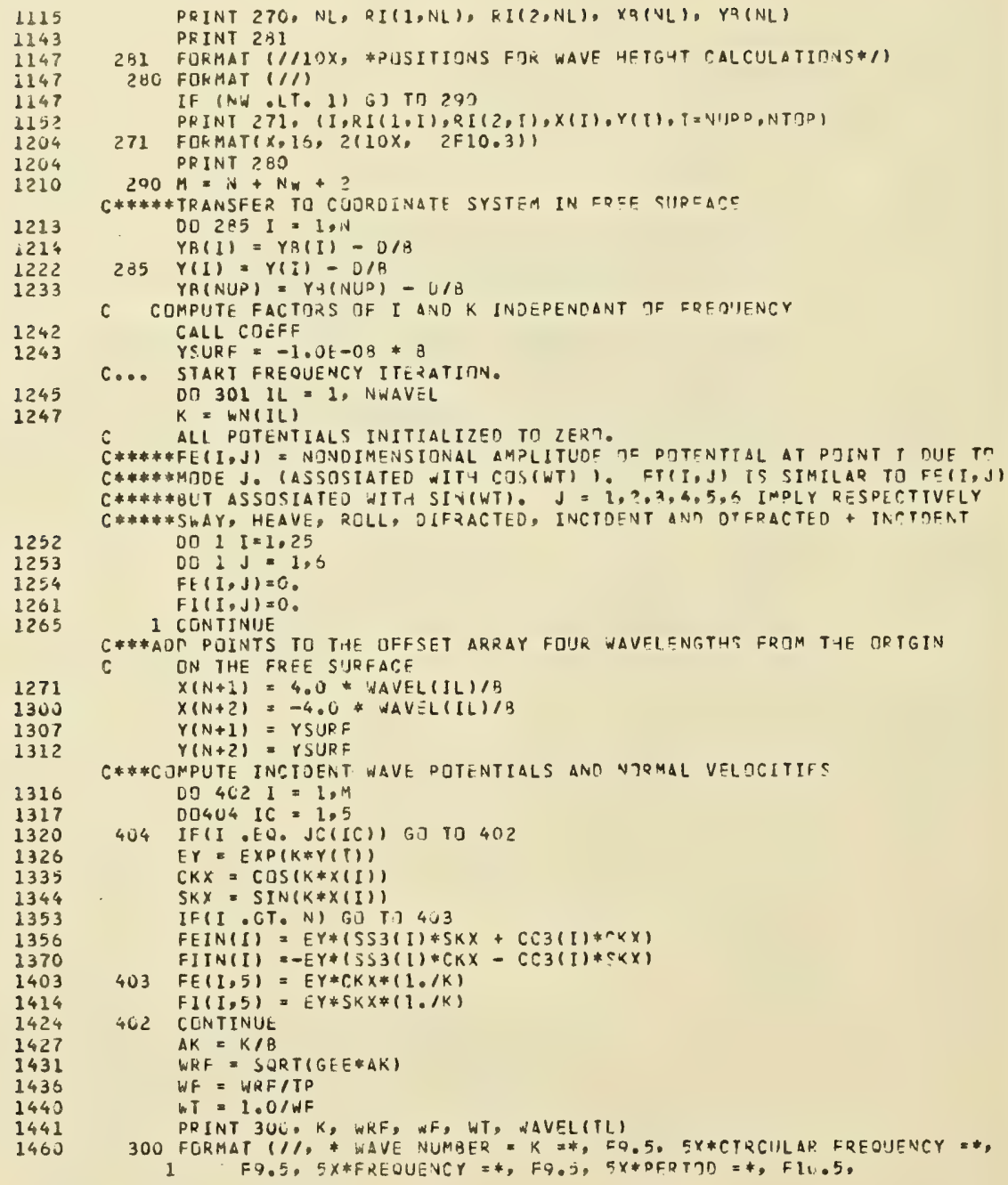

Table D-2. Continued 


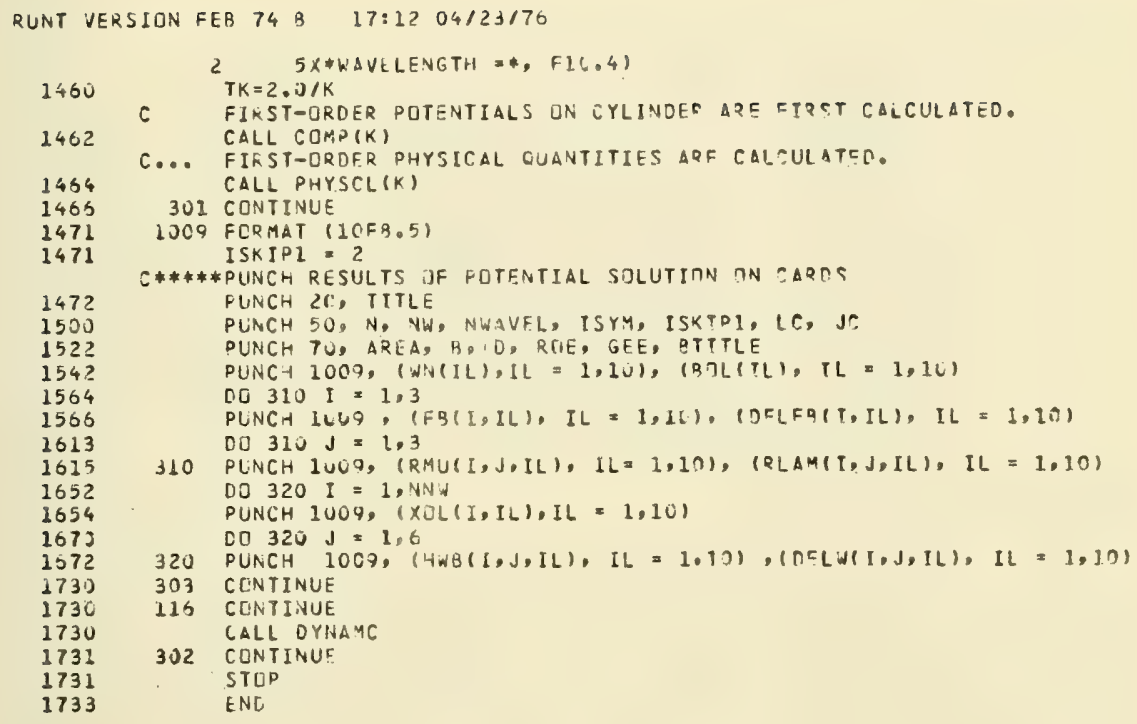

Table D-2. Continued 
262

272 312

312 316 317

SURROUTINE DYNAMC

COMMEN RI $12(25,25), \operatorname{RKE} 6(25,25)$, POT $(25, ? 5), 40 W(25,25), F F(25,6)$, IFI $(25,6), R I(25,25), R J(25,25), R K(25,4), R L(25,4)$, $2 R M U(3,3,10)$, $\operatorname{RLAM}(3,3,10), F B(3,10), \operatorname{DELFP}(3,10), \operatorname{HWB}(25,6,10)$, 3 CELW $(25,6,10), X O L(25,10)$

COMMON/ONE/X(25), Y (25), XB(25), YB(25), ANG (?5), OEL (25), VV(25)

1, FEIN(25), FIIN(25), RNURM(25,3), J: (5)

COMMON ITWOI N, NNW, NWAVEL, ISYM, TSKIO, NC, PIE, GAMMA,M, TK, TP COMMQN/THREE/ WAVEL(10), WN(10), BOLI, . TL

COAMON/FOUR/RAR $(3,10), \operatorname{OELR}(3,10), \operatorname{HWR}(25,3,13), \operatorname{DELWR}(25,3,10)$,

2 HWT $(25,10)$, DELNT $(25,10), \operatorname{RKHYD}(3,3)$, RKYIR $(3,3)$. RKTB(3,3),

$3 \times G, Y G$, RMASS, RINERT, DAMP(3)

CDMMON /SEVEN/ AREA, B, D, POE, GEE, QTITLE(3), TITLE(R)

COMMUN/TEN/DELT $(2,3)$, FOR $(2,10)$, PHAS $(2,1)), \angle \cap R N D(2,10), \operatorname{PHASD}(2,10)$

DIMENSION $A(6,6), C(6)$, ERASE $(6)$

IF (ISKIP.NE. 2) GO TO 100

$C * * * *$ READ POTENTIAL CUEFS IF ISKIP $=2$

READ 1009, (WNIIL), IL =1, 10), (BחLITL), IL. 1,10$)$

1009 FDRMAT(10F8.3)

DO $110 I=1,3$

READ $1009,(F B(I, I L), I L=1,10),(T F L F B(T, I L), I L=1,10)$

$D O 110 \mathrm{~J}=1,3$

110 READ 1009, (RMU(I,J,IL), IL=I,10), (RLAY(I,J,IL), IL = 1, 19)

DD $1201=1, \mathrm{NNW}$

READ $1009,(X O L(I, I L), I L=1,10)$

$D O 120 \mathrm{~J}=1.6$

120 READ IUJ9, (HWB(I,J,IL), IL = I, In), (DFLW(I,J,IL), IL $=1,10)$

100 CONTINUE

C*****OUTPUT POTENTIAL COEFS

CALL POTOUT

IFIISKIP. EO. I) GO TO 146

C****\#READ DIMENSIONAL JYORESTATIC SPRING CONSTANTS

READ 1UUB, ( $(R K H Y D(I, J), J=1,3), I=1,3)$

C**\#*START LOOPING THROUGH DIFFERENT DYNAMIC CONFTGURATIONS DO $140 K 1=1,54$

READ 1CIU, AREA, B, XG, YG, RMASS, OINERT, DAMP(1),OAMP(2), TAMP(?), 1 NPUNCH

1010 FORMAT $(6 F 10.3,3 F 5.2,15)$

IF (EUF, 5) 121, 122

121 STOP

122 CONTINUE

DU $5 \mathrm{KZ}=1,3$

5 IF(DAMP(KZ) EQ. $-C .0) \operatorname{DAMP}(K 2)=0.0$

C XG,YG = COQROINATES OF THE CENTER TF GQAVITY OF THE BDOY

C .....NOTE. MOMENTS AND MIMEVTS OF TNERTIA ARE COMPUTFD

ABJUT THE CENTER OF GRAVITY

DAMP ADDS CURRECTIJN FJR VISCOUS DP NTNLTNEAR DAMPING

C*****REAO DIMENSIONAL MOORING SPRING CINSTANTS

READ $1008,((R K M U R(I, J), J=1,3), I=1,3)$

1003 FORMAT (9F8.3)

C*****NONDIMENTIJNALIZE SPRING CONSTANTS, YACS, MIMNNT TF INERTIA

C*****AND CG COORUINATES

$0=A R E A *$ RDE* GEE/B

OO $130 I=1,3$

DO $130 \mathrm{~J}=1,3$

Table D-2. Continued 


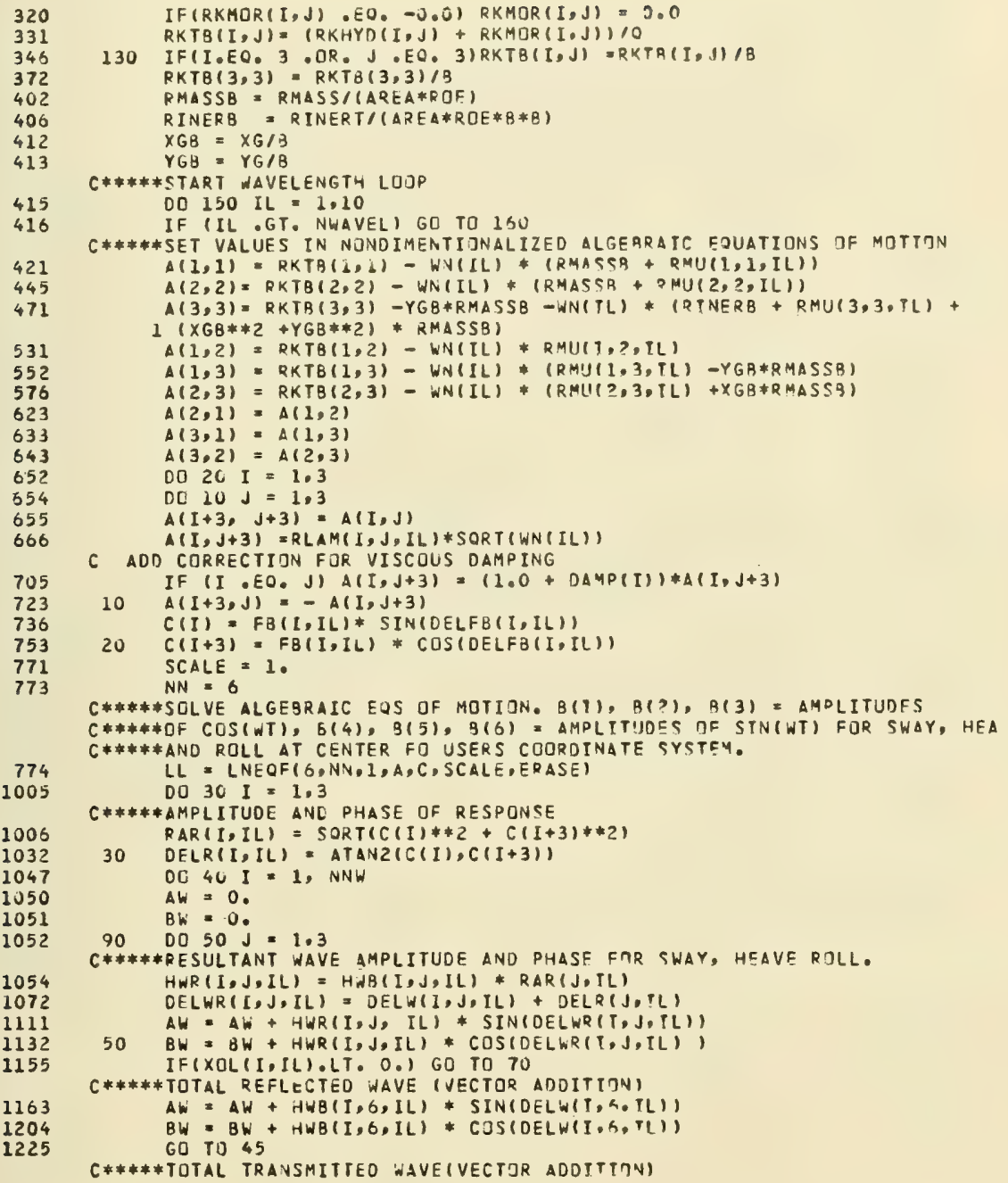

Table D-2. Continued 


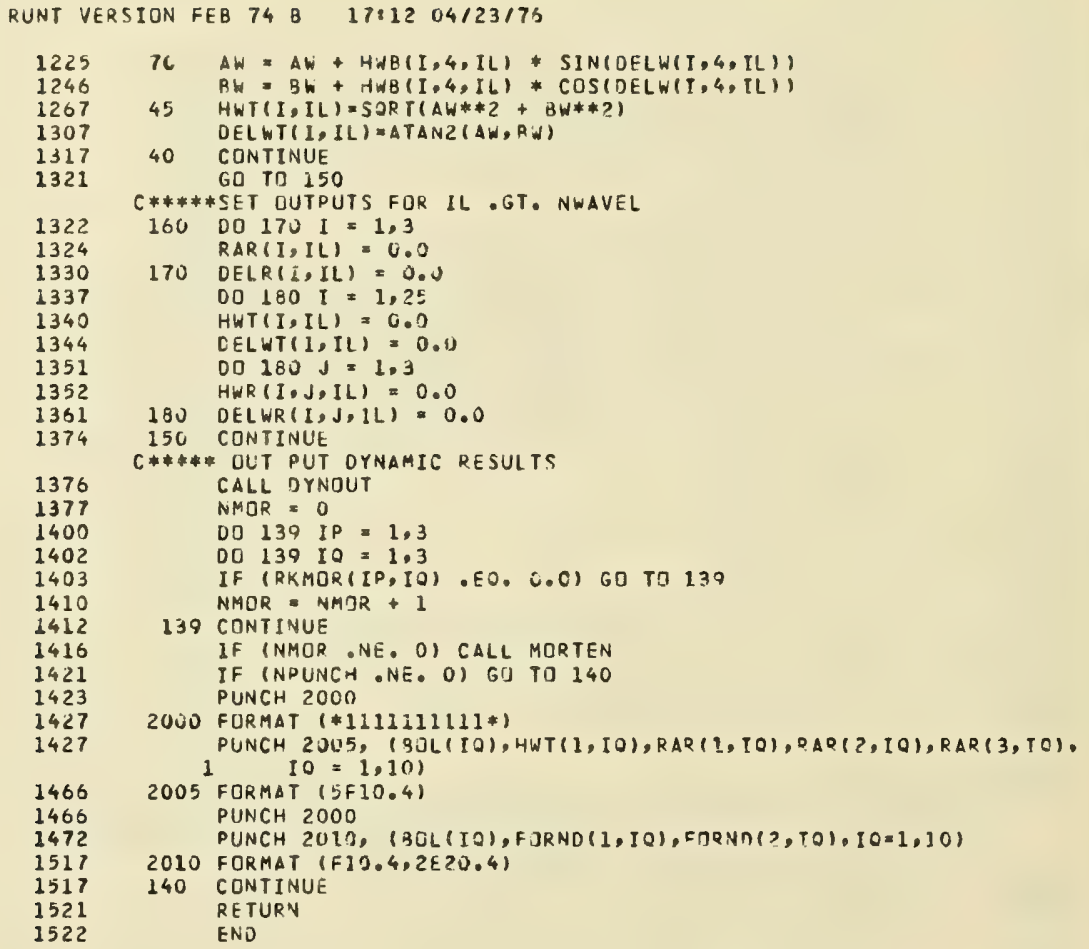

Table D-2. Continued 
SUBROUTINE MORTEN

2

C** SUERQUTINE MDRTEN COMPUTES FJRCES IN THE MOJRTNG LINES COMMON/FOUR/RAR $(3,10), \operatorname{DELR}(3,10), \operatorname{HWR}(25,3,11), \operatorname{DELWR}(25,3,10)$,

2 HWT $(25,10)$, DELWT $(25,10), R K A Y D(3,3)$, QKMDO $(3,3)$, RKTA $(3,3)$,

$3 \times G, Y G$, RYASS, RINERT, DAMP (3)

COMMON /SFVEN/ AREA, B, D, ROE, GFE, RTITLC(3), TITLE(8)

COMMON/TEN/DELT $(2,3)$, FUR $(2,10)$, PHAS(2,13), FTRND $(2,10), 0 H A C D(2,10)$

READ 10, (IDE $(T(I, J), J=I, 3), I=1,2)$

10 FORMAT (6F10.2)

C DELT $(1, I), I=1,3$ = CHANGE IN FORCE IN SUIREWARO MODRING LINE

C PER UNIT DISPLAEEMENT TN SWAY, YEAVE AND RQLL

$\sqsubset$ DELT(2,I),I=1,3 = CHANGE IN FORCE TV SFAWARD MQORING LINE

C

$C A B=1.0 /(R O E * G E E * A R E A)$

CENS $=180.0 / A C O S(-1.0)$

DO $100 \mathrm{~J}=1.2$

PRINT 20

20 FORMAT ( $/ / / / 20 X$ \#MORING LINE MDDEL RESILTS* 1 )

IF (J.EQ. 1) PRINT 18

IF (J.EQ. 2) PRINT 19

18 FQRMAT ( $30 X *$ SHDREWARD MOORING LINE*I)

19 FORMAT (30X*SEAWARD MOORING LINE*/)

PRINT 30, (DELT $(J, K), K=1,3)$

3U FORMAT ( F CHANGE IN FORCE PER UNIT DISPLACEMENT IN SWAY, HEAVE*

1 * AND ROLL, RESPECTIVELY $=*$, 3F19.4111

C***COMPUTE FORCES IN MOORING LINES AND PHASE

OO $50 I=1,10$

$A A-\operatorname{RAR}(1,1) \neq D E L T(J, 1)$

$A B=\operatorname{RAR}(2, I) * D E L T(J, 2)$

$A C=R A R(3, I) \neq D E L T(J, 3) / B$

$T S=A A * S I N(D E L R(1, I))+A B * \operatorname{SIN}(D E L Q(2, T))+A C * \operatorname{SIN}(D E L R(3, T))$

$T C=A A * C O S(D E L R(1, I))+\triangle B * C O S(D E L R(2, T))+A C * C O S(D E L R(3, T))$

FOR $(J, I)=S O R T(T S * T S+T C * T C)$

PHAS $(J, I)=A T A N Z(T C, T S)$

FORND $(J, I)=C A B * F O R(J, I)$

50 CONTINUE

PHASD $(J, I)=$ CONS*PHAS $(J, I)$

C*\#PRINT RSSULTS

PRINT $80,($ FOR $(J, I), I=1,10),(\operatorname{PHAST}(J, T), I=1,10)$,

1. (FORND $(J, I), I=1,10)$

BO FORMAT (3X*MOORING LINE RESPONSE*/5X*FQRCE IMPLITUDE/ETA*, $11 x$,

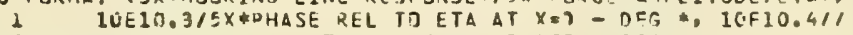

IUO CONTINUE

$5 \times 3$ OHFORCE $\triangle M P L I T J D E / R J E * G * A R E A * E T A, 10 F 10.3$ )

\section{RETURN}

END

Table D-2. Continued 


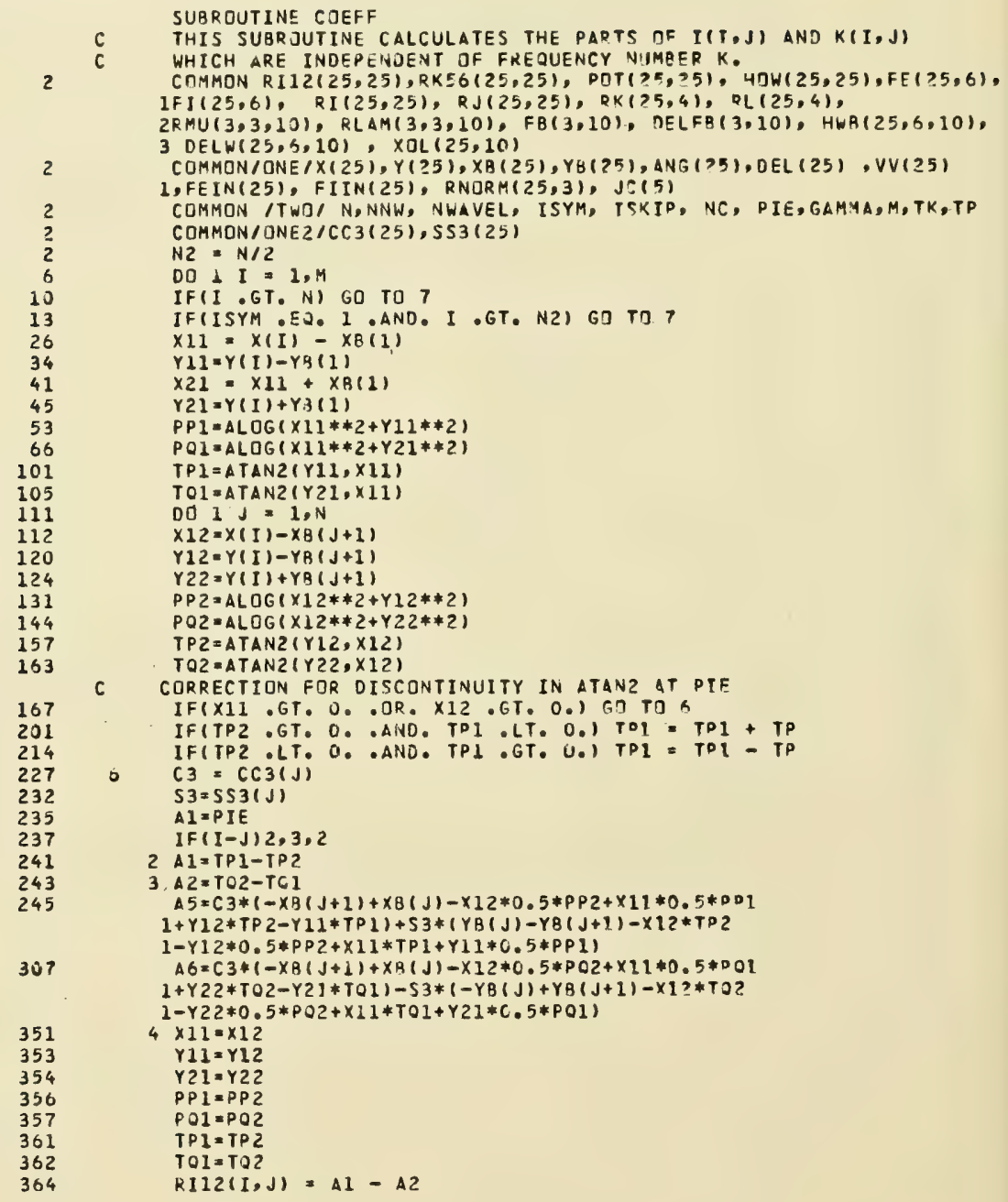

Tabile D-2. Continued 
COEFF

RUNT VERSIL.N FEB 74 \& $15: 19 \quad 03 / 13176$

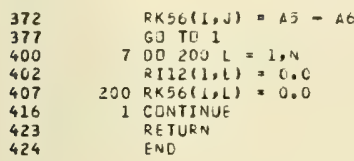

Table D-2. Continued 


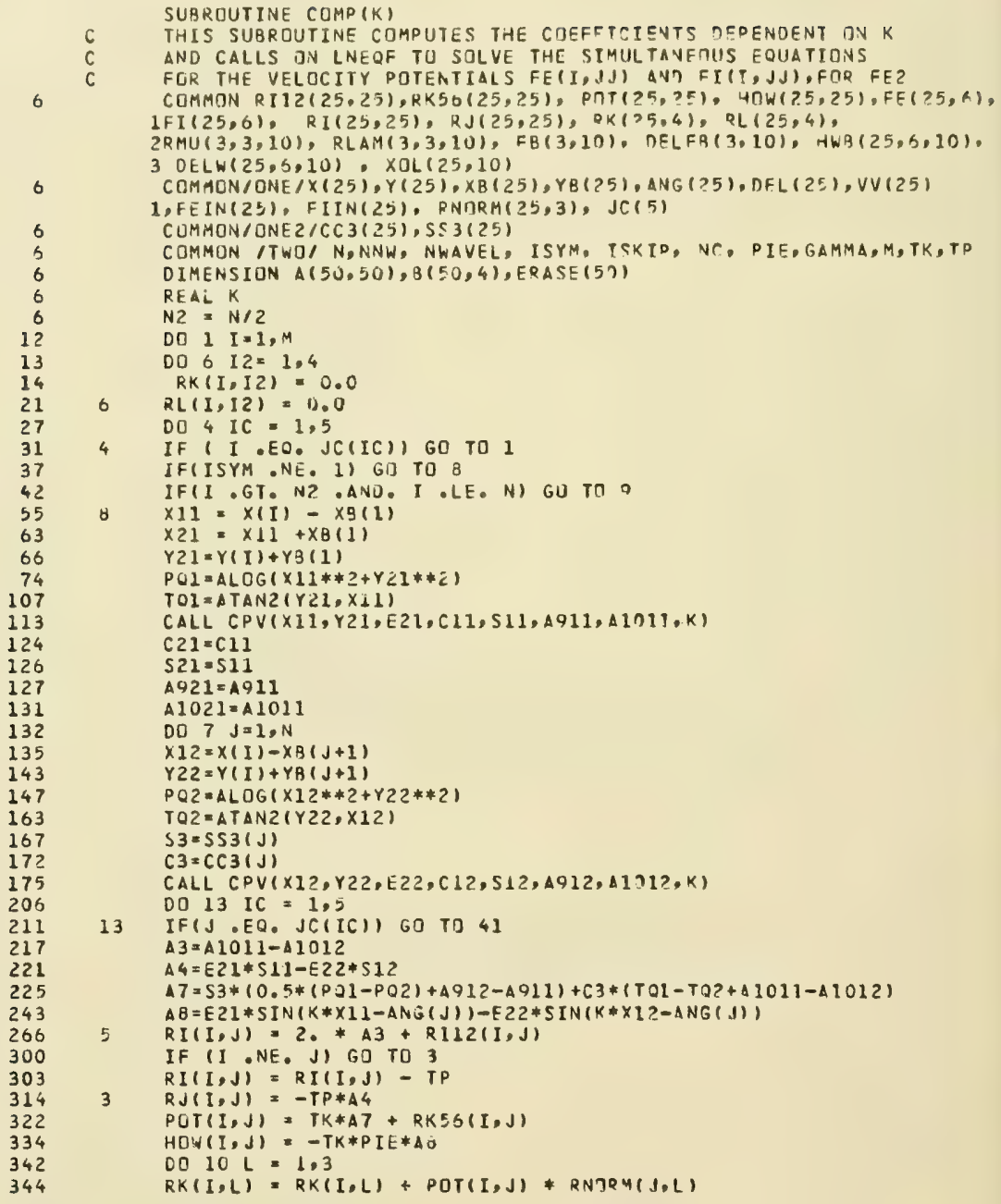

Table D-2. Continued 


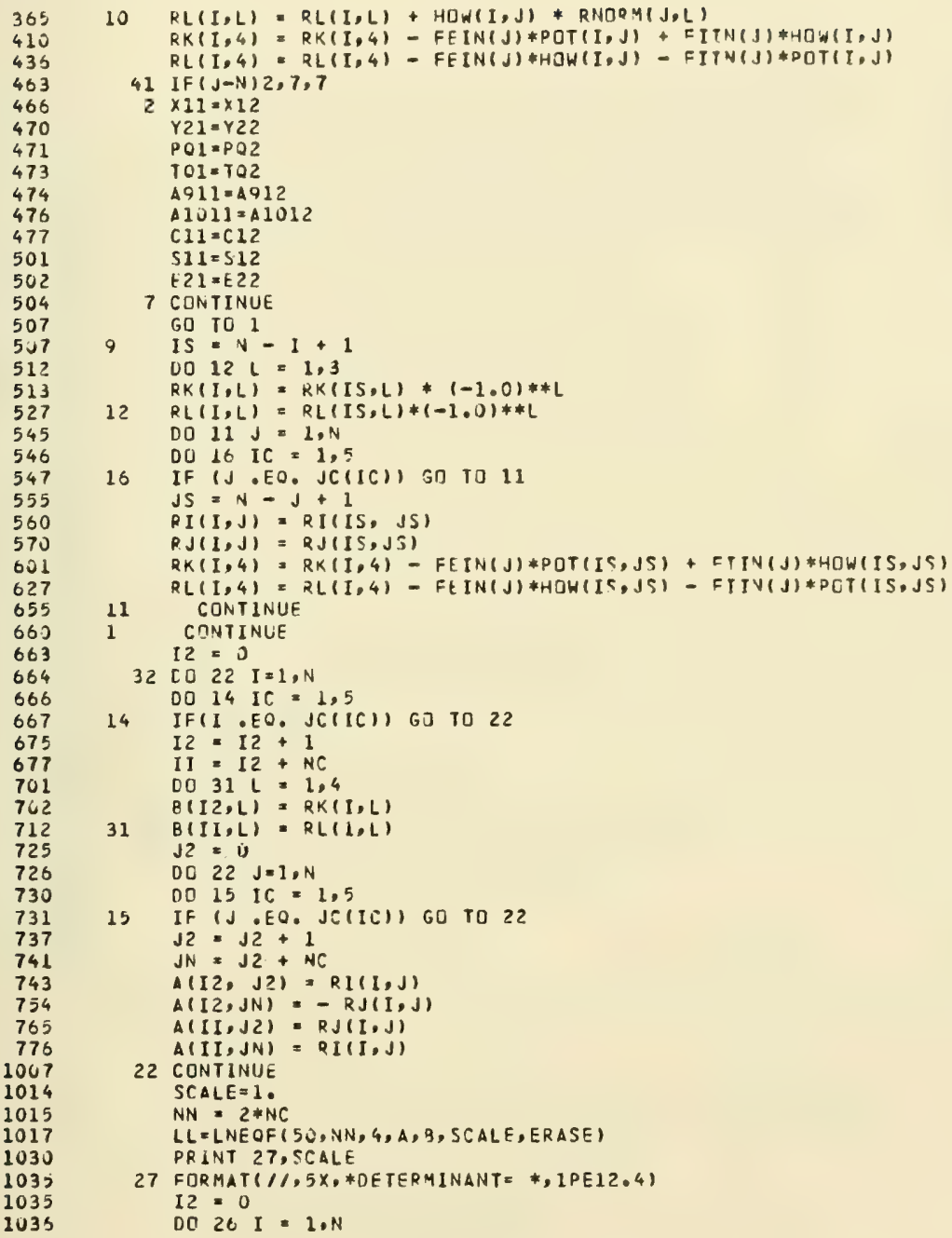

Table D-2. Continued 


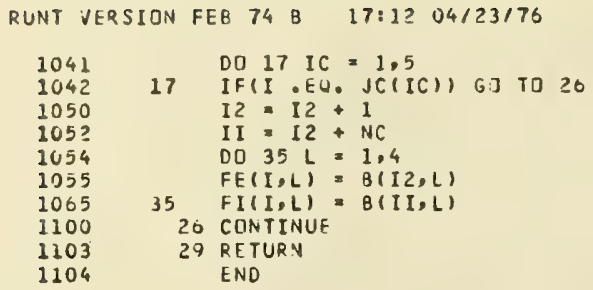

Table D-2. Continued 


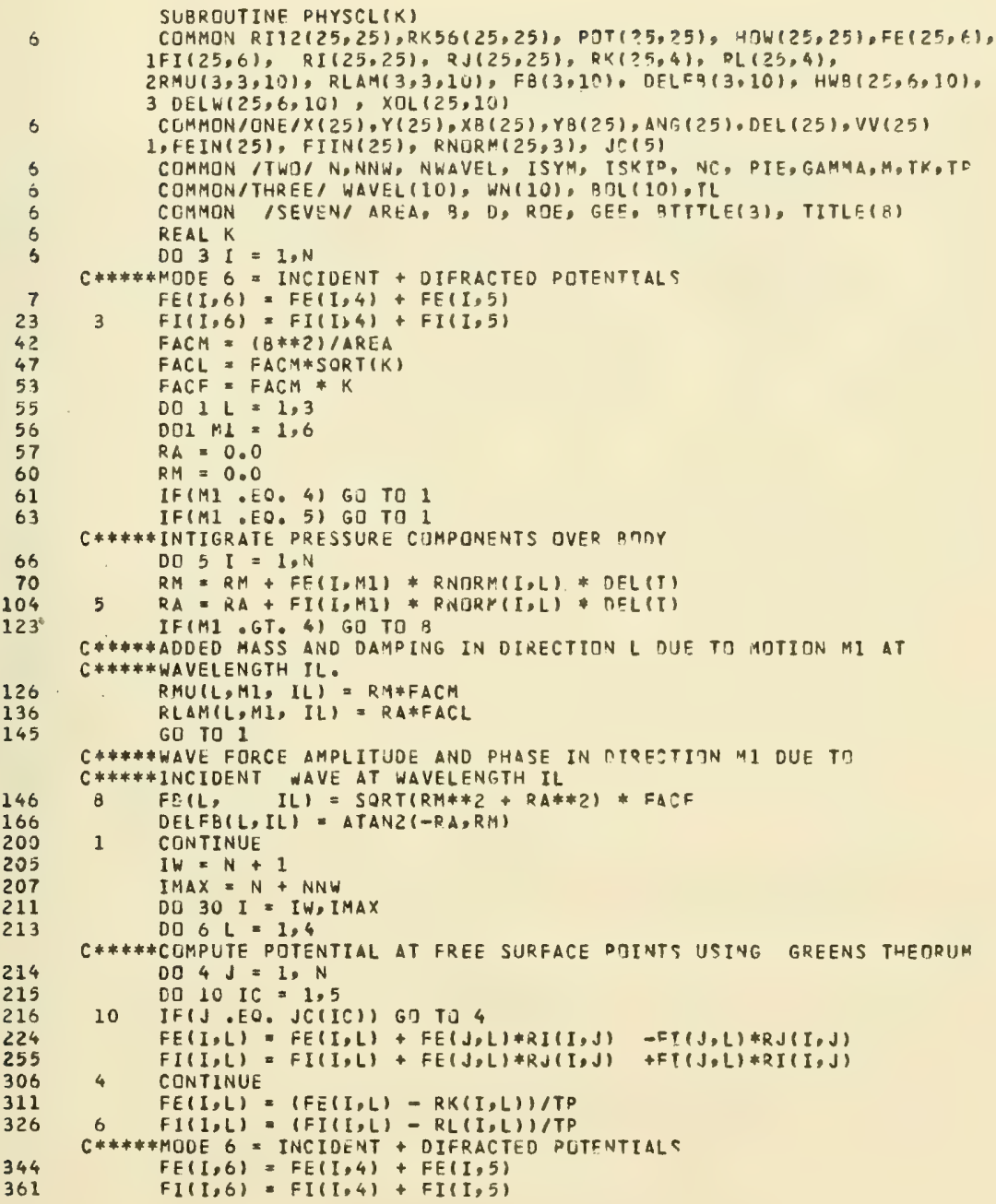

Table D-2. Continued 


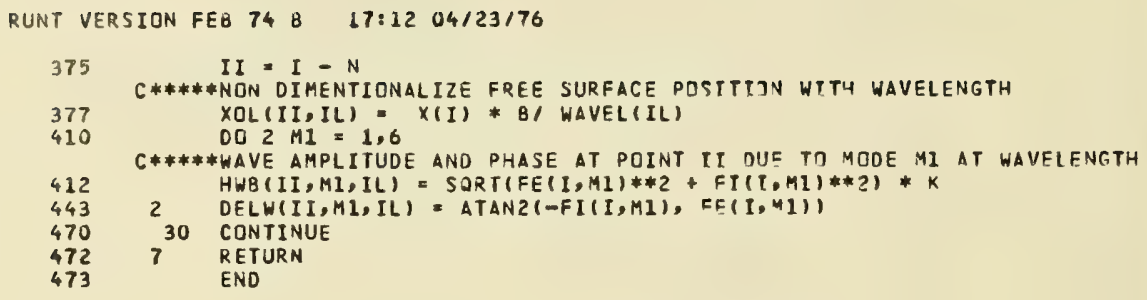

Table D-2. Continued 
SUBROUTINE PUTOUT

COMHON RI $12(25,25), R K 50(25,25), \operatorname{PDT}(25,75), 40 W(25,25), F E(25,5)$, IFI $(25,6), \quad R I(25,25), \operatorname{RJ}(25,25), \operatorname{RK}(25,4), \quad \operatorname{R}(25,4)$,

2RMU $(3,3,10), \operatorname{RLAM}(3,3,10), F B(3,10), D E L F 9(3,10)$, HWB $(25,6,10)$, 3 DELW(25,6,10), XOL $(25,10)$

COMMON/TWO/ N, NNW, NWAVEL, ISYM, ISXIO, NE, PIE, GAMMA,M,TK, TP COMMDN/THREE/ WAVEL $(10)$, WN(IO), BCL(10), IL

COMMON ISEVEN/ AREA, B, D, ROE, GEE. BTITLF(3), TITLE(8)

COMMON, EIGHT/LBLMU $(3,3,3), \operatorname{LBLAM}(3,3,3), \operatorname{LBLFB}(3,3), \operatorname{LPLHNR}(7,3)$,

$1 L B L(10,3), \operatorname{DEG}(3,10)$

1001 FORMAT $(1 / 3 X, 3410, /(5 x, 3416,10 F 17.4))$

1002 FORMAT $(/ / 3 x, 341), /(5 x, 3410,10 F 10.4 / 5 x, 3410,10 F 10.411)$

1003 FORMAT( $5 X, 3 A 10,10 F 10.4,5 X, 3410,10 F 10.4$,

1004 FORMATI //3X, 3AI0, 2X, 10F10.4/3X, 3110,2X, 10F10.4) PRINT 2000, BTITLE

2000 FOKMAT (IHI, 20X, *NONOIMENSIDNAL DOTENTIAL COEFFICIENTS* /// $25 \times$ $1 * W=\operatorname{SORT}(G / B), W 2=G / B * / 25 X * B=*, 3410 /$

$125 X * G$ ACCELERATIDN OF GRAVITY*I

$125 X \%$ DEE = MASS DENSITY OF FLIITO 1

$225 \times$ *ETA = INCTOENT WAVE AMPLITUDE */25X, *WAVEL \# INCIDENT DR GENE $3 R A T E D$ WAVE LENGTH*//1)

DO $9 \mathrm{IL}=1,10$

$9 \quad D E G(2, I L)=S Q R T\{(G E E * B O L(I L)) /(T D * R)\}$

PRINT $1004,(L B L(1, K), K=1,3),(B O L(I L), I L=1,10)$,

$1(L B L(2, K), K=1,3),(D E G(1, I L), I L=1,10)$

PRINT 1001, (LBL $(3, K), K=1,3),(((L) L A U(I, J, K), K=1,3)$,

I (RMU(I,J,IL), IL $=1,10), J=1,3), I=1,3)$

PRINT 1COI, $(L B L(4, K), K=1,3),(((L, L A 4(T, J, K), K=1,3)$,

$I(R L A M(I, J, I L), I L=1,10), J=1,3), I=1,31$

DO $1 \mathrm{I}=1,3$

DO IIL $=1,10$

1 DEG(I,IL) $\approx 57.298$ DELFB(I,IL)

PRINT 1002, (LBL $(5, K), K=1,3),((L A L C R(I, K), K=1,3)$,

I(FB(I,IL),IL $=1,10)$. (LBL(S,K), K $=1,3),(D F G(I, I L), I L=1,10)$

$2, I=1,3)$

DO $21=1, \mathrm{NNW}$

DO B IL $=1,10$

$D E G(1, I L)=0, C$

IFIIL.GT. NWAVEL, GO T] 8

$D E G(I, I L)=X O L(I, I L) \neq 8 / B O L(I L)$

8 CONTINUE

PRINT 1CO2, (LBL $(B, K), K=1,3),(L \mathrm{LL}(9, K), K=1,3)$,

1 (XOLII,IL), IL $=1,10),(L B L(10, K), K=1,3),(D E G(1, I L), I L=1,10)$

DO $3 J=1,3$

CO 3 IL $=1,10$

3 DEG (J,IL) $=57.298 *$ DELW(I,J,IL)

PRINT IC03, ((LBLHUB $(J, K), K=1,3),(4$ I B (T,J,IL), IL = I, IC),

$1(L B L(7, K), K=1,3),(\operatorname{DEG}(J, I L), I L=1,10), J=1,3)$

IF $(X O L(I, 1)$. LT . . . .) GO TO 4

DO $5 I L=1.10$

5 DEG(I,IL) $=57.298 *$ DELW(I, 6,IL)

PRINT 1003, (LBLHWB $(7, K), K=1,3)$, (HWB I, S, IL), IL $=1,10)$,

$1(L B L(6, K), K=1,3),(D E G(1, I L), I L=1,1$ )

GO 102

$4 \quad D O 7 \mathrm{~J}=1,3$

Table D-2. Continued 


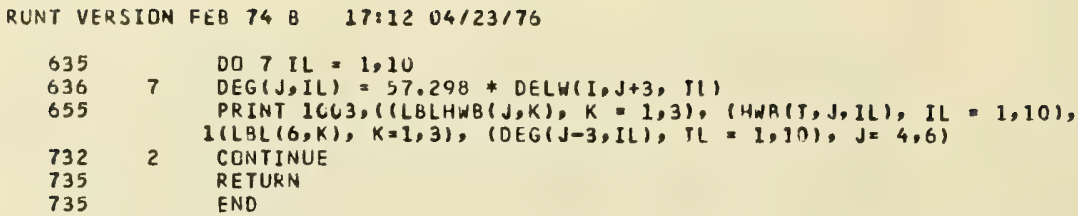

Table D-2. Continued 
FUNCTION LNEOF(M,N,NL, A, B, DTRMNT, Z )

C.. SDLVES SIMULTANEJUS LINEAR EQUATIONS BY GAUSSTAN REDUCTION.

C.. FORTRAN IV EQUIVALENT DF LNEQS.

12

12

14

15

17

20

34

35

52

55

57

60

63

65

73

75

102

113

124

125

132

143

154

155

165

167

175

205

207

230

231

252

255

257

205

275

277

315

316

317

321

322

323

325

342

362

REAL A $(M, M), B(M, M), Z(M), D T R M N T, R M A X, R V E X T, W, D \cap V$

$N M I=N-1$

$0040^{\circ} J=1, N M 1$

$J 1=J+1$

C.. FIND ELEMENT OF COL J, RJWS J-N, WHICH HAS MAX ABSJLUTE VALUF. L MAX $\approx$ J

$R M A X=A B S(A(J, J))$

DO $8 \mathrm{~K}=\mathrm{J} I, N$

RNEXT= $A B S(A(K, J))$

IF (RMAX GE. RNEXT) GO TO 6

RMAX $=$ RNEXT

LMAX $=K$

e CONTINUE

IF (LMAX. NE. J) GJ TO 10

C.. MAX ELEMENT IN CDLUMN IS ON DIAGONAL

If $(A(\mathrm{~J}, J)) 20,94,20$

C.. MAX ELEMENT IS NOT JN DIAGONAL. EXCHBVGF ROWS J ANO LMAX.

$100012 \mathrm{~L}=\mathrm{J}, \mathrm{N}$

$W=A(J, L)$

$\Delta(J, L)=\Delta(L M \Delta X, L)$

$12 A(L M A X, L)=W$

DO $14 L=1, V 1$

$W=B(J, L)$

$B(J, L)=B(L M A X, L)$

$14 B(L M A X, L)=N$

DTRMNT = OTRYNT

C. ZERD CDLUMN J BELO\& THE DIAGDNAL.

$20 \mathrm{~J}(\mathrm{~J})=1,(A(\mathrm{~J}, \mathrm{~J})$

DO $30 \mathrm{~K}=\mathrm{J} 1, \mathrm{~N}$

If $(A(K, J)) 22,30,22$

$22 W=-Z(J) * A(K, J)$

$0024 \mathrm{~L}=\mathrm{J} L, N$

$24 A(K, L)=W * A(J, L)+A(K, L)$

$0026 \quad \mathrm{~L}=1, \mathrm{Nl}$

$26 \quad B(K, L)=W * B(J, L)+B(K, L)$

30 CONTINUE

40 CONTINUE

IF $(A(N, N)) 42,74,42$

$42 Z(N)=1 \cdot / A(N, N)$

C.. OBTAIN SOLUTION SY SACK SUBSTITUTION. DO $50 \quad L=1, N 1$

$50 B(N, L)=Z(N) * B(N, L)$

DO $60 \quad K=1, N M 1$

$J=N-K$

$J 1=j+1$

DO $58 \quad L=1, N I$

$h=0$.

$0056 \quad I=J I, N$

$56 W=A(J, I) * B(I, L)+W$

$58 B(J, L)=(B(J, L)-W) * Z(J)$

60 CONTINUE

Table D-2. Continued 


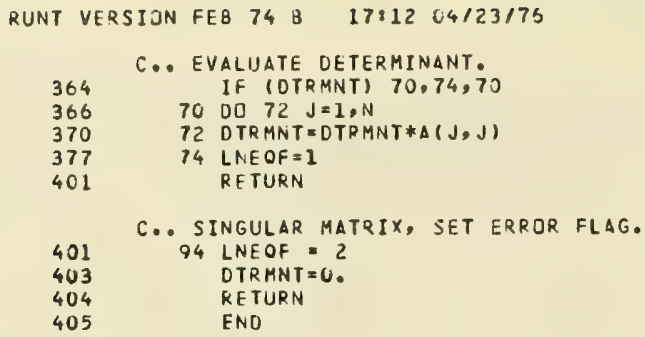

Table D-2. Continued 


\section{13
13
13
15
24}

SUBRDUTINE CPV $(X, Y, E, C 1, S 1, A 9, A 10, K)$
C... CAUCHY PRINCIPAL VALUE INTEGRAL

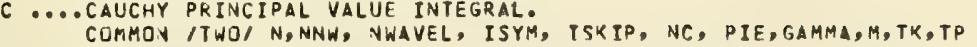
COMMON/SIX/XN(5),CN(5)

REAL $K$

IF (Y. GE, 0.0$) Y=-1.0 E-0 B$

TT=ATANZ $(Y, X)$

$T H=P I E / Z_{0}+T T$

C.....FOR NEGATIVE $X$, GORRECTIUN TU RANGE DF ATAN2. $I F(X, L T \cdot 0) T H=.T H+T P$

$A A=K \notin Y$

$E=E X P(A A)$

$B B=K * X$

$C I=\cos (B B)$

$S I=S I N(B R)$

$R=K * \operatorname{SQRT}(X * * 2+Y * * 2)$

SUM $1=0$.

SUM $2=0$.

IF(R.GE.10.) GO TO 13

SLIM $11=0$.

SUM $22=0$.

$F A C=1.0$

SUM $1 C=1$.

$\operatorname{sum} 2 C=1$.

SDL TH=0.

$\mathrm{CDLTH}=0$.

ASSIGN 3 TO LDC

IF $(X, E Q, 0,1)$ SSIGN B TO LOC

$R L=1.0$

DO $] \quad L=1,100$

$D L=L$

$F A C=F A C * D L$

$R L=R * R L$

$D L F A C=F A C * U L$

$D L T H=D L * T H$

$A 1=R L / O L F A C$

IF (ABS (CDLTH),LE.1.E-GT)GO TO 2 SUMIC =ABS $(\triangle 1 /$ SUMI)

IF(SUMIC.LE,I.E-0)5)GO TO 7

$2 C D L T H=C O S(D L T H)$

SUMII $=A I * C O L T H$

SUM I $=$ SUMI + SUM II

7 GO TO $L D C,(3,8)$

8 SUMZC $=0$.

GO TO 5

3 IF (ABS (SOLTH),LE.I,E-CT)GT TO 4 SUM $Z C=A B S(A 1 /$ SUM? $)$

IF (SUM?C.LE, L,E-NS)GD IT 5

4 SOLTH $=S I N(D L T H)$

SUM $22=A 2 * S O L T H$

SUM $2=$ SUM $2+\operatorname{SUM} 22$

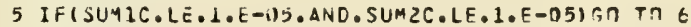

1 CONTINUE

$6 C=G A M M A+A L J G(R)+S U M L$

C..... DISCONTINUITY OF 2PIE IF X NEGATIVE TN EI FINNCTION.

Table D-2. Continued 


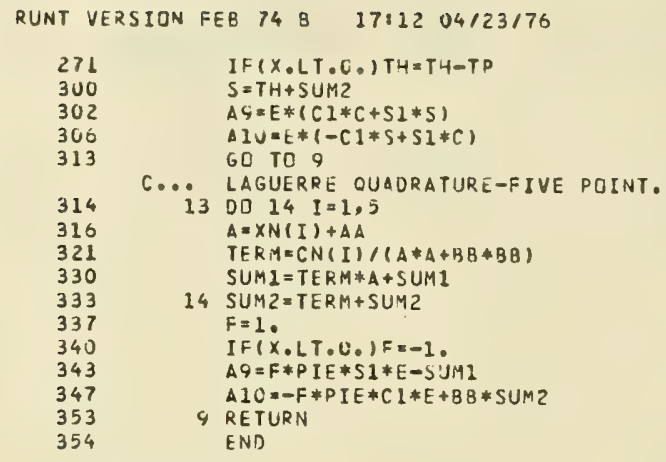

Table D-2. Continued 
SUBROUTINE OYNJUT

COMMON RII2(25,25), RKS6(25, 25$)$, POT $(25,25), 40 W(25,25), F E(25,6)$, IFI $(25,6), \quad R I(25,25), R J(25,25), \operatorname{RK}(25,4), R L(25,4)$,

ZRMU $(3,3,19), \operatorname{RLAM}(3,3,10), F B(3,10), \operatorname{DELFB}(3,10), \operatorname{HWB}(25,6,30)$, 3 DELW $(25,6,10), X D L(25,10)$

COMMON /TWO/ N, NNA, NWAVEL, ISYM, ISKIP, NC, PIE, GAMMA,M, TK,TP COMMON/THREE/ WAVEL(10), WN(10), BOL(10), TL

COMMON/FOUR/RAF $(3,1)\}, \operatorname{OELR}(3,16), \operatorname{HWR}(25,3,13), \operatorname{DELWR}(25,3,10)$,

2 HWT $(25,10), D E L W T(25,10), R K H Y D(3,3), Q<M D Q(3,3), \operatorname{RTB}(3,3)$.

$3 \times 6, Y G$, RMASS, RINERT, DAMP(3)

COMMON /SEVEN/ AREA, B, D, RDE, GEE, BTITLE(3), TITLE(P)

CLMMON ININE/ LBLRAR (3,3), LBLHWR (5.3), LILR $(5,3)$

COMMON, EIGHT/LBLMU $(3,3,3), \operatorname{LBLAM}(3,3,3), \operatorname{LALFB}(3,3), \operatorname{LBLHWB}(7,3)$,

1L $L L(10,3)$, OEG $(3,10)$

1001 FORMAT $(/ / 3 x, 3410, /(5 x, 3410,10 F 10.4))$

IUO2 FORMAT (//3X, 3A10, / (5x, 3A10, 10F10.4, /5x, 3410, 10F10.4/)

1003 FORMAT( $5 x, 3410,13 F 10.4,5 x, 3410,13 F 10.41)$

1004 FORMAT( $1 / 3 X, 3410,2 X, 10 F 10.413 X, 3410,2 X, 10 F 10.4)$

PRINT 2000, AREA, 9, XG, YG, RMASS, RINSRT,DAMP(1),DAMP(2),DAMP(3)

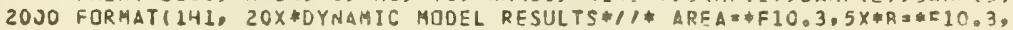
$15 X * X G=F 10.3,5 X * Y G=* F 10.3,5 X * M A S S=\# F 10,3.5 X * I N E R T I \Delta=* F] 0.3 / 1$

3* ADDITIONAL DAMPING AODED- IN SWAY-*FG.?* LAMDAII IN $4 F A V F-$ 3*F6.2* LAMOAZ2 IN ROLL-*F6.2* LA4DA33* /1)

PRINT $2001,((\operatorname{RKHYD}(I, J), J=1,3), I=1,3),((\operatorname{RKMTR}(I, J), J=1,3), I=1,3)$ 2001 FORMATI * SPRING CONSTANTS $1 \quad K 22 \quad K 23 \quad K 31 \quad K 32 \quad K 33 * 1$

2* HYDROSTATIC*7X, YF $10.3 /$ * MCQRING*11X.9FI0.3/1/1

VO $9 \mathrm{IL}=1.10$

$9 \quad C E G(1, I L)=\operatorname{SQRT}((G E E * B O L(I L)) /(T P \& B))$

PRINT $1 \cup 04,(L B L(1, K), K=1,3),(B \cap L(I L), T L=1,10)$,

$1(L B L(2, K), K=1,3),(C E G(1, I L), I L=1,10)$

$001 I=1,3$

$001 \mathrm{IL}=1,10$

1 DEG $(1, I L)=57.298 *$ DELR(I,IL)

PRINT 1002, (LRLR $(1, K), K=1,3),((L B L Q A R(T, K), K \equiv 1,3)$,

1 (RAK(I,IL),IL $=1,1),(L B L(6, K), K=2,3),(D E G(I, I L), I L=1,10), I$ $2=1,31$

DO $21=1, \mathrm{NNW}$

$D D 8 I L=1,10$

$8 \quad D E G(1, I L)=X O L(I, I L) * B / B O L(I L)$

PRINT IU)Z, (LBL $(3, K), K=1,3),(L A L(9, K), K=1,3)$,

$1(X O L(I, I L), I L=1,1(i),(L B L(10, K), K=1,3), \quad(D F G(1, I L), I L=1,10)$

$\mathrm{DO} 3 \mathrm{~J}=1,3$

DO 3 IL $=1,10$

3 LEG (J,IL) $=57.298 \div D E L W R(I, J, I L)$

PRINT 1J03, ( (LULHWR $(J, K), K=1,3),(H W R(T, J, I L), I L=1, I 0)$,

$1(L B L(6, K), K=1,3),(D E G(J, I L), I L=1,10), J=1,3)$

IF $(X O L(I, 1) \cdot L T, 0$,$) GO TO 4$

LO 5 IL $=1,10$

$\operatorname{OEG}(2, I L)=57.298$ DELWT(I,IL)

5

$D E G(1,1 L)=57.278 *$ DELW(I, $6, I L)$

PRINT 1003, (LHLHWR(7,K), K=1,3), (LWB(T, K, IL), IL $=1,1 \mathrm{C})$,

$1(L B L(6, K), K=1,3),(D E G(1, I L), I L=2,1))$

PPINT 1003, (LBLHAR(4,K),K=1,3), (HWT(I,IL), (L = 1, 12),

1 (LBL $(6, K), K=1,3), \operatorname{CDEG}(2, I L), I L=1, I \cap)$

Table D-2, Continued 
DYNOUT

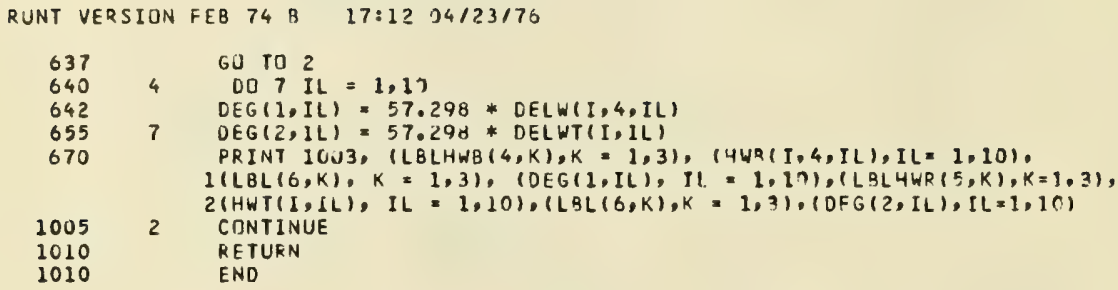

Table D-2. Continued 


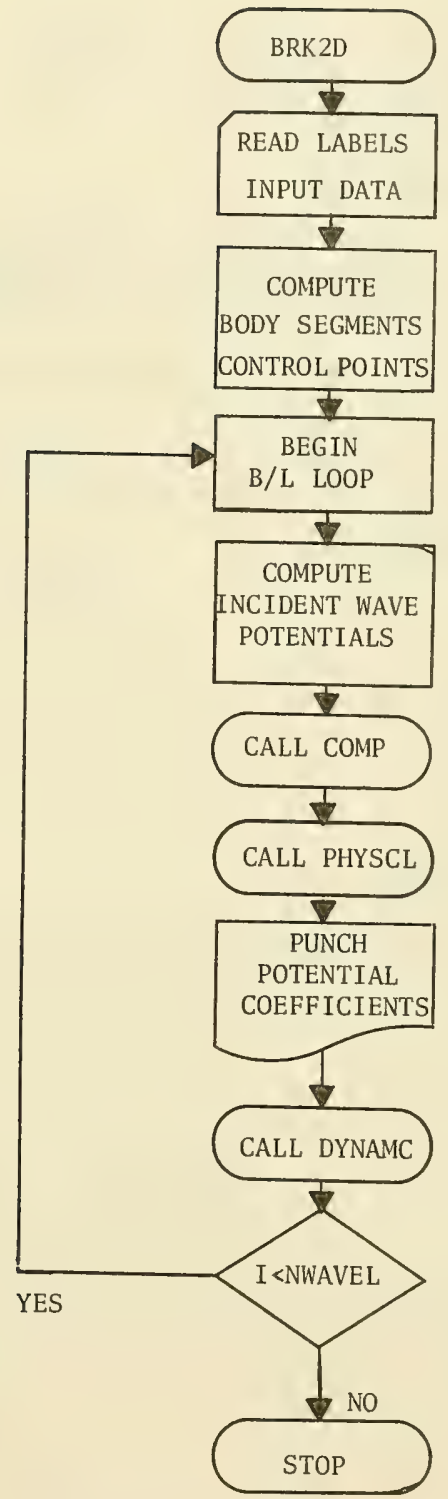

Figure. Flow chart for program BRK2D. 
7. Program Comments and G lossary of Terms.

The program listing contains many comments which aid in following the logic of the program. Descriptions of variables also appear where they are read into the program.

8. Run Time and Memory Size.

BRK2D requires about 70 seconds of central processor time on the CDC 6400 computer to compile and compute results for 10 different beam wavelength ratios. A central memory of about 55,000 octal is required.

9. Run and Card Deck Setup Procedures and Special Operation Instructions.

In order to run the FORTRAN source program deck on the University of Washington CDC 6400 , the following deck is required:

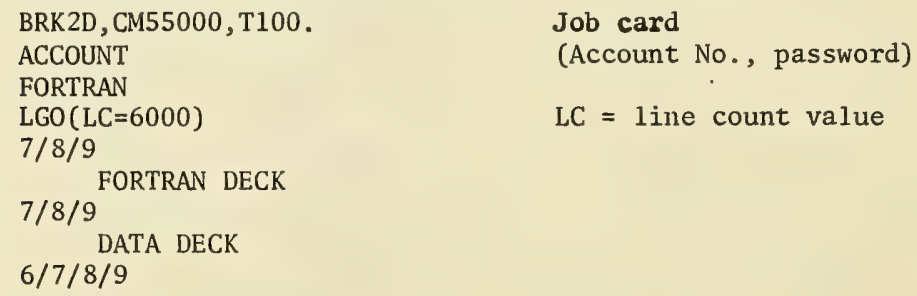

10. Sample Output Data.

Table D-3 is the output for the Oak Harbor breakwater. The input is given in Table $\mathrm{D}-1$. 


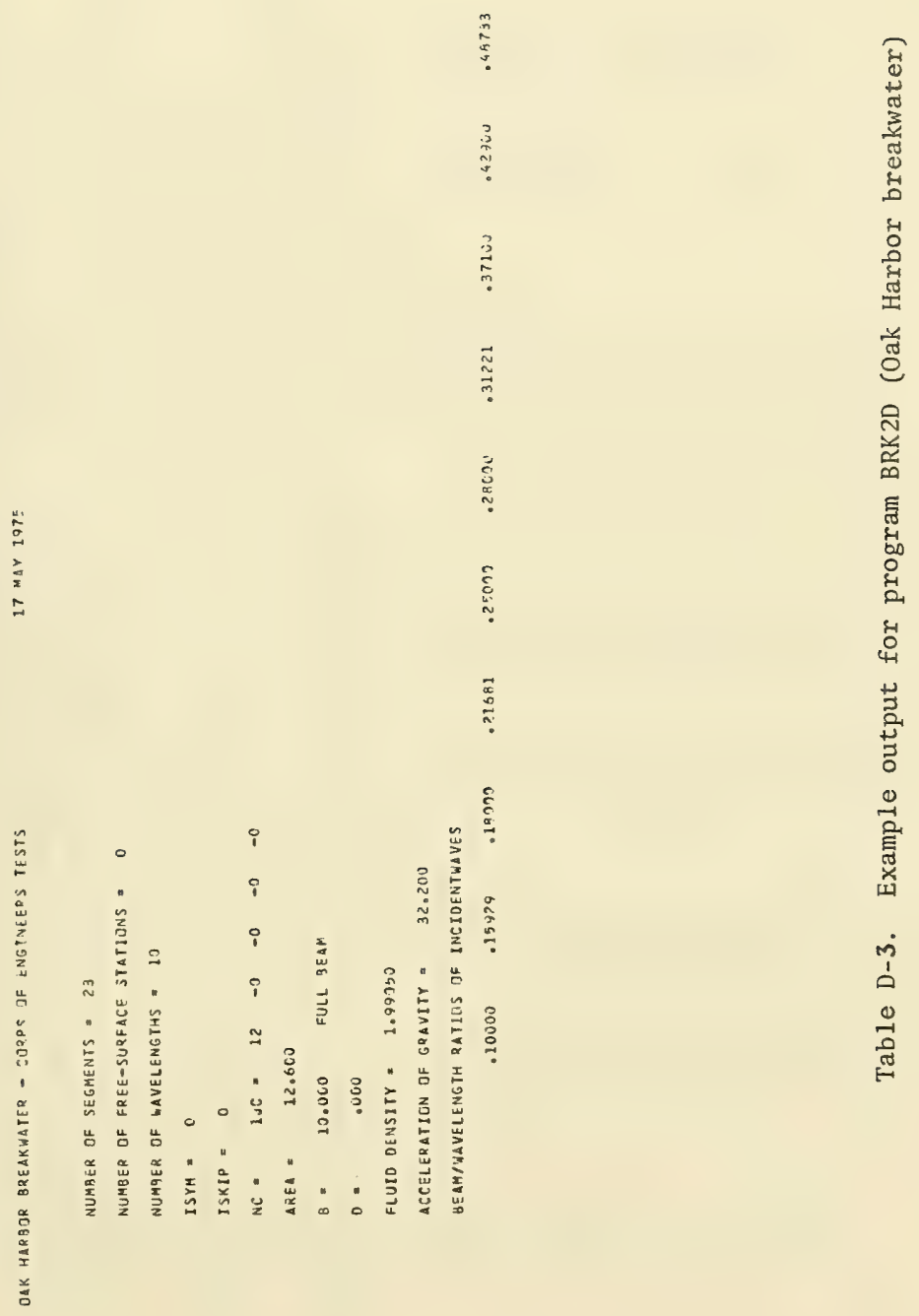


政

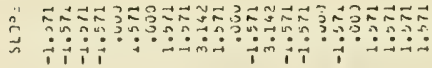

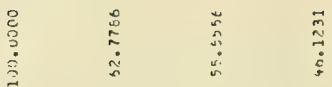

$\frac{8}{3}$

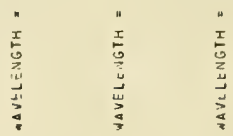

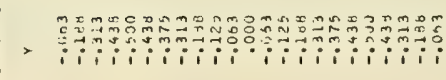

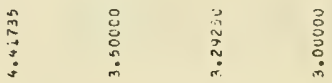

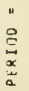

\begin{tabular}{|c|c|}
\hline " & " \\
\hline 8 & 음 \\
\hline $\overrightarrow{\vec{\alpha}}$ & $\bar{z}$ \\
\hline
\end{tabular}

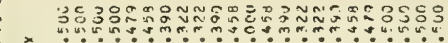

$\frac{2}{2}$

ว

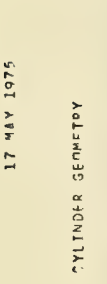

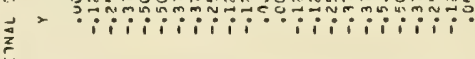

$c o c c c o s$
$c$

岸

3

先

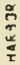

몸

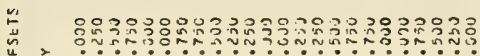

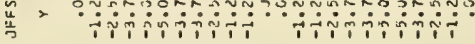

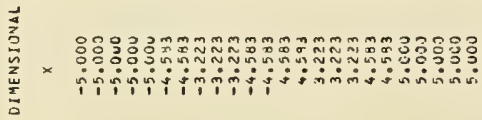

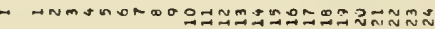

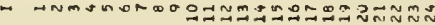

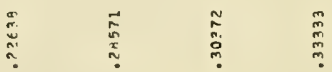

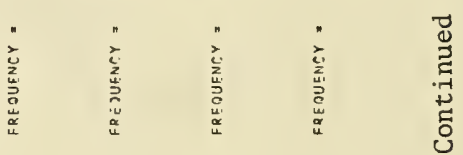

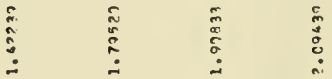

m

苗

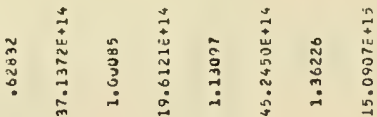

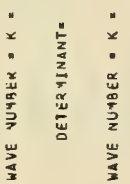

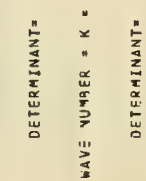




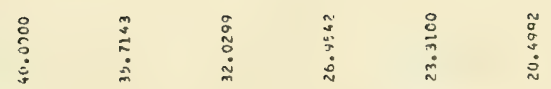

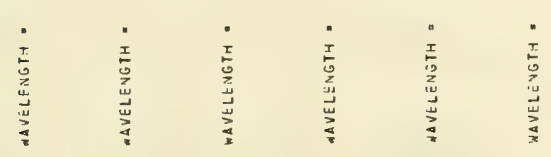

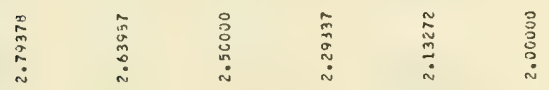

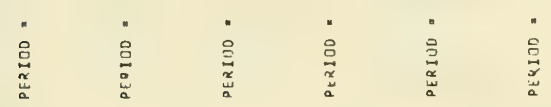

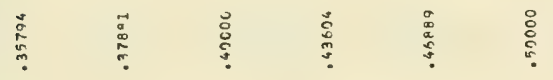

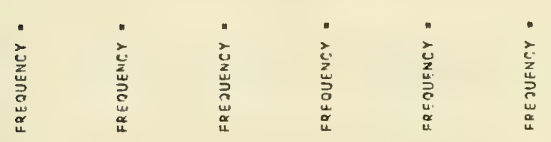

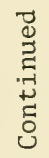

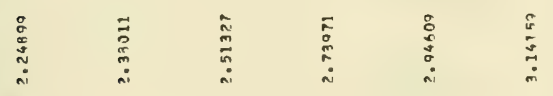

" i j

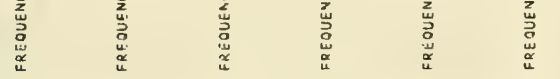

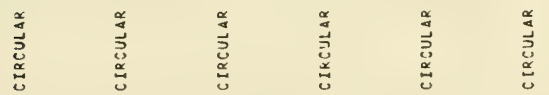

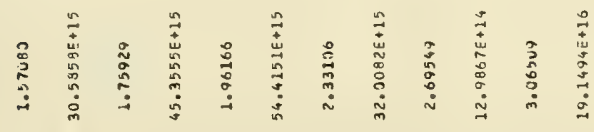

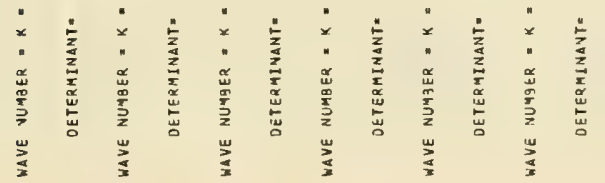




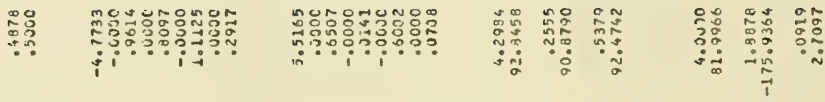

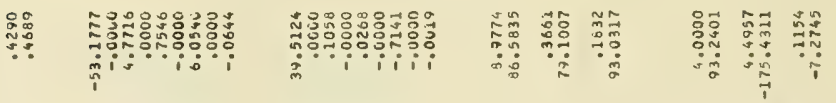

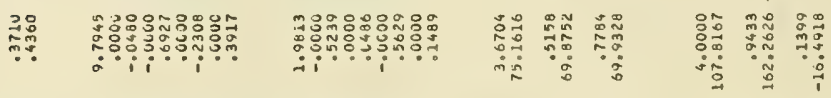

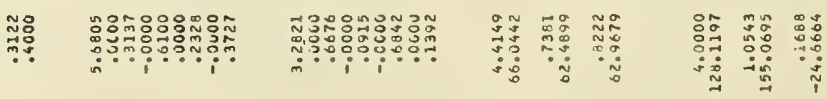

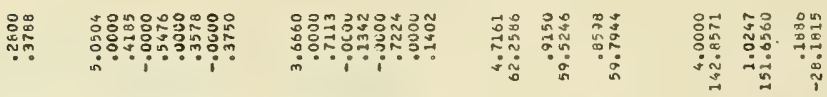

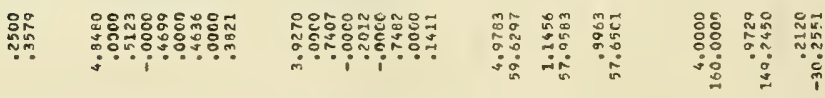

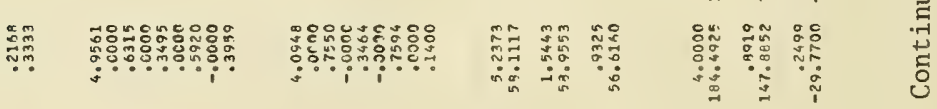

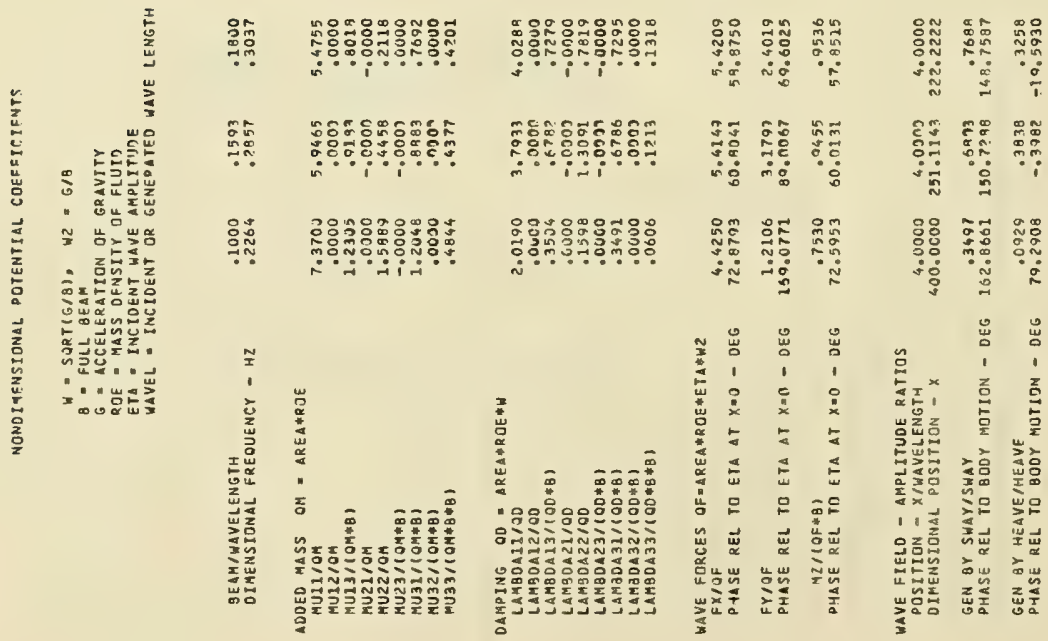




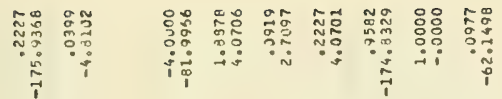

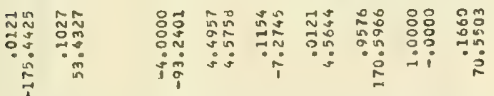

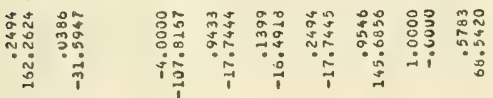

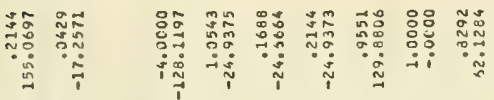

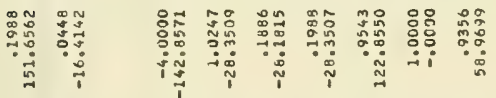

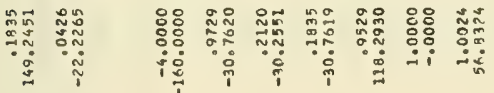

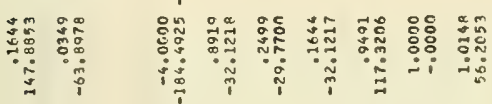

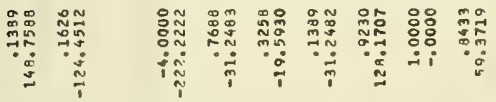

ن.

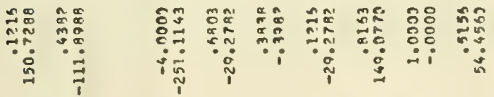

$\underset{\pi}{\frac{\pi}{9}}$

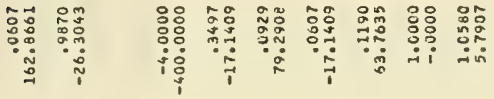

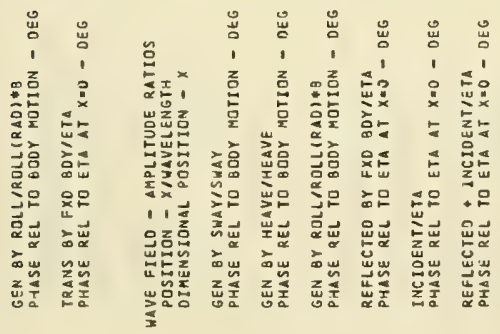




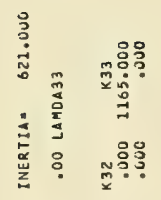

突

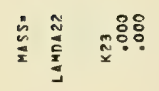

先

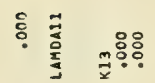

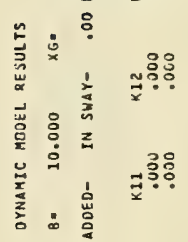

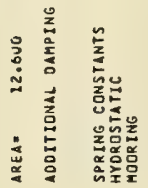

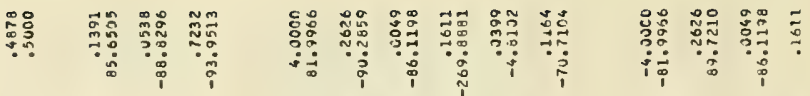

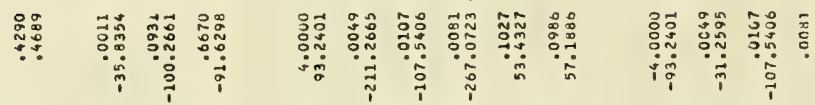

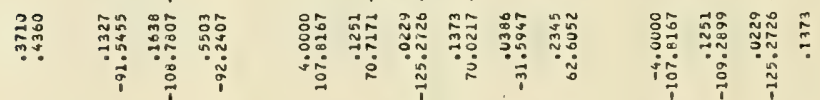

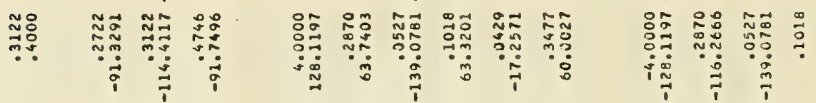

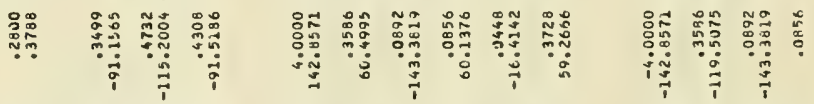

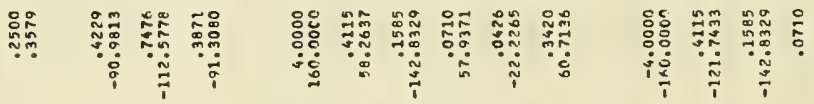

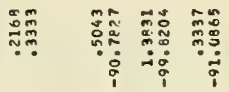

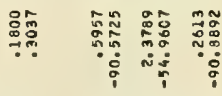

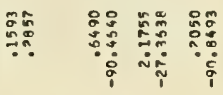

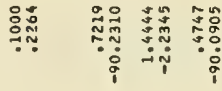

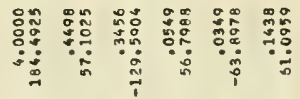

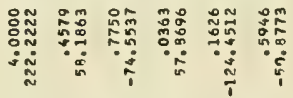

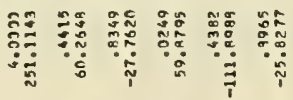

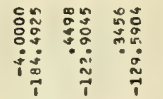

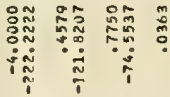

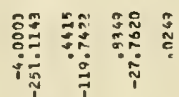

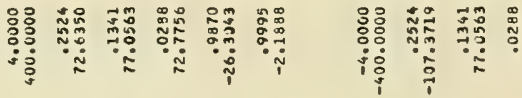

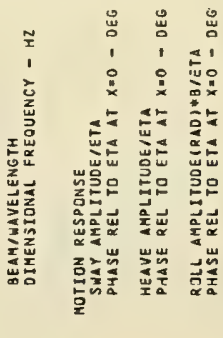

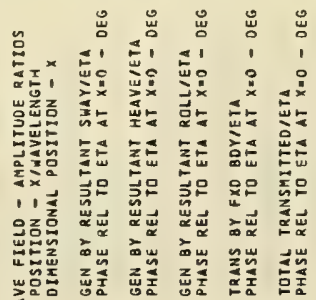

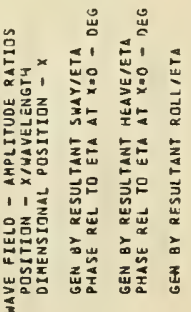

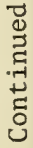

í ले 


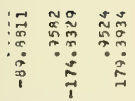

苟

产

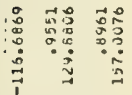

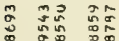

范

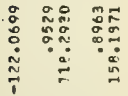

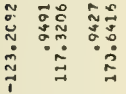

ㅍّㅁ

逭:

㟧

七就

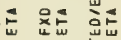

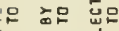

岕 总岃

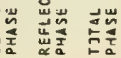




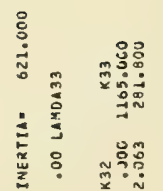

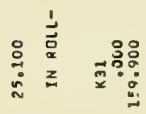

䒺

:

2. 2 2

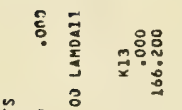

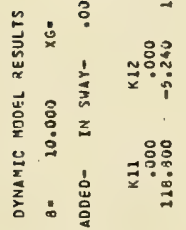

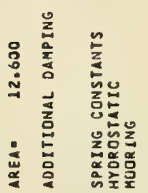

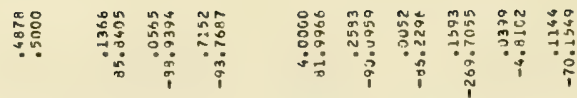

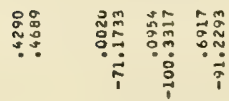

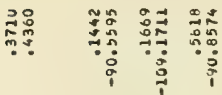

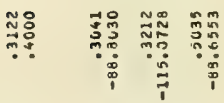

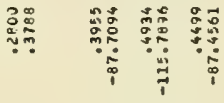

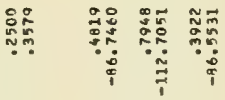

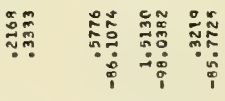

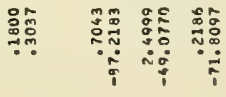

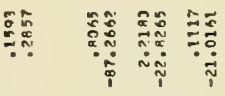

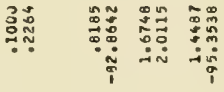

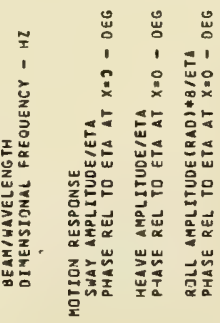

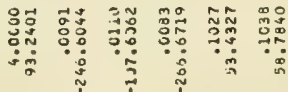

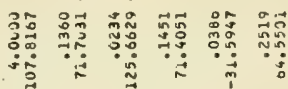

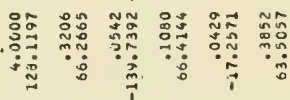

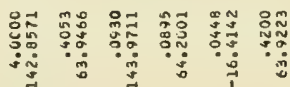

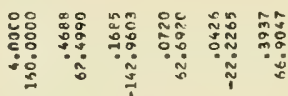

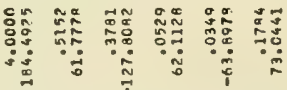

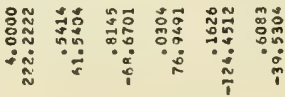

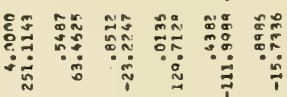

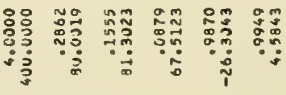

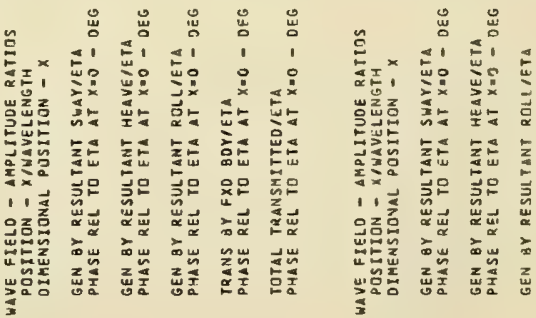

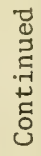

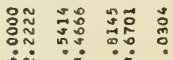

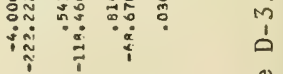

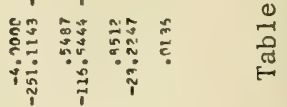

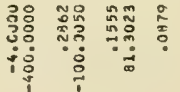

s 


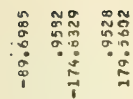

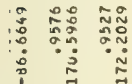

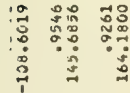

นี

政

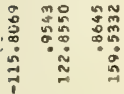

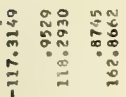

喜

$\fallingdotseq \cong$

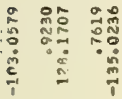

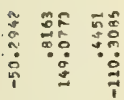

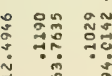

(1)

范

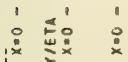

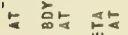

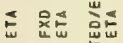

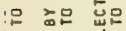

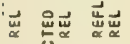

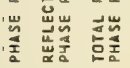

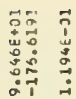

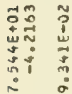

ร.

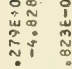

草

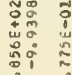

i :

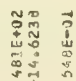

का

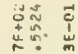

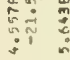

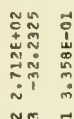

พับ

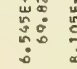

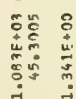

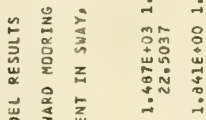

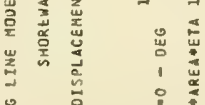

势

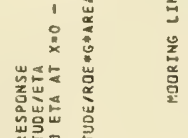

幽吊 룬

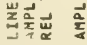

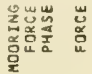

ن

กำ

ำ

구

กิ

虫苛

다:

ำ

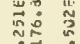

जा:

กิ๊

(1)

บั

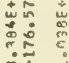

का :

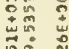

$\because=$

의용

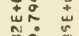

:

กิ

出

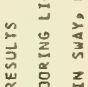

ㅎํㅇㅇㅇ

沝

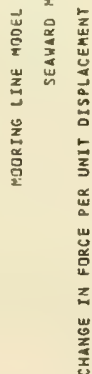




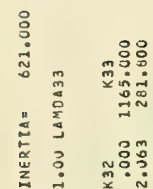

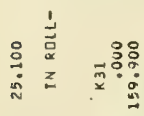

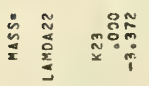

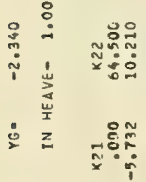

¿

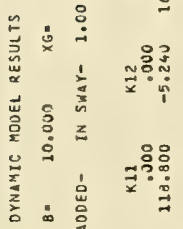

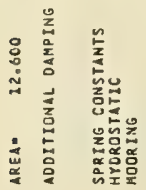

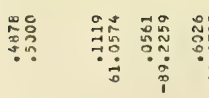

经

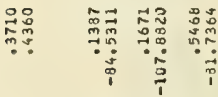

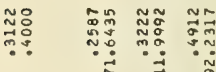

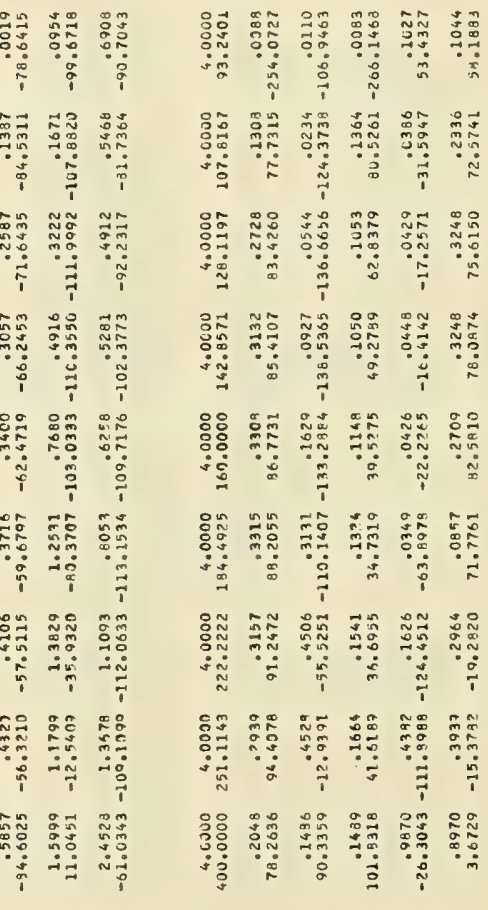

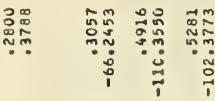

然

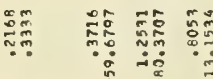

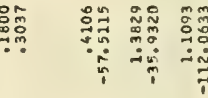

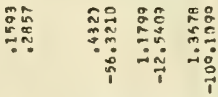

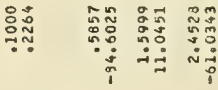

彳

㟧 岁

薄

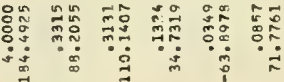

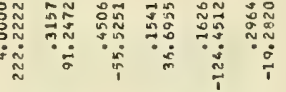

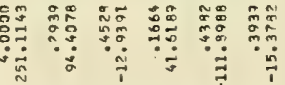

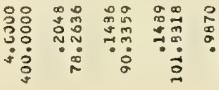

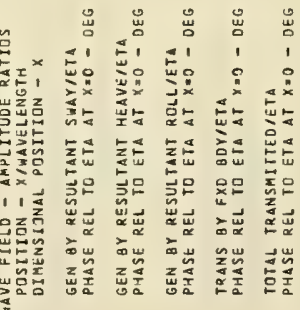

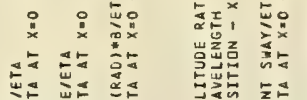

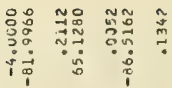

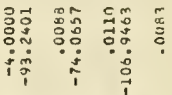

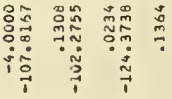

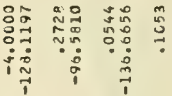

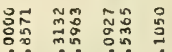

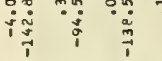

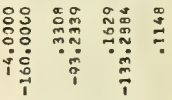

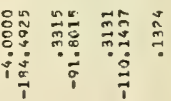

유

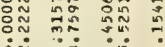

i

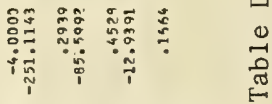

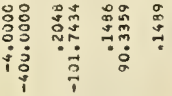

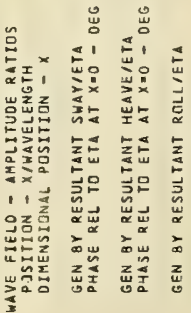

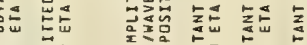

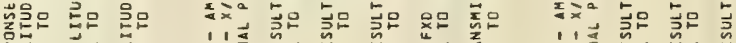

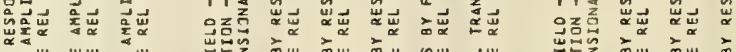

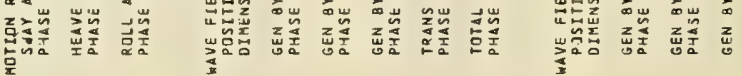




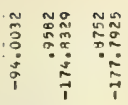

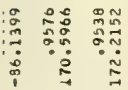

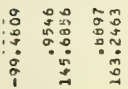

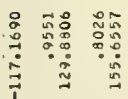

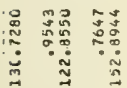

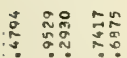

要

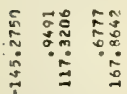

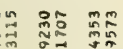

藏

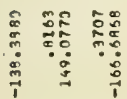

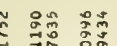

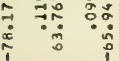

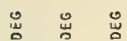

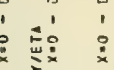

上敦到

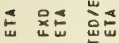

은도

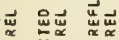

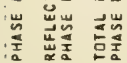

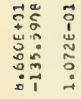

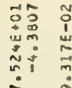

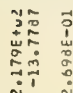

วै

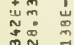

ก

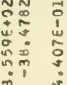

旅

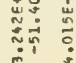

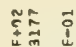

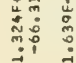

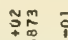

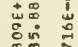

i 5

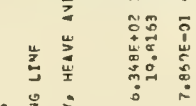

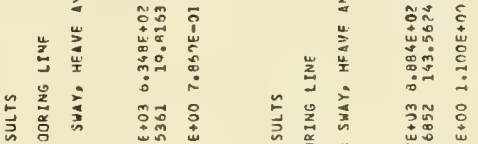

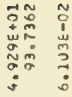

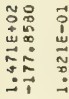

จำ

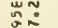



우료 $\vec{i}$

势

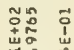

तี

证

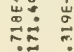

กN

贵票

क्ष

No

ำ

每

?ำ

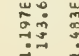

मे

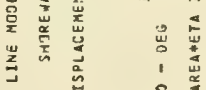

范

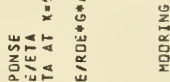

造势

岂荠㟧

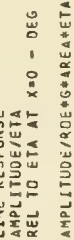

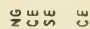

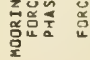


Consider the problem of the nonlinear interactions of waves at two distinct frequencies traveling in the same direction. The complete boundary value problem is well known.

The Laplace equation,

$$
\nabla^{2} \phi=0 \text {, }
$$

applies throughout the fluid below the free surface.

The boundary condition,

$$
\frac{\partial^{2} \phi}{\partial t^{2}}+g \frac{\partial \phi}{\partial y}+2 \nabla \phi \cdot \nabla \frac{\partial \phi}{\partial t}+\frac{1}{2} \nabla \phi \cdot \nabla(\nabla \phi \cdot \nabla \phi)=0,
$$

must be satisfied on the free surface, $y=\eta$. The boundary condition on the bottom is:

$$
\lim _{y \rightarrow-\infty} \frac{\partial \phi}{\partial y}=0
$$

for an infinitely deep fluid. In addition a radiation condition requiring the generated waves to travel away from the body is needed to ensure uniqueness of the solution.

In this formulation the $\mathrm{x}$ axis lies in the direction of incident wave propagation.

The difficulty in solving this boundary value problem stems from the nonlinearity of the free-surface boundary condition.

In order to "linearize" the free-surface boundary condition, expand the velocity potential, $\phi$, in a Taylor series about the undisturbed free surface:

$$
\begin{aligned}
\phi(x, n, t) & =\phi(x, 0, t) \\
& +n\left[\frac{\partial \phi(x, y, t)}{\partial y}\right]_{y=0}+\frac{1}{2} n^{2}\left[\frac{\partial \phi(x, y, t)}{\partial y}\right]_{y=0}+0\left(n^{3}\right)
\end{aligned}
$$

Also expand $\eta$ and $\phi$ in power series:

$$
\begin{aligned}
& \eta(x, t)=\varepsilon \eta^{(1)}(x, t)+\varepsilon^{2} \eta^{(2)}(x, t)+o\left(\varepsilon^{3}\right), \\
& \phi(x, y, t)=\varepsilon \phi^{(1)}(x, y, t)+\varepsilon^{2}{ }^{(2)}(x, y, t)+o\left(\varepsilon^{3}\right) .
\end{aligned}
$$


Substituing the expansion for $\phi$ into the free-surface boundary condition:

$$
\begin{aligned}
& \varepsilon \frac{\partial^{2} \phi(1)(x, y, t)}{\partial t^{2}}+\varepsilon^{2} \frac{\partial^{2} \phi(2)}{\partial t^{2}}+g \varepsilon \frac{\partial \phi(1)}{\partial y}+g \varepsilon^{2} \frac{\partial \phi(2)}{\partial y} \\
& +2\left[\varepsilon\left\{\frac{\partial \phi(1)}{\partial x} \vec{i}+\frac{\partial \phi(1)}{\partial y} \vec{j}\right\}+\varepsilon^{2}\left\{\frac{\partial \phi(2)}{\partial x} \vec{i}+\frac{\partial \phi(2)}{\partial y} \vec{j}\right\}\right] \cdot \\
& {\left[\vec{i} \frac{\partial}{\partial x}+\vec{j} \frac{\partial}{\partial y}\right]\left[\varepsilon \frac{\partial \phi(1)}{\partial t}+\varepsilon^{2} \frac{\partial \phi(2)}{\partial t}\right]} \\
& \left.+\frac{1}{2}\left[\varepsilon \frac{\partial \phi(1)}{\partial x} \vec{i}+\frac{\partial \phi(1)}{\partial y} \vec{j}\right\}+\varepsilon^{2}\left\{\frac{\partial \phi(2)}{\partial x} \vec{i}+\frac{\partial \phi(2)}{\partial y} \vec{j}\right\}\right] \cdot \\
& {\left[\vec{i} \frac{\partial}{\partial x}+\vec{j} \frac{\partial}{\partial y}\right]\left[\left[\varepsilon\left\{\frac{\partial \phi(1)}{\partial x} \vec{i}+\frac{\partial \phi(1)}{\partial y} \vec{j}\right\}+\varepsilon^{2}\left\{\frac{\partial \phi(2)}{\partial x} \vec{i}+\frac{\partial \phi(2)}{\partial y} \vec{j}\right\}\right] \cdot\right.} \\
& \left.\left[\varepsilon\left\{\frac{\partial \phi(1)}{\partial x} \vec{i}+\frac{\partial \phi(1)}{\partial y} \vec{j}\right\}+\varepsilon^{2}\left\{\frac{\partial \phi(2)}{\partial x} \vec{i}+\frac{\partial \phi}{\partial y} \vec{j}\right\}\right]\right]+0\left(\varepsilon^{3}\right)=0 \\
& \text { on } y=\eta \cdot
\end{aligned}
$$

Now use the Taylor expansion for $\phi(x, n, t)$ and neglect terms of or$\operatorname{der} \varepsilon^{3}$ in the boundary condition:

$$
\begin{aligned}
& \varepsilon\left\{\frac{\partial^{2} \phi(1)(x, 0, t)}{\partial t^{2}}+\varepsilon \eta(1)(x, t) \frac{\partial^{3} \phi(1)}{\partial y \partial t^{2}}\right\}+\varepsilon^{2} \frac{\partial^{2} \phi(2)}{\partial t^{2}} \\
& +g \varepsilon\left\{\frac{\partial \phi(1)}{\partial y}+\varepsilon \eta(1)(x, t) \frac{\partial^{2} \phi(1)}{\partial y^{2}}\right\}+g \varepsilon^{2} \frac{\partial \phi}{\partial y} \\
& +2 \varepsilon^{2}\left[\frac{\partial \phi(1)}{\partial x} \frac{\partial^{2} \phi(1)}{\partial t \partial x}+\frac{\partial \phi(1)}{\partial y} \frac{\partial^{2} \phi(1)}{\partial t \partial y}\right]+O\left(\varepsilon^{3}\right)=0 .
\end{aligned}
$$

Grouping terms by order:

First Order $\varepsilon$ :

$$
\frac{\partial^{2} \phi(1)}{\partial t^{2}}+g \frac{\partial \phi(1)}{\partial y}=0 \text { on } y=0 \text {. }
$$

Second order $\varepsilon^{2}$ :

$$
\begin{aligned}
& \frac{\partial^{2} \phi(2)}{\partial t^{2}}+g \frac{\partial \phi}{\partial y}+\eta(1) \frac{\partial}{\partial y}\left\{\frac{\partial^{2} \phi(1)}{\partial t^{2}}+g \frac{\partial \phi}{\partial y}\right\}+2 \frac{\partial \phi}{\partial x} \frac{\partial^{2} \phi^{(1)}}{\partial x \partial t} \\
& +2 \frac{\partial \phi(1)}{\partial y} \frac{\partial \phi(1)}{\partial y \partial t}=0 \quad \text { on } y=0 .
\end{aligned}
$$


Using the dynamic boundary condition on the free surface, one finds:

$$
n(x, t)=-\frac{1}{g}\left\{\frac{\partial \phi}{\partial t}+\frac{1}{2} \nabla \phi \cdot \nabla \phi\right\} \quad \text { on } y=n \text {. }
$$

Substituting the expansions into this equation yields:

$$
\begin{aligned}
& \varepsilon \eta^{(1)}(x, t)+\varepsilon^{2} \eta^{(2)}+0\left(\varepsilon^{3}\right)=-\frac{1}{g}\left\{\frac{\partial \phi}{\partial t}+\frac{1}{2} \nabla \phi \cdot \nabla \phi\right\}_{y=0} \\
& -\frac{n}{g} \frac{\partial}{\partial y}\left\{\frac{\partial \phi}{\partial t}+\frac{1}{2} \nabla \phi \cdot \nabla \phi\right\}_{y=0}+0\left(\eta^{2}\right) .
\end{aligned}
$$

Substituting for $\phi$, the right-hand side becomes:

$$
\begin{aligned}
& =-\frac{1}{g}\left\{\varepsilon \frac{\partial \phi(1)}{\partial t}+\varepsilon^{2} \frac{\partial \phi(2)}{\partial t}+\frac{\varepsilon^{2}}{2}\left[\left(\frac{\partial \phi(1)}{\partial x}\right)^{2}+\left(\frac{\partial \phi(1)}{\partial y}\right)^{2}\right]\right\} \\
& -\frac{\varepsilon^{2} \eta(1)}{g}\left\{\frac{\partial^{2} \phi(1)}{\partial y \partial t}\right\}+0\left(\varepsilon^{3}\right), \quad \text { on } y=0 .
\end{aligned}
$$

First Order $\varepsilon$ :

$$
\eta^{(1)}(x, t)=-\frac{1}{g} \frac{\partial \phi^{(1)}(x, 0, t)}{\partial t} .
$$

Second Order $\varepsilon^{2}$ :

$$
\begin{aligned}
& \eta^{(2)}(x, t)=-\frac{1}{g}\left\{\eta^{(1)} \frac{\partial \phi^{(1)}}{\partial y \partial t}+\frac{\partial \phi^{(1)}}{\partial t}\right\}-\frac{1}{2 g}\left\{\left(\frac{\partial \phi^{(1)}}{\partial x}\right)^{2}+\left(\frac{\partial \phi^{(1)}}{\partial y}\right)^{2}\right\} \\
& \text { on } y=0
\end{aligned}
$$

or

$$
\begin{aligned}
& \eta^{(2)}(x, t)=-\frac{1}{g}\left\{-\frac{1}{g} \frac{\partial \phi(1)}{\partial t} \frac{\partial^{2} \phi(1)}{\partial y \partial t}+\frac{\partial \phi(2)}{\partial t}\right\}-\frac{1}{2 g}\left\{\left(\frac{\partial \phi(1)}{\partial x}\right)^{2}\right. \\
& \left.+\left(\frac{\partial \phi(1)}{\partial y}\right)^{2}\right\} \text { on } y=0 .
\end{aligned}
$$

Using the first-order relationship above in the second-order boundary condition on the free surface (E-9), one finds:

$$
\begin{aligned}
& \frac{\partial^{2}{ }^{(2)}}{\partial t^{2}}+g \frac{\partial \phi}{\partial y}=+\frac{1}{g} \frac{\partial \phi}{\partial t} \frac{\partial}{\partial y}\left\{\frac{\partial^{2} \phi^{(1)}}{\partial t^{2}}+g \frac{\partial \phi(1)}{\partial y}\right\} \\
& -2 \frac{\partial \phi(1)}{\partial x} \frac{\partial^{2} \phi^{(1)}}{\partial x \partial t}-2 \frac{\partial \phi(1)}{\partial y} \frac{\partial^{2} \phi^{(1)}}{\partial y \partial t}
\end{aligned}
$$


1. First-Order Solution of the Boundary Value Problem.

This solution results from the superposition of the velocity potentials for individual waves:

$$
\begin{aligned}
& \phi^{(1)}(x, y, t)=\frac{g A_{1}}{\omega_{1}} e^{k_{1} y} \cos \left(k_{1} x-\omega_{1} t+\delta_{1}\right) \\
& +\frac{g_{2}}{\omega_{2}} e^{k_{2} y} \cos \left(k_{2} x-\omega_{2} t+\delta_{2}\right) .
\end{aligned}
$$

Check the solution:

$$
\nabla_{\phi}^{2}(1)=0 \text {. }
$$

$\lim _{y \rightarrow-\infty} \frac{\partial \phi^{(1)}}{\partial y} \rightarrow 0$ because of exponential function.

$$
\begin{aligned}
& \frac{\partial_{\phi}^{2}(1)}{\partial t^{2}}+g \frac{\partial \phi}{\partial y}=-g \omega_{1} A_{1} e^{k_{1} y} \cos \left(k_{1} x-\omega_{1} t+\delta_{1}\right) \\
& -g \omega_{2} A_{2} e^{k}{ }_{2}^{y} \cos \left(k_{2} x-\omega_{2} t+\delta_{2}\right) \\
& +g\left\{\omega_{1} A_{1} e^{k} t \cos \left(k_{1} x-\omega_{1} t+\delta_{1}\right)\right. \\
& \left.+\omega_{2} A_{2} e^{k}{ }_{2}^{y} \cos \left(k_{2} x-\omega_{2} t+\delta_{2}\right)\right\}=0 .
\end{aligned}
$$

Therefore, this is a solution.

Surface elevation then becomes:

$$
\begin{aligned}
& \eta^{(1)}(x, t)=-\frac{1}{g} \frac{\partial \phi^{(1)}(x, 0, t)}{\partial t}=-A_{1} \sin \left(k_{1} x-\omega_{1} t+\delta_{1}\right) \\
& -A_{2} \sin \left(k_{2} x-\omega_{2} t+\delta_{2}\right) .
\end{aligned}
$$

To prepare for the second-order solution, construct the right-hand side of the free-surface boundary condition (E-14):

$$
\begin{aligned}
& {\left[\frac{1}{2} \frac{\partial \phi(1)}{\partial t} \frac{\partial}{\partial y}\left\{\frac{\partial^{2} \phi(1)}{\partial t^{2}}+g \frac{\partial \phi(1)}{\partial y}\right\}-2 \frac{\partial \phi(1)}{\partial x} \frac{\partial^{2} \phi(1)}{\partial x \partial t}\right.} \\
& \left.-2 \frac{\partial \phi(1)}{\partial y} \frac{\partial^{2} \phi(1)}{\partial y \partial t}\right]_{y=0}=\frac{1}{g}\left\{g A_{1} \sin \left(k_{1} x-\omega_{1} t+\delta_{1}\right)\right. \\
& \left.+g A_{2} \sin \left(k_{2} x-\omega_{2} t+\delta_{2}\right)\right\}\{0\}-2\left\{-\omega_{1} A_{1} \sin \left(k_{1} x-\omega_{1} t+\delta_{1}\right)\right.
\end{aligned}
$$




$$
\begin{aligned}
& \left.-\omega_{2} A_{2} \sin \left(k_{2} x-\omega_{2} t+\delta_{2}\right)\right\} \times\left\{\omega_{1}{ }^{2} A_{1} \cos \left(k_{1} x-\omega_{1} t+\delta_{1}\right)\right. \\
& \left.+\omega^{2}{ }_{2} A_{2} \cos \left(k_{2} x-\omega_{2} t+\delta_{2}\right)\right\}-2\left\{\omega_{1} A_{1} \cos \left(k_{1} x-\omega_{1} t+\delta_{1}\right)\right. \\
& \left.+\omega_{2} A_{2} \cos \left(k_{2} x-\omega_{2} t+\delta_{2}\right)\right\} \times\left\{\omega_{1}{ }^{2} A_{1} \sin \left(k_{1} x-\omega_{1} t+\delta_{1}\right)\right. \\
& \left.+\omega_{2}{ }^{2} A_{2} \sin \left(k_{2} x=\omega_{2} t+\delta_{2}\right)\right\}=0 .
\end{aligned}
$$

Since this condition is homogeneous, the first-order potential is the solution to the second-order problem.

\section{Second-Order Results.}

The free-surface elevation will be modified when terms of second order are included:

$$
\begin{aligned}
& n^{(2)}(x, t)=\frac{1}{g^{2}}\left\{\frac{\partial \phi(1)}{\partial t} \frac{\partial^{2} \phi(1)}{\partial y \partial t}\right\}-\left.\frac{1}{2 g}\left\{\left(\frac{\partial \phi(1)}{\partial x}\right)^{2}+\left(\frac{\partial \phi(1)}{\partial y}\right)^{2}\right\}\right|_{y=0} \\
& =+\frac{1}{g^{2}}\left\{g A_{1} \sin \left(k_{1} x-\omega_{1} t+\delta_{1}\right)+g A_{2} \sin \left(k_{2} x-\omega_{2} t+\delta_{2}\right)\right\} x \\
& \left\{A_{1} \omega_{1}^{2} \sin \left(k_{1} x-\omega_{1} t+\delta_{1}\right)+A_{2} \omega_{2}^{2} \sin \left(k_{2} x-\omega_{2} t+\delta_{2}\right)\right\} \\
& -\frac{1}{2 g}\left\{\left[-\omega_{1} A_{1} \sin \left(k_{1} x-\omega_{1} t+\delta_{1}\right)-\omega_{2} A_{2} \sin \left(k_{2} x-\omega_{2} t+\delta_{2}\right)\right]\right. \\
& \left.+\left[\omega_{1} A_{1} \cos \left(k_{1} x-\omega_{1} t+\delta_{1}\right)+\omega_{2} A_{2} \cos \left(k_{2} x-\omega_{2} t+\delta_{2}\right)\right]\right\}
\end{aligned}
$$

or

$$
\begin{aligned}
g{ }^{(2)}(x, t)= & \omega_{1}{ }^{2} A_{1}{ }^{2} \sin ^{2}\left(k_{1} x-\omega_{1} t+\delta_{1}\right) \\
& +\omega_{1}{ }^{2} A_{1} A_{2} \sin \left(k_{2} x-\omega_{2} t+\delta_{2}\right) \sin \left(k_{1} x-\omega_{1} t+\delta_{1}\right) \\
& +\omega_{2}{ }^{2} A_{1} A_{2} \sin \left(k_{1} x-\omega_{1} t+\delta_{1}\right) \sin \left(k_{2} x-\omega_{2} t+\delta_{2}\right) \\
& +\omega_{2}{ }^{2} A_{2}{ }^{2} \sin ^{2}\left(k_{2} x-\omega_{2} t+\delta_{2}\right) \\
& \frac{1}{2}\left\{\omega_{1}{ }^{2} A_{1}{ }^{2} \sin ^{2}\left(k_{1} x-\omega_{1} t+\delta_{1}\right)\right. \\
& +2 \omega_{1} \omega_{2} A_{1} A_{2} \sin \left(k_{1} x-\omega_{1} t+\delta_{1}\right) \sin \left(k_{2} x-\omega_{2} t+\delta_{2}\right)
\end{aligned}
$$




$$
\begin{aligned}
& +\omega_{2}{ }^{2} A_{2}{ }^{2} \sin ^{2}\left(k_{2} x-\omega_{2} t+\delta_{2}\right) \\
& +\omega_{1}{ }^{2} A_{1}{ }^{2} \cos ^{2}\left(k_{1} x_{1}-\omega_{1} t+\delta_{1}\right) \\
& +2 \omega_{1} \omega_{2} A_{1} A_{2} \cos \left(k_{1} x-\omega_{1} t+\delta_{1}\right) \cos \left(k_{2} x-\omega_{2} t+\delta_{2}\right) \\
& +\omega_{2}{ }^{2} A_{2}{ }^{2} \cos ^{2}\left(k_{2} x-\omega_{2} t+\delta_{2}\right) .
\end{aligned}
$$

Using the trigonometric relationships:

$$
\begin{aligned}
& g n^{2}(x, t)=\omega_{1}{ }^{2} A_{1}{ }^{2} \sin ^{2}\left(k_{1} x-\omega_{1} t+\delta_{1}\right)+\omega_{2}{ }^{2} A_{2}{ }^{2} \sin ^{2}\left(k_{2} x-\omega_{2} t+\delta_{2}\right) \\
& +\frac{1}{2} \omega_{1}{ }^{2} A_{1} A_{2}\left\{\cos \left[\left(k_{1}-k_{2}\right) x-\left(\omega_{1}-\omega_{2}\right) t+\delta_{1}-\delta_{2}\right]\right. \\
& \left.-\cos \left[\left(k_{1}+k_{2}\right) x-\left(\omega_{1}+\omega_{2}\right) t+\delta_{1}+\delta_{2}\right]\right\} \\
& +\frac{1}{2} \omega_{2}^{2} A_{1} A_{2}\left\{\cos \left[\left(k_{1}-k_{2}\right) x-\left(\omega_{1}-\omega_{2}\right) t+\delta_{1}-\delta_{2}\right]\right. \\
& \left.-\cos \left[\left(k_{1}+k_{2}\right) x-\left(\omega_{1}+\omega_{2}\right) t+\delta_{1}+\delta_{2}\right]\right\} \\
& -\frac{1}{2}\left\{\omega_{1}{ }^{2} A_{1}{ }^{2}+\omega_{2}{ }^{2} A_{2}{ }^{2}\right\}-\omega_{1} \omega_{2} A_{1} A_{2} \cos \left[\left(k_{1}-k_{2}\right) x\right. \\
& \left.-\left(\omega_{1}-\omega_{2}\right) t+\delta_{1}-\delta_{2}\right] .
\end{aligned}
$$

Combining further:

$$
\begin{aligned}
& g{ }^{(2)}(x, t)=-\frac{1}{2} \omega_{1}{ }^{2} A_{1}{ }^{2} \cos \left[2\left\{k_{1} x-\omega_{1} t+\delta_{1}\right\}\right] \\
& -\frac{1}{2} \omega_{2}{ }^{2} A_{2}{ }^{2} \cos \left[2\left\{k_{2} x-\omega_{2} t+\delta_{2}\right\}\right] \\
& -\frac{1}{2}\left(\omega_{1}^{2}+\omega_{2}{ }^{2}\right) A_{1} A_{2} \cos \left[\left(k_{1}+k_{2}\right) x-\left(\omega_{1}+\omega_{2}\right) t+\delta_{1}+\delta_{2}\right] \\
& +\frac{1}{2}\left(\omega_{1}^{2}-2 \omega_{1} \omega_{2}+\omega_{2}{ }^{2}\right) A_{1} A_{2} \cos \left[\left(k_{1}-k_{2}\right) x-\left(\omega_{1}-\omega_{2}\right) t+\delta_{1}-\delta_{2}\right],
\end{aligned}
$$

which is the final form for the second-order term for free-surface elevation. 
Now, turn to the equation for pressure which is necessary to compute the force on the body.

Take the pressure to be zero at the free surface. Then Bernoulli's equation may be written:

$$
P=-\rho \frac{\partial \phi}{\partial t}-\frac{1}{2} \rho \nabla \phi \cdot \nabla \phi-\rho g y \text {. }
$$

Substituting the expansion for $\phi$ :

$$
\begin{aligned}
& P=-\rho\left\{\varepsilon \frac{\partial \phi(1)}{\partial t}+\varepsilon^{2} \frac{\partial \phi}{\partial t}+\frac{1}{2}\left[\varepsilon^{2}\left(\frac{\partial \phi(1)}{\partial x}\right)^{2}\right.\right. \\
& \left.\left.+\varepsilon^{2}\left(\frac{\partial \phi}{\partial y}\right){ }^{2}\right]+g y\right\}+o\left(\varepsilon^{3}\right) .
\end{aligned}
$$

Since $\phi^{(2)}=0$, we can drop this term and proceed to separate the equation by order:

$$
p^{(1)}=-\rho \frac{\partial \phi(1)}{\partial t}-\rho g y
$$

and

$$
p^{(2)}=-\frac{\rho}{2}\left[\left(\frac{\partial \phi^{(1)}}{\partial x}\right)^{2}+\left(\frac{\partial \phi^{(1)}}{\partial y}\right)^{2}\right] .
$$

Substituting the velocity potential into the equation, one finds:

$$
\begin{aligned}
& p^{(1)}=-\rho g\left\{A_{1} e^{k_{1} y} \sin \left(k_{1} x-\omega_{1} t+\delta_{1}\right)\right. \\
& \left.+A_{2} e^{k_{2} y} \sin \left(k_{2} x-\omega_{2} t+\delta_{2}\right)+y\right\}
\end{aligned}
$$

for the first order, and

$$
\begin{aligned}
& P^{(2)}=-\frac{\rho}{2}\left\{\left[-\omega_{1} A_{1} e^{k}{ }_{1}^{y} \sin \left(k_{1} x-\omega_{1} t+\delta_{1}\right)\right.\right. \\
& \left.-\omega_{2} A_{2} e^{k_{2} y} \sin \left(k_{2} x-\omega_{2} t+\delta_{2}\right)\right]^{2} \\
& +\left[\omega_{1} A_{1} e^{k}{ }_{1}^{y} \cos \left(k_{1} x-\omega_{1} t+\delta_{1}\right)\right. \\
& \left.\left.+\omega_{2} A_{2} e^{k}{ }^{y} \cos \left(k_{2} x-\omega_{2} t+\delta_{2}\right)\right]^{2}\right\}
\end{aligned}
$$

for the second order. Note that this is identical to part of the 
equation for surface elevation. The second-order pressure may be reduced to:

$$
\begin{aligned}
& p^{(2)}=-\frac{\rho}{2}\left\{\omega_{1}{ }^{2} A_{1}{ }^{2} e^{2 k_{1} y}+\omega_{2}{ }^{2} A_{2}{ }^{2} e^{2 k_{2}-}\right. \\
& \left.-2 \omega_{1} \omega_{2} A_{1} A_{2} e^{\left(k_{1}+k_{2}\right) y} \cos \left[\left(k_{1}-k_{2}\right) x-\left(\omega_{1}-\omega_{2}\right) t+\delta_{1}-\delta_{2}\right]\right\}
\end{aligned}
$$

which indicates that the second-order pressure is composed of a component independent of time and at the-"difference frequency".

This is surprising since the equation for the free-surface elevation (eq. 18) includes terms at twice the incident wave frequencies and at the sum of these two frequencies. Using trigonometric relationships the first two terms in equation $(E-23)$ could be expanded to yield terms at twice the incident wave frequency. A term at the sum of the two incident wave frequencies may appear in the pressure computed using the velocity potentials representing wave diffraction or forced oscillation. It might also appear if the present analysis were carried to the third order. The derivation included here was intended to reveal the presence of a low-frequency component in the exciting force and has not been used to determine the other velocity potentials or carried beyond the second order.

3. List of Special Symbols for Appendix E.

$$
\begin{array}{ll}
A_{1}, A_{2} & =\text { Wave amplitudes } \\
g & =\text { Acceleration of gravity } \\
k_{1}, k_{2} & =\text { Wave numbers, } \frac{\omega_{1}}{g}, \frac{\omega_{2}}{g}, \text { respectively } \\
x, y & \text { Cartesian coordinates (x-directed parallel to the } \\
& \text { direction of wave propagation, y-directed vertically } \\
\delta_{1}, \delta_{2} & =\text { Wave phase angles } \\
n(x, t)= & \text { Free-surface elevation } \\
\phi(x, y, t)= & \text { Velocity potential } \\
\omega_{1}, \omega_{2}= & \text { Wave circular frequencies }
\end{array}
$$




\section{Proposed Oak Harbor Floating Breakwater (Davidson, 1971).}

a. Physical Properties.

$$
\begin{aligned}
& \mathrm{m}= \text { mass per unit length }=25.1 \mathrm{slug} / \mathrm{ft} \\
& \mathrm{I}= \text { mass moment of inertia }=621 \mathrm{slug}-\mathrm{ft}^{2} / \mathrm{ft} \\
& x_{\mathrm{g}}= \begin{array}{r}
\text { x-coordinate of center of gravity }=0.0 \mathrm{ft} . \\
\quad \text { on centerline) }
\end{array} \\
& \mathrm{y}_{\mathrm{g}}= y \text {-coordinate of center of gravity }=-2.34 \mathrm{ft} \text { (below WL) } \\
& \mathrm{KH}_{22}= 64.5 \mathrm{lb} / \mathrm{ft} / \mathrm{ft} \\
& \mathrm{KH}_{33}= 1,165 \mathrm{ft}-1 \mathrm{~b} / \mathrm{ft} \\
& \mathrm{All} \text { other } \mathrm{KH}_{\mathrm{ij}}=0
\end{aligned}
$$

b. Mooring Line Tension Response (change per unit displacement).

$$
\begin{aligned}
& \frac{\Delta T}{\Delta x}=1,170 \mathrm{lb} / \mathrm{ft} \\
& \frac{\Delta T}{\Delta y}=281 \mathrm{lb} / \mathrm{ft} \\
& \frac{\Delta T}{\Delta \theta}=1,710 \mathrm{lb}
\end{aligned}
$$

c. $\quad$ Computed Mooring Spring Constants (depth $=29.5$ feet)

$$
\begin{aligned}
& \mathrm{KM}_{11}=119 \mathrm{lb} / \mathrm{ft} / \mathrm{ft} \\
& \mathrm{KM}_{12}=-5.24 \mathrm{lb} / \mathrm{ft} / \mathrm{ft} \\
& \mathrm{KM}_{13}=166 \mathrm{lb} / \mathrm{ft} \\
& \mathrm{KM}_{21}=-5.73 \mathrm{lb} / \mathrm{ft} / \mathrm{ft} \\
& \mathrm{KM}_{22}=10.2 \mathrm{lb} / \mathrm{ft} / \mathrm{ft} \\
& \mathrm{KM}_{23}=-3.37 \mathrm{lb} / \mathrm{ft} \\
& \mathrm{KM}_{31}=1601 \mathrm{~b} / \mathrm{ft} \\
& \mathrm{KM}_{32}=2.06 \mathrm{lb} / \mathrm{ft}
\end{aligned}
$$




$$
\mathrm{KM}_{33}=282 . \mathrm{ft}-\mathrm{lb} / \mathrm{ft}
$$

Rectangular Breakwater Tested by Nece and Richey (1972).

Physical Properties (at prototype scale). The cross section is a rectangle of beam 10 feet and draft 5 feet.

$$
\begin{aligned}
\mathrm{m} & =100 \mathrm{slugs} / \mathrm{ft} \\
\mathrm{I} & =2,740 \mathrm{slug}-\mathrm{ft}^{2} / \mathrm{ft} \\
\mathrm{x}_{\mathrm{g}} & =0.0 \mathrm{ft} \text { (on centerline) } \\
\mathrm{y}_{\mathrm{g}} & =-1.0 \mathrm{ft} \text { (below } \mathrm{WL}) \\
\mathrm{KH}_{22} & =640 \mathrm{lb} / \mathrm{ft} / \mathrm{ft} \\
\mathrm{KH}_{33} & =5,340 \mathrm{ft}-\mathrm{lb} / \mathrm{ft}
\end{aligned}
$$

All other $\mathrm{KH}_{i j}=0$

Al1 $\mathrm{KM}_{i j}=0$.

Rectangular Breakwater Tested by Sutko and Haden (1974).

Physical Properties of Mode1. The cross section is a rectangle of beam 0.333 feet and draft 0.222 feet.

$$
\begin{aligned}
& \mathrm{m}=0.143 \mathrm{slug} / \mathrm{ft} \\
& \mathrm{I}=0.023 \mathrm{slug}-\mathrm{ft}^{2} / \mathrm{ft} \\
& \mathrm{x}_{\mathrm{g}}=0.0 \mathrm{ft} \text { (on centerIine) } \\
& \mathrm{y}_{\mathrm{g}}=-0.123 \mathrm{ft} \text { (below WL) } \\
& \mathrm{KH}_{22}=20.7 \mathrm{lb} / \mathrm{ft} / \mathrm{ft} \\
& \mathrm{KH}_{33}=0.244 \mathrm{ft}-1 \mathrm{~b} / \mathrm{ft} \\
& \mathrm{A} 11 \text { other } \mathrm{KH}_{i j}=0 \\
& \mathrm{Al1} \mathrm{\textrm {KM } _ { i j }}=0
\end{aligned}
$$

Alaska-Type Breakwater.

a. Physical Properties.

$\mathrm{m} \quad=62.3 \mathrm{slug} / \mathrm{ft}$ 
$I=4,234$ slug-ft/ft

$x_{g}=0.0 \mathrm{ft}$

$y_{\mathrm{g}}=-1.3 \mathrm{ft}$ (below WL)

$\mathrm{KH}_{22}=528 \mathrm{lb} / \mathrm{ft} / \mathrm{ft}$

$\mathrm{KH}_{33}=32,885 \mathrm{ft}-\mathrm{lb} / \mathrm{ft}$

All other $\mathrm{KH}_{\mathrm{ij}}=0$

b. Mooring Line Tension Response (change per unit displacement).

$\frac{\Delta \mathrm{T}}{\Delta \mathrm{x}}=97.0 \mathrm{lb} / \mathrm{ft}$

$\frac{\Delta \mathrm{T}}{\Delta \mathrm{y}}=90.5 \mathrm{lb} / \mathrm{ft}$

$\frac{\Delta \mathrm{T}}{\Delta \theta}=-572 \quad 1 \mathrm{~b}$

c. Computed Mooring Spring Constants ( $\mathrm{tide}=+7.0$ feet).

$\mathrm{KM}_{11}=3.0 \mathrm{lb} / \mathrm{ft} / \mathrm{ft}$

$\mathrm{KM}_{12}=0.245 \mathrm{lb} / \mathrm{ft} / \mathrm{ft}$

$\mathrm{KM}_{13}=-9.23 \mathrm{lb} / \mathrm{ft}$

$\mathrm{KM}_{21}=0.302 \mathrm{lb} / \mathrm{ft} / \mathrm{ft}$

$\mathrm{KM}_{22}=1.91 \mathrm{lb} / \mathrm{ft} / \mathrm{ft}$

$\mathrm{KM}_{23}=-2.68 \mathrm{lb} / \mathrm{ft}$

$\mathrm{KM}_{31}=-9.52, \mathrm{~b} / \mathrm{ft}$

$\mathrm{KM}_{32}=-2.82 \mathrm{lb} / \mathrm{ft}$

$\mathrm{KM}_{33}=88.9 \mathrm{ft}-1 \mathrm{~b} / \mathrm{ft}$

5. Friday Harbor Breakwater.

a. Physical Properties.

$$
\begin{aligned}
& m=61.02 \text { slugs } / f t \\
& I=4,160 \text { slugs }-\mathrm{ft}^{3} / \mathrm{ft}
\end{aligned}
$$




$$
\begin{aligned}
& x_{g}=0.0 \mathrm{ft} \text { (on centerline) } \\
& y_{g}=-0.49 \mathrm{ft} \text { (below } W \mathrm{~L} \text { ) }
\end{aligned}
$$$$
\mathrm{KH}_{22}=884 \mathrm{lb} / \mathrm{ft} / \mathrm{ft}
$$$$
\mathrm{KH}_{33}=55,610 \mathrm{ft}-1 \mathrm{~b} / \mathrm{ft}
$$

$$
\text { All other } \mathrm{KH}_{i j}=0
$$

b. Mooring Line Tension Response.

$$
\begin{aligned}
& \frac{\Delta T}{\Delta x}=222 \quad 1 \mathrm{~b} / \mathrm{ft} \\
& \frac{\Delta T}{\Delta y}=25.0 \quad 1 \mathrm{~b} / \mathrm{ft} \\
& \frac{\Delta T}{\Delta \theta}=657 \quad 1 \mathrm{~b}
\end{aligned}
$$

c. Computed Mooring Spring Constants (tide $=+5.33$ feet).

$$
\begin{aligned}
& \mathrm{KM}_{11}=6.46 \mathrm{lb} / \mathrm{ft} / \mathrm{ft} \\
& \mathrm{KM}_{12}=0.510 \mathrm{lb} / \mathrm{ft} / \mathrm{ft} \\
& \mathrm{KM}_{13}=18.5 \mathrm{ft}-1 \mathrm{~b} / \mathrm{ft} / \mathrm{ft} \\
& \mathrm{KM}_{21}=0.510 \mathrm{lb} / \mathrm{ft} / \mathrm{ft} \\
& \mathrm{KM}_{22}=0.390 \mathrm{lb} / \mathrm{ft} / \mathrm{ft} \\
& \mathrm{KM}_{23}=1.71 \mathrm{ft}-1 \mathrm{~b} / \mathrm{ft} / \mathrm{ft} \\
& \mathrm{KM}_{31}=18.61 \mathrm{~b} / \mathrm{ft} \\
& \mathrm{KM}_{32}=1.71 \mathrm{lb} / \mathrm{ft} \\
& \mathrm{KM}_{33}=64.6 \mathrm{ft}-1 \mathrm{~b} / \mathrm{ft}
\end{aligned}
$$




\section{APPENDIX G}

\section{DATA SUMMARY SHEETS FOR FRIDAY HARBOR}

FLOATING BREAKWATER (WINTER 1975)

Appendix $G$ contains a summary of all the data recorded at the Friday liarbor breakwater during the winter season of 1975 . Seven tapes were recorded during this period, with a total of 95 records. The tapes are numbered in sequence from FH7-1 through FH13-8. The date of each tape is given along with the pertinent statistical data for each record in the tapes. The number of days and hours given for each record begins with the day and hour given for that particular tape.

All minimum and maximum values are measured from zero mean. The transmitted wave data were digitally high-pass filtered (cutoff frequency was 0.05 hertz) before these calculations to remove tidal draft. 


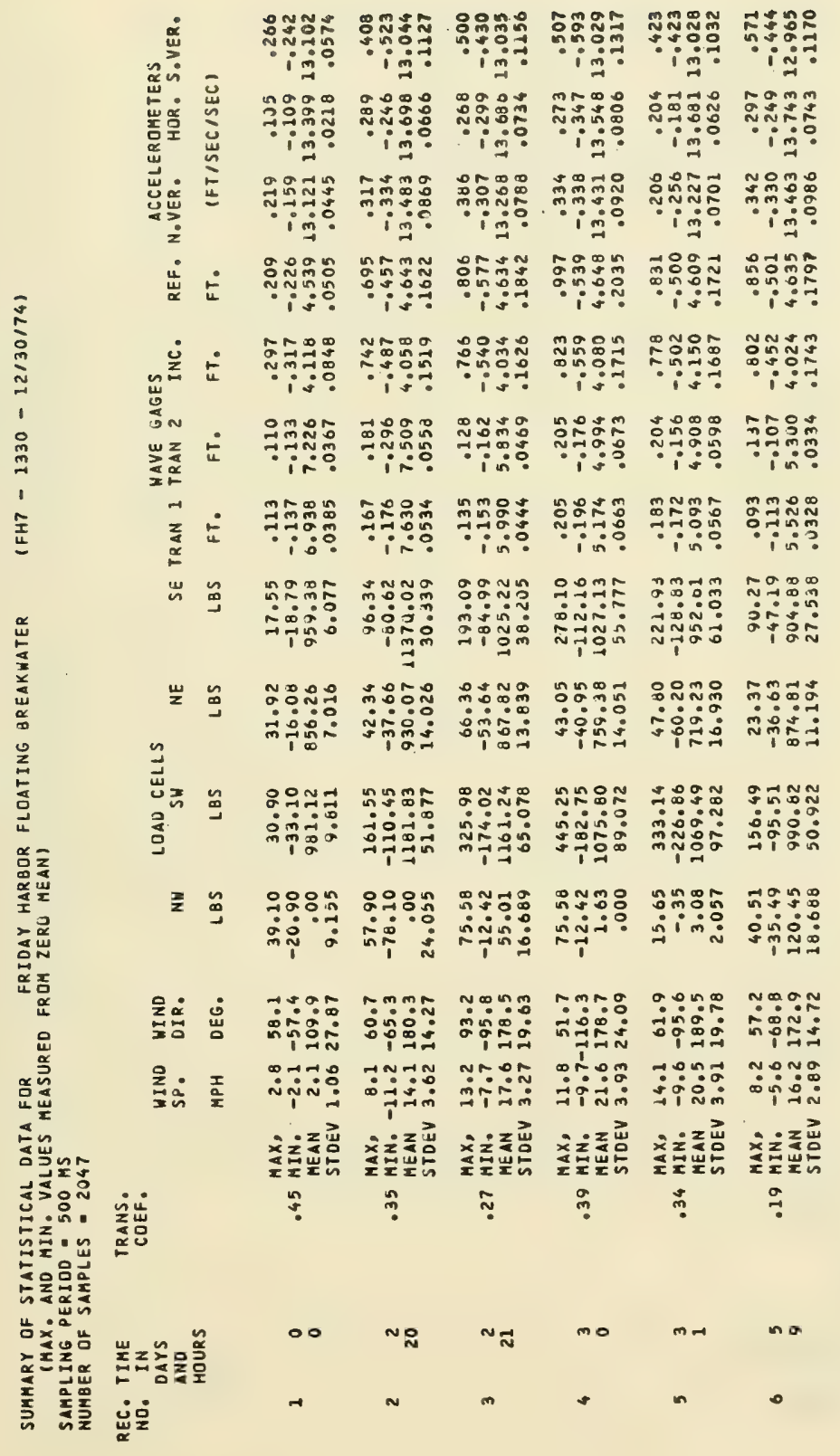




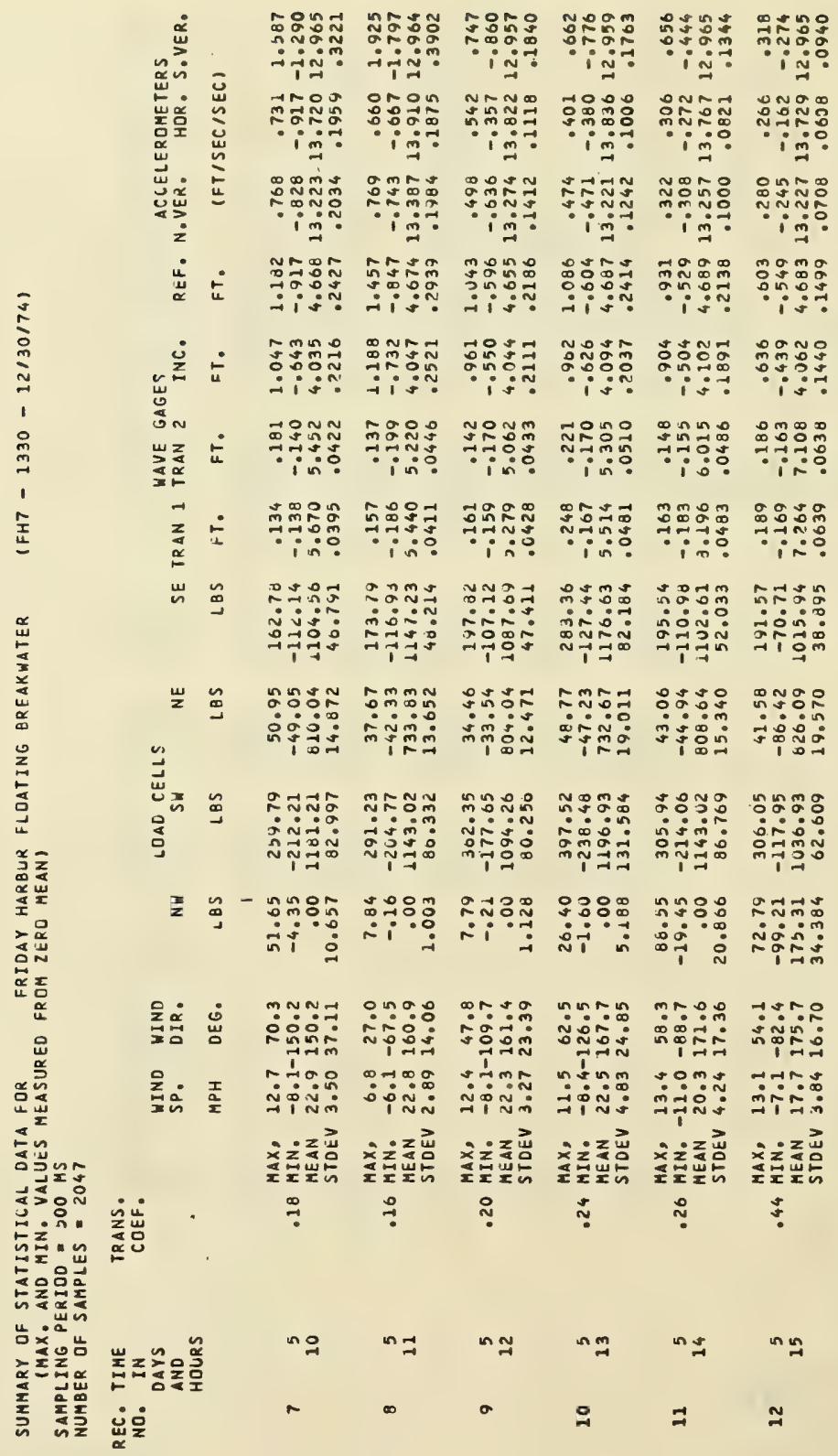




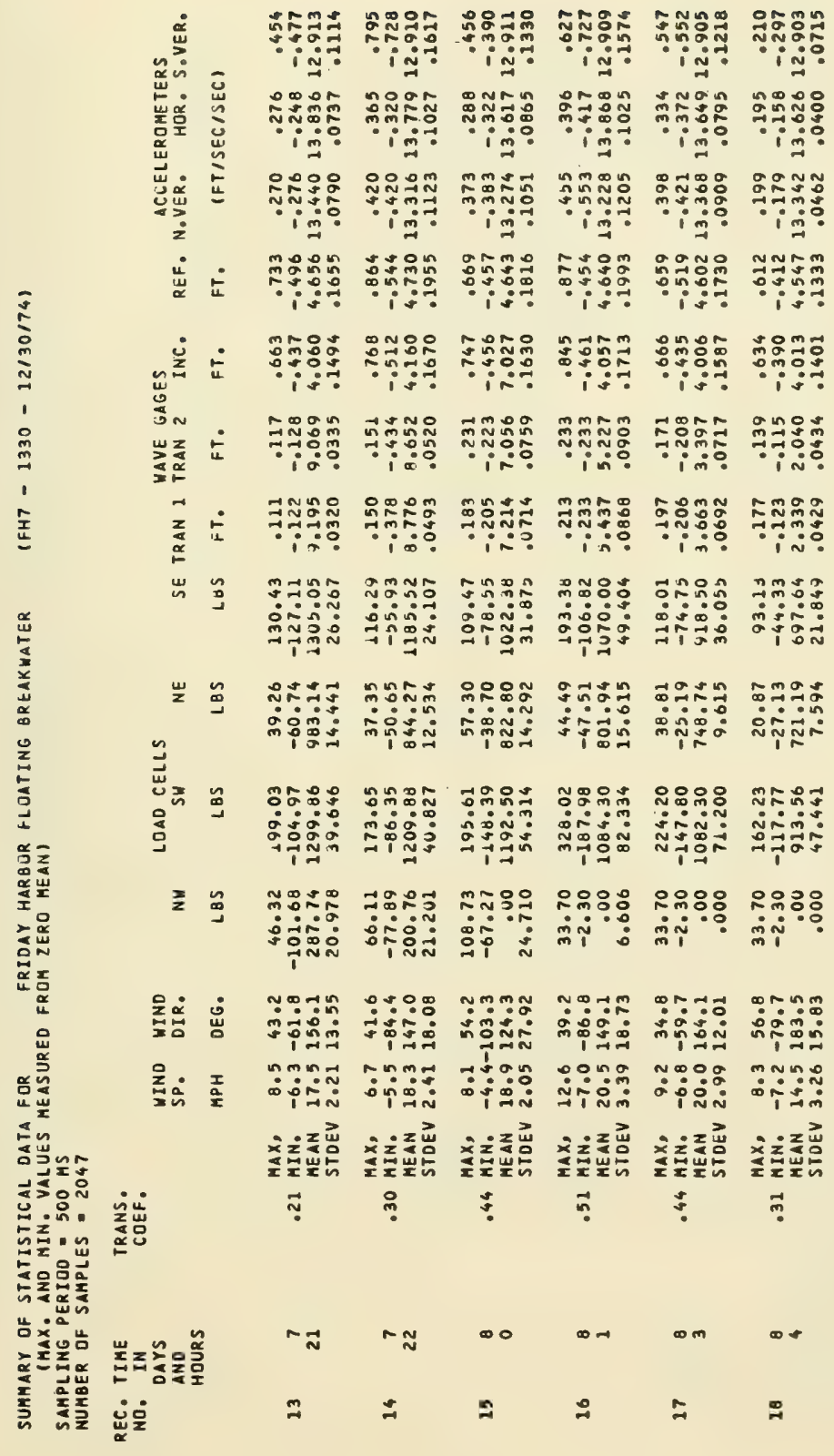




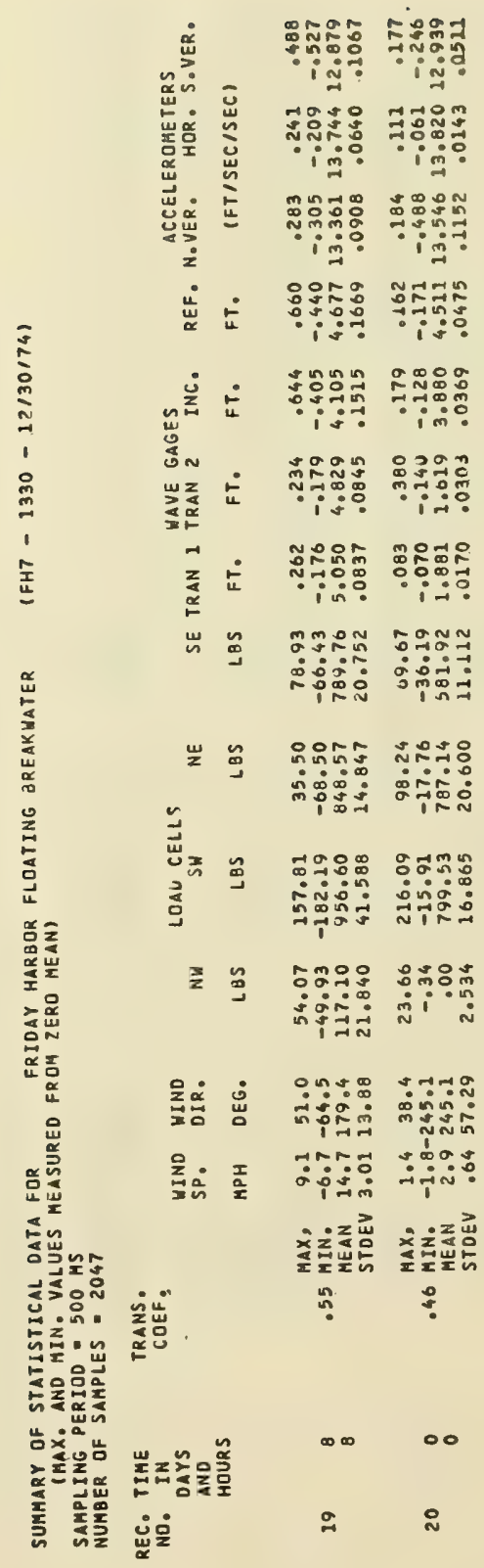




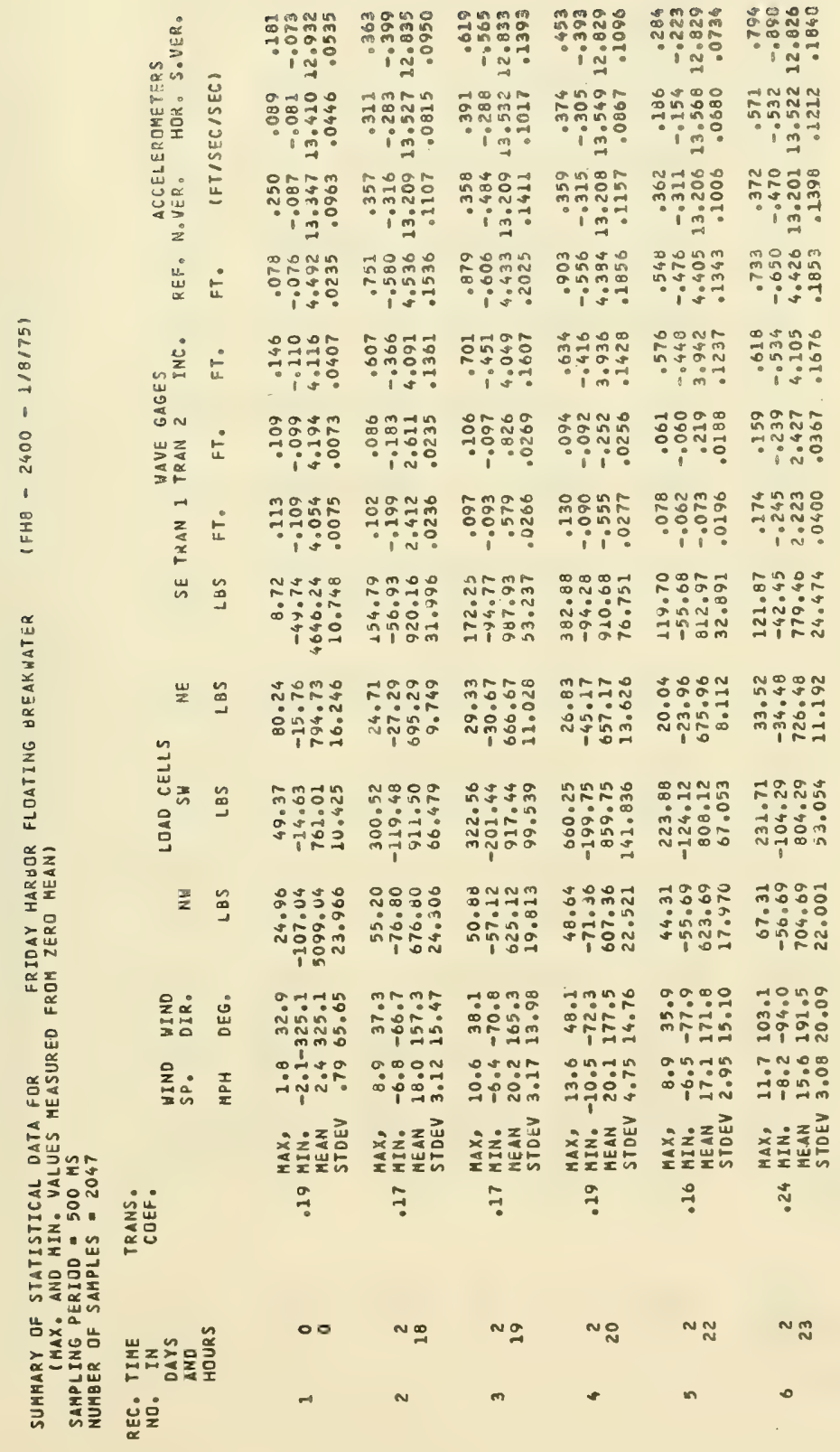




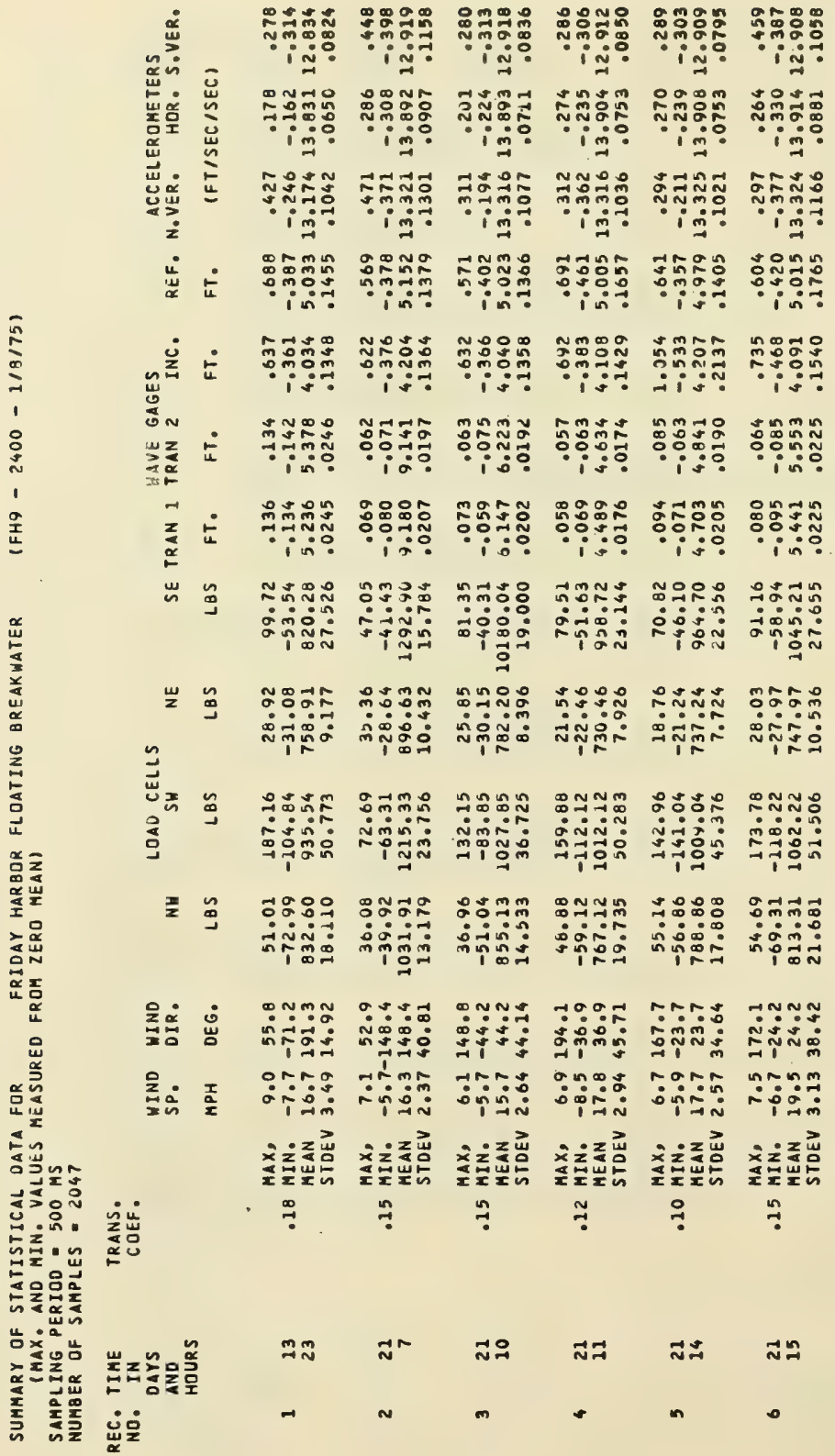




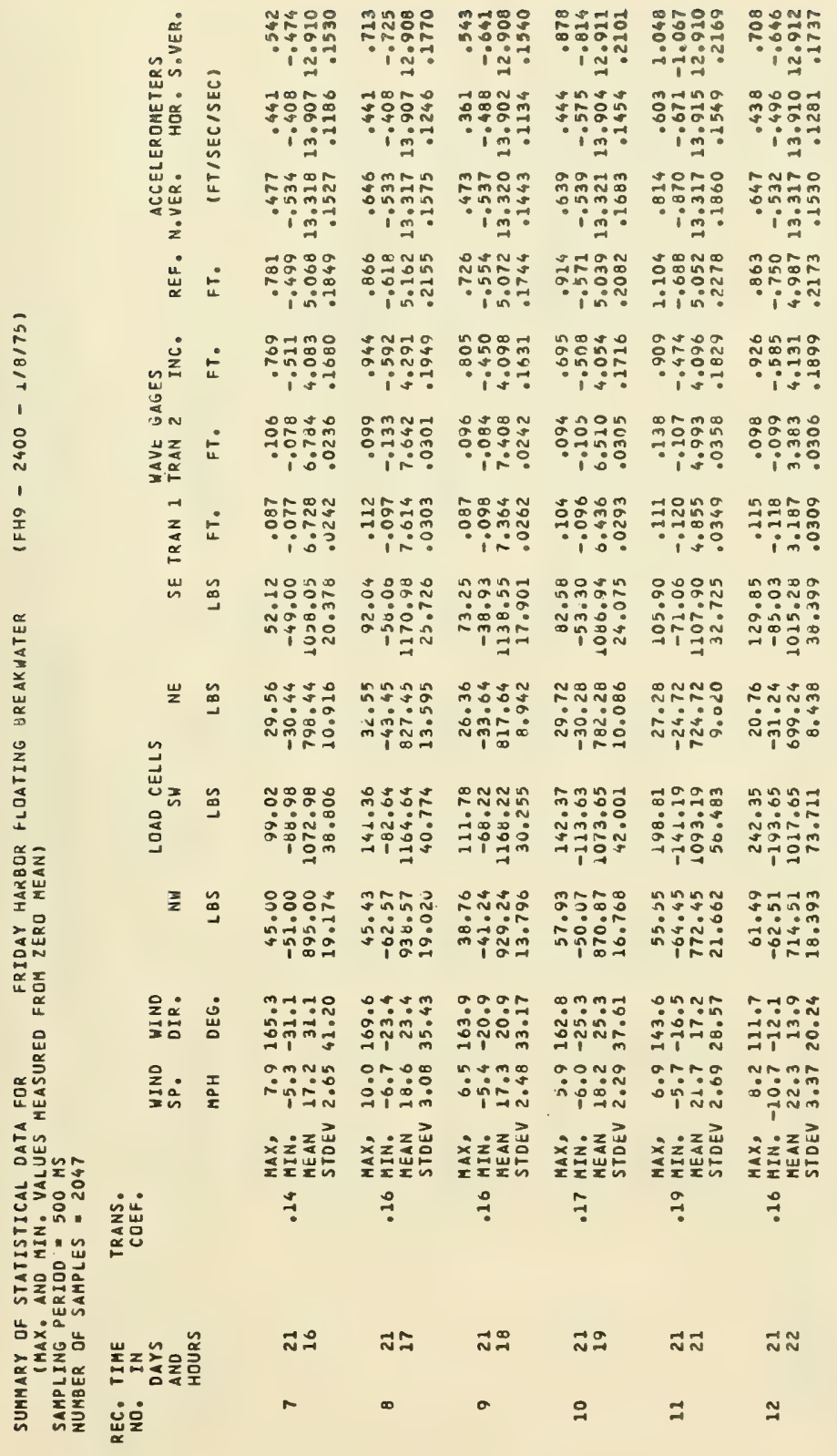




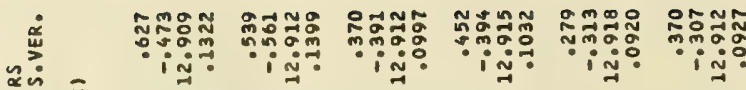

点焉 出 总

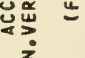

soon

ANo

moo in

?กำ

ษับต

บำกㄱำ

명ำ

?.?

ธักีี กับํํㅇ

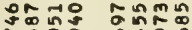

$\rightarrow$

im

ตับ

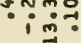

㟧秕

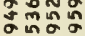

요요요

i:?

? mom

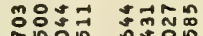
ำำ

\section{立 \& \\ 造}

온ำ

?:

$0 m m \infty$

ำำ저

: $: \div$

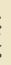

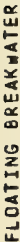

唫政

운

唋

둔

요

옴

品步

En

岂出

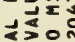

كुㅇ․․

=

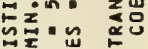

둔은묻

的

u. a

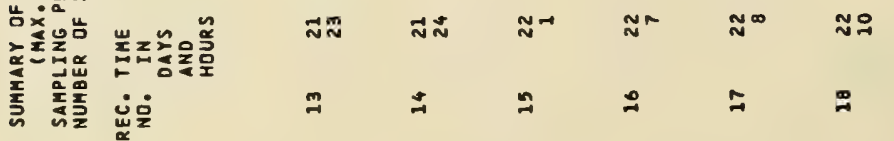

กำกัก 崩

z

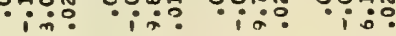

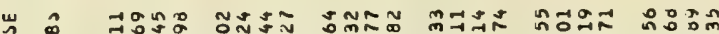

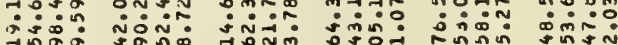

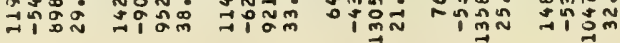

山 n ninin mr

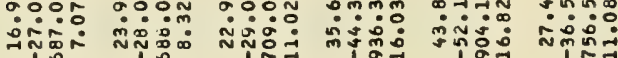
蛋

₹

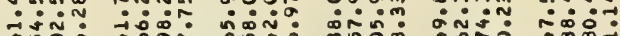

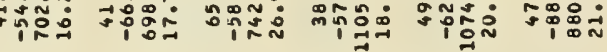

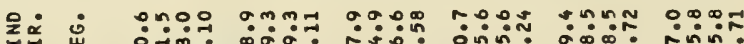
范

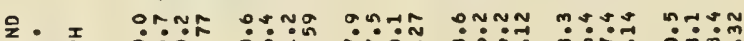

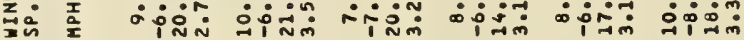

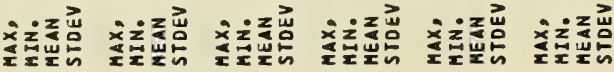
$\stackrel{\circ}{\because}$
$\because$
$\div$
$\cong$

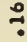
$\because$ 


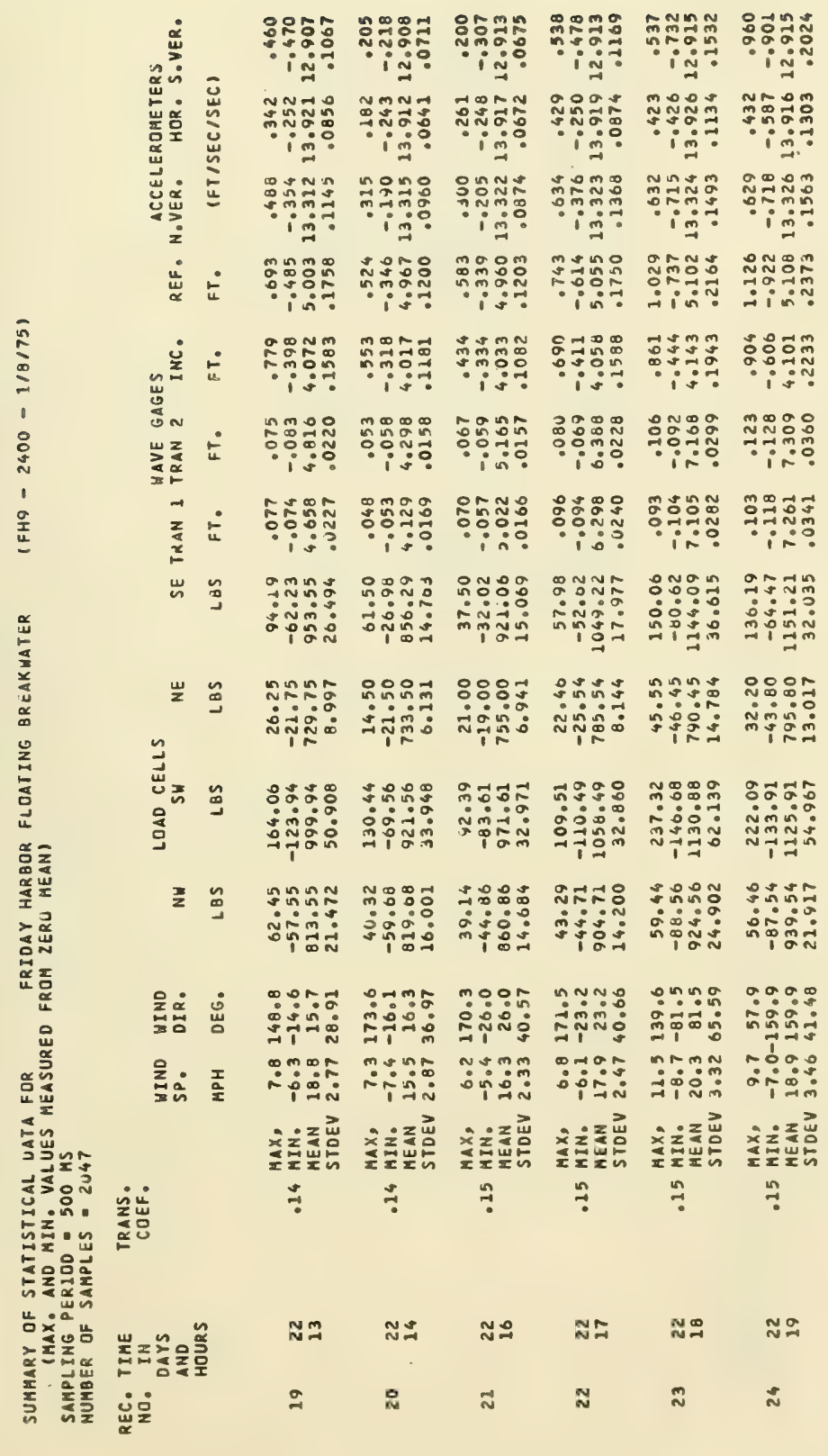




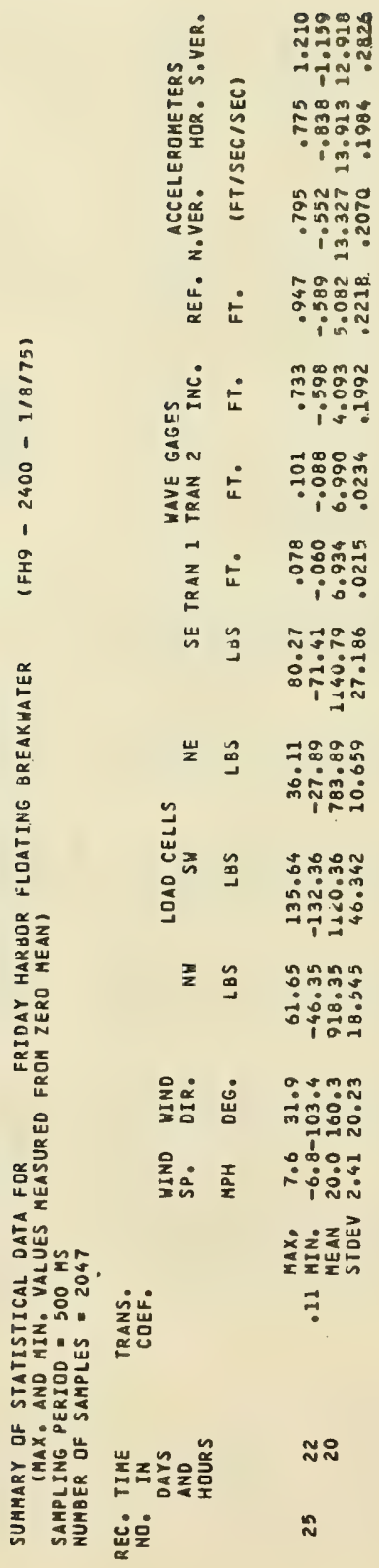




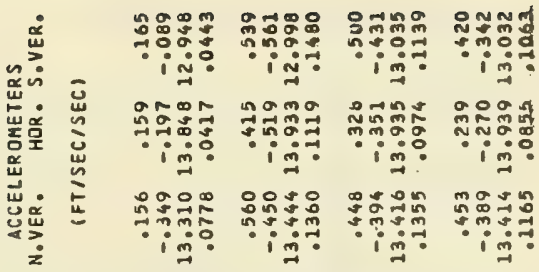

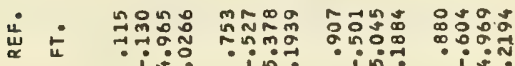

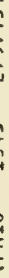

焉

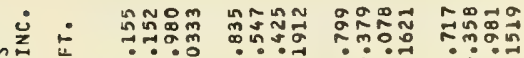

出

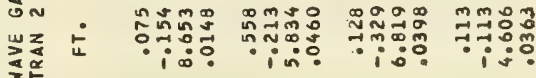

- NEีN

z

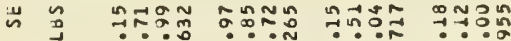

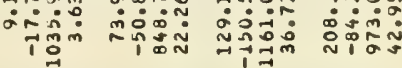

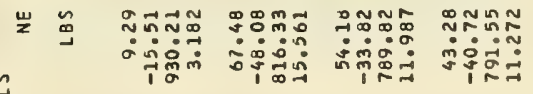

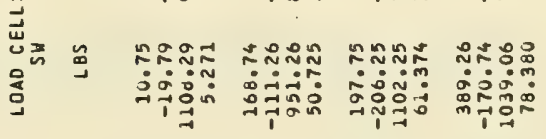

客

$\ll \stackrel{\circ}{\sim}$

z 물: $\lim _{m}$ a

ax

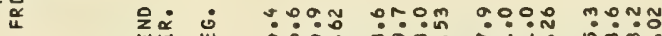

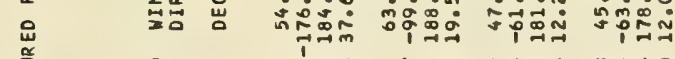

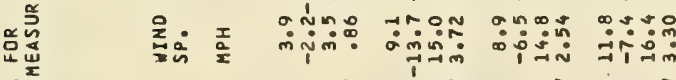

$\mathbb{1}$

出

$0 \operatorname{lin}^{2}$

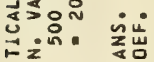

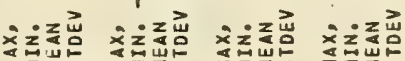

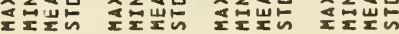

$\backsim \sim_{w} \cong 0$

in

พิ

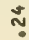

$\stackrel{m}{\sim}$

ㅇㅇㅇ뭉

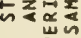

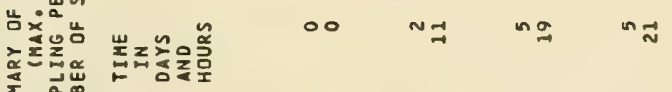

齐 臸 


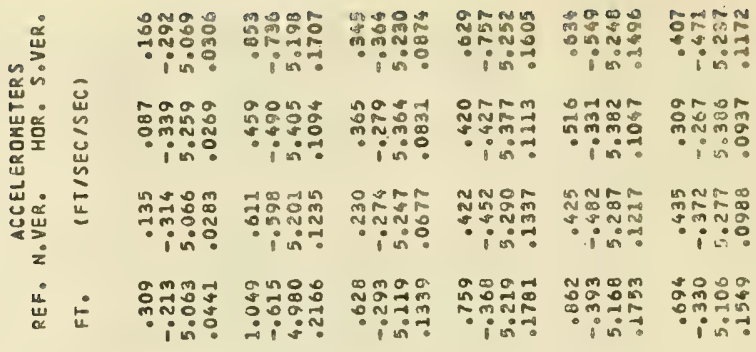
总 Ja nam Un

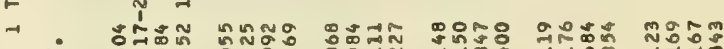
z

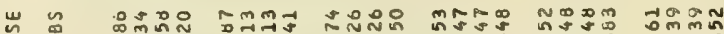

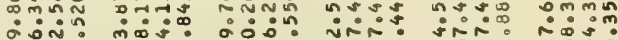

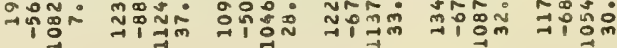

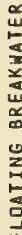

总

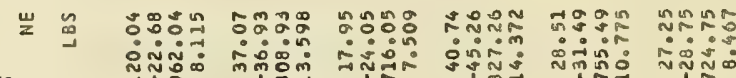
n

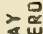

感

운둥

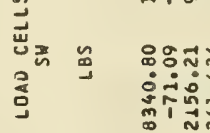

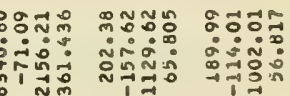

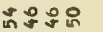

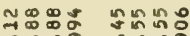

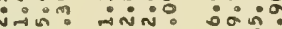

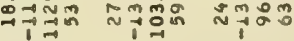

— กํำ

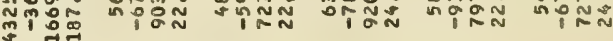

旁

\section{$\cos 20$}

$+\infty \infty m 000$

$\because \because:$

$\because \because \div 00 \infty \infty$

㝕运

iimi

유뭉

$\sin :$

에교

$\min$

$\rightarrow \infty \infty$

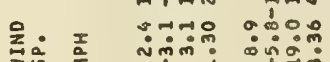

0.0

mbNo

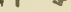

$\rightarrow \frac{1}{20}$

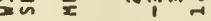

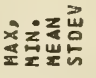

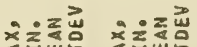

$\because \cdots$

anm

Dलm

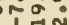

$\rightarrow 1 \rightarrow$ क

तิ ลีं

:

$\stackrel{0}{\circ}$

$\because$

x릴⿺

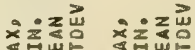

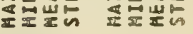

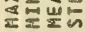

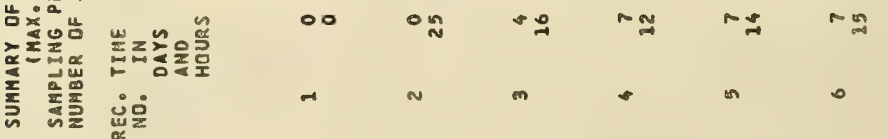




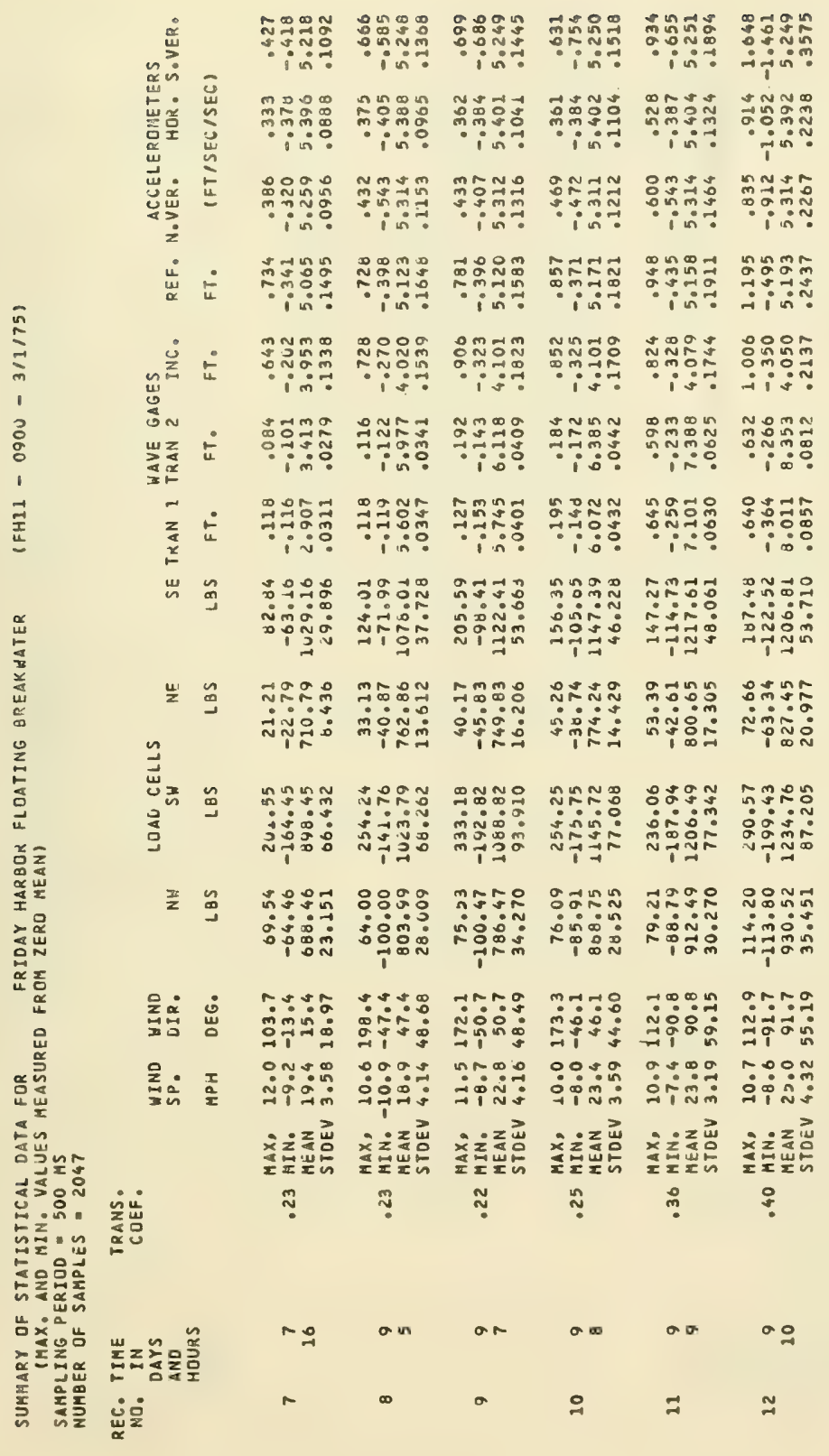




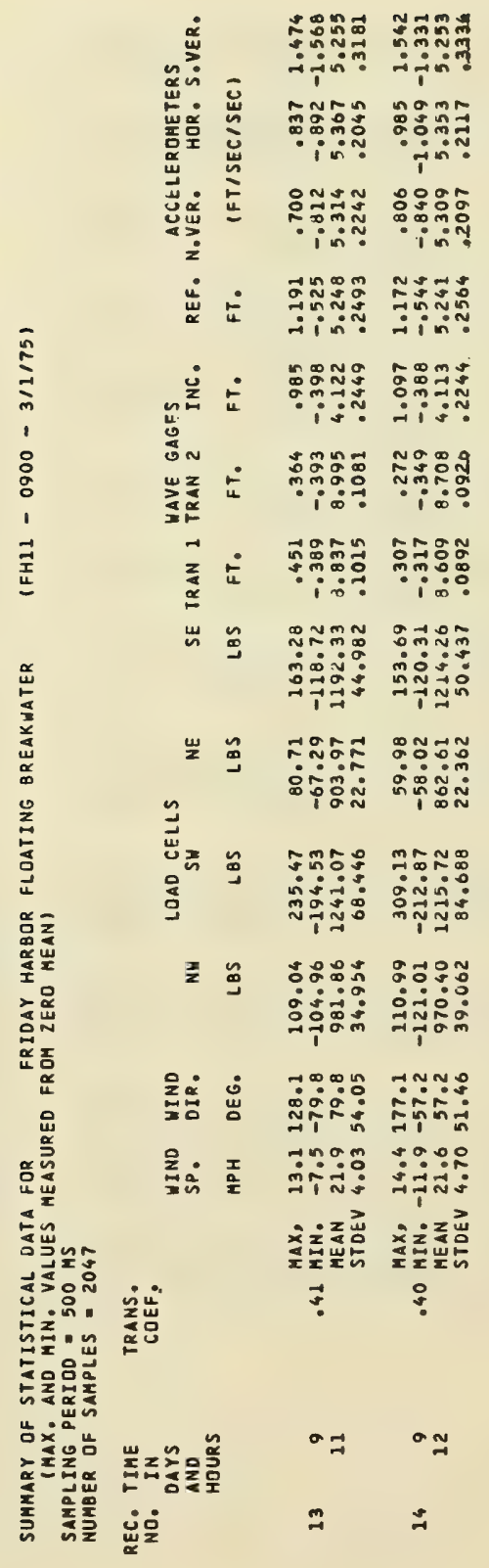




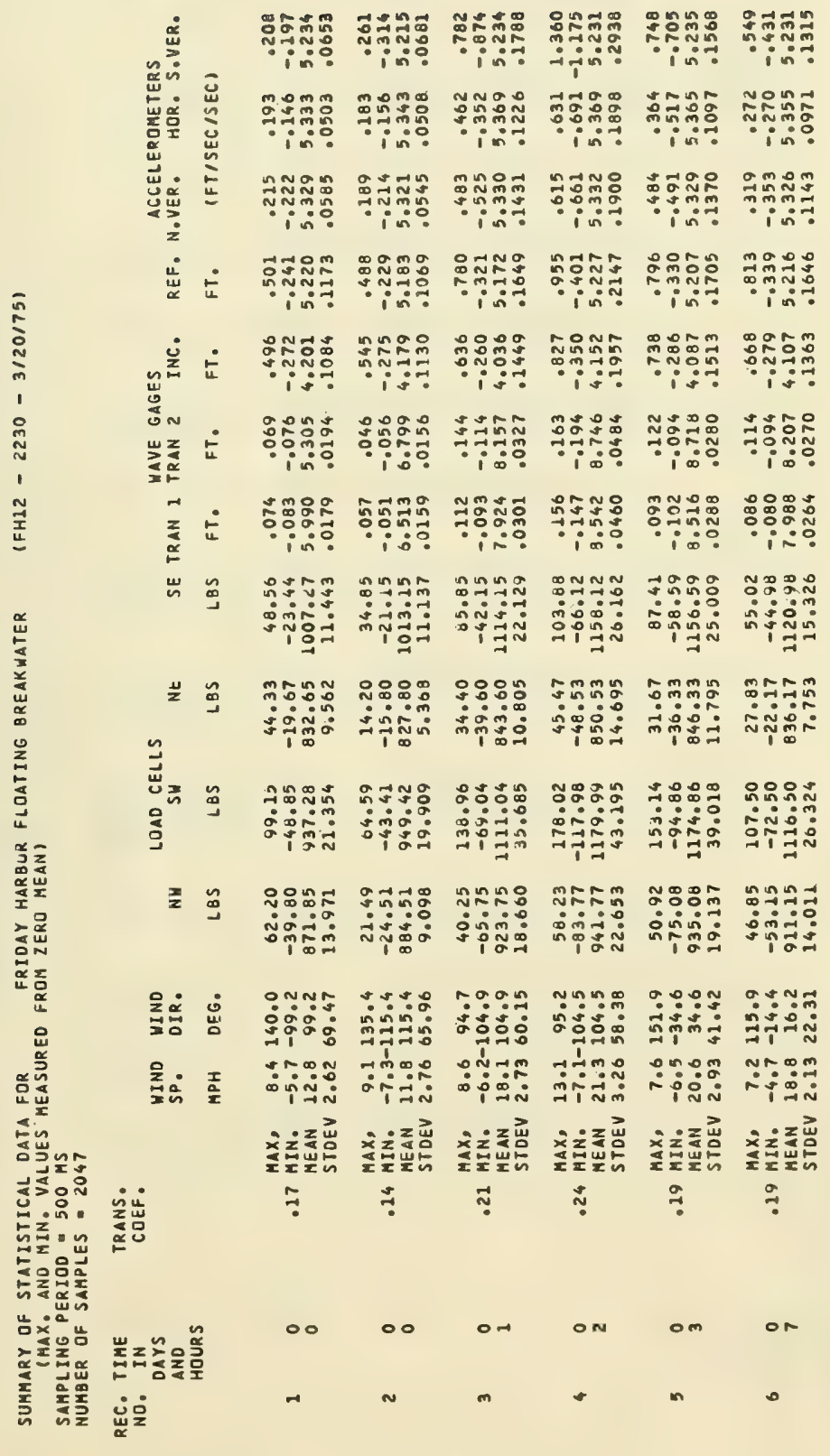




\begin{tabular}{|c|c|c|c|c|c|c|c|}
\hline 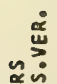 & & 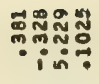 & 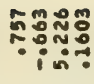 & 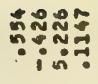 & 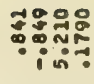 & 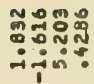 & $\stackrel{-1}{-}$ \\
\hline 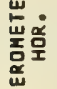 & 总 & 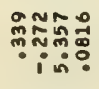 & 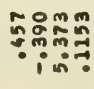 & 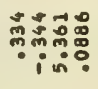 & 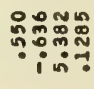 & $\stackrel{m}{\overrightarrow{0}}$ & \\
\hline ب̂. & $\underline{\underline{z}}$ & 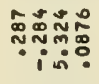 & בิ & 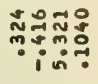 & 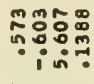 & \begin{tabular}{c}
\multirow{4}{*}{} \\
\multirow{2}{*}{}
\end{tabular} & \\
\hline$\ddot{u}$ & $\dot{ }$ & 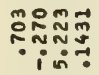 & 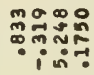 & 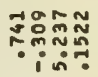 & 竎 & & \\
\hline
\end{tabular}

出

嵌

\section{ธิ}

㠇

$\operatorname{lon} \pi$

0000

20용

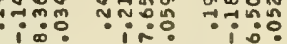

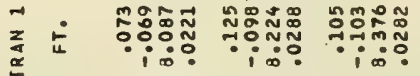

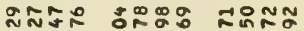

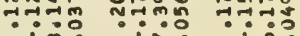

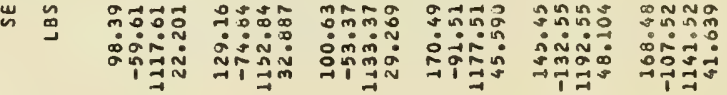

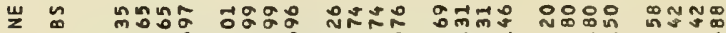

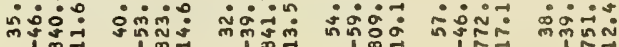

\begin{tabular}{|c|c|c|c|c|c|}
\hline 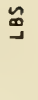 & 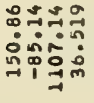 & 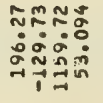 & 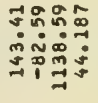 & 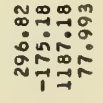 & 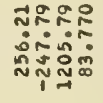 \\
\hline
\end{tabular}

z

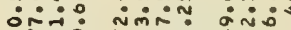

일ำ

ํำ

5000 กิด

i용

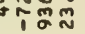

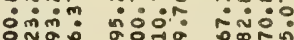

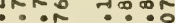

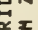

은 迹

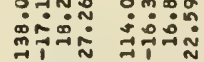

Ommm

$\rightarrow \infty$

$\rightarrow \infty \infty$

iกn 崖

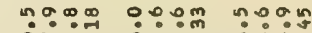

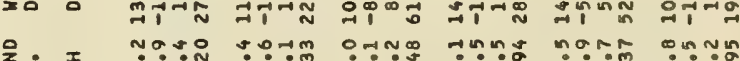

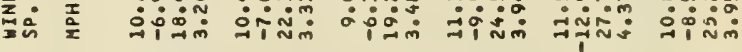

通灵是.

z

出出嵒

文妀常

춘현

x를

출련

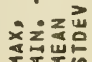

추룸

$\because$

ำ

․

․

$\stackrel{\sim}{*}$

$\stackrel{ }{?}$

동으물

的㩆

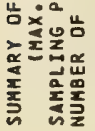

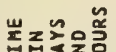

$\circ 0$

$0=$

$\circ \stackrel{m}{\rightarrow}$

ㅇำ

on

후울

$\boldsymbol{\infty}$

o

$\stackrel{\circ}{-1}$

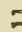

N 


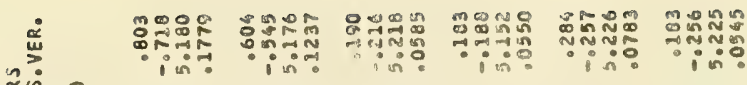

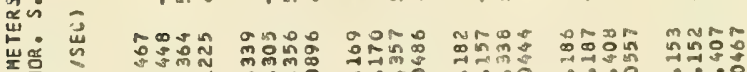

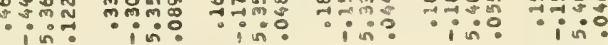

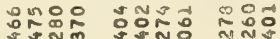

in

$\rightarrow$

$\because \because 30$

NNO

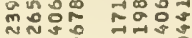

$\because \because$ :

z

$\stackrel{\text { m }}{N}$

崫

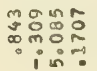

NoOm nms

bast

in

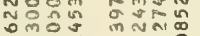

N⿴囗十ㅇำ

는

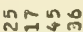

is?

$\because$ in?

ivi:

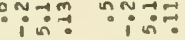

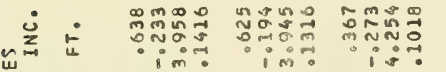

mNำ

and

ans

$\because \because 00$

$\cos 2$

m.7.․․․

岁

$\geq \geq$

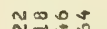

$\checkmark N N=$

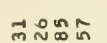

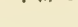

is

.$$
\text { sis }
$$

$\underset{\square}{\stackrel{3}{a}}$

虫

in

$\because \because \% \div$

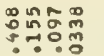

손ำ

an $0 N$

$\because \dot{0}$ :

$\because: 0$

:ㅇํㅇ

ํํํํำ

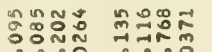

ธี

$5 \mathrm{~m} N$

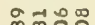
in.

in:

$\because \because 0$

$\because 0$ m

i: $: 0$

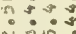

บํํำ

이요

คลำ

우유근

요요

का

$\therefore \infty 0^{\circ}$

ํํㅇㅇㅠ:

กำ.

in

$\infty$ N

$0 \%$

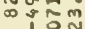

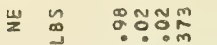

ํำํำ ㄴำ

制

$$
\text { (1) }
$$
ํํN유

ํํำ

争: :

NRin mo:

$-109$

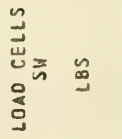

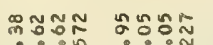

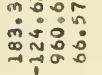

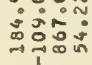

ํํㅇㅇㅛ

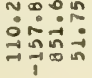

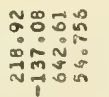

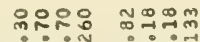

ำ

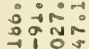

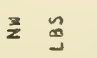

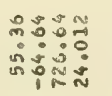

3:00

내용

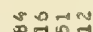

오은ํㅠ

कीज证然

学总

는 든

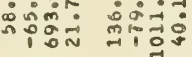

iิ

nim

O̊N:

บ.*.

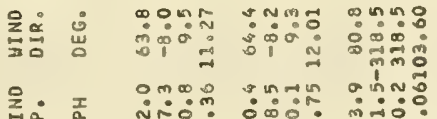

0000

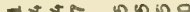

近

余

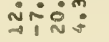

$x \geq z i m$

程崖占

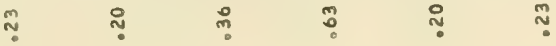

这㟧

0

$\min _{\rightarrow \rightarrow 1}$

영요

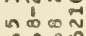

$\because 0 \%$

m웅:

ำ

-

भनज न

$\because \because \cdots$ m $\rightarrow$ -

In

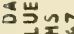

दो $>0$ 잉

․․․

战空

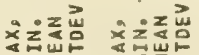

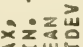

का

का in:

ㅇํㅁำ

战嵒衣

แa

焉

플 $\approx$ 气

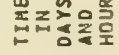

훙무

$m$

ก ำ

ก ำ

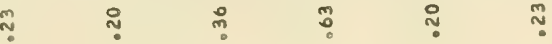

을

$x \dot{z} \geq \vec{z}$

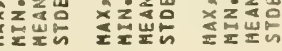

$\stackrel{m}{\sim}$ 


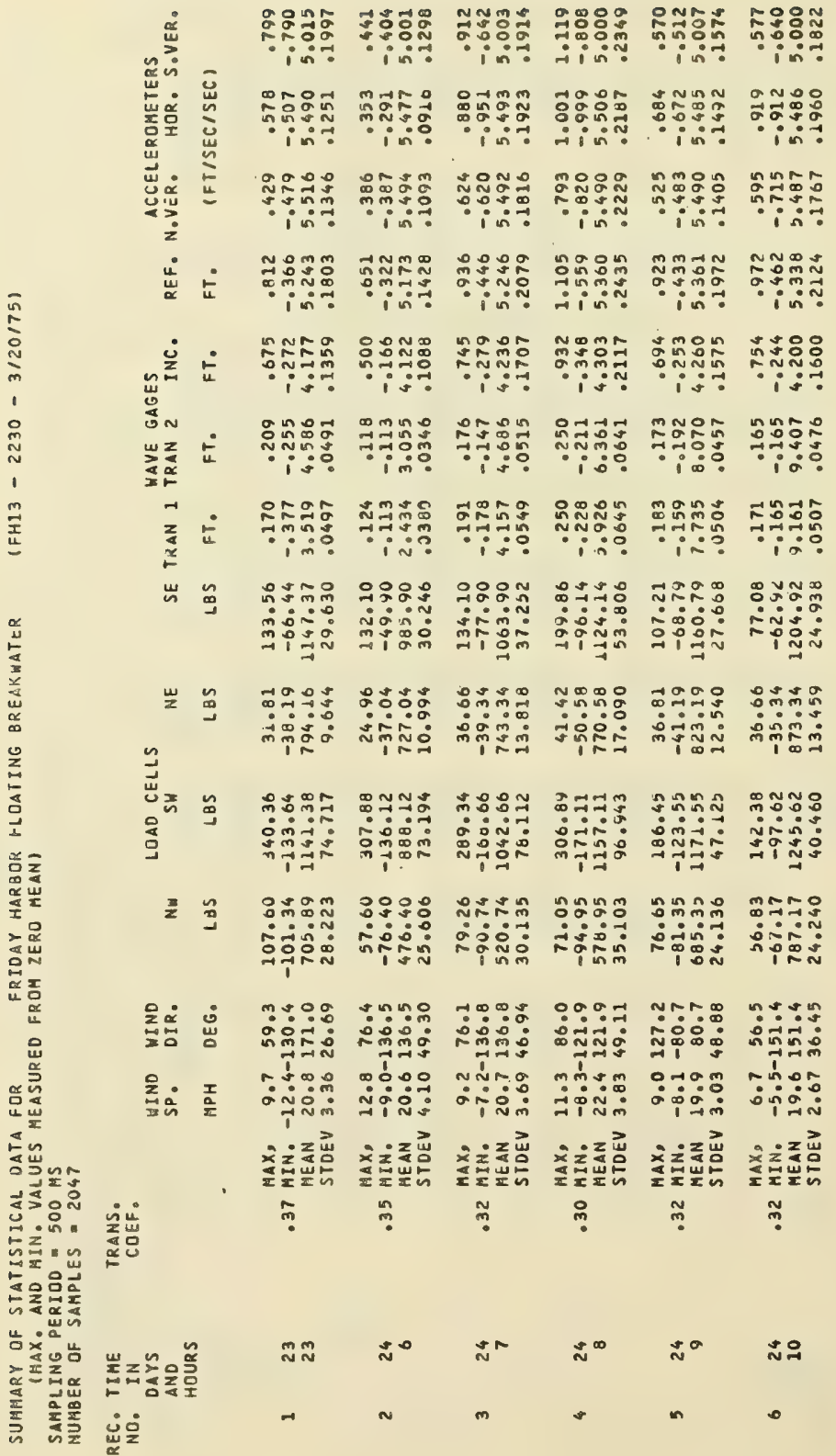




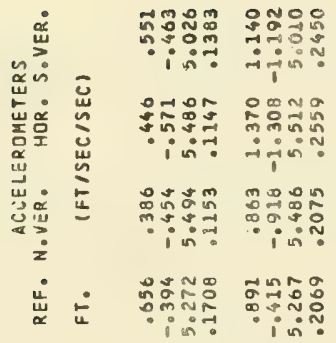

落 岁 $1+\overrightarrow{0}$

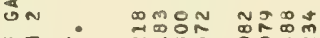
wz $\rightarrow \quad$ ormm $\quad$ anm $n$ z

แ Dinin 00 : $\operatorname{lat}_{\rightarrow \rightarrow 1}^{\infty}$ in

und

鲜文

욤

崩

뜸

世 mañ

岃

$=$ n $\approx$ \%

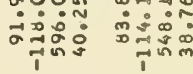

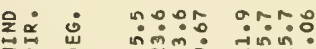

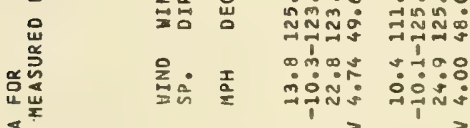

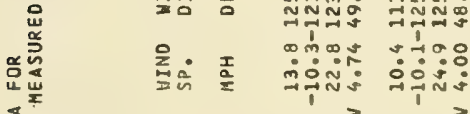

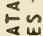

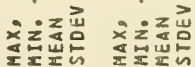

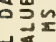

ड़ㅇㅇㅇㅇ

代的的出

กั ?

음뭄

的文乐空

告:

告造荝

กัศ

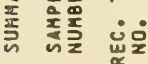




\section{APPENDIX $\mathrm{H}$}

INCIDENT AND TRANSMITTED WAVE SPECTRAL PLOTS

Appendix $H$ contains the incident and transmitted wave spectral plots dlong with the corresponding transmission response curve for 11 representative records. The data for the first nine were recorded at Friday Harbor, Washington, during the winter of 1975. Figures H-11 and : 12 were computed from similar data collected in Alaska during the winters of 1974 and 1975.

The original time series were high-pass filtered at a cutoff frequency of 0.05 hertz to remove tidal drift. Each series consisted of 2,048 data samples and were sampled at a period of 0.5 second for the Friday Harbor data and 0.44 second for the Alaska data.

The standard deviations and corresponding overall transmission coefficients for each of the Friday Harbor plots are given in Appendix G. 
INJIJIJ JJO2 NOISSIWSNYYI

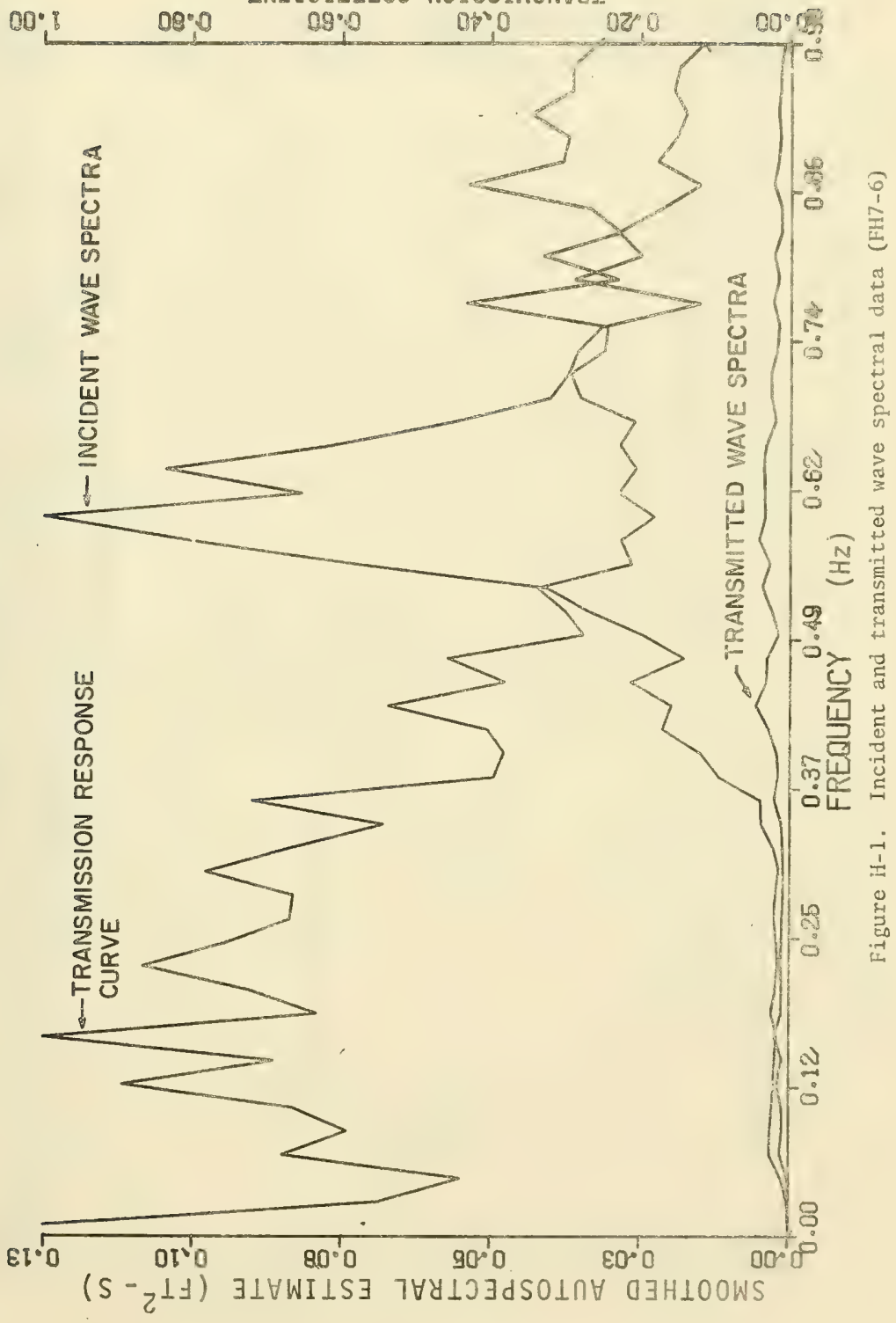




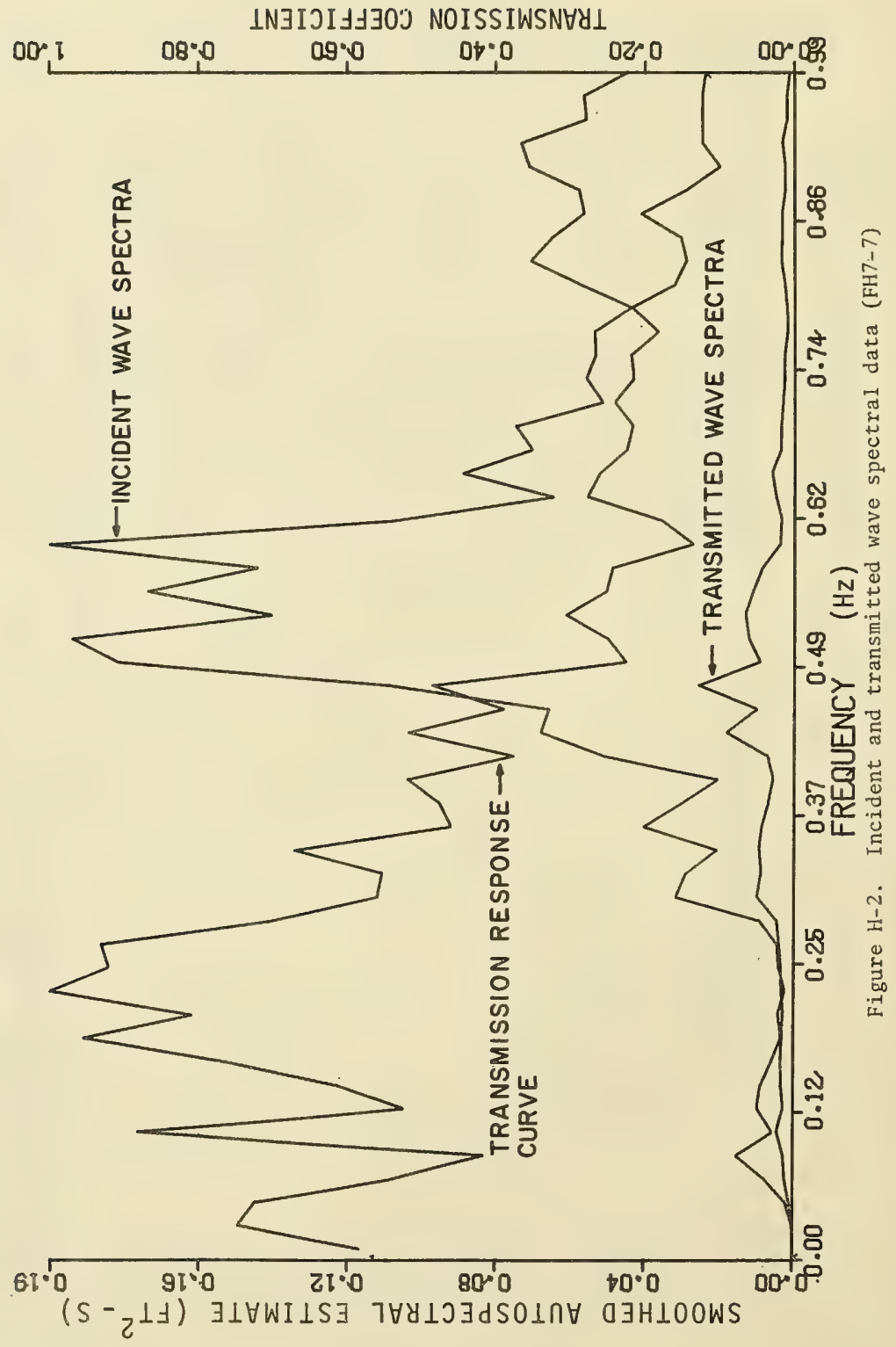




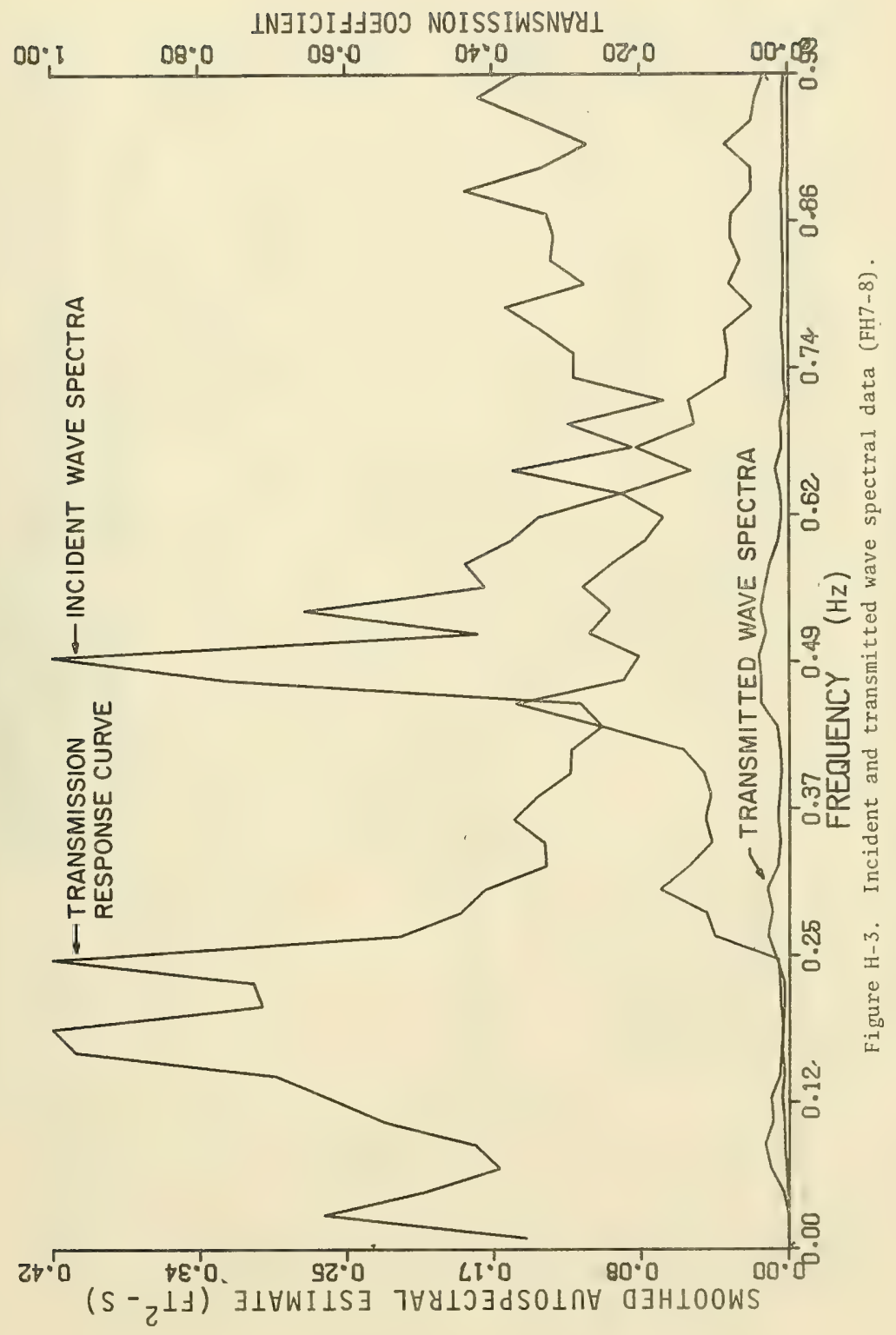




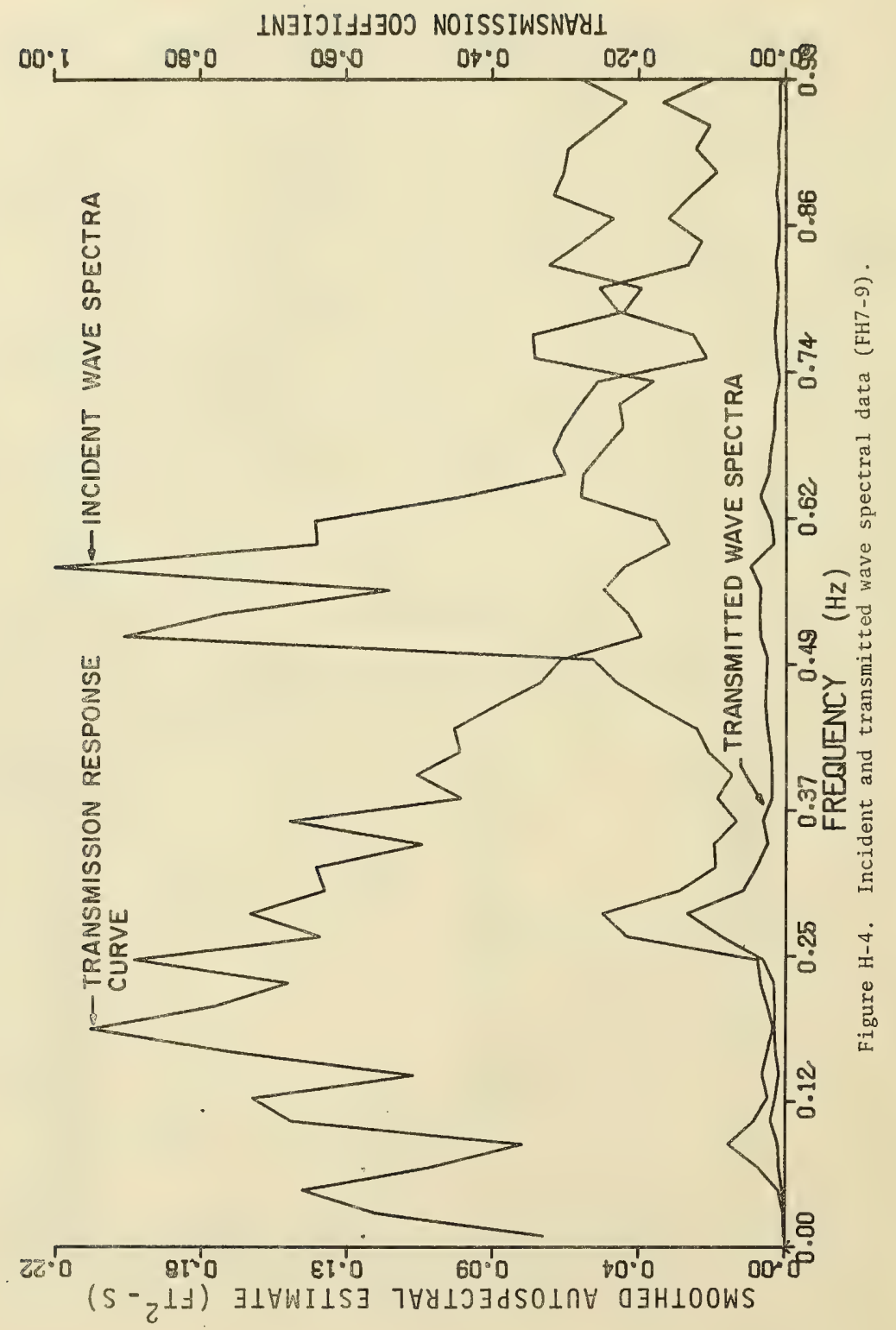




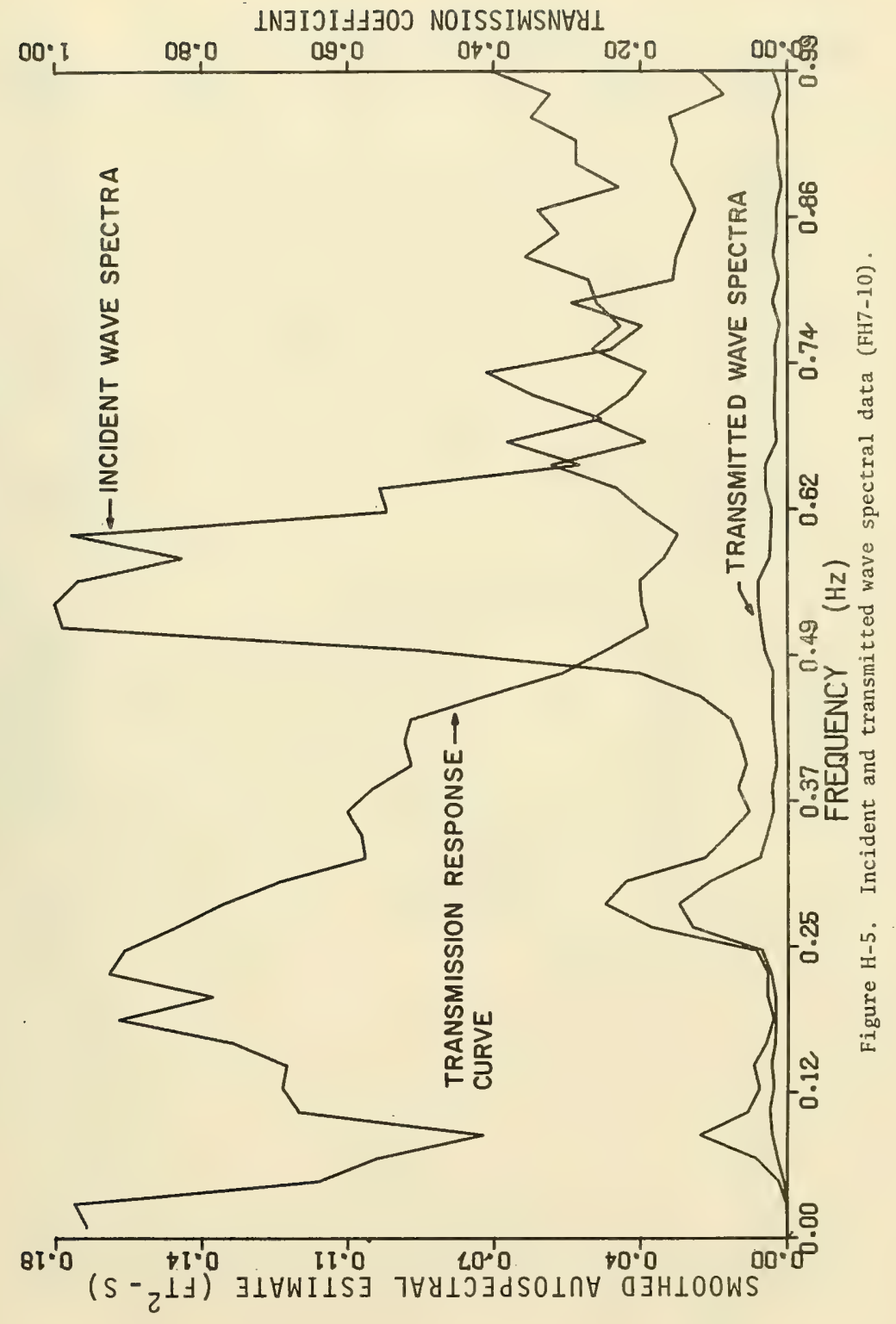




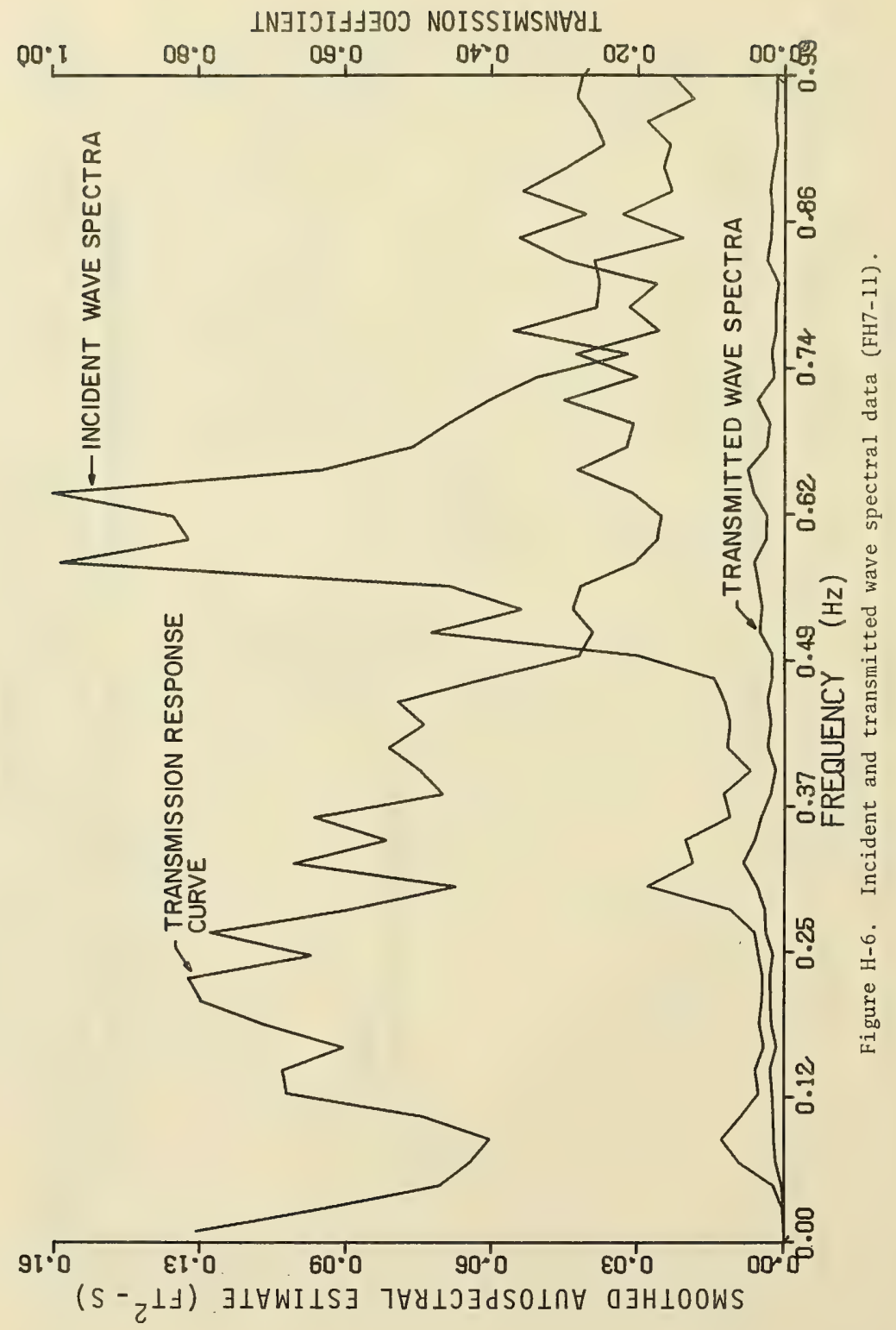




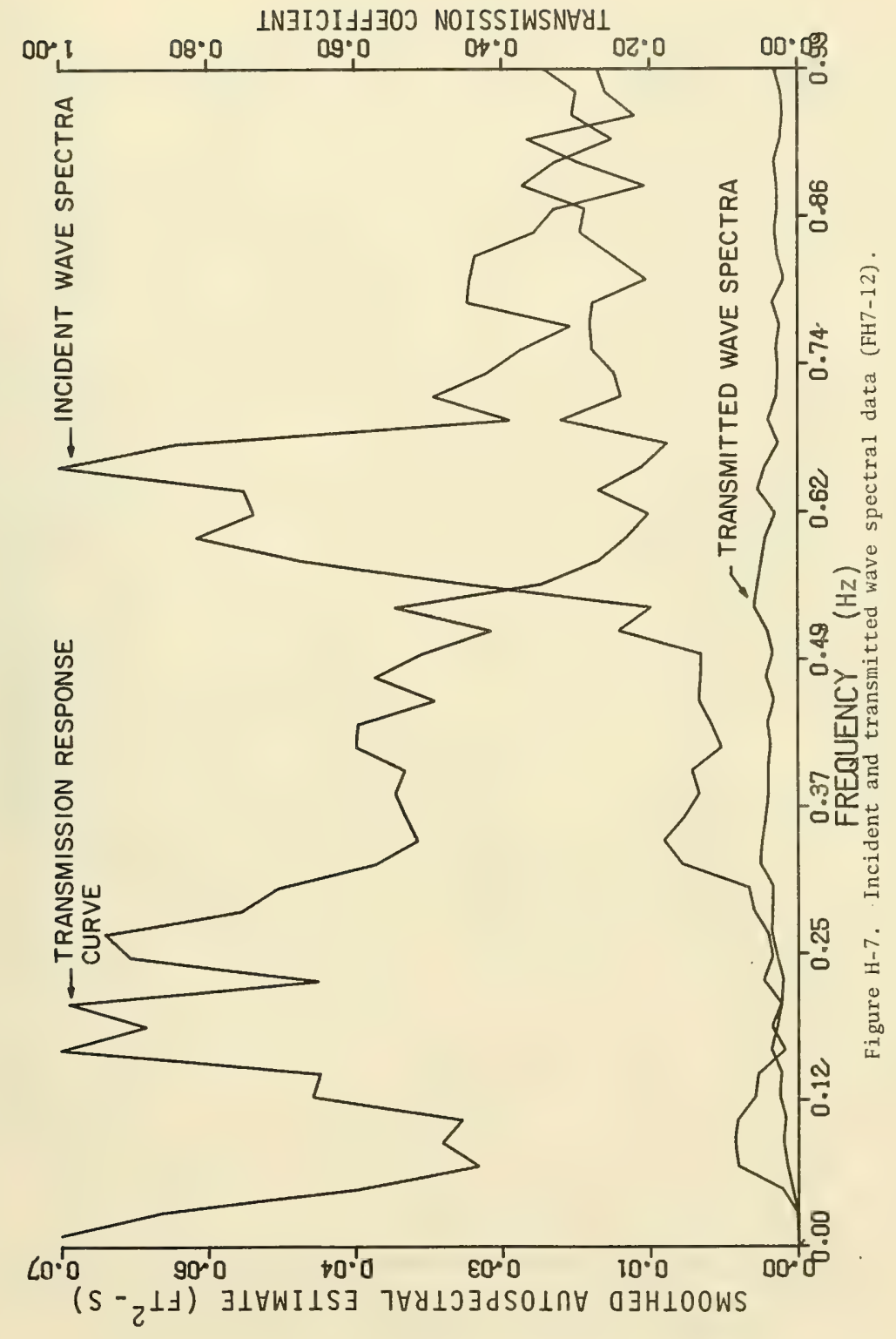




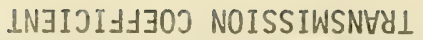

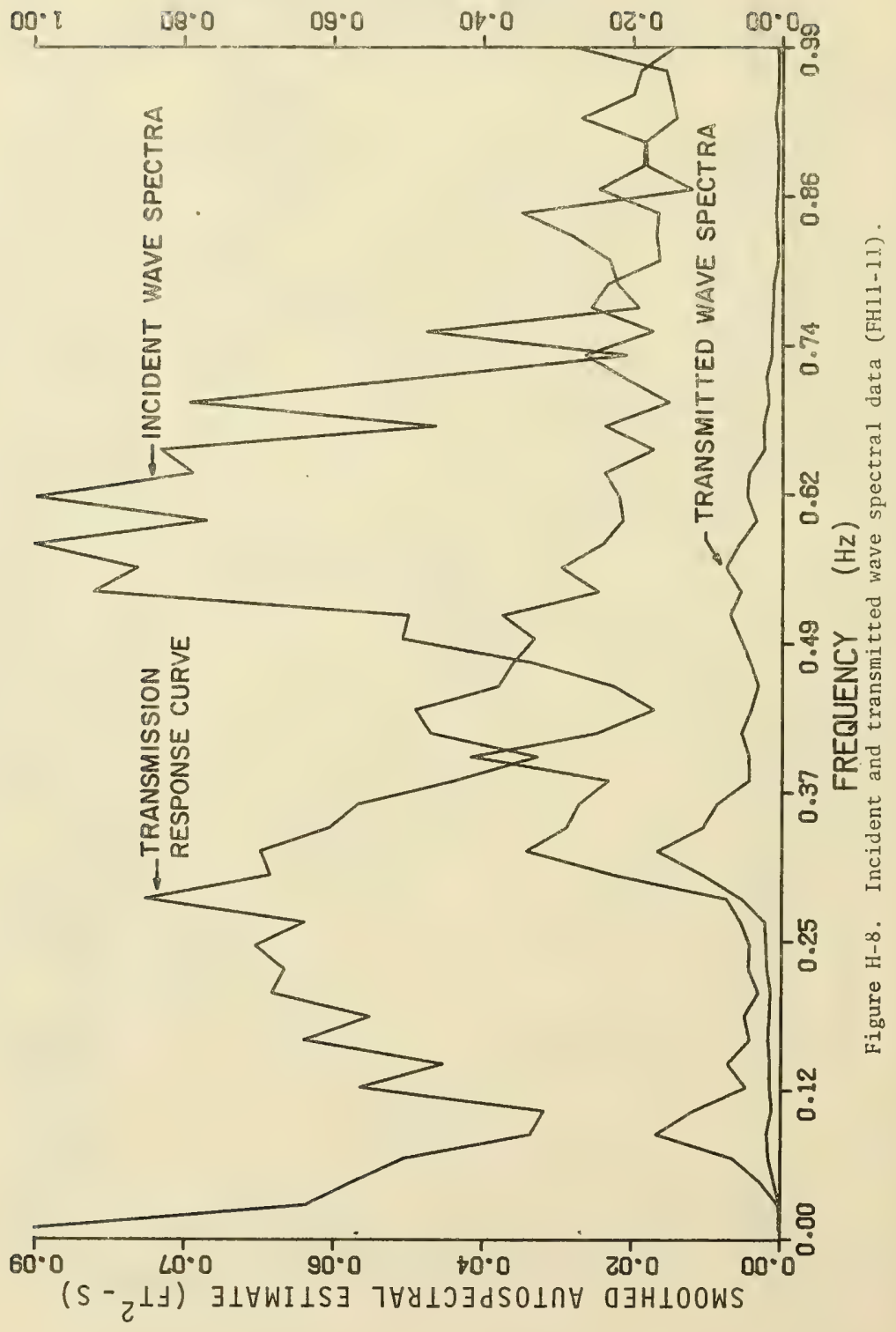




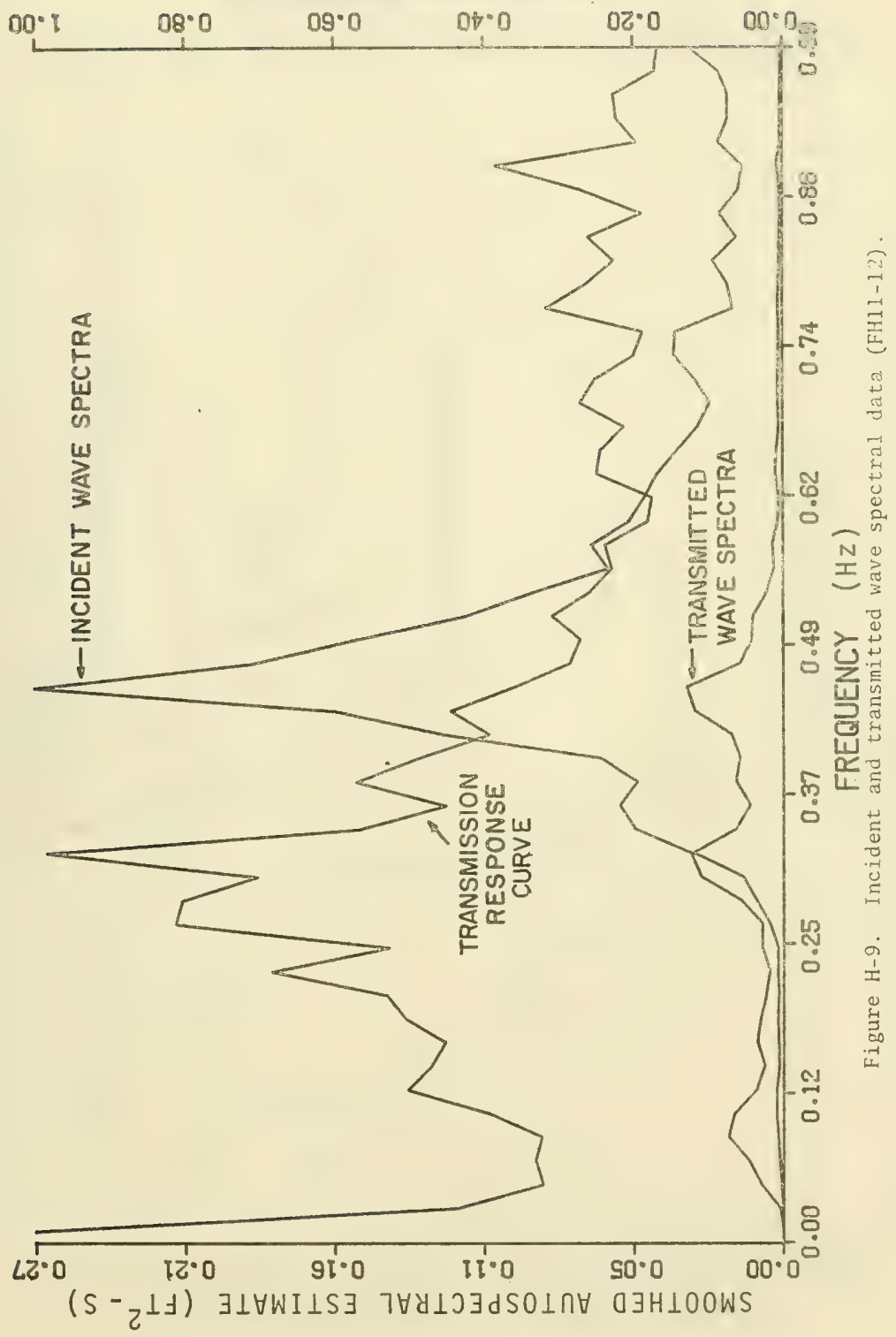


INJIJI $J \pm J O J$ NOISSIWSNHYI

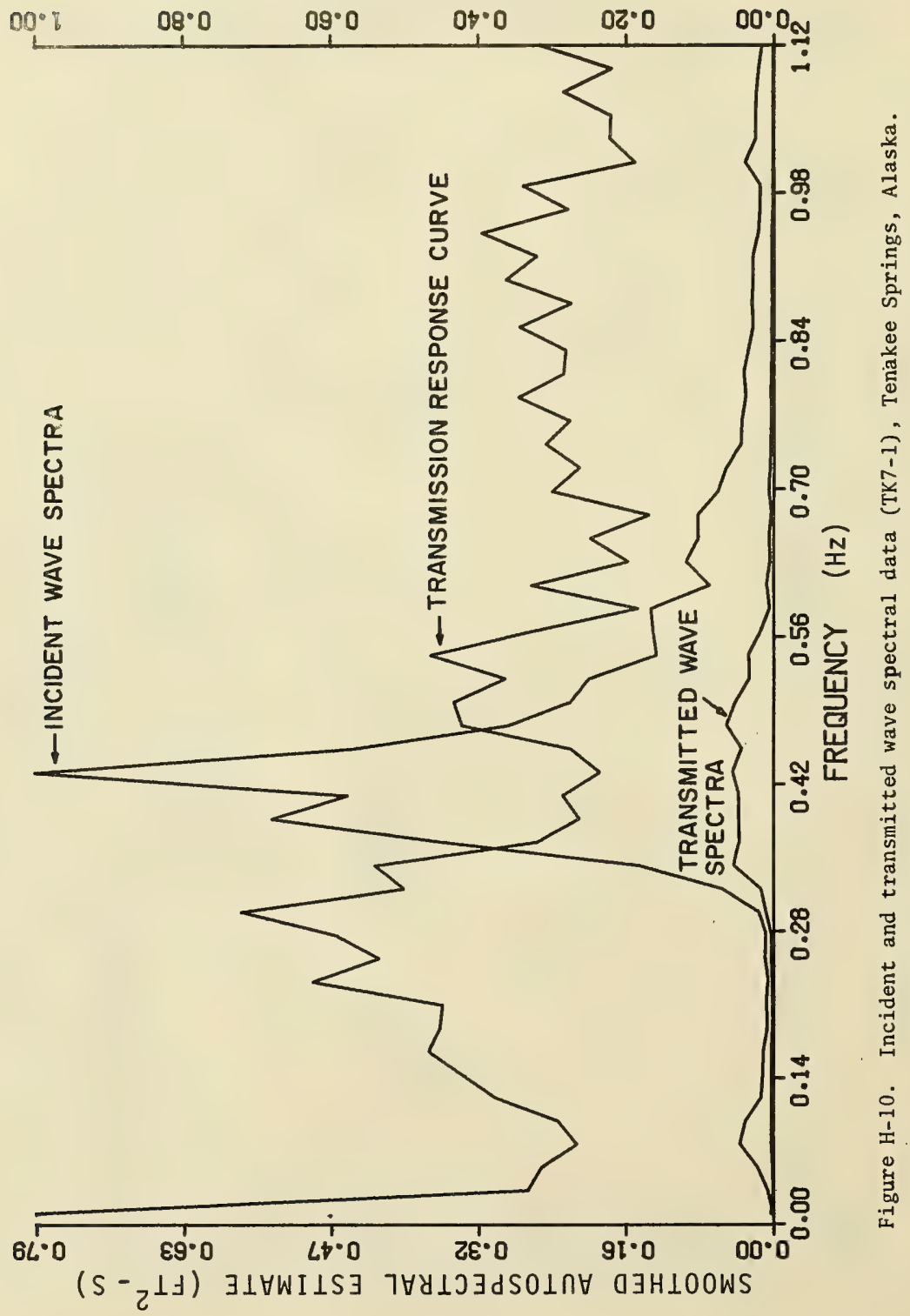




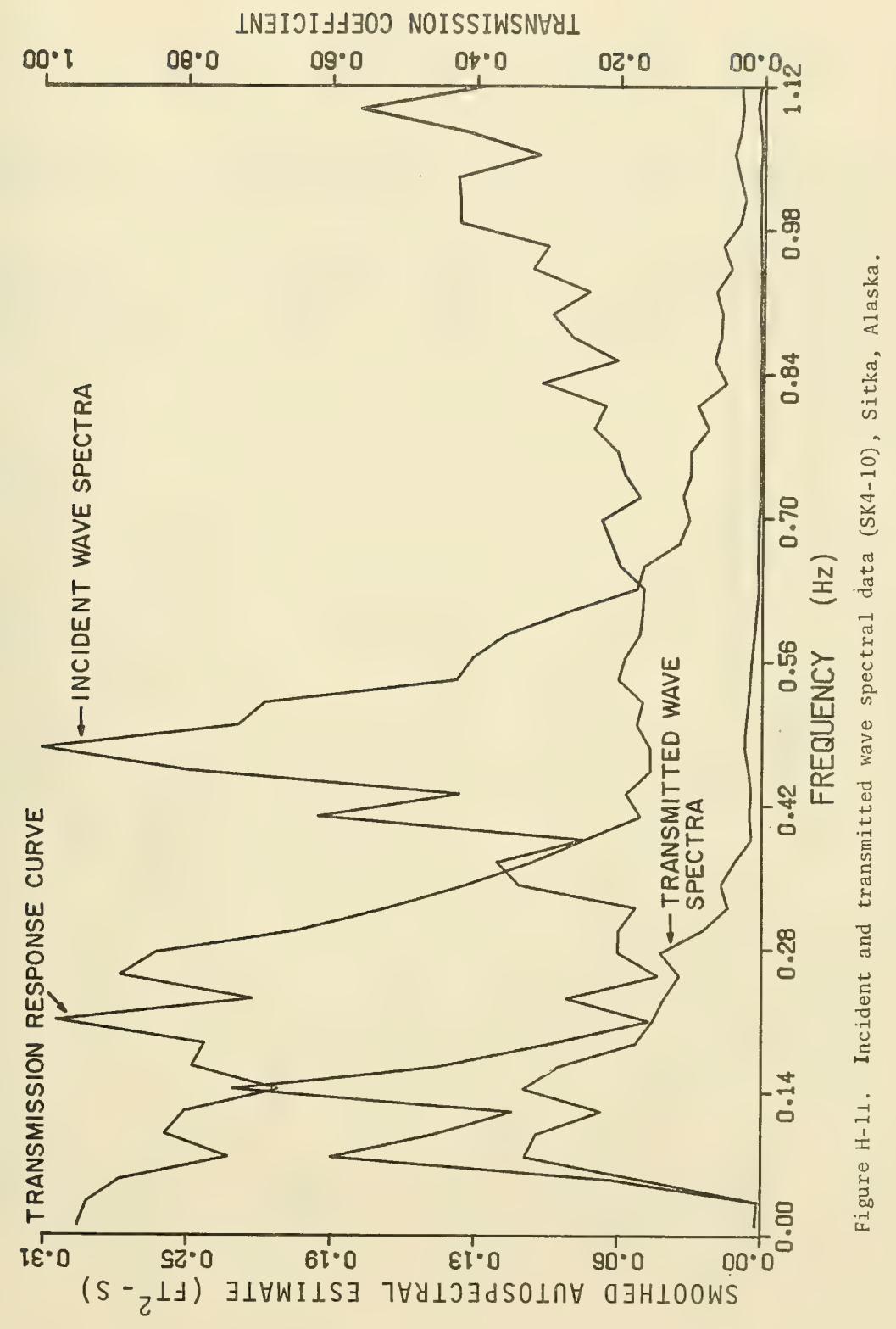




\section{APPENDIX I}

\section{LOW-FREQUENCY SPECTRAL ANALYSIS OF FORCE DATA}

Appendix I contains the low-frequency autospectral and cross-spectrai plots for record FH7-8. The data were recorded at Friday Harbor, Washington, on 6 January 1975 at 0030 hours.

The original time series were low-pass filtered at a cutoff frequency of 0.2 hertz and every eighth data point used to generate a new time series. This gives 256 points with a sampling period of 4 seconds. 


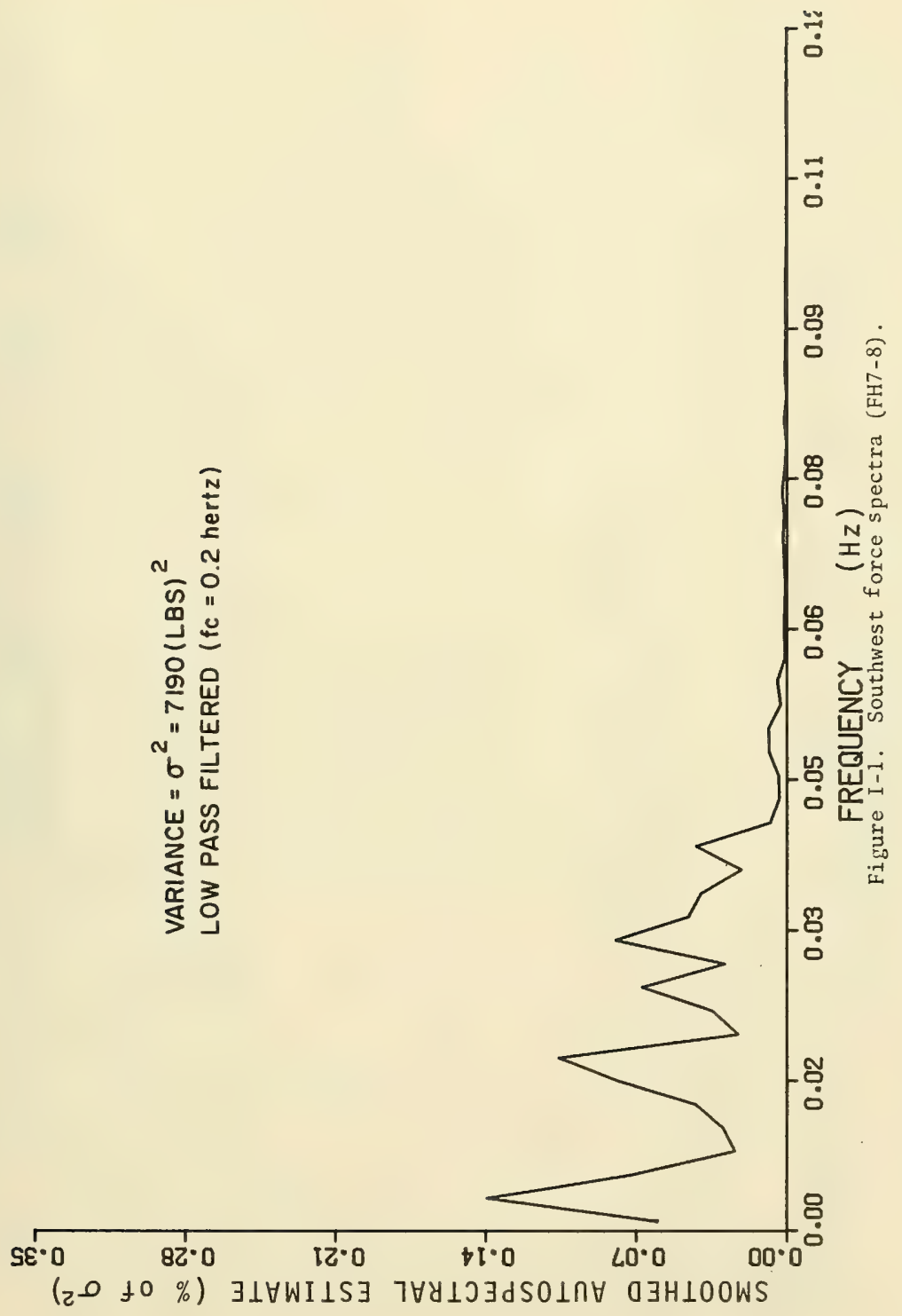




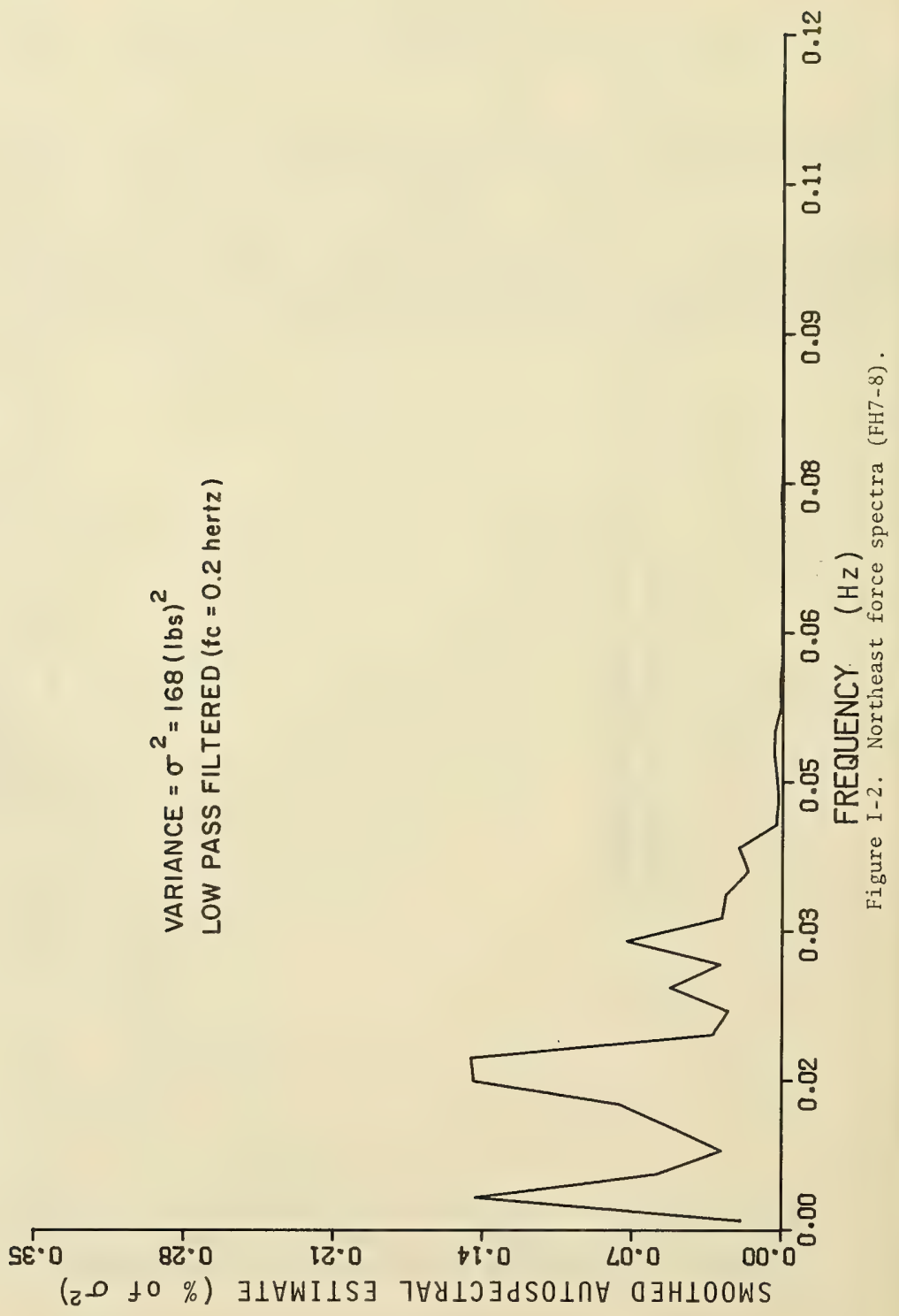




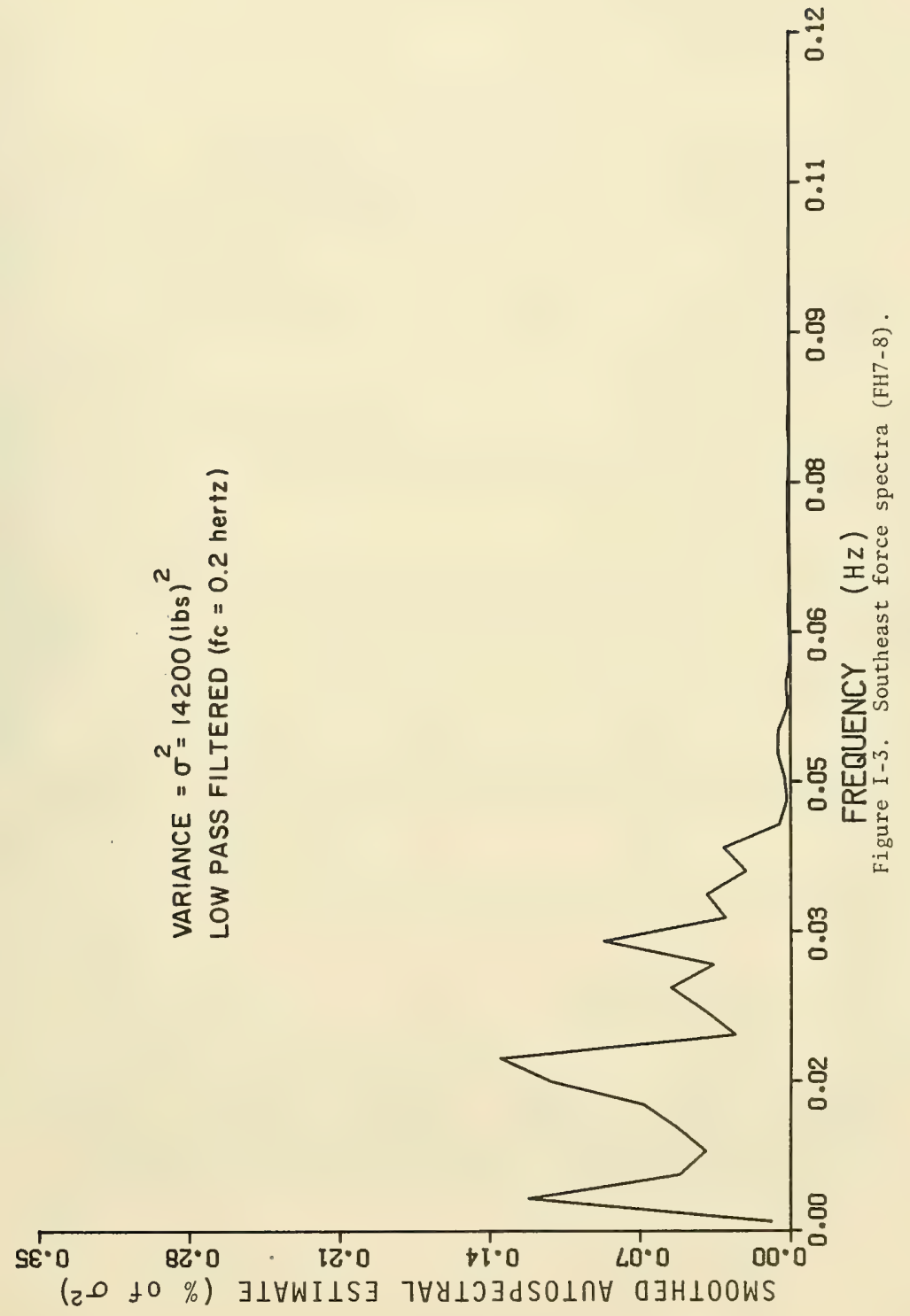




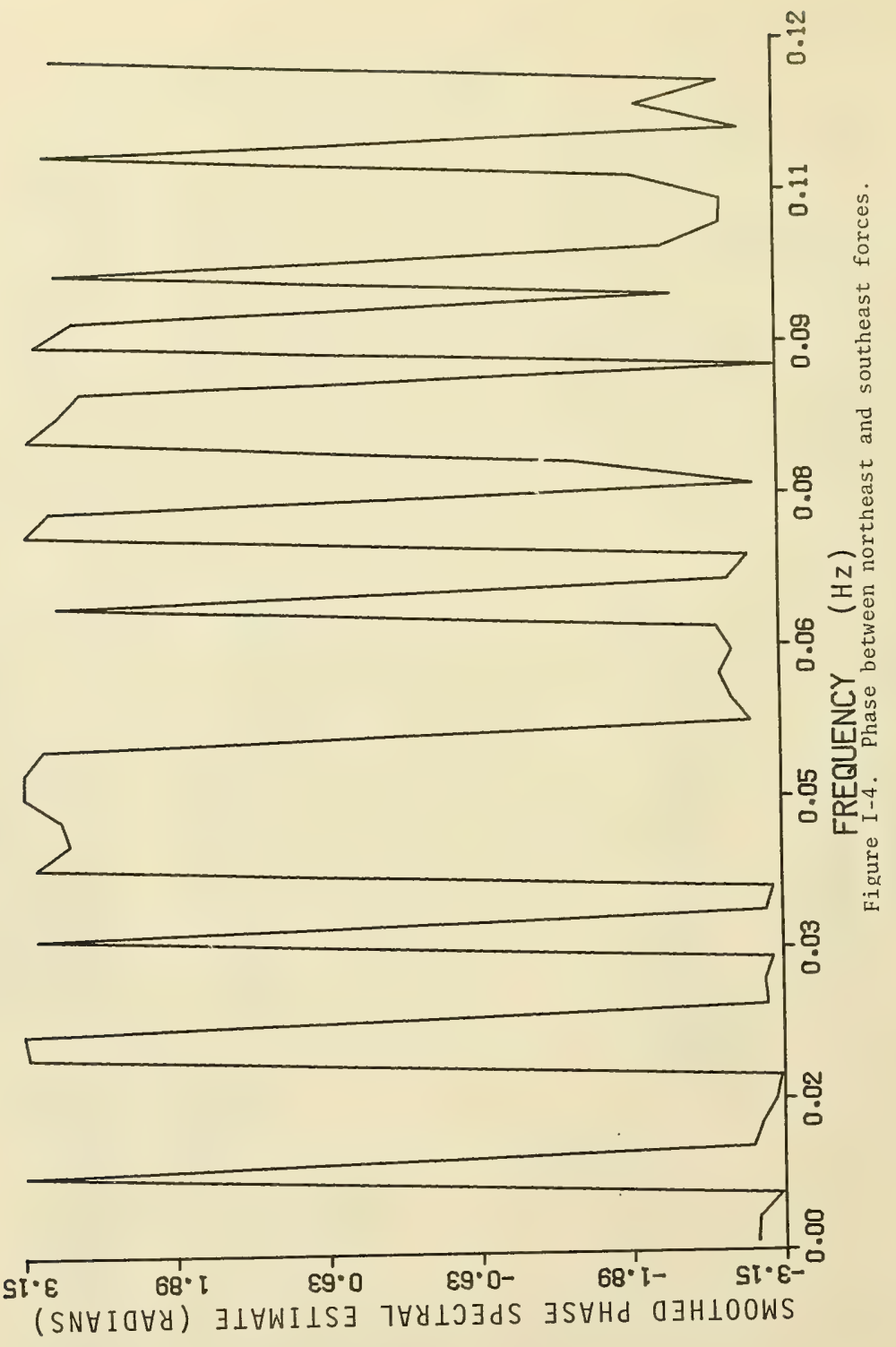




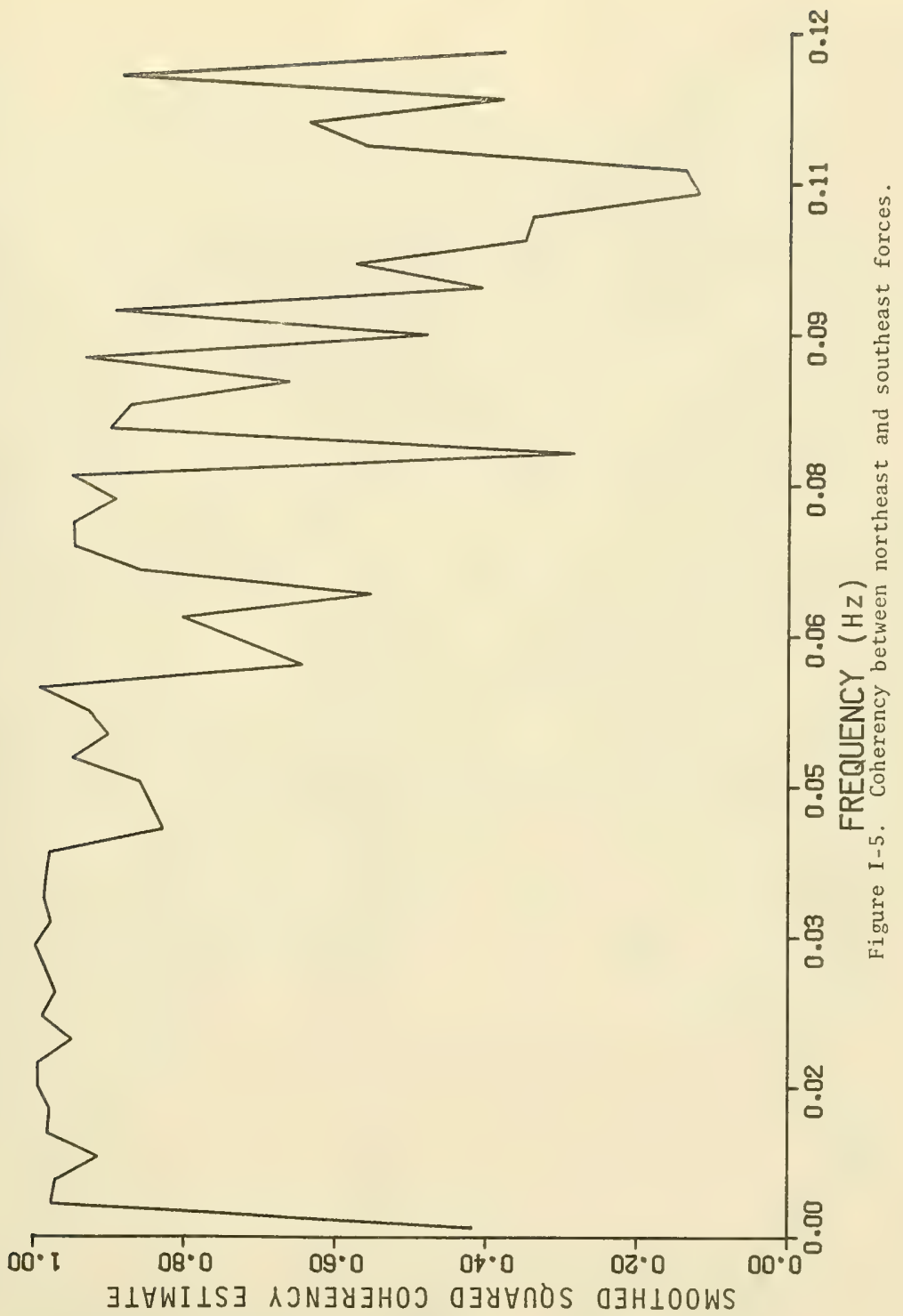




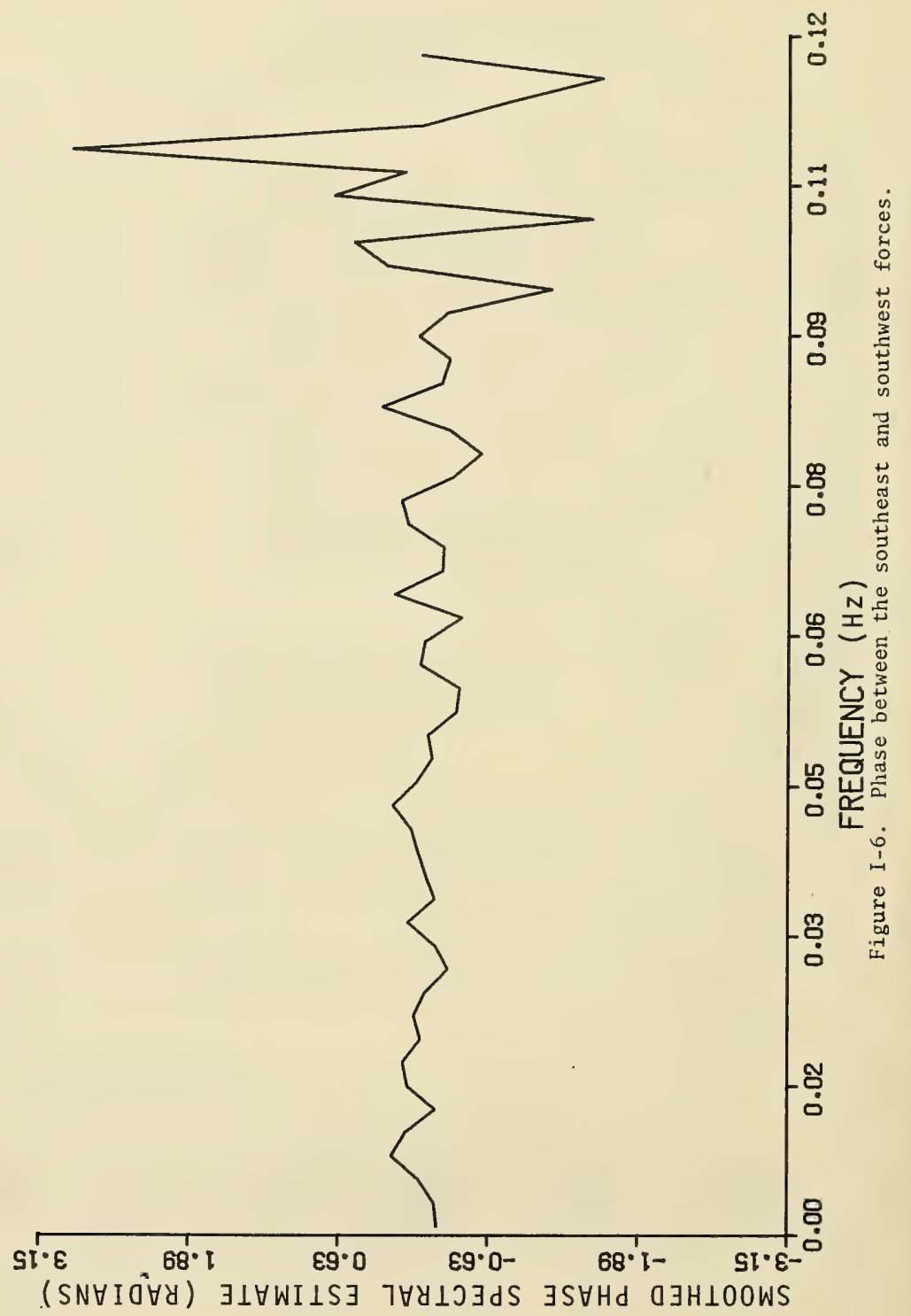




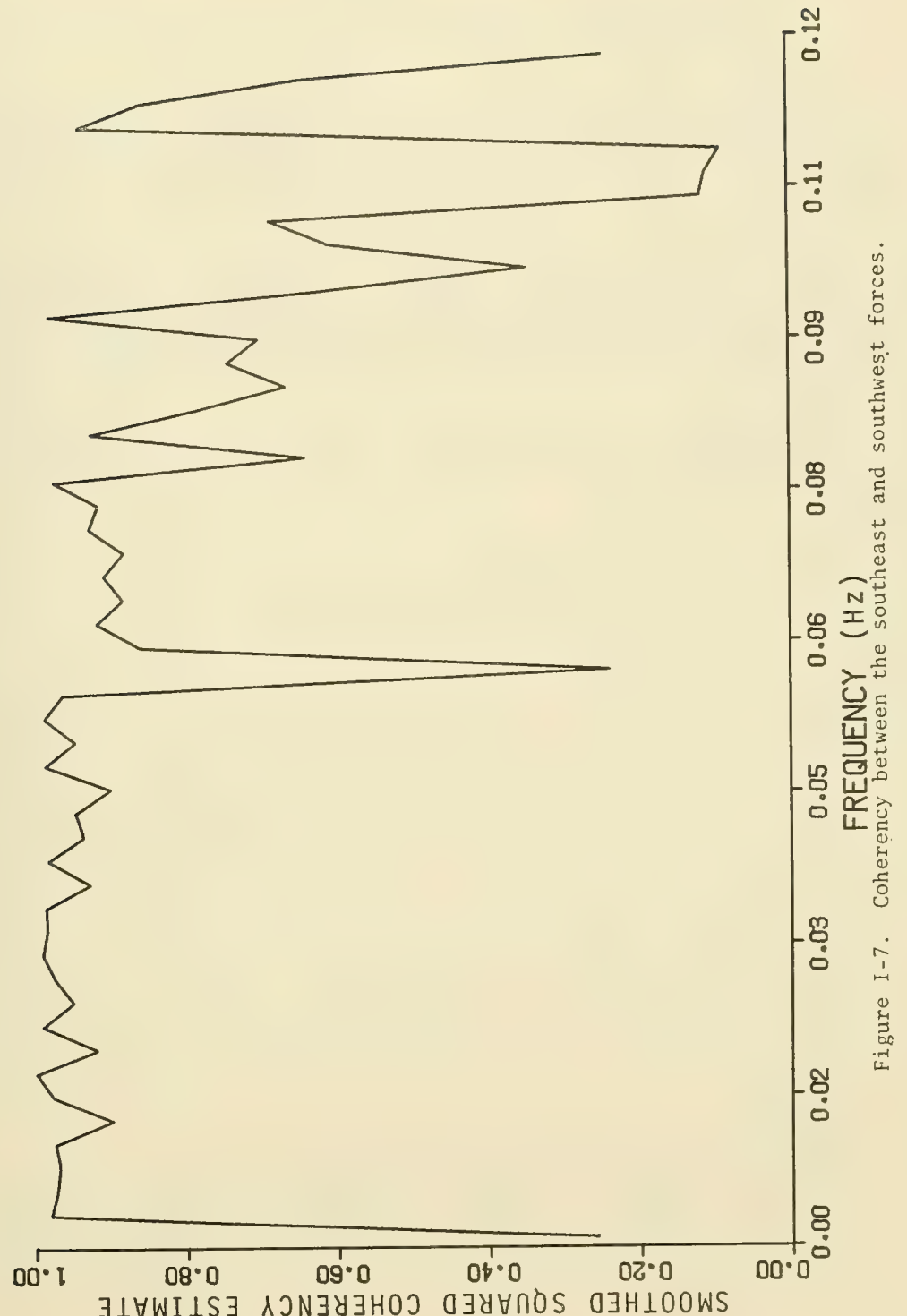




\section{APPENDIX $J$ \\ HIGH-FREQUENCY SPECTRAL ANALYSIS OF FORCE AND MOTION DATA}

Appendix $J$ contains the incident wave spectral plot along with the autospectral and cross-spectral plots for the force and motion data for record FH7-8. The data was recorded at Friday Harbor, Washington, on 6 January 1975 at 0030 hours.

The incident wave spectra was unfiltered. All the force and motion spectral data were digitally high-pass filtered at a cutoff frequency of 0.1 hertz. The autospectral data is plotted as a percent of the variance, i.e.,the total area under the spectra. Wave heights, forces, and motions were measured in feet, pounds, and feet per second square, respectively.

All spectra were computed from 2,048 data points sampled at $0.5-$ second intervals. 


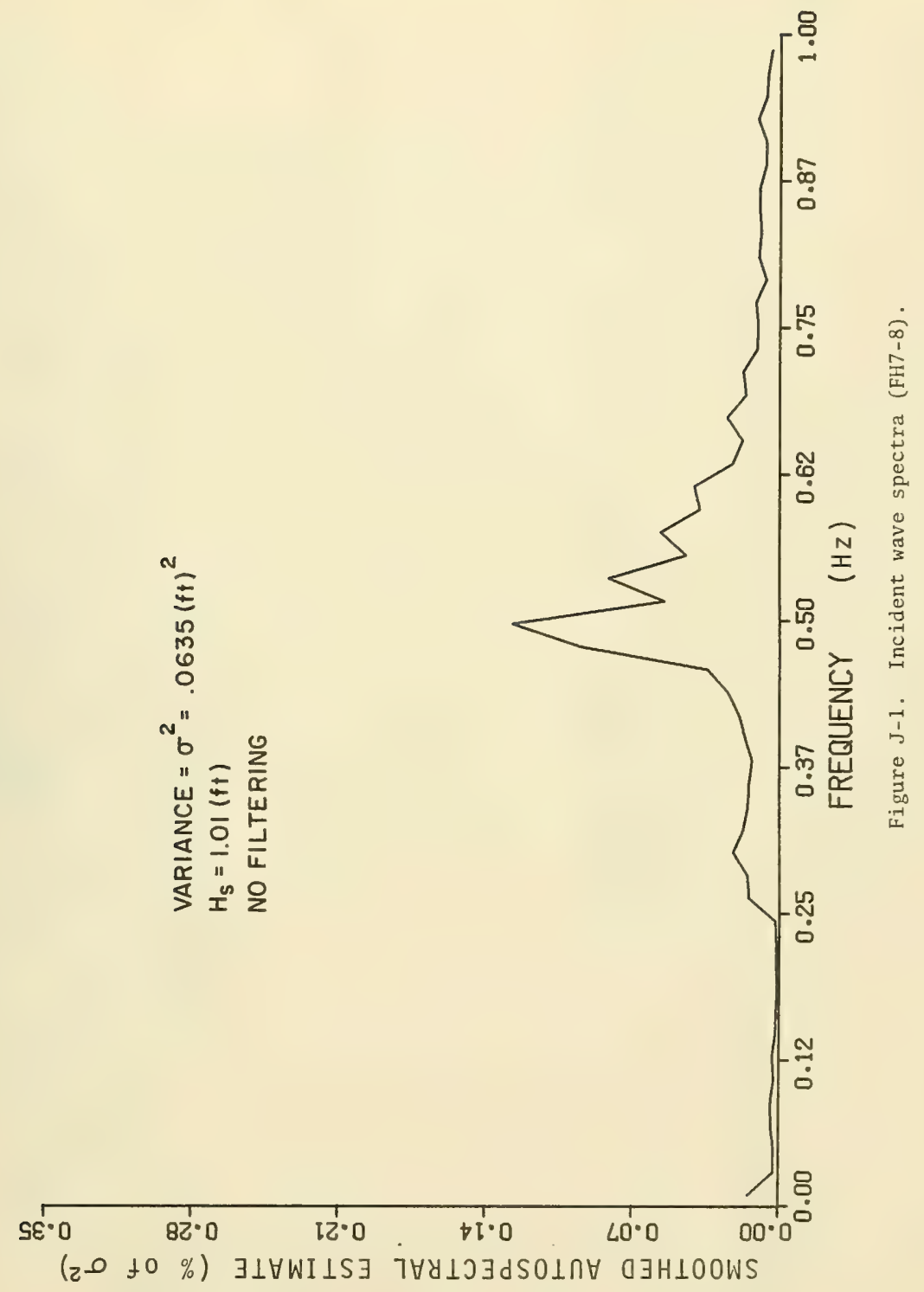




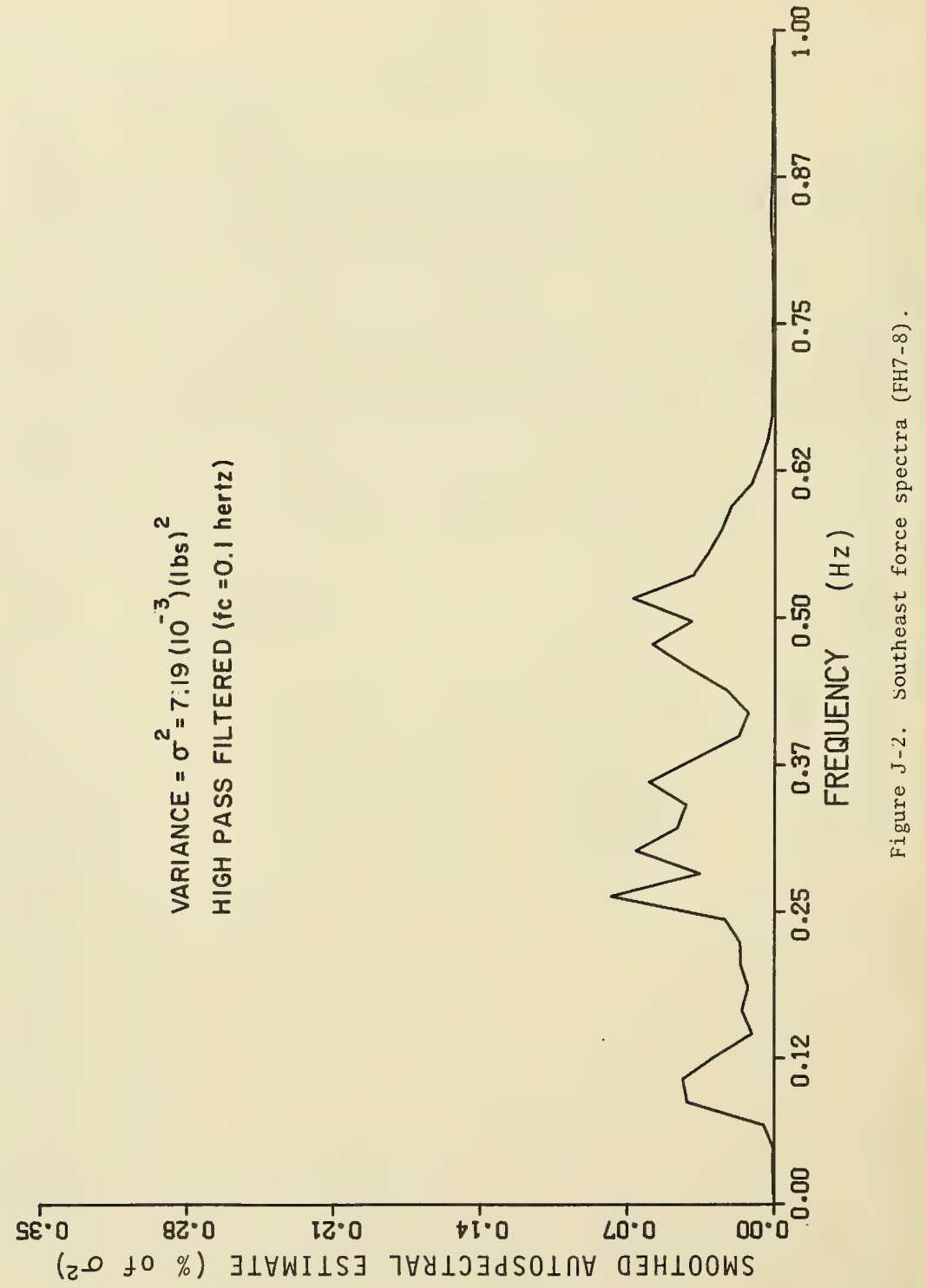




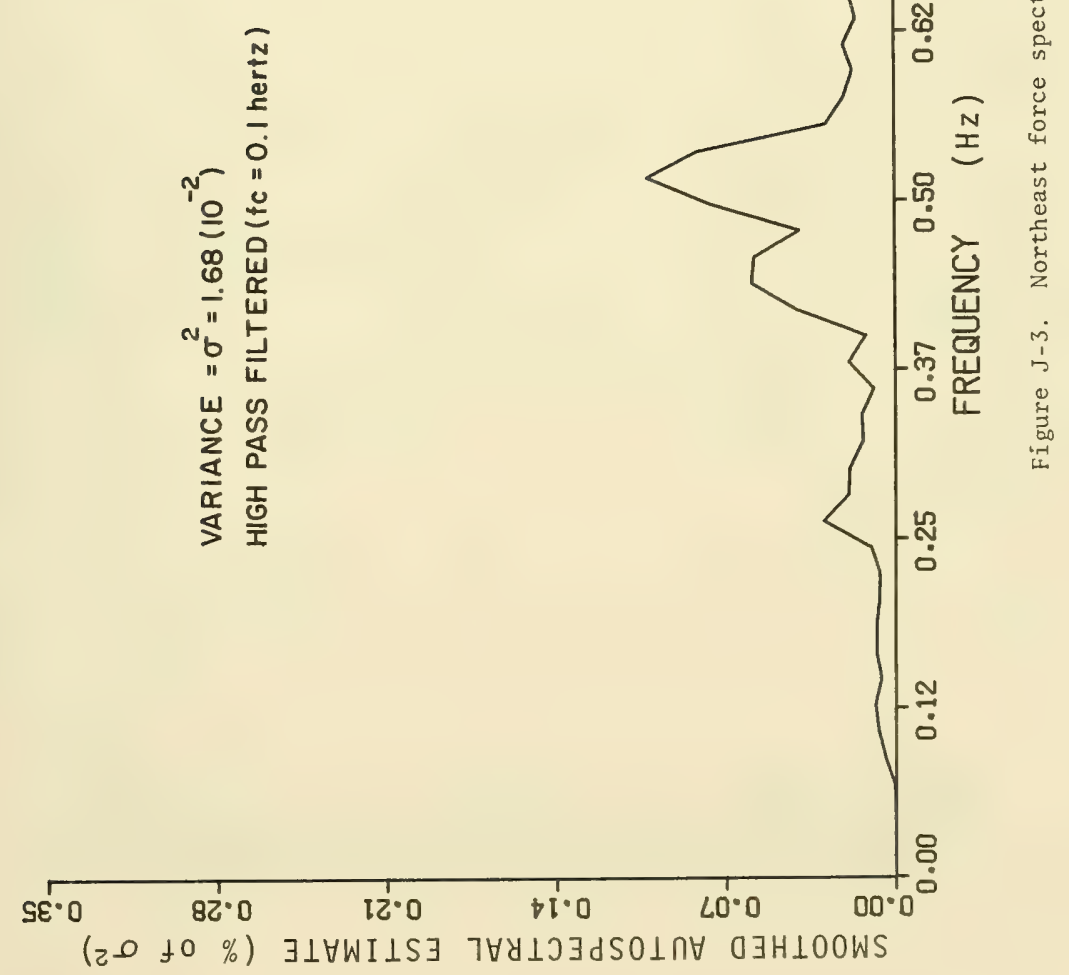




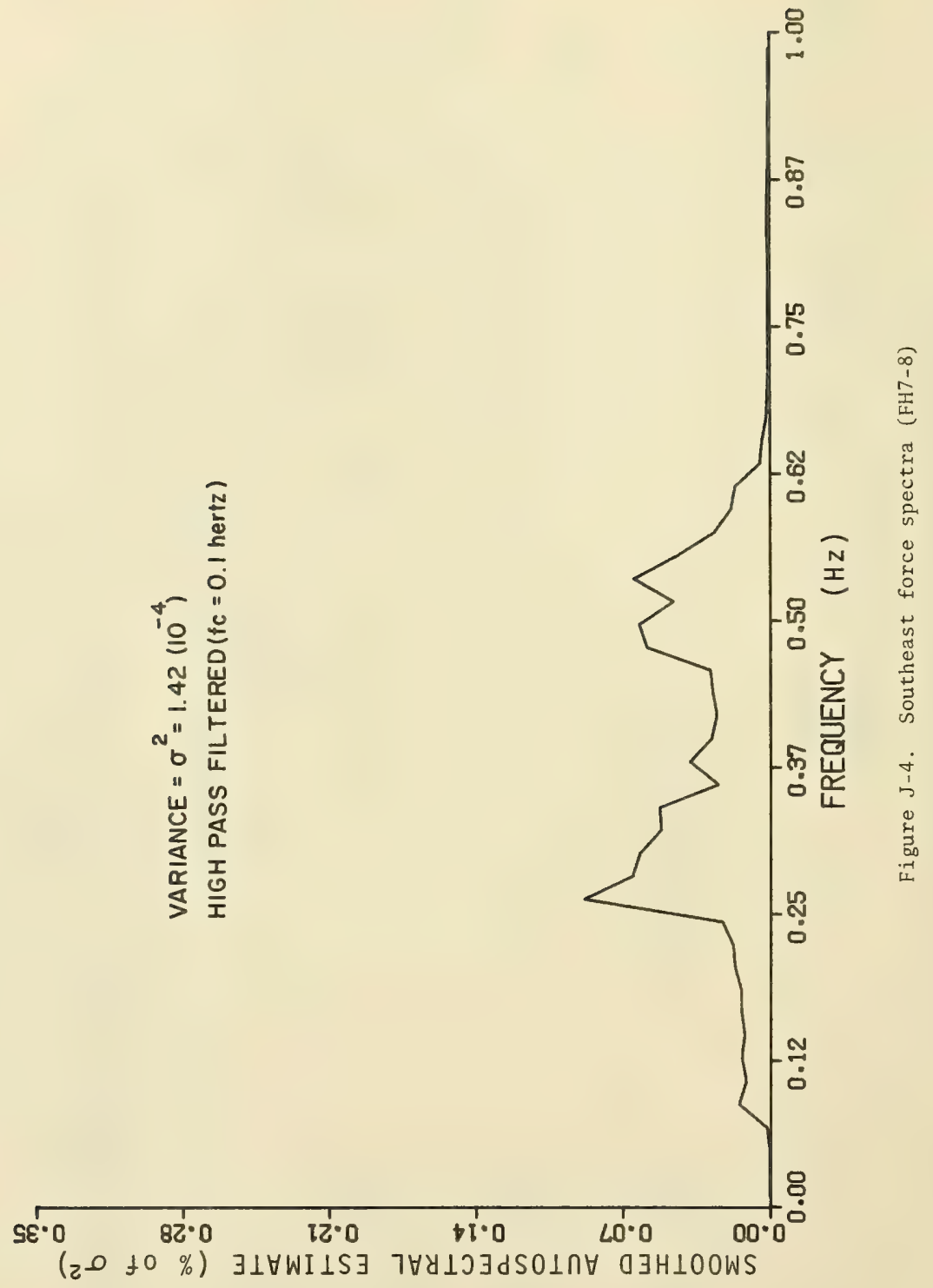




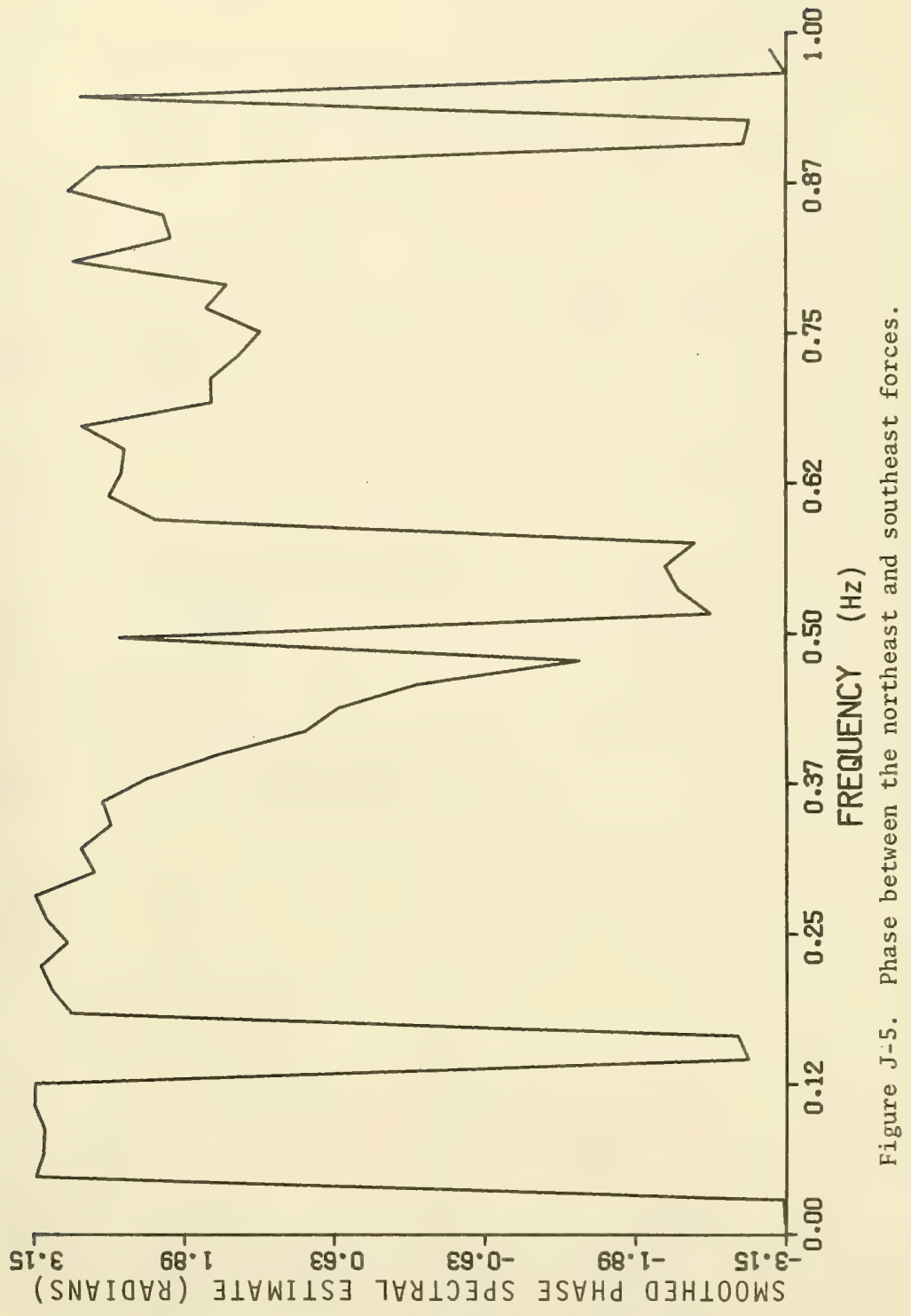




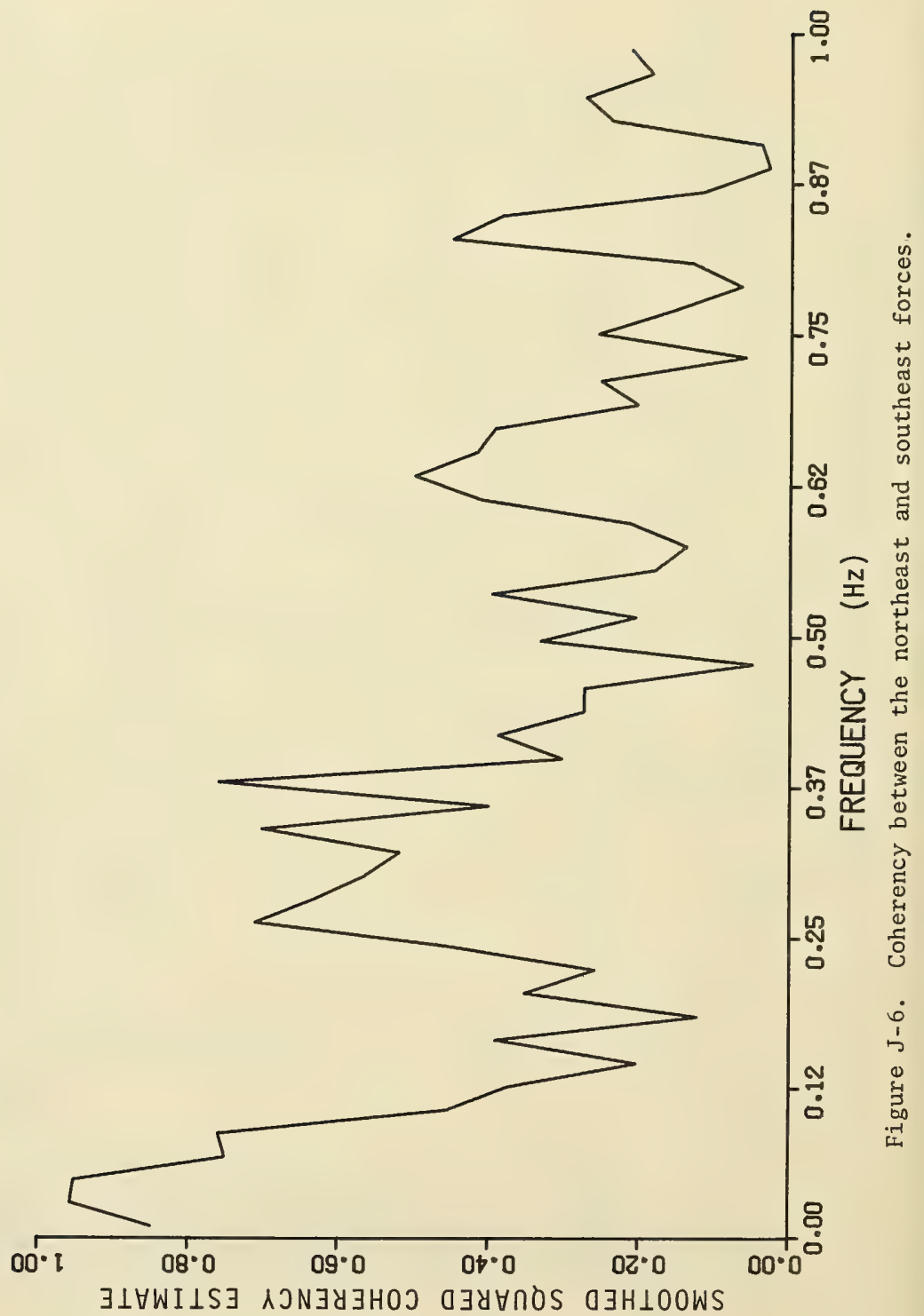




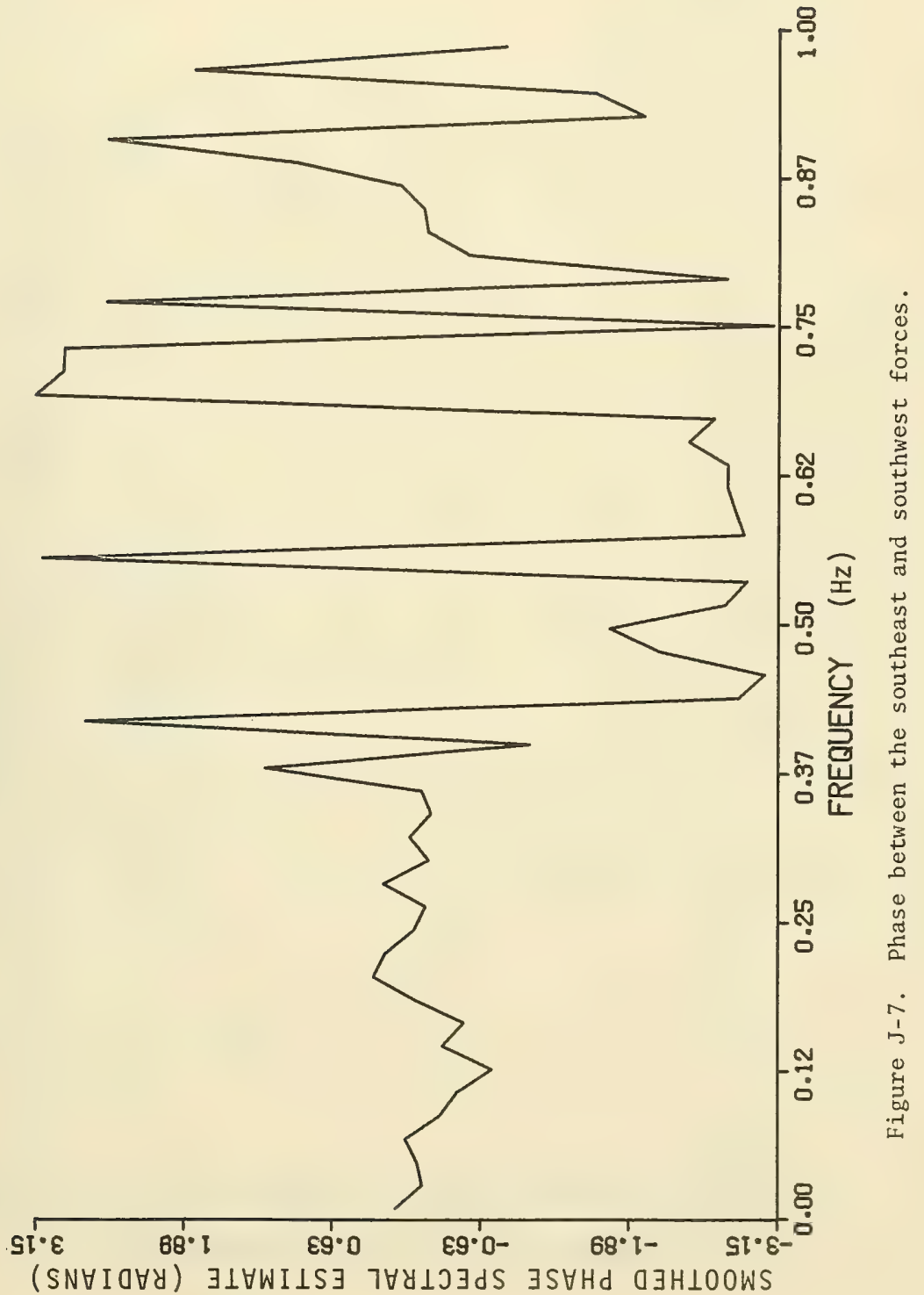




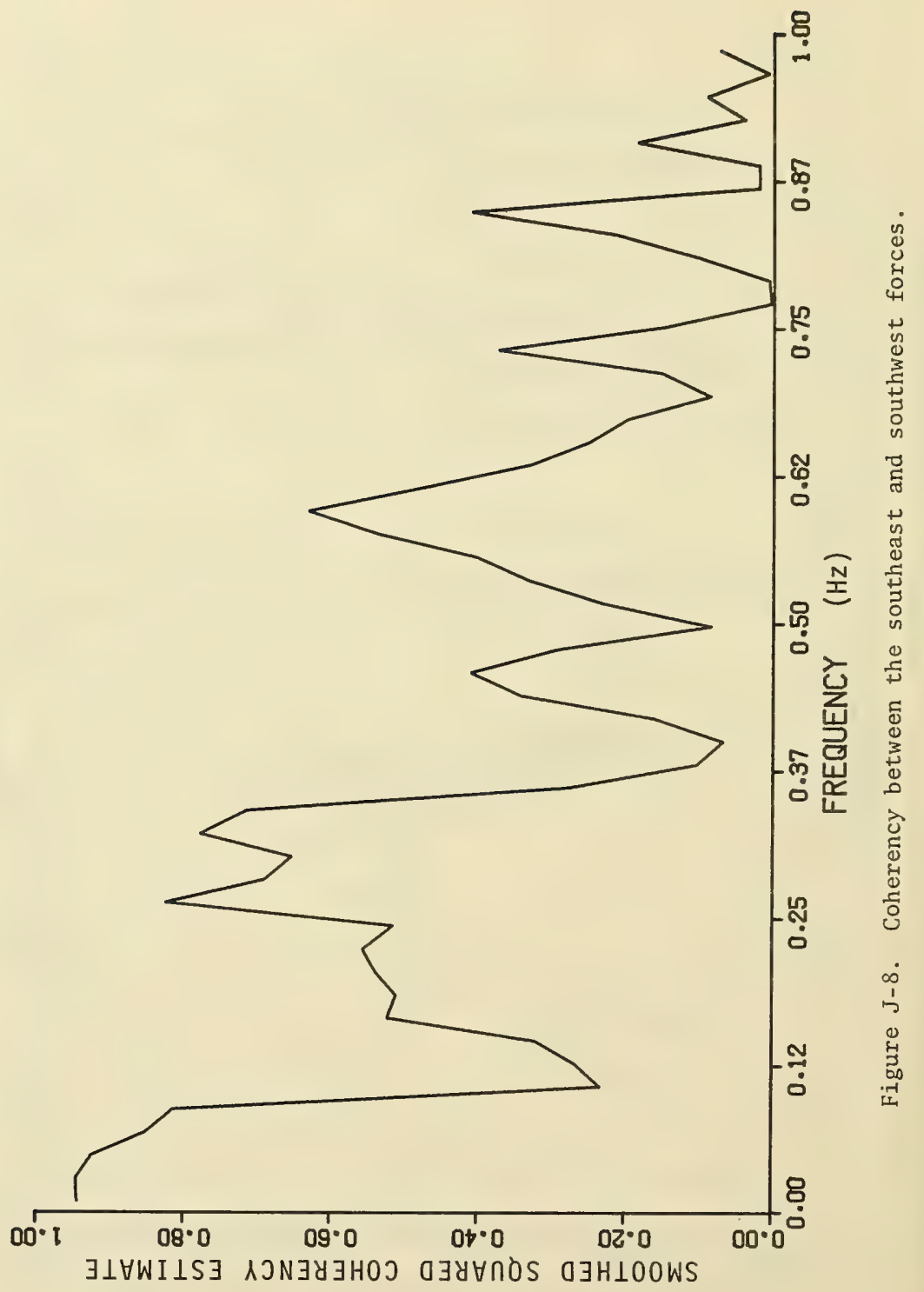



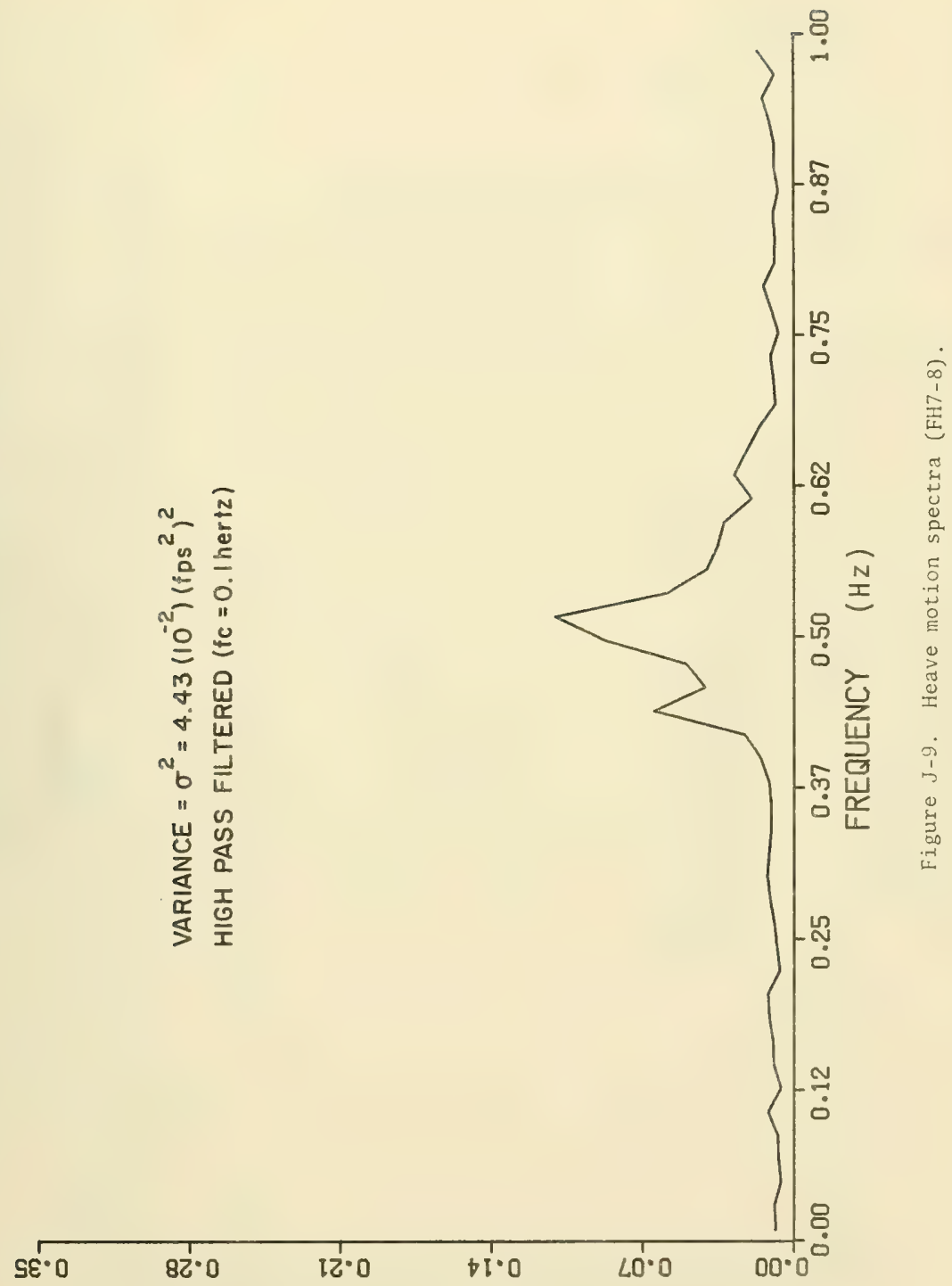

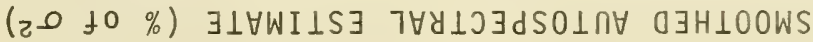



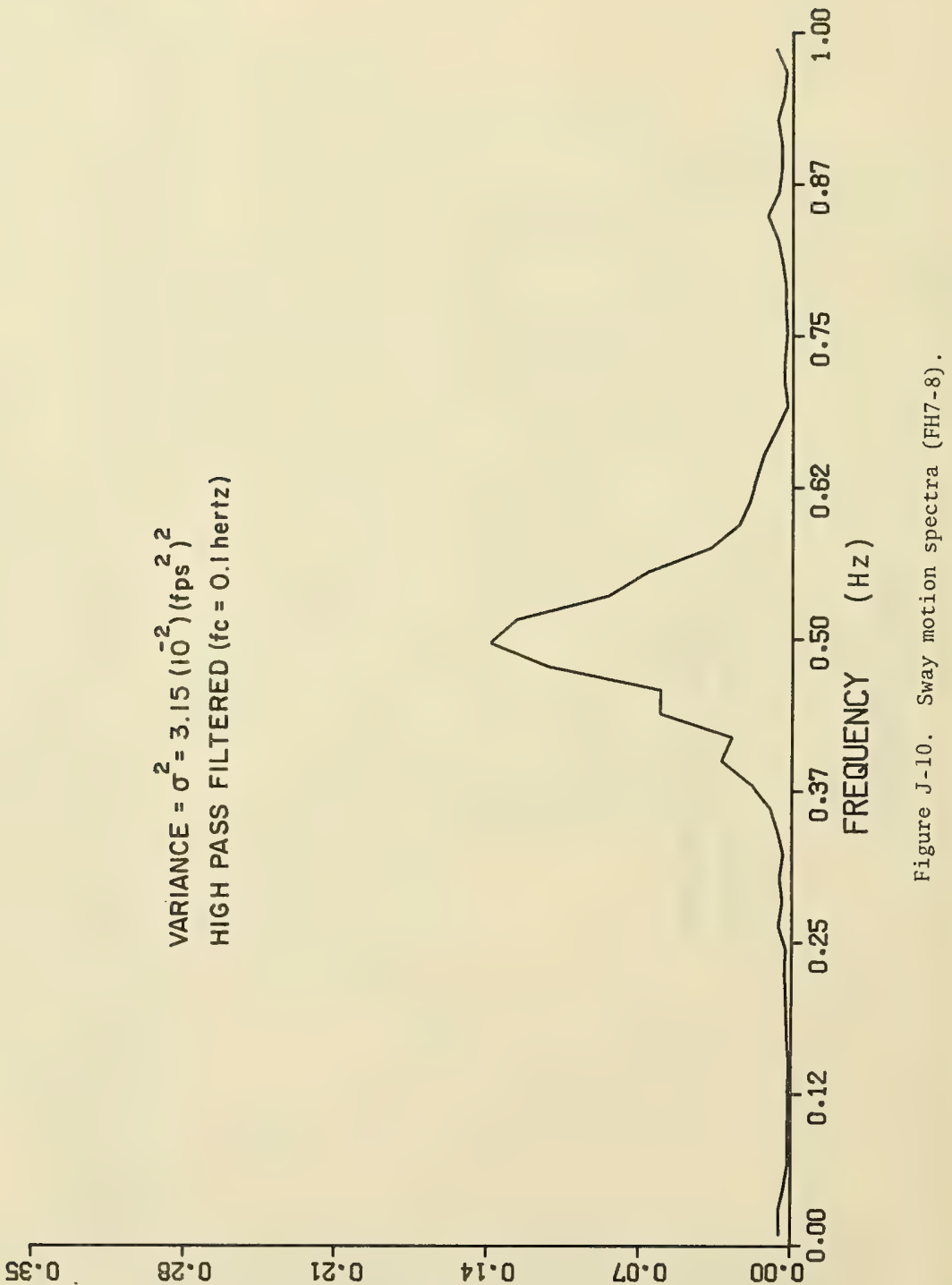

(ट 

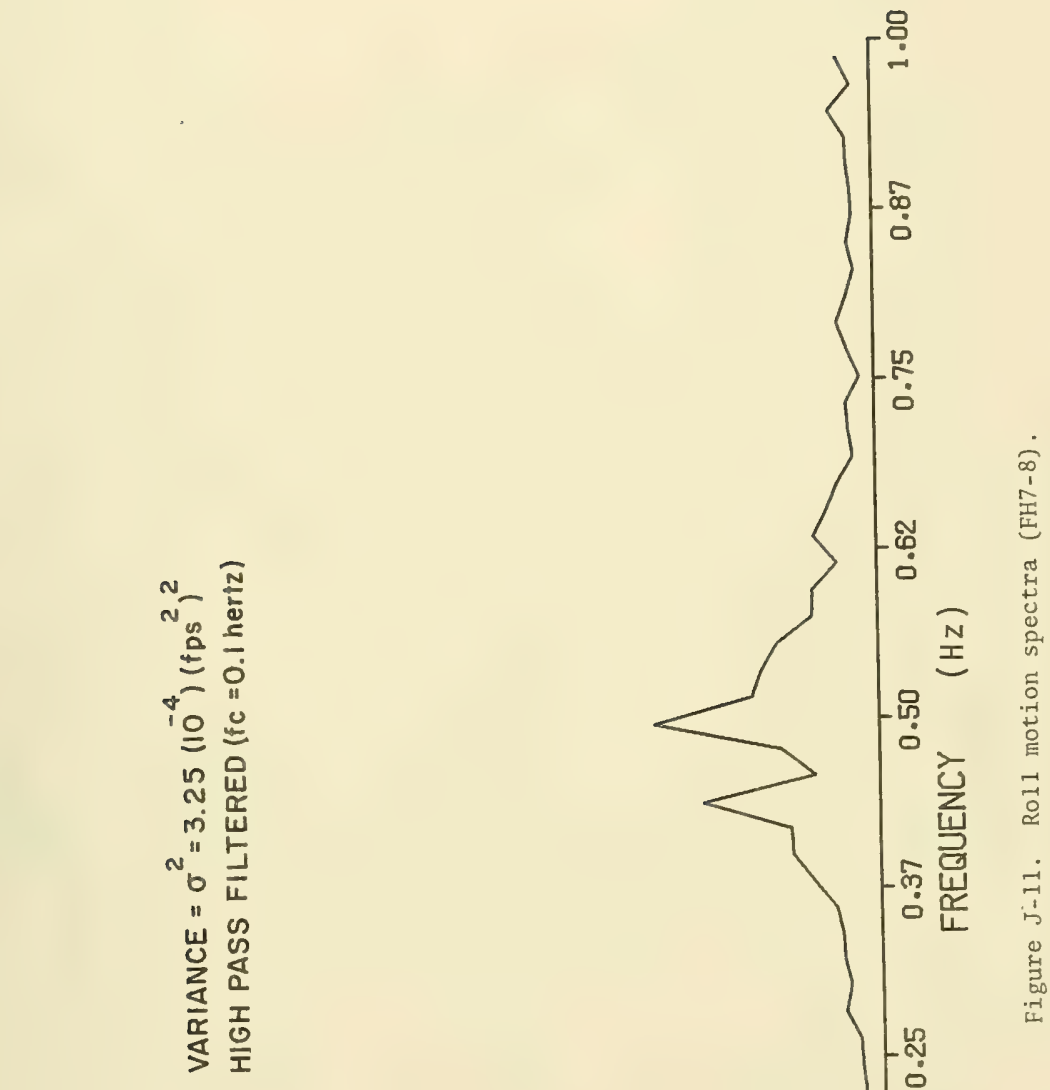

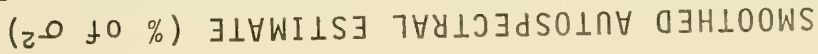




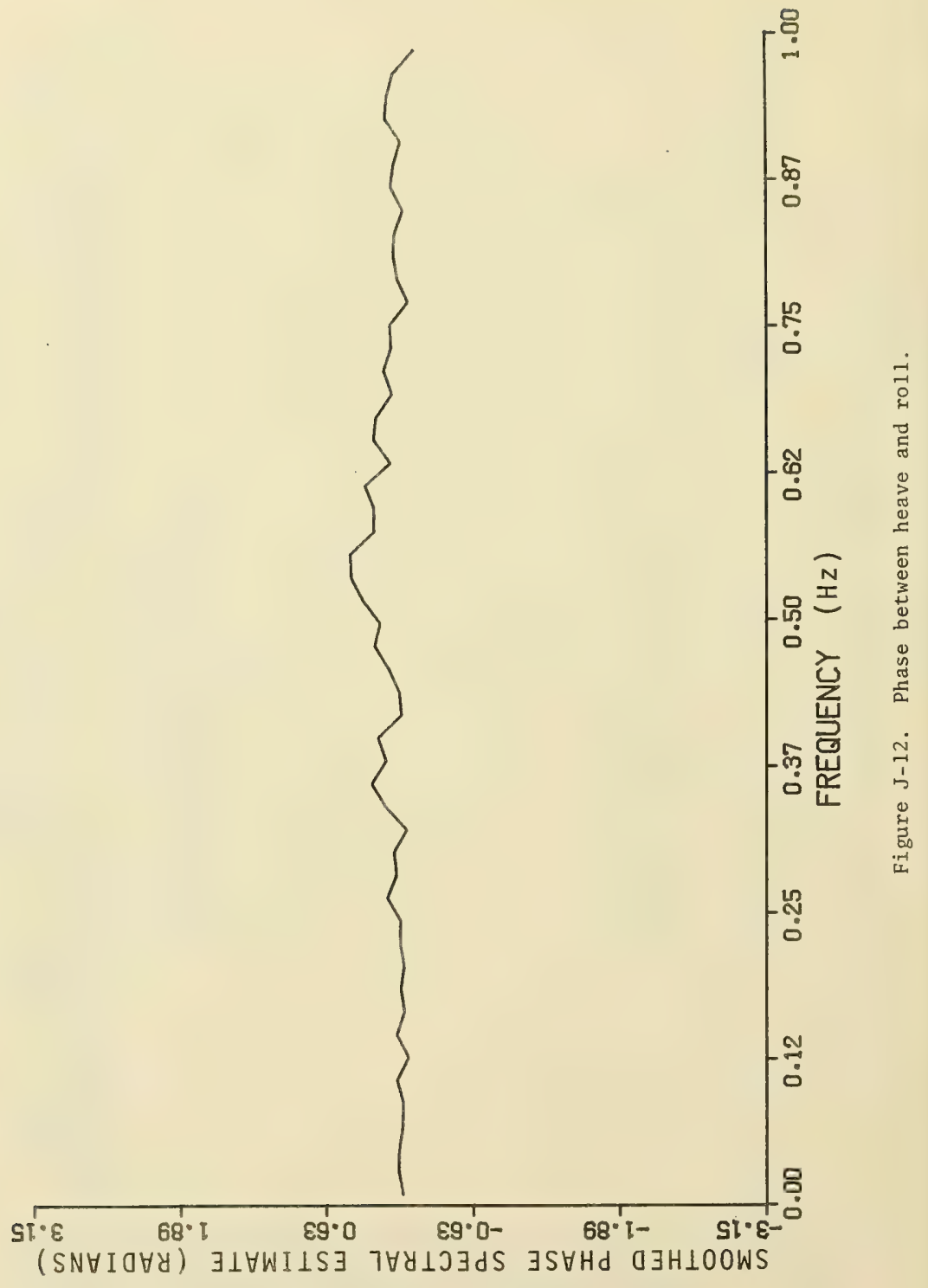




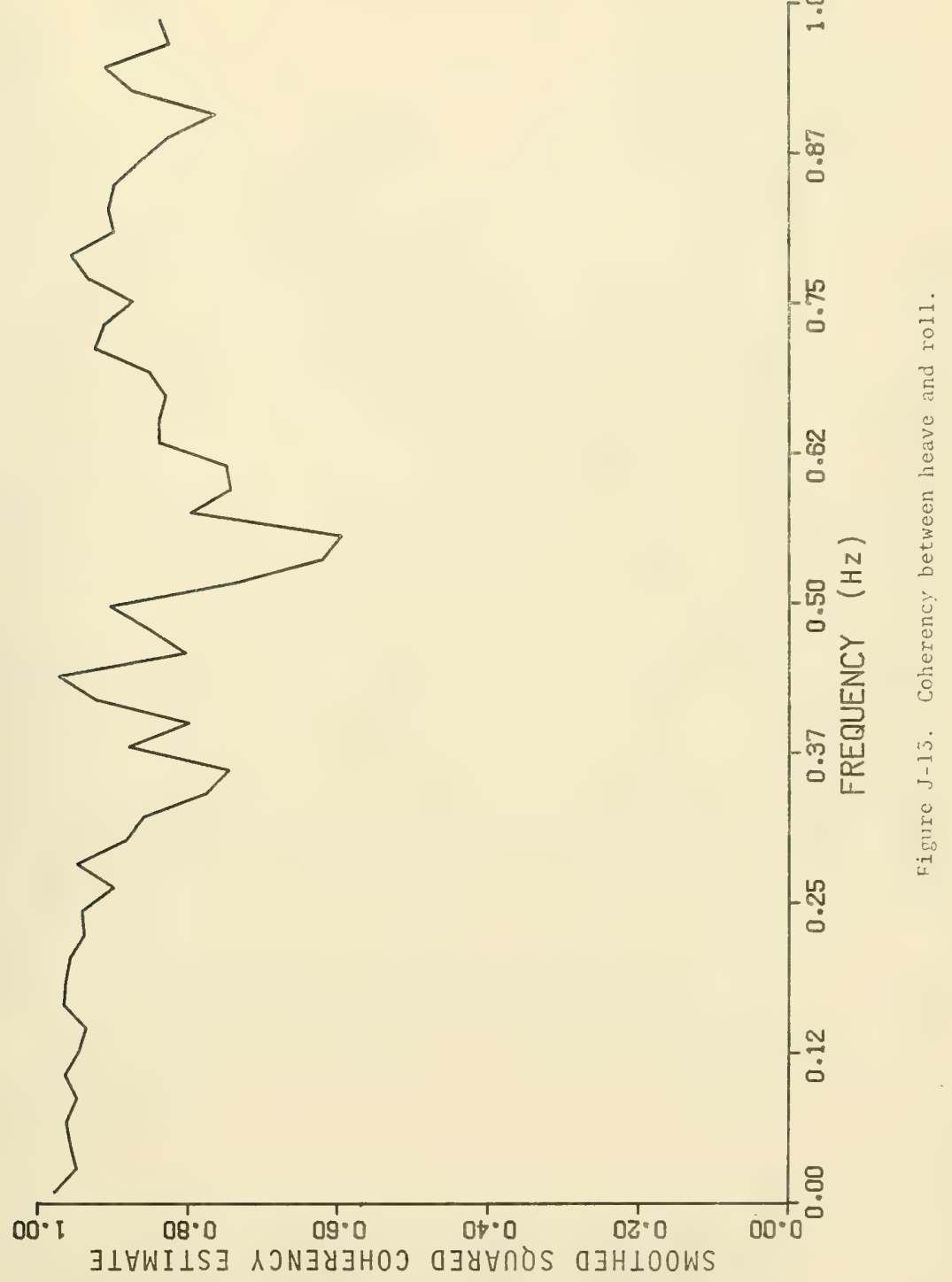




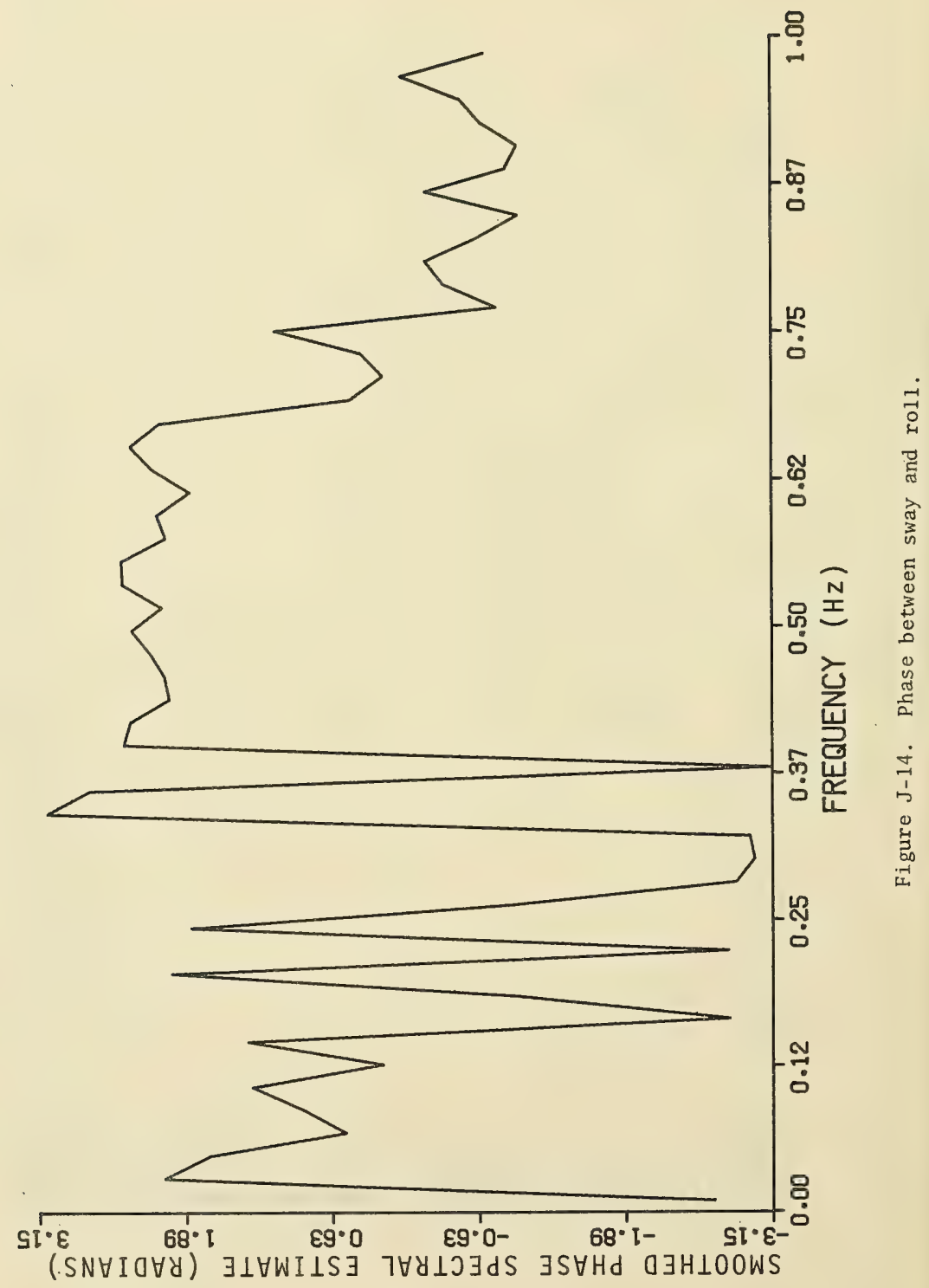




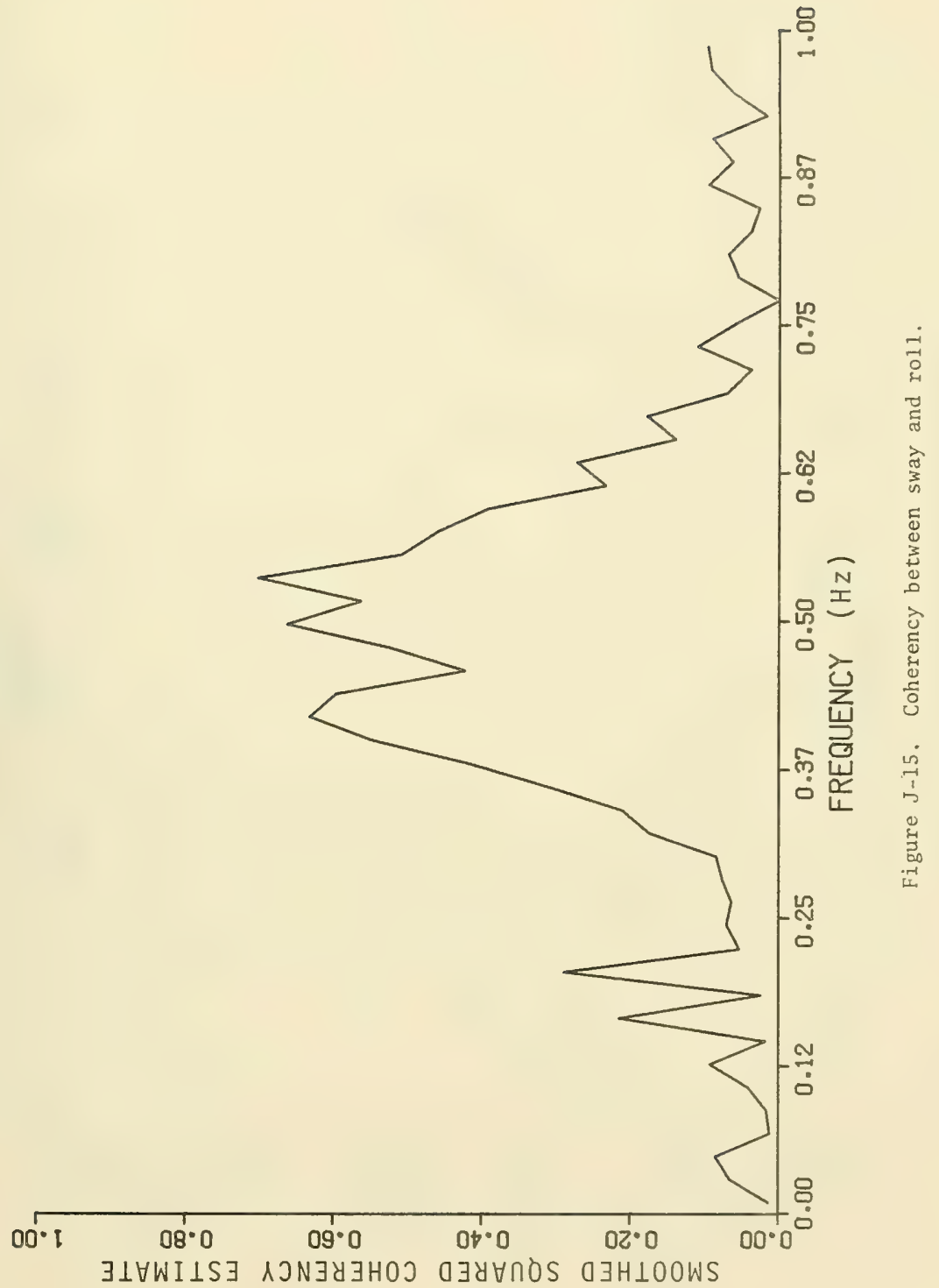




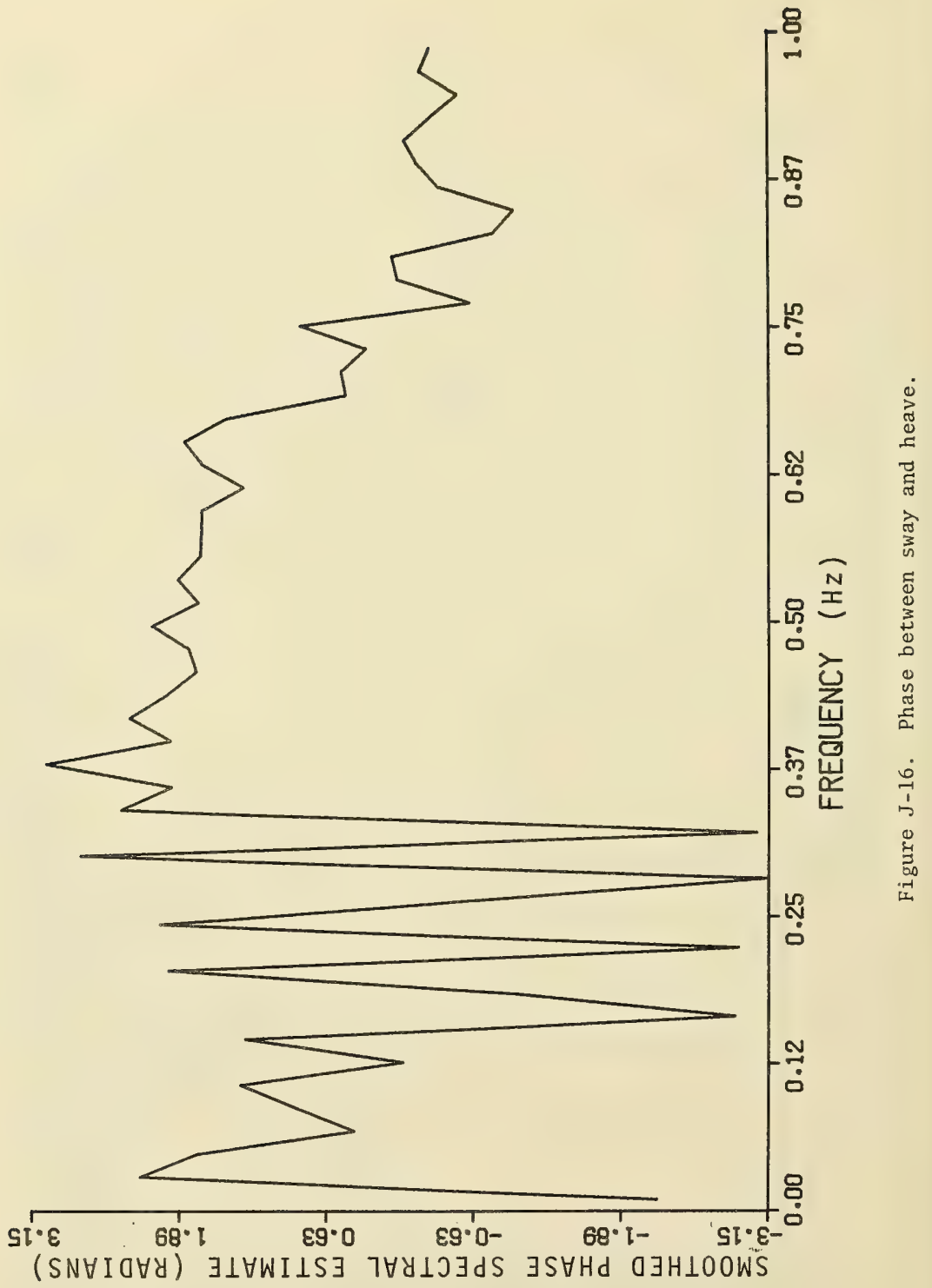




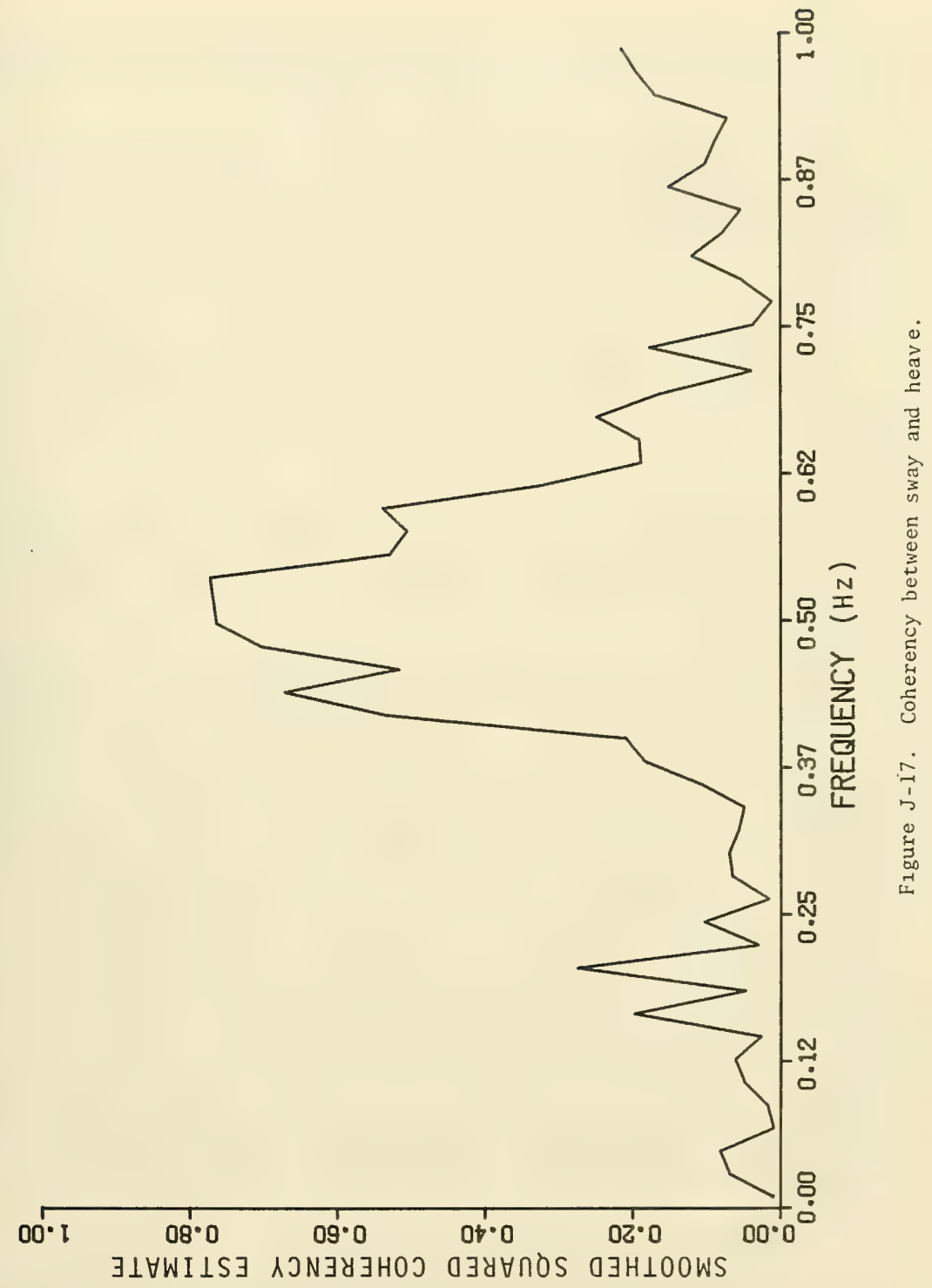


APPENDIX K

WAVE MEASUREMENT

1. Wave Staff Design.

A block diagram of the wave staff and associated electronic circuits is shown below:

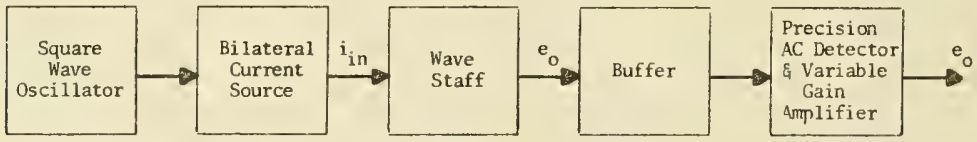

The wave staff itself consists of a length of PVC tubing which is spirally wound with a resistance wire, such that when it is immersed in seawater, the electrical resistance varies in direct proportion to the length of the exposed staff.

The electronic circuits driving the wave staff consist of a fixed frequency square wave oscillator (having a precisely controlled output amplitude) driving a precision bilateral current source with an output current directly proportional to the input voltage. Thus, the wave staff is driven by a current source of constant magnitude, but one which changes direction with each one-half cycle of the square wave oscillator. The output of the wave staff then is a square wave voltage with a magnitude (peak to peak) that is directly proportional to the length of the exposed wave staff. This output is fed to a high input impedance voltage follower circuit which serves as a buffer between the wave staff and the ac detector circuit. The precision ac detector circuit uses two operational amplifiers in conjunction with two diodes to form a precision full-wave rectifier circuit that is capable of operating at very low input voltages. Ordinary diode detector circuits cannot operate on ac signals of peak magnitude less than the forward voltage drop of the diodes and produce large conversion errors unless the signal magnitude is large with respect to the diode voltage drop. A gain control has been incorporated in the detector circuit so that full-scale output can be set at any positive value up to +10 volts with a wave staff resistance of 300 ohms up to 3,000 ohms.

Alternating current is used to drive the wave staff to avoid both the corrosion effects that would occur if direct current were used and the dc offset which occurs as a result of the use of dissimilar metals in a conducting solution. The latter is eliminated by use of ac coupling in the output from the wave staff.

Bench tests of the wave staff electronic circuits were made using a 1,000-ohm variable precision resistor in place of the wave staff. The 
circuit was adjusted to produce an output range of 0 to 10 volts with the resistor varied from 0 to 1,000 ohms. Linearity was determined to be 0.1 percent of full scale over this range.

Tests were also made to determine the effect of temperature on sensitivity and zero drift. A decrease in sensitivity was noted with decreasing temperature of about 0.03 percent of reading per ${ }^{\circ} \mathrm{Celsius}$ over the temperature range of 0 to $24^{\circ} \mathrm{Celsius.} \mathrm{A} \mathrm{zero} \mathrm{drift} \mathrm{of} 2$ millivolts was also noted over the same temperature range. A +10 percent change in supply voltage from the nominal +15 volts produced no observable change in output. If we assume an operäting temperature range of $+5^{\circ} \mathrm{Celsius,}$ the maximum error in the wave staff electronics due to the combined effects of nonlinearity and sensitivity variations with temperature is +0.2 percent of reading. Since the primary interest is in a dynamic measurement of waves, the zero drift noted will have negligible effect on the experiment since temperature variations of any appreciable magnitude will only occur over long periods of time compared to the wave periods.

Further calibration tests were conducted using actual wave staffs of 1-inch diameter and 20-foot lengths, and 3.5-inch diameter and 8-foot lengths at various depths of immersion in saltwater. These tests were conducted from a dock at Shilshole Bay on Puget Sound. Because of ripples and waves on the water of the order of 1 inch (peak-to-valley) it was difficult to obtain a highly precise measurement. The output was recorded on a strip chart recorder and it was therefore possible to average these variations to some degree. The readout resolution of the strip chart (and accuracy) is about $+1 / 4$ of a minor division. Ful1 scale across the chart is 50 minor divisions and, thus, the resolution is about 0.5 percent of full scale. Some nonlinearity is noted near full immersion (see calibration curve). Some offset was expected because of the finite resistance of the saltwater path in the ground return which is not taken into account during initial calibration of the wave staff unit. The initial calibration is made with the wave staff on the dock where full scale and zero are set by making actual contact between the ground wire and the wave staff resistance element at the corresponding ends. However, measurements were made of the resistance of the saltwater path to ground in the same location where the wave staffs were immersed and the value of resistance measured (on the order of 10 ohms) does not account for the offset observed at full immersion. In addition, the offset should occur at all readings and it does not. Therefore, it is believed that the nonlinearity observed is a result of some other phenomenon as yet undetemined. Both units produced highest accuracy near center scale with decreasing accuracy toward either end. Overall accuracy including end points is about +3 percent. If the range of operation is reduced so as not to use the last 1 foot on each end of the wave staff, the accuracy is improved to about +1 percent.

The output from the wave staff electronic circuit is fed directly into a voltage to frequency converter; the frequency output is then counted and stored on separate storage registers, once every $50 \mathrm{milli-}$ seconds. If an 8-bit register is used for the wave staff measurement, 
the maximum count that can be stored is 255; therefore, the sample time must be on the order of $25.5 \mathrm{milliseconds} \mathrm{(maximum} \mathrm{count} \mathrm{divided} \mathrm{by} \mathrm{maxi-}$ mum frequency output from voltage to frequency converter). The wave buoys use an 8-bit register with a 32.5-millisecond sample time while the wave staffs use a 16-bit register with a 250-millisecond sample time.

The error due to gain instability and nonlinearity of the voltage to frequency converter is of such low magnitude that it can be neglected and the overall accuracy of the recording is essentially the same as given for the wave staff unit by itself (i.e., between +1 and +3 percent depending on the range of operation on wave staff).

\section{Spar Buoy Design.}

Spar buoys were used at two of the sites because of their advantage in handling and transport and because they minimized the placement difficulties due to navigational hazards, water depth, and tidal conditions. The spar buoys were made of two PVC pipes coupled together near the center of the buoy. The lower section is a 15 foot by 6 inch pipe filled with styrofoam. The top section is 12 feet by 3 inches wherein the upper 8 feet is wound with a resistance wire which measures wave elevation. The wave staff electronics are mounted inside the top section, above the waterline, with the remainder being filled with a wood core to add stiffness. The buoys also have a 2.5-foot diameter damping plate mounted on the bottom and are anchored using a dual point mooring system with the anchor lines attached at the center of drag on the buoy to prevent it from being pulled underwater in strong currents. One of these buoys was tested in the Puget Sound just north of Seattle. Its performance exceeded expectations both in terms of minimized response to the waves and accuracy of wave height measurement. Figure $\mathrm{K}-\mathrm{l}$ gives a sample of the output from the buoy's wave staff in saltwater for a plus and minus 1 foot excitation of the buoy in heave. This was accomplished by pushing the buoy up and down by hand. Some distortion results from this approach which shows up in the output of the accelerometer mounted at the center of the response of the buoy in heave and roll in calm water. The natural periods for heave and roll taken from these plots are approximately 18 and 14 seconds, respectively. These are well out of the range of the 3-to-4-second wave periods expected at the site. Visual observations of the buoy in waves in excess of 1.5 feet indicated no observable heave or roll motion, but some yaw about the anchor line caused by the current and wind. This motion resulted in less than a 1 foot variation from the buoy's horizontal position in calm water and appeared to have periods in excess of 30 to 60 seconds. For comparative measurements, the buoy was located about 30 feet from an existing four-gage array of 1-inch diameter Oceanographic Services, Inc. resistance wire wave staffs. A comparison of simultaneous output from the two wave staffs (buoy mounted and stationary) is shown in Figure K-4. The autospectras computed from data obtained from one of the stationary wave staffs and from the spar buoy, in a 25-miles per hour storm with 


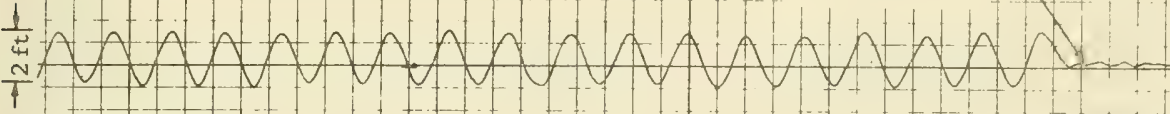

\section{ZERO VALUE T}

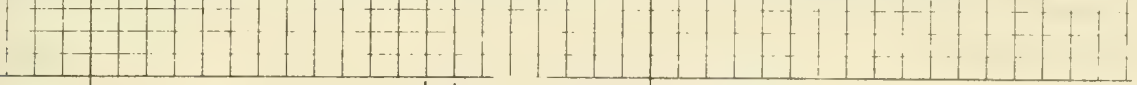

$\rightarrow+2.4$ SEC . SPAR BUOY WAVE STAFF

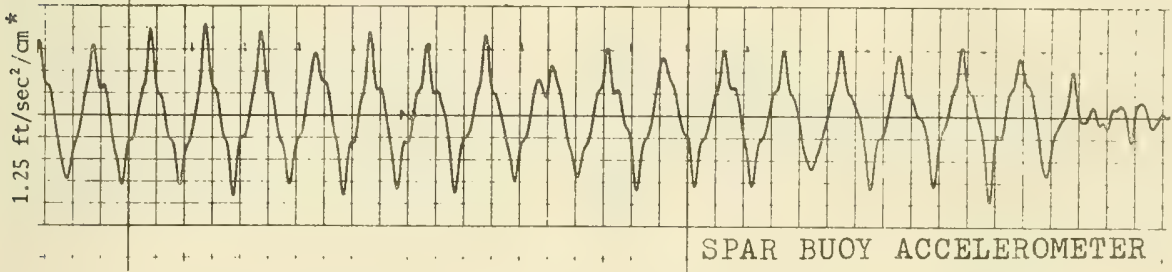

$\$ 0.4 \mathrm{~cm} / \mathrm{scale}$ div.

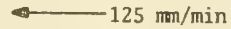

Figure K-1. Wave and acceleration data for par uoy,

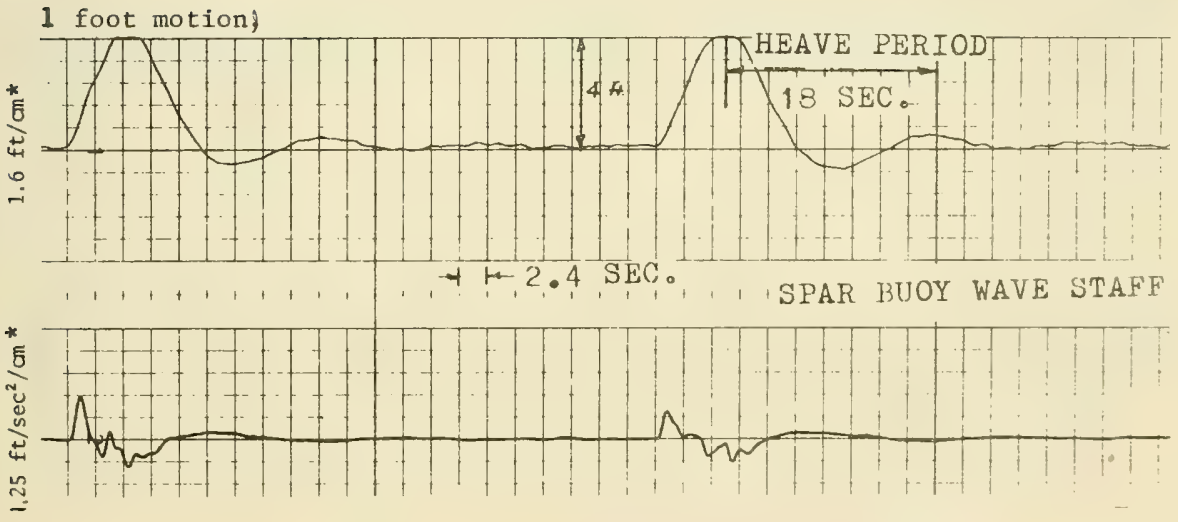

Figure K-2. Spar buoy heave response. 


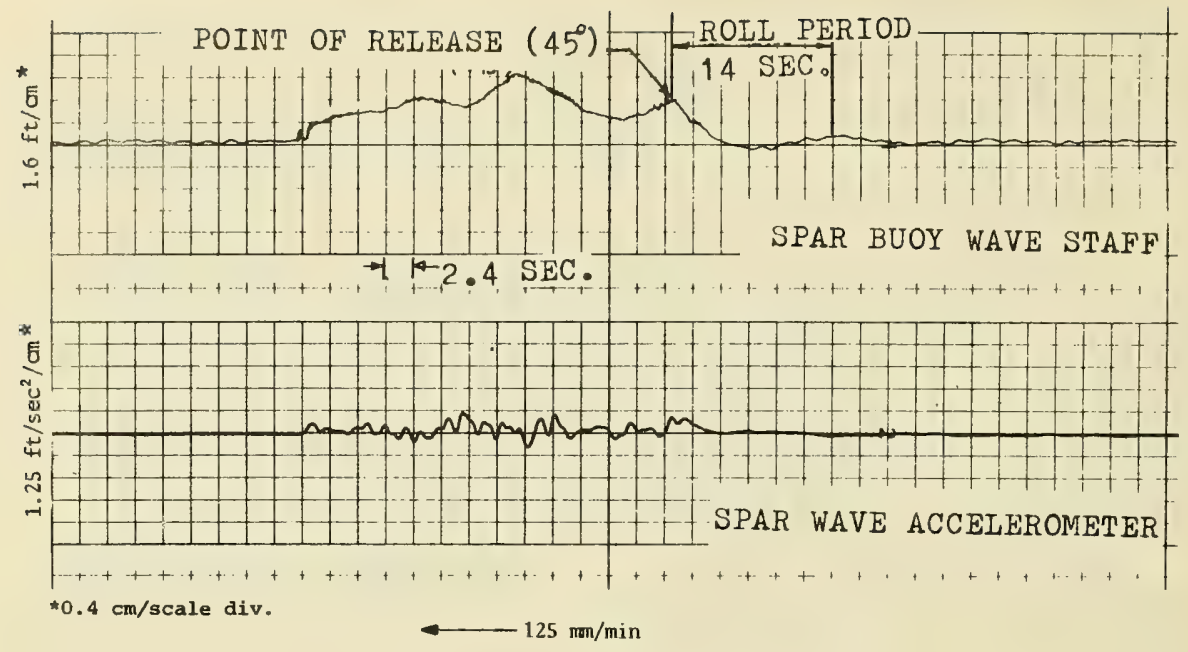

Figure K-3. Spar buoy roll response.

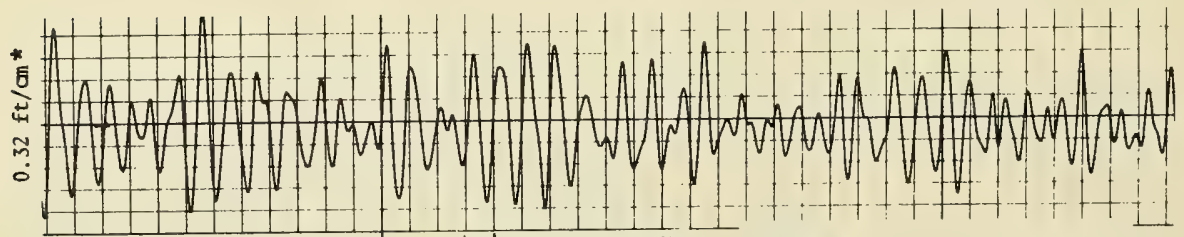
$\rightarrow+2.4$ SEC $0_{+}$SPAR BUOY WAVE STAFF ++

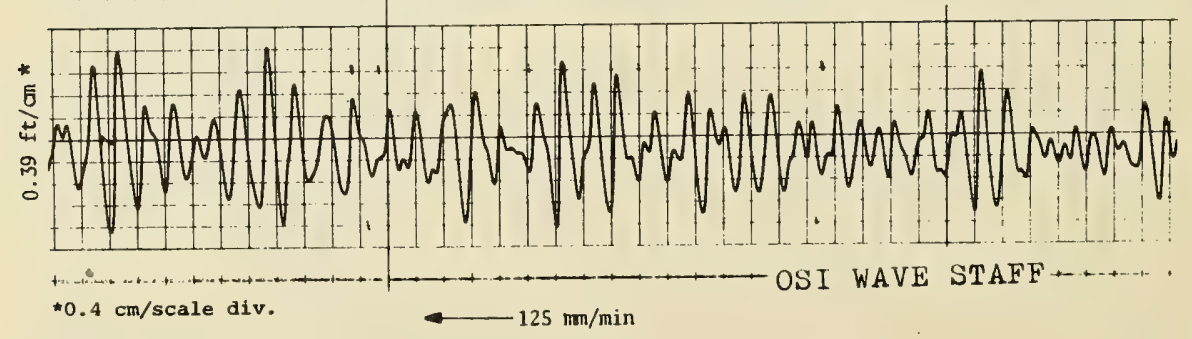

Figure K-4. Wind wave data for spar buoy and stationary staff. 
maximum wave heights in excess of 1.5 feet are shown in Figure K-5.

These spectra were computed from simultaneous records of 20 minutes in length. 


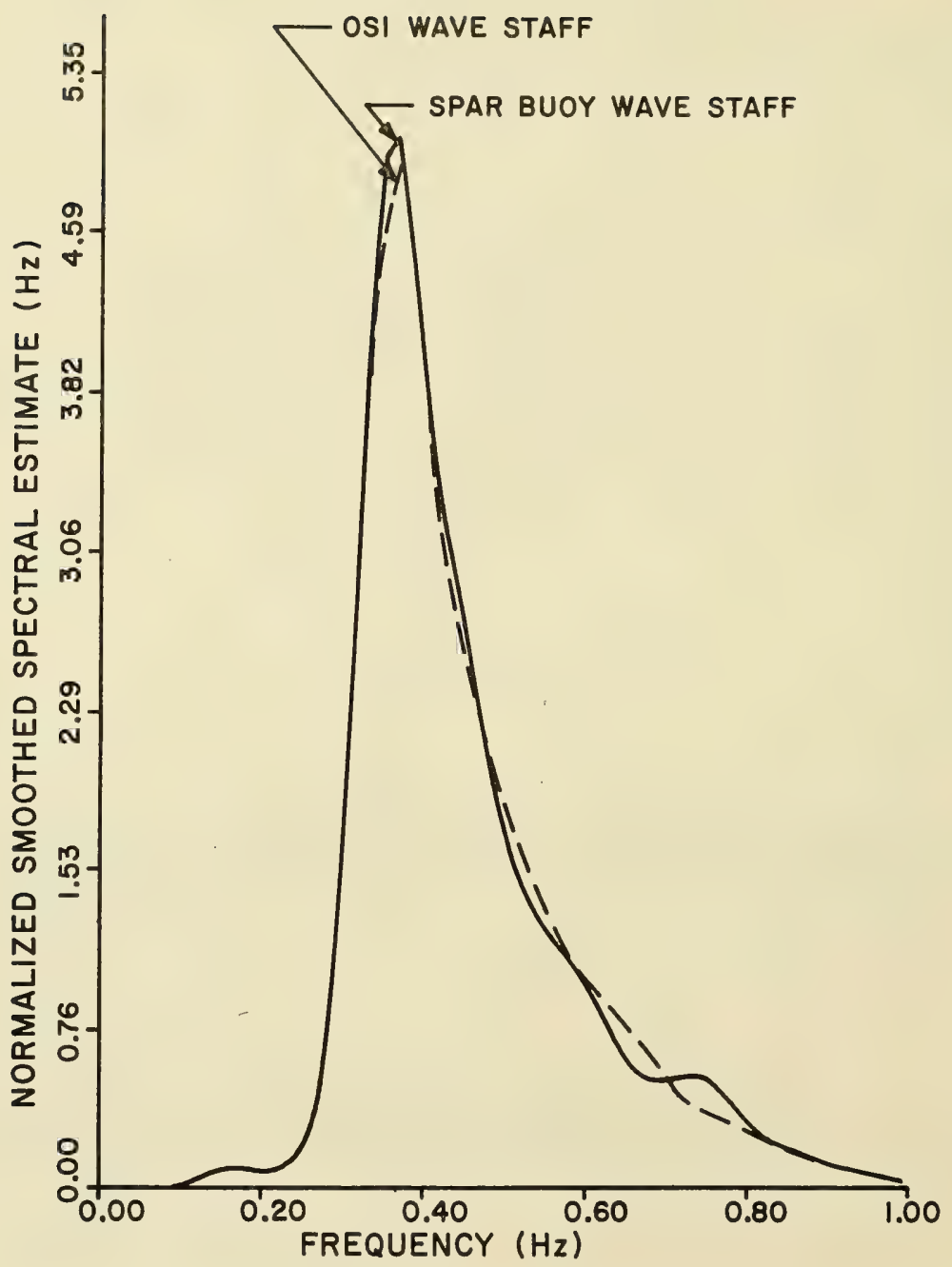

Figure K-5. Wave spectra from spar buoy and stationary staff. 


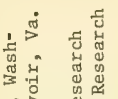 \\ में क्षे कै \\ 范艺 \\ 제 \\ का . 0 .

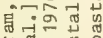 \\ तो of 0 \\ 㞾岕品 \\ 廿 :

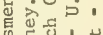 \\ की

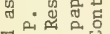 \\ 牙的舟}

प्र

廿

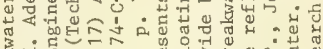

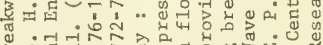

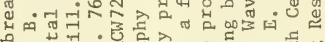
4 m

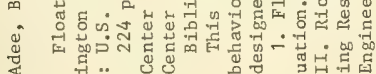

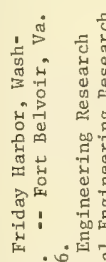

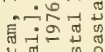

तथ

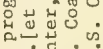

है

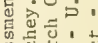

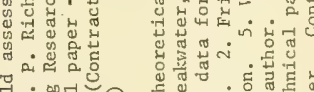

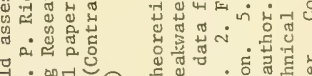

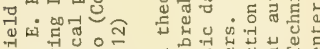

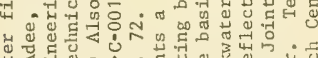

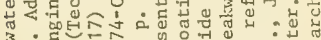

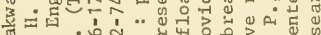

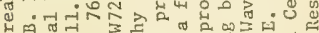

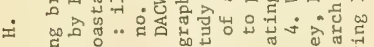
๓

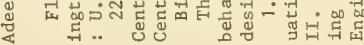

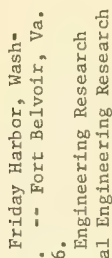

ㄷํㅇํำ

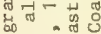

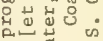

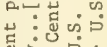

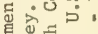

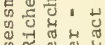

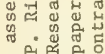

Piा कू

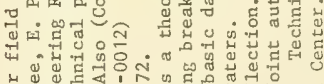

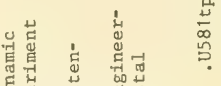

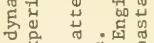

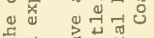

a क ₹

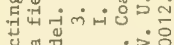

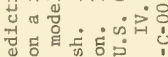

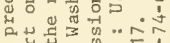

मै०

4.

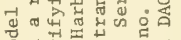

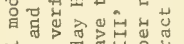

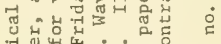

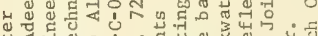

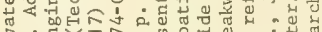

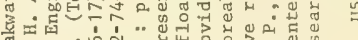

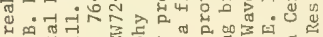

×

.

๓

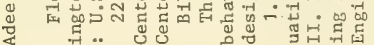

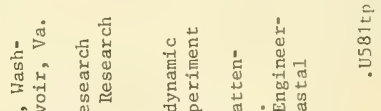
मै०े

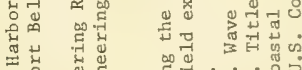

बू.

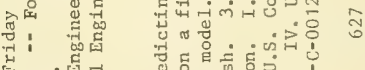

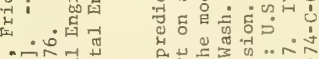

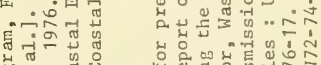

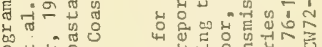

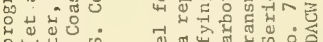

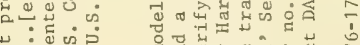

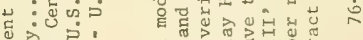

论

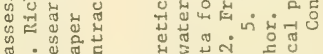

(2)

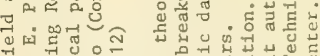

4.

में द्वुत

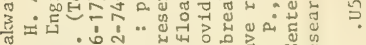

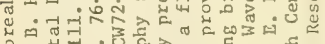

× $\quad$ os

क

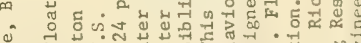





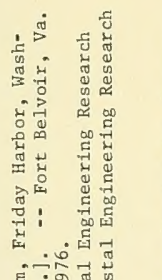

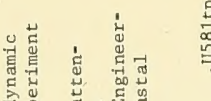

总

于.

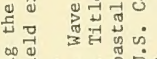

ज्ञ

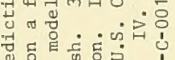

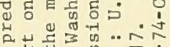

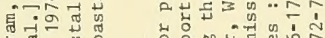

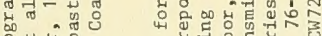

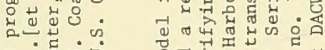

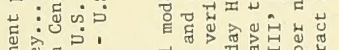

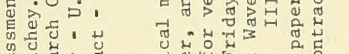

कूष

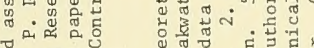

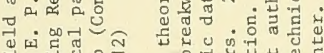

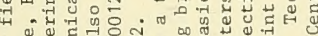

4.

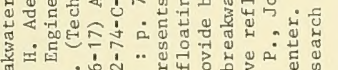

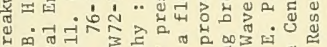

.

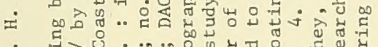

क

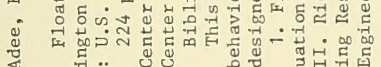

สิ่

$$
\stackrel{7}{\dot{\vdots}}
$$

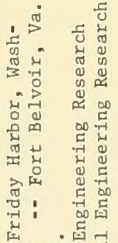

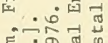

䨔 -

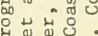

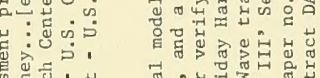

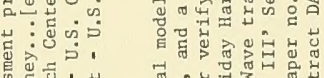

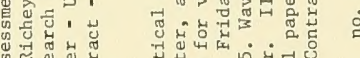

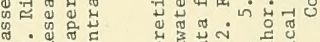

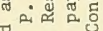
1. 山े.

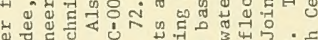

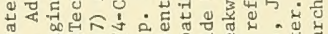

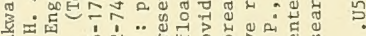

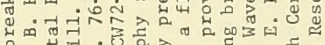

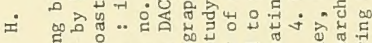
क ज्ञ -

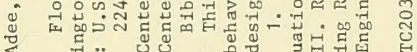

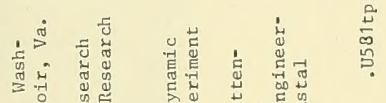

के ڤ

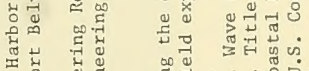

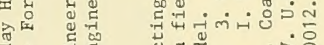

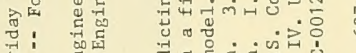

म. 司

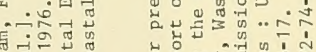

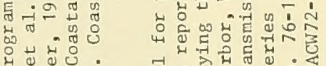

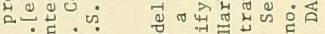

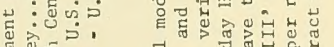

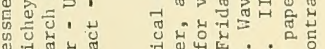

कृ

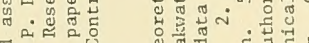

प्र. 007 记

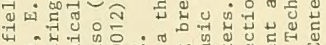

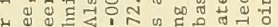

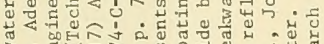
उ.

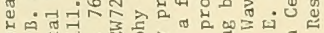

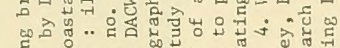

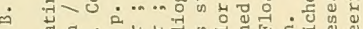

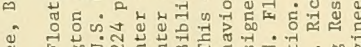

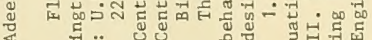

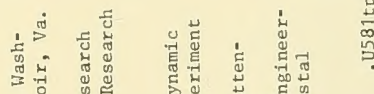

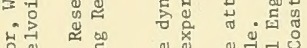

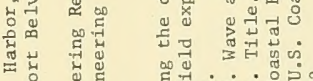

ज्ञ

गु

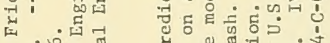

$\therefore \div$ -

त्रु-

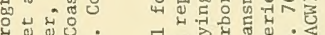

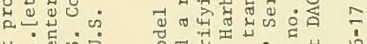

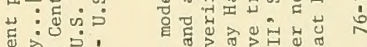

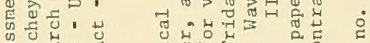

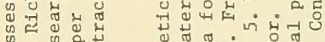

क.

च्र.

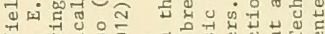

4 बु

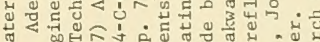

उ.

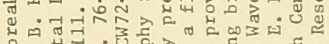

- में

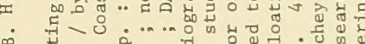

๓

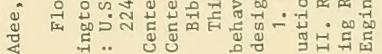




